\title{
Unpacking "Third Culture Kids": \\ the Transnational Lives of Young People at an International School in Indonesia
}

\author{
Danau Tanu
}

(19729595)

B.A. (Hons), 1999

This thesis is presented for the degree of Doctor of Philosophy of

The University of Western Australia

School of Social Sciences

Disciplines of Anthropology \& Sociology and Asian Studies 


\begin{abstract}
This thesis studies young people who experience a high-level of international mobility while they are growing up either directly (by moving geographically) or indirectly (by attending an international school with a transient student body). They are referred to as "Third Culture Kids (TCKs)" or "global nomads" in the Anglophone literature and popular discourse. I propose the need to view TCKs as "transnational youth" in order to move the analysis beyond the literature's current methodological limitations, Eurocentrism, and focus on the individual to the neglect of socio-historical context. I use an anthropological approach, methodological cosmopolitanism, and postcolonial critique to contextualize the way young people experience international mobility and the cosmopolitan space of an international school in a capitalist, postcolonial world.
\end{abstract}

Fieldwork was conducted for one year in 2009 and consisted mainly of participant observation of high school students (grades 9 to 12 , about 14 to 18 years old) at an international school catering to expatriate and wealthy Indonesian families in Jakarta, Indonesia. I also conducted in-depth interviews with over 140 students, staff, and parents from the school, as well as alumni of international schools in various countries. With over sixty nationalities represented in the student body and over twenty nationalities in the teaching staff, the international school was a setting in which national and transnational discourses of imagined communities converged and competed with one another. Consequently, the students negotiate boundaries as a matter of daily living, yielding concentrated data for analysis relating to intercultural dynamics and cosmopolitan practices.

The data show that cosmopolitan practices of peaceably engaging with the Other are diverse, situational, and embedded within relations of power. Whether or not these practices are recognized as cosmopolitan at the international school hinges on the way difference is defined by the notion of being "international". I propose that the school's ideology of being "international" is a vehicle through which both national and transnational class structures are reproduced. Becoming "international", I show, is mutually constitutive with becoming "western", becoming "Asian", and even becoming "Indonesian". Each of these processes represents ways of practising cosmopolitanism that emerges out of socio-cultural inequalities. 
Young people experience the educational space of an international school in diverse and complex ways. I explore these complexities by interrogating the ideology of being "international" that dominated the field site. I argue that the school's vision is to educate students to become "international", which the school articulates as a set of ideas and practices about engaging peaceably with others across difference. Notwithstanding this ideal, I propose that being "international" in the context of the school is characterized by speaking English, maintaining a sense of distance from the local, and being "western". I argue that this is a Eurocentric form of cosmopolitanism, which has implications for social relations on campus.

This thesis examines the intricate ways in which transnational youth engage with the dominant ideology of being "international", and find alternative ways to practise cosmopolitanism. The tension between the shared experience of a transnational (educational) space that privileges a Eurocentric form of cosmopolitanism and the differing ways in which various actors experience this space draws out the thematic focus of each chapter. 


\section{Candidate's Declaration}

This thesis does not contain work that I have published, nor work under review for publication. 


\section{Acknowledgements}

I thank the participants of this research who shared their time and stories with me. I thank them for being open, vulnerable, and kind. My greatest worry in writing this dissertation was to do justice to their experiences, views, and willingness to share. It is impossible to do so, but I hope I have not failed too miserably.

To my two supervisors I owe several years of gratitude for seeing me through and showing me by example that a woman can do much. This has meant a lot to me. To Lyn Parker I want to pay special thanks for being encouraging, dedicated, and helping me grow intellectually. $\mathrm{CY}$ was right about you being an awesome supervisor, and motherly too. To Loretta Baldassar I owe much for the many strategic advice that advanced my argument beyond what I could imagine. I loved being challenged by you. Thank you also for keeping me on track and being forgiving.

Many thanks to Yukimi Shimoda, Richard Martin, Marco Cuevas-Hewitt and Thijs Schut for their feedback on drafts and the robust discussions. Martin Forsey, Richard Davies, Victoria Burbank, Chang Yau Hoon, Ethan Blue, Rob Cover, and James Farrer gave insightful comments that helped develop my arguments. Brice Royer, Ruth Van Reken and Reto Hofmann deserve very warm thanks for their continued support for this project. I am also grateful to Katie Glaskin and my colleagues in Asian Studies and Anthropology \& Sociology at The University of Western Australia for their regular feedback on drafts, the discussions we have, and their support, namely: Vanessa Caparas, Kara Salter, Lara McKenzie, Hariyadi, Leah Maund, Gemma Bothe, Crystal Abidin, Irma Riyani, Angelika Riyandari, Kieran Golby, Joshua Esler, Carly Lane, Mee Mee Zaw, Jocelyn Cleghorn, Maki Meyer, Moshe Bernstein, Noresma Jahya, Richard Lyons, and Alka Sabharwal. And very special thanks go to Suzie Handajani, Margherita Viviani, Wen Wen Zhang, Gabrielle Désilet, Andrew Broertjes, Carol Kaplanian, Mitchell Low, Jonathan Ciawy Tay, Wee Loon Yeo, Cathryne Sanders, Rebecca Rey, Nicole Beattie, Asim Aqeel, Claire Molloy and Christie Blaikie for their input, friendship and support.

Also, I would never have fallen in love with the Arts had it not been for my high school teachers: Rick Butler who taught me how to write (he would have been a great professor), and Nancy Venhola who taught me how interesting the social sciences could be.

More importantly, I am most grateful to my father and mother, Bachri and Toshiko, as well as my sister, Mayapada, for their unconditional love and support. Without them this thesis would not have been possible. 


\section{Contents}

Chapter 1 An anthropology of transnational youth

1. From "Third Culture Kids" to "transnational youth"

2. "Cosmopolitanism" as a conceptual framework 12

3. Structure of thesis 16

Chapter 2 "Third Culture Kid": Narrating transnational belonging 21

1. "Was I ever mislabelled?" 22

2. Third Culture Kids: Who are they? 23

2.1. Mobility and adolescence 25

2.2. Mobility and imagined communities $\quad 27$

2.3. Cultural chameleon 28

2.4. Becoming "normal" 28

2.5. Mutual intelligibility $\quad 30$

3. A shared sense of place: "I needed to know that story" 32

4. Embodied history: "It was a different experience" 35

5. Who's cosmopolitan third space? 38

6. Conclusion 39

Chapter 3 Situating the researcher and fieldwork 41

1. The researcher's story 42

1.1. Hereditary cosmopolitanism 42

1.2. Like a second generation immigrant $\quad 44$

1.3. English and linguistic imperialism 45

1.4. School as a site of cultural reproduction $\quad 46$

1.5. Mobility and (cultural) displacement 47

1.6. Between local and expat, Asian and western 50

1.7. Self-identifying as a Third Culture Kid 52

2. Situating the researcher 53

3. Why do a school ethnography? 54

4. Fieldwork 55

4.1. Participant observation $\quad 55$

4.2. Ethnographic interviewing 59

4.3. Ethnographic writing 61

5. Conclusion 62

Chapter 4 Being "international": the field site and its context 63

1. The International School (TIS) and Jakarta 64

2. Articulating internationalism: "Being the best for the world" 68

2.1. Mission: educating "responsible world citizens" 68

2.2. Curriculum: the International Baccalaureate program 69

2.3. Rituals: for global citizenship 70 
2.4. Imagined communities: a global international school community 71

2.5. Symbols: nationalities, flags, and Obama 71

2.6. More rituals: United Nations Day 73

2.7. Students: Being "international" 74

3. It's American. It's European. It's Western. It's Asian. It's international? 75

4. Mapping student cliques 76

5. The gatekeepers for being "international" 79

6. The internationalization of education 80

7. Conclusion $\quad 84$

Chapter 5 English: the language of power and cosmopolitanism 85

1. Becoming "international” by speaking English 85

2. "English is the power language" 87

3. The coloniality and globality of English 88

4. "When I Spoke English I Felt Smart!" 92

5. Speaking "without" an accent 96

6. Linguistic and cultural boundaries within the family 98

7. Associating English and "expat" with high status 103

8. "Natural" English: the native-non-native speaker dichotomy 105

9. Conclusion 107

Chapter 6 Living in Disneyland: uneasy relations with the local 109

1. A "western" expatriate community 109

2. Constructing the host country as "Disneyland" 111

2.1. The "wonders of Disneyland" 111

2.2. The exotic Other 114

2.3. "I miss the riots" 115

2.4. An unfamiliar, dangerous Other 116

3. International schools as the center of student life 118

4. Propped up by an economic structure: the pay scale 121

5. Hidden curriculum: "It's our daily experience here" 126

6. Internalizing hierarchies 130

$\begin{array}{ll}\text { 7. Conclusion } & 131\end{array}$

$\begin{array}{lll}\text { Chapter } 7 & \text { In pursuit of cosmopolitan capital } & 133\end{array}$

1. Parent gatherings: the dominance of Euro-American cultural capital 133

1.1. Parent coffee mornings and a Third Culture Kid information evening 134

1.2. Open house night 135

1.3. Korean parents' meeting: miraculous encounters 136

2. Ideal cosmopolitanism meets pragmatic cosmopolitanism 138

3. "We can't all expect to live the same way" 139

3.1. Measuring student involvement 140

3.2. Internalizing negative views 140

3.3. Moving to "a higher social class" 142 
4. School choices in national and transnational contexts

5. Managing cultural identity in national and transnational contexts $\quad 145$

$\begin{array}{ll}\text { 5.1. Kairi } & 145\end{array}$

$\begin{array}{ll}\text { 5.2. Yae } & 146\end{array}$

5.3. David 148

6. Postcolonial elites meets the transnational middle-class 151

7. In pursuit of "international" passports 156

$\begin{array}{ll}\text { 7.1. Anaya } & 157\end{array}$

$\begin{array}{ll}\text { 7.2. Afra } & 158\end{array}$

7.3. Deborah 159

8. Conclusion 160

Chapter 8 Becoming "white": the politics of hanging out and school belonging 163

1. Racializing status and student cliques 164

1.1. "The white kids...are popular" 164

1.2. "You mean...the normal people?" 165

1.3. They seem mixed, but are basically white 168

2. Spatial practices: Reproducing status through hangout areas 170

$\begin{array}{ll}\text { 2.1. Reproducing racialized spaces } & 171\end{array}$

$\begin{array}{ll}\text { 2.2. Gendered spaces } & 174\end{array}$

2.3. Social capital: the power to make groups 178

3. School belonging 180

4. Cultural affinity with staff 183

4.1. Discomfort at "being preferred" 183

4.2. Rapport building for students with Euro-American capital 185

4.3. Rapport building for students without Euro-American capital 188

5. Conclusion 191

Chapter 9 Becoming "Asian": Alternative processes of cosmopolitanization 193

1. Changing names, changing identities 193

2. A nameless, faceless "Other" 196

3. Invisible diversity 200

4. Creating home turf 201

4.1. "English infested society" 202

4.2. From cultural hybrid to becoming "Japanese" 203

5. Changing friendship circles with age 207

6. Missing being "Korean" 211

6.1. Imagining "Korea" 212

6.2. Using Korean "roots" to build international "routes" 213

7. Becoming "international" by becoming "Asian" 215

$\begin{array}{ll}\text { 8. Conclusion } & 218\end{array}$

Chapter 10 Cosmopolitanizing intimate desire 221

1. Racializing beauty and attraction 222

1.1. Indian girls like white guys, Indian boys like white girls 222 
1.2. "She thinks we're just pebbles on the roadside" 225

1.3. Pre-emptive strike $\quad 228$

2. "Endogamy" for transnational youth? 231

2.1. Chinese Southeast Asians 232

2.2. Westernized Asians and Asianized westerners 232

2.3. Indians with western accents 233

3. Sex and the transgression of class and racial lines 234

3.1. "When you're a nice girl, you don't hang out with foreigners" 235

3.2. "But I'm not like those mba-mba" 237

4. Becoming “Indonesian", becoming "men" 238

4.1. "Visitors must have respect" 238

4.2. Defending girls 240

5. Conclusion 244

Chapter 11 Cosmopolitan ambivalence 247

1. Becoming "white", becoming "Asian" 247

1.1. Shifting positionalities 248

1.2. Friendships based on interest? 252

2. Becoming not-Indonesian 254

3. Becoming "Japanese", becoming "haafu" 255

3.1. "Southeast Asians are...just a factory outlet" 256

3.2. Subverting national hierarchies $\quad 257$

4. Competing to become "international" 259

4.1. Diversity made visible and invisible by race 259

4.2. Reproducing cosmopolitan hierarchies like fractal patterns 260

4.3. A new "We are the world" 264

5. Conclusion 266

Chapter 12 Growing up in a transnational world 269

1. Methodological cosmopolitanism 269

2. Contributions to the literature 272

3. Implications for future research $\quad 274$

3.1. Diversity of international schools $\quad 274$

3.2. Social lives 276

3.3. Applying methodological cosmopolitanism to other groups 277

$\begin{array}{ll}\text { References } & 279\end{array}$ 


\section{List of Figures}

Figure 1: PolVan Cultural Identity Box

Figure 2: An example of seating during assemblies. 174

Figure 3: Main senior hangout area for Class of 2009.

Figure 4: Main senior hangout area for Class of 2010.

Figure 5: Creating home turf 203 


\section{Chapter 1}

\section{Toward an Anthropology of Transnational Youth}

"Cultures" do not hold still for their portraits.

-James Clifford (1986, p. 10)

"Let me get this straight," said the immigration official at Raleigh-Durham airport in North Carolina, reviewing the documents that would allow me onto U.S. soil for the first time. "You have a French passport, which was issued in Indonesia, you were born in Australia, and your J-11 visa for entry into the United States of America was delivered in Venezuela. Is that right?"

Indeed, it was. What made the official even more wary was the fact that I sounded distinctly American, without a trace of a foreign accent. "Your English is amazing, how much time have you spent in the United States?" he asked. "Approximately 18 minutes," I said. "This is my first time."

He was incredulous when I explained that I had acquired an American accent while studying in international schools overseas, but eventually issued me a verbal "Welcome to America." It was to be my fifth country of residence in 17 years, only two years of which were spent in France, my "passport country".

-From an article in the "New York Times" by Anne-Sophie Bolon (2002)

"This is my country, so the bules (white folks) ${ }^{1}$ shouldn't mess in our country," said Dae Sik while perched precariously on the back of a bench near the school fountain. Dae Sik was an international school student who spoke Indonesian, English, and Korean. He was talking about Indonesia, the place where he grew up. Yet, Dae Sik was technically South Korean: his passport said so; his name said so; and ethnically speaking he was. I decided to press him on this point: "But, aren't you Korean?" I asked. "Of course," he responded, "it's in the blood." As far as Dae Sik was concerned, there was nothing inconsistent about seeing Indonesia as his country, while at the

\footnotetext{
1 "Bule" is Indonesian slang for "white person". At TIS, those who were considered white by others or self-identified as white also occasionally referred to themselves as bule.
} 
same time identifying himself as Korean.

-A conversation with a student at an international school in Indonesia (2009)

This thesis is about people who experience international mobility directly or indirectly while they are growing up. Some experience it directly by moving multiple times from country to country with their parents. ${ }^{2}$ Others experience it indirectly, for example, by attending an international school that has a transient, internationally mobile student body, and finding that their schoolmates come and go with every new academic year. Anne-Sophie Bolon and Dae Sik (above) are two of many examples. They are referred to as "Third Culture Kids (TCKs)" or "global nomads" in the Anglophone literature and popular discourse, but I will refer to them using the shorthand "transnational youth" for reasons I outline below. These people grow up transnationally, are expected to be "international" by default, and learn to make meaning out of the old and new structures that influence their lives. But they are not homogeneous. Although the cohort I studied shared a degree of economic privilege, they experienced and interpreted their transnational upbringing in different ways depending on their cultural and national background. This thesis explores the impact that factors such as culture, class, "race" and gender, have on a transnational upbringing. Contrary to the existing TCK literature that assumes a neutral playing field for all TCKS regardless of the above mentioned factors, I use an anthropological approach and postcolonial critique to contextualize the way young people experience international mobility and transnational (educational) spaces within the sociohistorical specificity of a capitalist, postcolonial ${ }^{3}$ world.

This thesis is as much about transnational youth as it is about the international schools that many of them attend across the globe. In many ways, the students and the school are mutually constitutive (Willis, 1977). The ideology of being "international" that often characterizes international schools together with the elite, heterogeneous communities that comprise them profoundly influence the social lives and perceptions of transnational youth. Based on their ideology of being "international", these schools generally claim to nurture "global citizens"

\footnotetext{
${ }^{2}$ The U.S. State Department estimates that there are 6.8 million U.S. citizens living abroad in 2013, many of whom are dependents of U.S. citizens working overseas and would be considered transnational youth for the purposes of this study (U.S. Department of State, 2013). The total number of people living or used to live outside their passport countries as dependents for all countries in the world is significant.

${ }^{3}$ According to Mignolo (Mignolo, 2000, p. 45), the hyphenated "post-colonial" indicates a temporal shift to the time after decolonization, and the non-hyphenated "postcolonial" indicates an analytic shift to an intellectual perspective that critiques Eurocentrism. I use the latter in this thesis to signify the relevance of colonial cultural legacies on the experiences of transnational youth.
} 
who are internationally-minded, feel "at home in the world", prejudice-free, and thus able to transcend national and cultural boundaries (Hayden \& Thompson, 1995; Hill, 2007, 2012; James, 2005). This set of attributes is defined in the sociological literature as signifying a form of "cosmopolitan" identities (Hannerz, 1996; Nussbaum, 1996) that has been critiqued for being elitist (Calhoun, 2008; Delanty, 2009). A central theme of my thesis is therefore an analysis of what it means to be "international" (in the context of these elite schools) tested against the notion of cosmopolitanism. I argue that the school's claim to being "international" and nurturing "global citizens" needs to be carefully critiqued because the various identityboundaries that define and separate people do not automatically disappear over time through cultural mixing at these schools. They are blurred, shifted, or reinforced as young people learn to engage with the Other and interpret their experience of cultural and/or geographic displacement.

In this thesis, I adopt the sociological notion of "cosmopolitanism" as a useful conceptual framework for interrogating the school's ideology of being "international" and the processes by which young people with a transnational upbringing are assumed to become "international" (Beck \& Sznaider, 2006; Delanty, 2009). I define "cosmopolitanism" as a set of ideas and practices of being open to and peaceably engaging with others who are considered different (Delanty, 2009; Hannerz, 1996). My central thesis argument is that the cosmopolitan practices of transnational youth are diverse, situational, and embedded within national and transnational hierarchies that are informed by the socio-historical context (Calhoun, 2008; Vertovec \& Cohen, 2002; Werbner, 2008). Gerard Delanty (2009, p. 53) writes of cosmopolitanism as a social theory that, "Cosmopolitanism refers to the multiplicity of ways in which the social world is constructed through the articulation of a third culture." I argue that "being international" only represents one form of the many forms of cosmopolitanism that transnational youth practise. Further, at an international school where national and transnational economic and cultural hierarchies converge, the ideology of being "international" represents a form of cosmopolitanism that is Eurocentric. Whether or not various practices of cosmopolitanism are recognized as "international" hinges on the way difference is defined by this Eurocentric ideology.

Being "international" is a way of imagining a global community, but I show that it is also the ideological vehicle through which both national and transnational hierarchies are reproduced by privileging "western" ways of being. I use the term "western" and "Euro-American" 
interchangeably with an emphasis on Anglophone culture. Contrary to the ideology of being "international" that permeates the school and is reflected in the literature on TCKs and international schools, multiple practices of cosmopolitanism are present at these schools. In this thesis I use the analytical concept of cosmopolitanism to refer to any form of peaceably engaging with others across difference, and the emic concepts of the ideology of being "international" or internationalism to refer specifically to the Eurocentric form of cosmopolitanism promoted by the school.

The ethnographic focus of this study is an international school located in Jakarta, Indonesia that caters to the children of foreign expatriate and wealthy, upper class Indonesian families. I shall call the school by a pseudonym, "The International School (TIS)", to protect its anonymity. With over 60 nationalities represented in the overall student body and 20 nationalities in the teaching staff, TIS was a space where national and transnational discourses of imagined communities converged and competed with each other. As students flood out of the classrooms at recess, one can hear a Russian teenager speaking fluent, colloquial Indonesian to a classmate; Indian teenagers speaking English with a western accent, then switching to an Indian accent and back again within a matter of seconds, depending on who they are talking to; a Taiwanese teenager speaking English, Mandarin and Indonesian in one sentence. This was a typical scene at TIS. This thesis centres on the social lives of transnational youth at an international school.

Data are drawn mainly from 12 months of fieldwork conducted in 2009. The two main methodologies were participant observation of TIS's high school students on campus and in Jakarta at large, and in-depth interviews with over 140 students, staff and parents from the school, as well as alumni of international schools in various countries. I conducted two weeks of additional participant observation at a smaller international school, which informed the analyses. High school consisted of grades 9 to 12, with student ages ranging from 14 to 18 years, though at least one student interviewee was 19 years old. I chose to study a high school for two reasons. Firstly, while at least one ethnographic study had been done on an international elementary school, no similar work had been done on high schools. Secondly, I personally felt more comfortable interacting with teenagers than young children. Transnational youth negotiate boundaries as a matter of daily living, thus yielding concentrated data for analysis relating to social relations in a diverse transnational setting. 
In this chapter, I discuss how this thesis departs from the existing literature in its methodological and analytical approaches, and in so doing show that the term "transnational youth" is most apposite to refer to the cohort I studied. I then illustrate how I will apply methodological cosmopolitanism to the study of people with a transnational upbringing, before outlining in more detail the key arguments and structure of the thesis.

\section{From "Third Culture Kids" to "transnational youth"}

There is a paucity of anthropological literature on young people, let alone young people with a transnational upbringing (see Amit-Talai \& Wulff, 1995; Nilan \& Feixa, 2006). Most research that does focus on young people still takes national imaginaries as its starting point, even when it makes cross-cultural comparisons or considers issues of globalization. There are three main bodies of literature relevant to the study of transnational youth: psychological and sociological work on children of mobile professionals that rely on the concept "Third Culture Kids"; ${ }^{4}$ education research on international education and international schools; and anthropological work on western expatriates, children of expatriates, and local elites attending international schools. Overall, the literature struggles to move beyond categorical binaries such as the West-the Rest and national-international. I propose that these limitations can be overcome using cosmopolitanism as an alternative analytical framework and treating the transnational as the methodological starting point.

I first came across the term "Third Culture Kids (TCKs)" in January 2007 through a friend with whom I used to go to an international school in the 1990s. She said, "Do you know that we're TCKs?" It was not until I read the book Third Culture Kids: Growing up among worlds by David Pollock and Ruth Van Reken (2009[2001]) and eventually began the research for this dissertation in the following year, that I realized how deeply the term resonated with me personally due to my own transnational upbringing. The basic "profile" of a TCK as defined in the literature is that they grow up outside their "parents' culture", are interculturally competent, feel they are a part of many cultures and yet do not fully belong to a single one, and instead their "sense of belonging is in relationship to others of similar background." ${ }^{5}$ । provide a fuller discussion of the literature and my own story in Chapters 2 and 3; here I will just say that the literature contributed to our understanding of the impact of multiple

\footnotetext{
${ }^{4}$ They are also referred to as global nomads or internationally mobile children, and by their sub-groups-military brats, missionary kids, diplomat kids, etc.

${ }^{5}$ From "The TCK Profile" seminar material" $(1989,1)$ as cited in Pollock and Van Reken $(2001$, p. 19)
} 
geographic and cultural displacements on transnational youth and challenged the dominant notion of singular identities.

Anne-Sophie Bolon, with whom I began, is a case in point. The immigration officer was confounded that none of Bolon's answers relating to the multiple categories used to imagine communities matched the other-nationality (French), place of previous residence (Indonesia), place of birth (Australia), current place of residence (Venezuela), language (English), and accent (American). The nation-state remains the dominant point of reference in constructing difference and imagining communities (Anderson, 1983). Languages and accents are not merely practical tools of communication. They signify membership of certain socio-cultural groups (Bourdieu \& Thompson, 1991). Bolon's account exemplifies the disjunctures between the communities imagined by oneself and those imagined by sometimes powerful others. Bolon's imagined community is that of a third culture, which stands in contrast to the imagined national community that the immigration officer had in mind, as symbolized by Bolon's French passport. As Arjun Appadurai (1996, p. 32) writes, “One man's imagined community is another man's political prison."

Dae Sik's story also defies the notion of singular identities, while highlighting other categories of difference that remain pertinent to cultural imaginings. Dae Sik used the expression "it's in the blood" to refer to a sense of primordial belonging to Korea based on descent and ethnicity. He homogenized and racially constructed the western students at his school as "bule" or white "Other", and thereby positioned himself with the Indonesian "Us" by declaiming a sense of (borrowed) nationalism. Conflicting uses of categories of difference-ethnic, national, and racial-co-exist with ease in Dae Sik's expression of his identity and he seamlessly shifted between them, depending on what was being asked of him. As Stuart Hall (1993, p. 362) states, "identity is always an open, complex, unfinished game - always under construction." Identity positions are held temporarily and situationally. Nationality, language, accents, ethnicity, race, place of birth, place of upbringing-this thesis will examine how transnational youth actively use these categories in intersecting and contradictory ways to negotiate boundaries in a transnational educational space.

Most literature on Third Culture Kids use approaches in psychology, sociology, and education, which emphasize developmental and socialization processes (e.g. Hayden \& Thompson, 1995; Kanan \& Baker, 2006; Pollock \& Van Reken, 2009[2001]; Schaetti, 2000). The literature in 
psychology focuses on individual identity development and the trauma of multiple separations caused by the international moves that TCKs make, not out of their own choice, but as a result of their parents' choices. Like studies on minority youth (e.g. Jensen, 2008; Phinney, 1990, 2008), it uses the concept of Third Culture Kids as an alternative model to the dominant developmental model of white males in industrialized western countries. The research is often conducted by those who self-identify as TCKs or have previously worked with TCKs.

The strength of the TCK literature is its ability to address the impact of mobility and cultural exposure on the psychological development of young people as individuals. I illustrate in Chapter 2 how the term "Third Culture Kid" can act as a powerful narrative tool to help those with a transnational upbringing locate an emotional homeland where they find the language to express their experience of multiple geographic and cultural displacement. I highlight the importance of "Third Culture Kids" as an emic (insider) term in providing a narrative or the language to describe, understand, and thus bring coherence to individual transnational experiences (e.g. Walters, 2006). However, this literature treats transnational young people as incomplete and in transition towards an idealized cosmopolitan adulthood. I prefer to see them as agents "actively engaged in the production of meaning for their own social lives", as Virginia Caputo $(1995$, p. 22) suggests. I treat transnational experiences as a normal part of the participants' lives and use the anthropological approach to shift the analysis from the individual to the group.

Defining the parameters of my anthropological research based on who is or is not a "Third Culture Kid" proved difficult from the outset, and increasingly so after I began my fieldwork. Rather than chasing research participants around the globe, as though mobility negates the importance of geographic context, I chose to focus on one physical site to enable a rich ethnographic account of who I thought were Third Culture Kids (Geertz, 1973). I knew from my own experience of having studied at international schools in Indonesia and Singapore that they offered a space where young people with a transnational upbringing congregate and I judged that it would be manageable for one researcher to study over a period of one year. When I arrived in the field, a teacher assured me, "You've come to the right place. They're all TCKs here." However, as I immersed myself in the social relations of TIS, it became clear that not all students were considered TCKs. Anne-Sophie Bolon would be considered a quintessential TCK, while Dae Sik would not. But Dae Sik's upbringing was also transnational in so far as he grew up outside his passport country and attended an international school that had a highly mobile 
student population. So, what exactly did the students have to be or do to be considered a TCK? And who were the gatekeepers for "TCKness"? The difficulty in defining the parameters of my research using the term "Third Culture Kid" led me to question its applicability and usefulness as an analytical concept.

As a concept, "Third Culture Kid" is Euro-American-centric and not reflexive of its own sociohistorical specificity. Ruth Hill Useem (see J. Useem, Useem, \& Donoghue, 1963) coined the term when she was conducting research in the 1960s on the third culture that mediated relations between the growing number of American expatriate workers and host country nationals in India at a time of global economic, political, and cultural transition from colonialism to American-led global capitalism. Useem noticed that her own children and those of other Americans were operating in a culture that was unlike that of young people growing up in the United States. They had been influenced by their experience of growing up in the host country, India. The term recently came into popular parlance among TCKs themselves and those working with transnational youth through Pollock and Van Reken's (2009[2001]) work, Third Culture Kids: Growing up among worlds.

Third Culture Kids are defined as those who spend their formative years outside their parents' home country ("first culture") as "visitors" in one or more host countries ("second culture") to develop a "third culture" or an "interstitial culture" (Pollock \& Van Reken, 2009[2001]; R. H. Useem \& Downie, 1976). Given the context in which it was coined, "Third Culture Kid" relies on binary frameworks, such as "home country"-"host country", and categories that appeared mutually exclusive, such as "American" and "Indian". These frameworks and categories are based on methodological nationalism, which assumes that "the nation/state/society is the natural social and political form of the modern world" and takes the nation-state as the starting point of analyses (Wimmer \& Glick Schiller, 2002, p. 302). This thesis will show that categories derived from methodological nationalism are unsustainable in a field where identities are a messy business-complex, shifting, and overlapping (Hall, 1996b).

More recently, Gene H. Bell-Villada and Nina Sichel (2011) traced the genealogy of the Third Culture Kid experience back to the colonial era, when European imperial powers sent their citizens overseas to serve in colonial outposts. In their introduction to a collection of memoirs, essays, and research Bell-Villada and Sichel (2011, pp. 4-5) write, "Many of these voluntary expatriates would in turn have offspring, who grew up as what we might today consider TCKs, 
and who might feel the same conflicting emotions vis-à-vis their 'mother country'...[C]olonialism, in a sense, first created Third Culture Kids". It is the contemporary significance of this historical lineage that I explore. The conflicting emotions are not unique to children of white colonial expatriates or mobile professionals. Scholars have written extensively on the impact of cultural displacement and hybridity on the (formerly) colonized, many of whom were equally mobile whether by choice or otherwise. My findings show that the experiences of TCKs of non-western background reveal a historical continuity with westernized local elites of former colonies and children of migrants in settler countries and former colonial metropolitan centres, but their stories have remained invisible in the TCK literature.

Generally speaking, the Anglophone literature relevant to the study of Third Culture Kids has been unable to integrate western and non-western perspectives for one of three reasons. First, the scope of research has been limited by methodologies that overlook the social processes involved in becoming "international". Second, it uses a Eurocentric perspective that fails to integrate the socio-historical context. Third, it uses the nation-state as its analytical starting point, and assumes the mutual exclusivity of the national and transnational. However, according to Beck and Sznaider (2006, p. 3), "the dualities of the global and the local, the national and the international, us and them, have dissolved and merged together in new forms", thus requiring new conceptual tools of analysis. This thesis addresses these limitations.

The ethnographic method I use allows me, as a researcher, to immerse myself in the lives of transnational youth and systematically observe the day-to-day social interactions that influence the ways in which they become "international". The literature on international schools emphasize the importance of the "informal aspects such as mixing with students of other cultures both inside and outside school" over the more formal aspects of international education in nurturing intercultural understanding (Hayden \& Thompson, 1995, p. 341; see Hill, 2007). TIS's advertising material likewise cites "immersion" as the only way to acquire "[t]rue [i]nternationalism". Despite acknowledging that social processes are crucial to becoming "international", ethnographic research by immersion on these social processes is rare. This thesis carefully examines the social lives of transnational youth and the social processes through which they become "international".

I employ a postcolonial lens to contextualize the experiences of transnational youth within the 
cultural legacies of colonial discourses. A postcolonial approach enables an analysis of the ways in which culture, "race", class, and gender intersect to create complex, multifaceted hierarchies in the capitalist present without losing sight of their "basis in the historical process of colonialism" (Ashcroft, Griffiths, \& Tiffin, 2006, p. 2; also Hall, 1996a). ${ }^{6}$ It allows for the study of the "super-diversity" present in transnational spaces, paying attention to the nuanced relationships between those who inhabit these spaces (Vertovec, 2007, p. 1024). In particular, postcolonial theory makes possible insights that "disengag[e] cosmopolitanism from purely Western assumptions" (Delanty, 2009, p. 5).

Previous anthropological studies that have applied a postcolonial analysis to people who live transnationally as adults argue that colonial discourses continue to influence the ways in which western expatriates perceive and interact with host country nationals (Fechter, 2007; Leggett, 2010). Even so, Anne-Meike Fechter and Katie Walsh (2010, p. 1197) acknowledge in their special issue on expatriate communities in former colonies that such studies have a "somewhat myopic focus on Western expatriates" (e.g. Benson \& O'Reilly, 2009; Coles \& Fechter, 2008; Farrer, 2010; Fechter, 2007; Korpela, 2010; Leonard, 2010). They recognize that there is a need to study other transnationals and locals and their relations with western expatriates.

The literature on expatriate and local children in the context of transnational spaces is similar. Much of this is embedded within the literature on TCKs, which do not take the socio-historical context into consideration as previously discussed. Outside of the TCK literature, I located two anthropological works that are relevant to my study. Karen O'Reilly (2009) studied British children who attended international schools with the locals in Spain which, unlike the TCK literature, analyses their experiences within the context of class reproduction. But again, she focuses on western expatriate children. Another notable work is Mark Allen Peterson's (2011) research on the children of the local elite from an American international school in Egypt. He analyses the way the Egyptian elite reproduce their eliteness by acquiring cosmopolitan capital through the consumption of western goods, including the western education offered by international schools. Peterson goes further than O'Reilly in interrogating the transnational relevance of western cultural capital. However, his focus is again not on the social dynamics among seemingly disparate groups in transnational spaces.

\footnotetext{
6I use "culture" to mean cultural capital (Bourdieu, 1986), which I elaborate on in Chapter 2; "race" to refer to the racial categories in the colonial sense; and "class" to mean economic capital (also Bourdieu, 1986).
} 
Likewise, the literature on international schools focuses on the experiences of expatriate children, namely western expatriates. However, Mary Hayden (2011) notes that the growing popularity of international education and the internationalization of national education means that national and international education are merging. Children of the local elite, particularly in former colonies, are also attending international schools as they were at TIS. While I will discuss the literature on international schools in greater detail in Chapter 4, I will just say here that there is a need to integrate the study of the experiences of expatriate and local children in transnational educational spaces.

Anglophone literature on expatriate communities and the local elite in transnational spaces has hitherto been conceptually limited in its ability to effectively integrate the perspectives and experiences of western and non-western populations. Despite its focus on the transnational, it still uses the national as its analytical starting point. Notably, most studies follow the lives of members of one or two particular nationality groups. In contrast, I will focus on the social interaction among a diverse set of transnational youth within a finite space. I will also apply the postcolonial lens to the study of children of expatriates, other transnational youth, and international schools. This will reveal the tension that ensues when a diversity of actors from countries of varying colonial history, such as Anne-Sophie Bolon and Dae Sik above, but who are equal targets of the globalizing mission, meet and interact in a finite space. Postcolonial theory can bring into relief the "vibrant and powerful mixture of imperial language and local experience" that occur in international schools (Ashcroft et al., 2006, p. 1).

I argue that the national and transnational need to be treated as mutually constitutive in order to analytically integrate the perspectives and experiences of westerners, locals and other nonwesterners who inhabit transnational spaces (Delanty, 2009; Smith, 2001). I define transnational spaces as social spaces wherein multiple national and transnational discourses converge. Although Michael P. Smith (2001, p. 174) refers to it as "translocality", I borrow his definition: "a fluid cross-border space in which social actors interact with local and extra-local institutions and social processes in the formation of power, meaning, and identities."

I show that national and transnational economic and cultural hierarchies intersect in the transnational spaces of international schools to affect the perceptions and experiences of young people. Bringing together the diverse range of experiences of mobility and international schools for young people into one theoretical space requires the use of a more encompassing 
term that avoids the definitional problem of "TCK". In this thesis I have opted to use the term "transnational youth" to mean simply any young person who is affected by international mobility either directly (by moving from country to country) or indirectly (by growing up in a transnational environment such as the international school where the people around them are highly mobile).

This thesis contributes to the scholarship on youth by taking the transnational as its analytical point of departure. As an anthropological study, it contextualizes the experiences and social dynamics of transnational youth within their socio-historical specificity. In locating transnational youth, I find the postcolonial lens most useful in highlighting the cultural inequalities present in transnational spaces. Most importantly, I propose an analytical shift from methodological nationalism to methodological cosmopolitanism (Beck \& Sznaider, 2006). I use cosmopolitanism as the conceptual framework to analyse how young people engage with what I call the school's ideology of being "international". However, as Wimmer and Glick Schiller (2002, p. 326) warns, in moving beyond methodological nationalism it is "important to remember the continued potency of nationalism." Beck and Sznaider (2006, p. 8) also write, "Cosmopolitanism and nationalism are not mutually exclusive, neither methodologically nor normatively." Hence, I incorporate the national context of the host society and other countries into the analysis. I also emphasize that I interrogate the school's ideology of being "international" and the cosmopolitan practices of transnational youth within the context of converging transnational and national discourses.

\section{“Cosmopolitanism” as a conceptual framework}

Theories of cosmopolitanism have proliferated over the last decade or so, suggesting that there are different ways of peaceably engaging with the Other. There seem to be as many ways of being cosmopolitan as there are hyphenated identities (see Cheah \& Robbins, 1998; Hansen, 2010; Vertovec \& Cohen, 2002; Werbner, 2008). Cosmopolitanisms include elite (e.g. Hannerz, 1996), colonial (Van der Veer, 2002), postcolonial (Parry, 1991), rooted (Abu-Rabia, 2008; Appiah, 1998, 2006), rural, feminist, and working-class (Werbner, 1999) or vernacular (Bhabha, 1996) cosmopolitanisms, just to name a few. Various notions of cosmopolitanism are used to analyse the impact of transnational interconnectivity upon actors who are differently situated. It is within this ongoing discussion that I locate my use of methodological 
cosmopolitanism, by which I mean the process of taking the everyday reality of peaceably engaging with the Other as the norm and using that as the starting point for analysis. In this thesis, I use cosmopolitanism as a conceptual framework to analyse the data, and to critique the ideology of being "international" that permeated my field site and that defines much of the literature on TCKs and international schools.

In this thesis, I differentiate between cosmopolitan ideologies, practices, capital, and subjectivities. Cosmopolitan ideologies pertain to attitudes and beliefs about peaceably engaging with the Other; cosmopolitan practices refer to the ways in which one engages with the Other; cosmopolitan capital refers to the cultural capabilities and social networks that enable one to practise cosmopolitanism (Bourdieu, 1986; Weenink, 2008); and cosmopolitan subjectivities refer to the ways in which people feel or do not feel cosmopolitan. I argue that cosmopolitan ideologies, practices, capital, and subjectivities are embedded within structures of power (Hall \& Werbner, 2008; Werbner, 1999).

Beck and Sznaider (2010, p. 389) make a distinction between "cosmopolitan philosophy and cosmopolitan sociology," or the "theory and praxis" of cosmopolitanism that is pertinent to this thesis. The former refers to the "moral ideal of cosmopolitanism (as expressed in Enlightenment philosophy)," which reflects the ideology of being "international" (p. 388). Being "international" is idealized as a sense of cultural mixing, a sense of belonging everywhere and nowhere, and the ability to transcend social categories of race, nation and culture when engaging with the Other (Chapter 4). It represents a form of cosmopolitanism that Brennan (2008, p. 44) describes as,

colloquially associated with broad fellow feeling, world travel, openness to cultural otherness, and so on...It both describes and endorses (endorses as it describes) the creation of a singularity out of newness, a blending and merging of differences becoming one entity.

However, this thesis argues that being "international" is practised from a position of power in transnational spaces, like TIS, where the dominant culture is Euro-American. Consequently, at TIS the "singularity" that Brennan refers to is dependent on one's access to Euro-American cultural capital. I define "cultural capital" as the way a person acts, thinks, and feels that would enable them to operate in particular cultural milieus, which I discuss in Chapter 2 (Bourdieu, 
1984).

One of the central arguments of this thesis is that the school's ideology of being "international" is a Eurocentric form of cosmopolitanism, and its Eurocentrism has implications on the social dynamics of the school. This ideology defines difference based on colonial conceptions of race and culture, and only recognizes as "international" the cosmopolitan practices that privilege Euro-American cultural capital. In this thesis, I show that the literature on Third Culture Kids and the dominant (Euro-American) culture of transnational educational spaces, privileges an elite internationalism that reflects contemporary international capitalist structures and continuity with the colonial. TIS reveals that being "international" is characterized by speaking (native) English, maintaining a certain distance with the local, having Euro-American capital by being "white" or "western", and engaging with those who are "racially" different. I show that while the ideology of being "international" promotes peaceable engagement among transnational actors, it also reproduces transnational and national class structures by privileging Euro-American capital. Meanwhile, the data reveals that there are many different ways of practising cosmopolitanism that do not reflect the purported ideal. I found that young people at TIS were practising cosmopolitanism in ways that did not fit the school's ideology, and this made them appear as though they were not being "international".

Cosmopolitanism is practised in many different forms specific to the socio-historical context because it is a dialogical process of engagement with the Other. I emphasize Delanty's (2009, p. 53) words that "the very notion of cosmopolitanism compels the recognition of multiple kinds of cosmopolitanism." I use cosmopolitanism as a conceptual framework that recognizes that openness to the Other lead to a multiplicity of ways in which social interactions and identifications occur in transnational spaces.

Cosmopolitan practices are driven by globalization, which is, as Hall (\& Werbner, 2008, p. 346) comments, "a deeply contradictory process" because it occurs through historical and contemporary "systems of inequality and power." Hall argues that contemporary cosmopolitanism is part of a global capitalist modernity built upon structures of global power and transnational inequalities. He differentiates between "cosmopolitanism of the above" and "cosmopolitanism from below" and gives starkly contrasting examples of the two: jet-setting global entrepreneurs who presumably choose to cross borders exemplify the former and boatriding refugees who have been "driven across borders" exemplify the latter (Hall \& Werbner, 
2008 , p. 346). For the former, global life is "a reward for status, education or wealth," while for the latter it is "one of the necessities imposed by the disjunctures of modern globalisation" (Hall \& Werbner, 2008, p. 347).

The people I studied experienced global mobility from a position of privilege in relation to the majority of the world's population. They are the children of a population who, Leslie Sklair (2001, p. 10) refers to as the transnational capitalist class: "It is domiciled in and identified with no particular country but, on the contrary, is identified with the global capitalist system." Nevertheless, the people I studied were not always in a position of privilege relative to the dominant culture within elite transnational spaces, because these spaces are not neutral. Further, because they move countries as dependents of mobile professionals rather than because of their own choice, in some ways transnational young people have no say in crossing cultural borders and have to practise cosmopolitanism from a place of relative lack of power. I argue that transnational youth practise both cosmopolitanism of the above and cosmopolitanism from a place of relative marginalization in relation to the context.

Crucially, the different ways in which young people experience transnational spaces influence the way they think and feel. Ortner $(2006$, p. 107) refers to this as "subjectivity" by which she means,

the ensemble of modes of perception, affect, thought, desire, and fear that animate acting subjects...as well [as] the cultural and social formations that shape, organize, and provoke those modes of affect, thought, and so on.

Cosmopolitan subjectivities are shaped within structures of power. Cosmopolitanism from above enables a sense of being "a citizen of the world". This kind of "felt cosmopolitanism" requires one to invoke privilege (Calhoun, 2008, p. 106). It is a Eurocentric form of cosmopolitanism that has historical continuity with the colonial discourse of being at home everywhere in the Empire (Chapter 4), as well as one that panders to the cultural requirements of a capitalist modernity (Chapter 7). I will show that this is the form of cosmopolitanism that characterized TIS's ideology of being "international". But in order to practise it, students needed Euro-American capital, which was not available to all in equal measure. Those unable to uphold or embody the school's ideology of internationalism, due to insufficient EuroAmerican capital, practised alternative forms of cosmopolitanisms, which were not necessarily 
recognized as such by their practitioners, let alone by the dominant school culture. These forms of cosmopolitanism were practised from a place of marginality vis-à-vis the dominant Euro-American culture of the school.

When practised from a place of marginality, cosmopolitan engagement with the Other produces a sense of ambivalence. Of this ambivalence, Hall (2008, p. 347) says, "this is inevitably the site of what Du Bois called 'double consciousness', and of what, somewhat unadvisedly perhaps, I have elsewhere called "hybridity'." In contrast to the felt cosmopolitanism of the dominant Euro-American culture, some students at the international school expressed their cosmopolitan tendency or hybridity as a process of becoming "Asian", among other things. In this thesis, I argue that transnational youth situationally shift between multiple practices of cosmopolitanism depending on their positionality, and in turn this shapes their subjectivities in different ways. They practise cosmopolitanism by becoming "western" and/or by becoming "Asian", "Indonesian", "Korean", etc. I illustrate that these processes are not necessarily mutually exclusive. Cosmopolitanism is an expression of mutual intelligibility among those who traverse existing socially constructed boundaries in the same way that nationalism expressed a sense of mutual intelligibility among those who traversed pre-existing non-national boundaries (Anderson, 1983). Cosmopolitan ideologies are prisms through which communities are imagined in an increasingly globalizing world.

\section{Structure of thesis}

This thesis explicates the Eurocentric nature of the ideology of internationalism at the international school through a discussion of how cultural capital, such as speaking English and being western or westernized, and unfamiliarity with the local, are constructed as "international". It then illustrates the complex ways in which transnational youth engage with and challenge this ideology, and find alternative ways to practise cosmopolitanism. The tension between the shared experience of a transnational space that privileges a Eurocentric form of cosmopolitanism and the differing ways in which various actors experience this space underlines the thematic focus of each chapter.

In Chapter 2, I provide an overview of the literature on Third Culture Kids and use the stories of participants to highlight issues of belonging shared by transnational youth. I show that the 
term Third Culture Kid narrates transnational belonging in emotionally powerful ways. However, I also argue that the literature has overlooked certain experiences due to its Eurocentric lens, and that therefore the term is more useful as an emic concept rather than an analytical concept.

I reflect on my own transnational upbringing and experience of international schools in Chapter 3 because they were crucial in identifying the major gaps in the existing research. This is followed by a brief discussion of the ethnographic method that is characterized by qualitative data collection and data analysis processes, and an exploration of the position of the researcher in the field. I argue that in transnational spaces, the researcher's position as an insider or outsider is fluid and shifts depending on with whom they are interacting.

Chapter 4 introduces the field site, The International School, and situates it in Jakarta, Indonesia as a postcolonial locale. It outlines recent historical developments since the Asian financial crisis of 1997 and their impact on the educational landscape in Indonesia. I also provide an overview of the student groupings to set the scene for the data chapters. I make a case for methodological cosmopolitanism in studying international schools and international education by conceptualizing the field site as a transnational educational space and contextualizing it in relation to the global trend towards internationalization of education. This chapter explicates the way TIS articulates its ideology of being "international". The rest of the thesis sets out to show that TIS's ideology is Eurocentric, which affects the social dynamics of the school.

As language is a theme that permeates the data, Chapter 5 outlines the way colonial and capitalist discourses relating to language, particularly English, shapes the subjectivities of transnational youth. I show that the English language shapes transnational youth because it is perceived as powerful and "international". This chapter provides an in-depth account of the participants' experience of internalized racism through their encounter with English at the international school, and the way they navigate around this issue in adulthood. It establishes English language fluency as cultural capital and marker of distinction in both national and transnational contexts.

Chapter 6 focuses on the school's engagement with the host country. I argue that the school community constructs the host country as an unfamiliar, dangerous Other and that the 
school's ideology of being "international" is dependent on maintaining a distance with the local. This distance helps construct the "international" community as western.

Chapter 7 further examines TIS's ideology of being "international" in relation to transnational and (multiple) national class structures that converge at TIS. Parents and students are driven by global economic and political forces to pursue Euro-American cultural capital. The cultural capital they pursue consists of, among others, the ability to speak English, western education, western mannerisms, access to higher education in the West, and passports to developed western countries. There is a gap between those who already possess these forms of cultural capital and those who do not. Those who are still in pursuit of this capital are perceived as not being genuinely committed to the school's internationalist ideals.

In Chapter 8, I turn the focus on the students' social dynamics by looking at with whom and where students choose to hang out. I argue that social status and spaces are racialized to reinforce the cultural affinity between students with Euro-American capital and teaching staff. The study of students' social relations also indicates that Indonesian students present an exception to the rule due to their economic capital. Assessments of school belonging and whether or not students are perceived to contribute to the school are affected by students' cultural capital. I also touch upon the gendered nature of the social hierarchy.

In Chapter 9, I show that practising cosmopolitanism is a social strategy for young people to negotiate boundaries based on their ambivalence regarding their hybrid identities and unequal positionality within a transnational space. Cosmopolitan practices are situational and can be seen as a process of becoming "international", "western", "Asian", "Indonesian", or "Korean", among others, depending on the student and the context.

The intricacies of intimate relations make such relations at once the most vulnerable and unsusceptible frontier to processes of cosmopolitanization. In Chapter 10 I demonstrate that colonial and capitalist discourses of race, culture, and gender influence sexual desirability and attraction in ways that bring into relief the dominance of the Euro-American culture at the international school. Transnational youth racialize beauty. Their cultural capital influenced whom they desired and by whom they felt desired. I show that some students were attracted to "whiteness", while others seemingly rejected it as a defence mechanism. 
Chapter 11 brings the thesis together by returning the focus to the Eurocentrism of the school's ideology of being "international" and its implications for student social dynamics. The school's ideology emphasizes visible diversity based on colonial discourses of "race". It looks favourably upon the visible "racial" heterogeneity of the English-speaking student groups by rendering their cultural homogeneity invisible. Similarly, it looks unfavourably upon the racial homogeneity of those who choose to segregate from or challenge the hegemonic cosmopolitan practices, by rendering their cultural heterogeneity invisible. This selective vision results in a Eurocentric cosmopolitan hierarchy, and it is within this framework that students used both acquired and inherited capital to compete to become "international". While TIS endeavoured to produce "global citizens", it did not sufficiently recognize that transnational spaces are not neutral and that cultural hierarchies based on global, regional, and national hierarchies continue to impact social relations among transnational youth.

In all, the data chapters together demonstrate that the ideology of being "international" reproduces the transnationalist capitalist class as well as national elites. Transnational youth employ cosmopolitan practices situationally as social strategies to manage their hybrid identities and navigate transnational spaces. In the next two chapters, I further explore the possibilities that ethnographic analysis offers in capturing the complexities of a transnational upbringing through a detailed discussion of the site, analytical tools, and methods involved in such an analysis. 


\section{Chapter 2}

\section{"Third Culture Kid": Narrating transnational belonging}

So we went back to the States. I went into the public school in Philadelphia and...the school didn't know what to do with me. I could not read, write, or speak English. So they were very confused. Here's this little American kid who has very low levels of comprehension. So they gave me an IQ test. I did extremely poorly on it, as you can imagine (smiling cheekily), because it was in English. And so I was labelled as educable mentally retarded and placed in a Special Education classroom for my eighth grade year.

...There was no ESOL (English for Speakers of Other Languages) program...in this school. So it was, in essence, my classroom-where I was gonna learn to read, write and speak English...All of my classmates had Down syndrome, or were blind, in wheelchairs, or mentally retarded, and that was my classroom...Then you got mainstream [classes] so I was able to go to P.E. (Physical Education) with the regular kids.

One of the first exercises I had to do in Special Ed. is to...have a label...a wooden plaque that we actually had to write our name in...in like wood carving. And I actually had to write my name "[Nathan]" and then "Special Ed" on it, and I had to wear that around my neck when I went out on the hallway. So that the little...the retarded kid could find his, you know...I could be helped back to my classroom if I got lost.

So I mean this is eighth grade...So as a TCK...as a kid who really...I mean as an educator, I look back and I go, "Oh my goodness, was I ever mislabeled!" I mean I was ESOL, yes, but I certainly wasn't educably mentally retarded.

-Interview with Nathan (17 March 2009)-an educator and an American who grew up in France and was fluent in French when he returned to the United States in $8^{\text {th }}$ grade

El-Zein (2002, p. 230) writes, "The migrant loses the concise language of familiarity and shared memory, the ability to evoke worlds of associations with a few hints and words." In effect, the migrant loses a sense of unspoken mutual intelligibility. I will show that the term "Third Culture Kid", which Nathan alludes to above, fills this loss of language and culture by narrating 
belonging in a transnational world. The meanings associated with the term represent an emotional homeland where those with a transnational upbringing find a sense of coherence and continuity to their fragmented experiences of repeated geographic and cultural displacements. "Third Culture Kid" narrates a shared memory of repeated loss of place and relationships with each move, and familiarity with cultural in-betweenness. I argue that "Third Culture Kid" is powerful as an emic (insider) term despite its limitations as an analytical concept.

This chapter reviews the literature on Third Culture Kids to highlight issues of belonging shared by transnational youth. I use Nathan's story to introduce the emic relevance of the term. I employ theories from developmental psychology and anthropology to demonstrate the importance of "Third Culture Kid" in narrating transnational identity and belonging through a sense of mutual intelligibility. However, I acknowledge that transnational youth are diverse. There are aspects to their experiences that are not shared across the board. I later return to Nathan's story to give an example of other forms of mutual intelligibility that transnational youth might evoke before. I also introduce Bourdieu's notion of habitus, capital, and bodily hexis as conceptual tools for studying the varying ways in which transnational youth evoke a sense of mutual intelligibility and its impact on their interaction with each other and engagement with the school's Eurocentric ideology of being international.

\section{“Was I ever mislabelled!”}

Nathan's parents were American and native speakers of English. But Nathan grew up in France where he attended local schools, then moved "back" to the United States for a year, as detailed above, before moving to Germany where he attended an international school. Nathan was fluent in French because he grew up mostly in France. By the time I met him in Jakarta in January 2009, Nathan sounded like a native speaker of English who had grown up in the United States; he explained that his accent is fluid because he tends to take on the regional American accent of the other speaker. However, his initial inability to speak English was, in effect, equated with having an intellectual disability and rendered him mute in the American context where he had returned for 8 th grade. His transnational experiences did not fit in with the mainstream narrative of a singular "American" identity except as something that was lacking compared to the norm. It was not until he encountered the term "Third Culture Kid" that he 
was able to make sense of his experiences of cultural displacement. Nathan recounted,

...so my parents, after one year, moved to Germany. We moved to an international school, where, for the first time in my life, I was actually with other international kids, TCK's. Everything else, I had been with French kids... and...not really understanding who I was as an American. Pretty negative experience when I went back to $8^{\text {th }}$ grade in America, you know, it didn't really leave a very good taste in my mouth. And then for the first time in an international school at $9^{\text {th }}$ grade, I realize "Oh, this is who I am."

And Dave Pollock ${ }^{7}$ actually came to speak at our school, and it was the first time that I had...heard this term, TCK. And that identity switched something in me. Understanding that...actually helped me. This help settle some things in me. Was I retarded, was I less than intelligent? Was I going to wrestle with this whole-was I French, was I American, was I German? But all of a sudden be[ing] given an identity, and surrounded with kids who had a similar identity, even though all of them had a different story, which is a part of the beauty of being a TCK is that our differences are actually the thing that unites us.

According to Nathan, he was "given an identity" through spending time with others who had shared his transnational experiences and discovering a language with which to narrate those experiences that did not fit into the French, American or German narratives of singular national identities (Walters, 2006). It "settle[d] some things" and "switched something" in Nathan. Ortner (2006, p. 125), borrowing from Sennett (1998), writes that narratives fulfil the "need for conceptual, cognitive, symbolic tools for reorienting and reconstituting the self" within a postmodern world. "Third Culture Kid" as an emic term situates the otherwise fragmented experiences of mobility and repeated geographic and cultural displacement within the larger socio-historical context of a transnational world. The next section is an overview of commonly cited characteristics of TCKs that form its narrative framework.

\section{Third Culture Kids: Who are they?}

"Third Culture Kid" refers to people who move internationally as they are growing up, often multiple times due to their parents' (usually father's) employment (R. H. Useem \& Downie,

\footnotetext{
${ }^{7}$ Co-author of the popular book on Third Culture Kids (Pollock \& Van Reken, 2009[2001]).
} 
1976). Their sojourn outside their "country of origin" is perceived as temporary. They are typically, though not exclusively, identified as children of expatriate professionals, missionaries, and military service people who usually expect to be moved to another country or repatriated to their country of passport at the end of their parents' assignment. They are typically characterized as adaptable, interculturally competent and having a global outlook, while also faced with challenges due to their transient lifestyle (Pollock \& Van Reken, 2009[2001]; Straffon, 2003). The most significant challenge stems from the fact that they experience transnational mobility while they are growing up. For many, this impacts on their sense of identity and belonging (Hayden \& Thompson, 1995; McLachlan, 2007; Pollock \& Van Reken, 2009[2001]; Schaetti, 2000). They have been variously labelled as "Third Culture Kids (TCKs)" (Pollock \& Van Reken, 2009[2001]), "global nomads" (McCaig, 2002) and "internationally mobile children" (Langford, 1998) in English, and "kikokushijo" (returnee children) in Japanese (e.g. Goodman, 1990, p. 10).

Pollock (Pollock \& Van Reken, 2009[2001], p. 13) write,

A Third Culture Kid (TCK) is a person who has spent a significant part of his or her developmental years outside the parents' culture. The TCK builds relationships to all of the cultures, while not having full ownership in any. Although elements from each culture are assimilated into the TCK's life experience, the sense of belonging is in relationship to others of similar background. ${ }^{8}$

According to the literature, TCKs relate well with others who have a similarly transnational upbringing, regardless of where those others were raised. It is in their shared experience of mobility, displacement, and hybridity - a shared third culture-that they find a sense of mutual intelligibility through which differences are (momentarily) suspended.

\footnotetext{
${ }^{8}$ From "The TCK Profile" seminar material, Interaction, Inc., 1989, 1 as cited in Pollock and Van Reken (2009[2001]). While Pollock and Van Reken use the broader term 'culture', other authors limit their definition to a narrower set of experiences. Norma McCaig (2002, p. 11) states that "Third Culture Kids" or "global nomads" are those "who are raised and educated internationally due to a parent's career choice." Barbara Schaetti $(2000$, p. 8) supports this definition, contending that "mobility based upon parental employment is a very particular experience." While the rigid parameters of these definitions are difficult to apply to an anthropological study of transnational youth, their use in non-anthropological fields offers valuable insight into the impact of mobility and multiple displacements on children and youth.
} 


\section{Mobility and adolescence}

When a young person is repeatedly uprooted from their social environment, it affects their sense of identity and belonging. Identity and belonging develop through interaction between the individual and their socio-cultural context, thus changing with the context (Erikson, 1959, 1968; Schaetti, 2000). I use "identity" to emphasize a developmental framework that narrates a sense of continuity and coherence out of seemingly fragmented life experiences and cultural personas, and "belonging" to emphasize a sense of mutual intelligibility resulting from shared experiences and understanding of the world.

The psychologist Erik Erikson $(1959,1968,2008)$ claims that adolescence marks a crucial phase in a person's development as they go through a process of establishing who they are within and who they are in relation to others. They begin to internally address the question, "Who am I?" to find a sense of self that remains more or less coherent in the face of change (Schachter, 2005, p. 141; Schwartz, 2001, p. 7). Berzonsky (2005, p. 129) explains, "[p]ersonal identity implies that a specific person continues to be the same person across varying conditions and over time." One way a young person explores this sense of self is through intimacy with another. Erikson (1968, p. 42) writes that, "to a considerable extent adolescent love is an attempt to arrive at a definition of one's identity by projecting one's diffused self-image on another and by seeing it thus reflected and gradually clarified. This is why so much of young love is conversation." It is through interaction with others that a person learns how they are similar and yet different to others. While intimacy is defined differently across cultures, the "feeling of knowing ourselves and being known by others" is a basic human need (Pollock \& Van Reken, 2009[2001], p. 142). Erikson (1959, p. 102) states that in adolescence "the young individual must learn to be most himself [sic - universal male] where he means most to others - those others, to be sure, who have come to mean most to him."

Those with a transnational upbringing find this process challenging due to their transient lifestyle. The people who know them and their socio-cultural context change frequently. Some move internationally multiple times. Others may only sojourn to one country before repatriating, but they can experience mobility indirectly through attending an international school that has a high student turn over rate because it caters for mobile expatriate families. These young people have to trade in their social network of relationships, crucial to adolescent development, for new ones each time they or their friends move. They need to start their 
relationships over and over again, re-explaining themselves and their history. While reinventing oneself can be constructive, it can interfere with the process of coming to know and being known by others. A therapist said of her clients who have a transnational upbringing that "few of them had any idea what it meant to be a person" (Pollock \& Van Reken, 2009[2001], p. 141).

My findings show that those who stayed in one international school over a long period of time adopted mechanisms to cope with their transient social networks. These coping mechanisms impacted upon the cultural dynamics on campus to undermine the school's efforts to reproduce practices of being international among its students.

Mobility also disrupts their sense of "home" (Ferstad, 2002; Pollock \& Van Reken, 2009[2001]). The people who mean the most to transnational youth may be geographically scattered. Thus, instead of a geographic place, many identify home in terms of relationships. For those close to their families, their home moves with the family, the only constant in their lives. Corrine $\mathrm{F}$. Ferstad (2002, p. 8) writes, "They move around the world with their families and often the people in the family become their roots."

Scholars who emphasize the importance of agency in identity development argue that having a sense of control over life decisions correlates to having a more secure sense of identity (Coleman, 2011; Schwartz, Côté, \& Arnett, 2005). However, as dependents, transnational children and youth have little control over their processes of displacement. Kanno (2000, p. 377) quotes Naomi Horoiwa (1987), who writes that "from the point of view of kikokushijo, ${ }^{9}$ going abroad is like a natural disaster: It comes when it comes; you have little control over it; and yet you have to deal with the consequences." To elaborate on this analogy, when a natural disaster wipes out a village or city, most would need to know why they lost their loved ones and the surroundings they were familiar with. Some may say the gods were angry, while others say a plate tectonic movement caused the earth to destabilize. Most will not simply shrug their shoulders and say, "Yeah, things happen." They look for explanations. Likewise, "Third Culture Kid" provides a framework to make sense of the consequences of multiple displacements occurring in childhood.

\footnotetext{
${ }^{9}$ A Japanese term referring to returnee children of Japanese expatriate workers who have been posted overseas by their company or organization (see Goodman, 1990).
} 


\section{Mobility and imagined communities}

Mobility challenges the way transnational youth relate to others at a collective level. They frequently negotiate socially constructed boundaries that vary with context as they are growing up, making it challenging for them to develop a singular, static, bounded sense of belonging that can produce a one word answer to the question, "Where are you from?" (Fail, Thompson, \& Walker, 2004). Pollock and Van Reken (2009[2001], p. 55) identify four simple ways a person can relate to the dominant culture in the following diagram:

\begin{tabular}{|c|c|}
\hline $\begin{array}{c}\text { Foreigner } \\
\text { Look different } \\
\text { Think different }\end{array}$ & $\begin{array}{c}\text { Hidden Immigrant } \\
\text { Look alike } \\
\text { Think different }\end{array}$ \\
\hline Adopted & Mirror \\
Look different & Look alike \\
Think alike & Think alike \\
\hline
\end{tabular}

Figure 1: PolVan Cultural Identity Box (@ 1996 David C. Pollock/Ruth E. Van Reken)

While increased mobility means that many today move from one box to another at some point in their lives, those who grow up transnationally often do not have a "Mirror" box.

One of the most researched issues in the literature on Third Culture Kids is their experience of cultural marginalization upon repatriation to their passport country. Richard Downie (1976) found that American citizens raised overseas who repatriated for college had to set aside their transnational experience in order to fit in because mainstream America would only validate one aspect of their identity-the American part. It is challenging to establish who one is in relation to others when only a fragment of one's self is being validated. Hall (1995, pp. 67-68) comments, "When it is we who are rearticulated, we don't like it so much." Barbara Schaetti described her own repatriation as challenging in her dissertation on "global nomads". She has a Swiss father and an American mother, both of whom were born in India, and had lived in ten countries before she was eighteen years old. Schaetti (2000, p. 10) writes,

I never questioned my identity, national or multicultural or otherwise, until I went "home" to the United States to live. I quickly learned that the American I was 
raised to be was not "American" in the way my new peers defined it. I shared none of the popular knowledge and few of the common experiences. The things I cared about were irrelevant to those around me. I behaved in ways considered "foreign" and spoke with an accent.

What Schaetti imagined as "American" and the reality she faced upon repatriation were different. There was a lack of a mutual intelligibility between Schaetti and her fellow American nationals.

\section{Cultural chameleon}

Mutual intelligibility is more than a shared language. Allan (2004, p. 90) describes the "invisible parts" of culture as "routine behaviour and unconscious habits, which are considered to be 'natural' and which are instinctively known and adhered to by everyone sharing that culture." The need to negotiate various cultural contexts cause some to act like cultural chameleons (Pollock \& Van Reken, 2001, p. 92). They learn to pick up the cultural cues, languages, accents, and mannerisms of their surroundings so as to blend in with the dominant culture. In Bourdieu's (1986, p. 243) words, they acquire "cultural capital", as I discuss later.

In these situations, identity is "strategic and positional", as argued by Hall (1996b). While transnational youth may know how to play the game of acting out certain parts of their identity at different times in order to fit in, many may not necessarily like playing the game and struggle to accept that their identity is multiple, fragmented and negotiable (Ang, 2001; Hall, 1996b). Acting as a cultural chameleon may seem to them as though they are putting on different personas. It may also appear to those around them as inauthentic (Pollock \& Van Reken, 2001, p. 93). Some who feel unable to weave a coherent narrative of their lives out of their multiple fragmented identities express a sense of loss by taking on what Erikson (2008, p. 236) calls a "negative identity", where being different is their identity. Their inability to fit in with the dominant culture causes them to "learn more about who they are not, rather than who they are" (Walters, 2006, p. 79).

\section{Becoming "normal"}

Consequently, coming across the term "Third Culture Kid" or meeting others who also had a 
transnational upbringing is, for many, a life changing experience (Fail, 2002; Schaetti, 2000; Walters, 2006). A participant in this research, with whom I shared some literature on TCKs, wrote an email describing the profound impact that the literature had on him (19 December 2008):

[T]here was an instant release and lots of things started to make sense...to hear that I wasn't the only person to be moved on a much deeper level by this understanding helps tremendously. Thank you so much for sharing this with me...And boy, it's fantastic not to have to fit into some other culture-box-it's hard not being Black, Trinidian, English, Scottish, American, Chinese or Ghanaian but instead a strange mixture of the above. That's a little hard to deal with. The weirdest thing is when I find the roles within my above mentioned mix clashing, which means that depending on my surroundings I am more or less masculine/black etc., but never the norm (emphasis originally in Bold). [I] don't know how much sense that makes, but understanding that I don't fit anywhere is a big relief.

The deep sense of relief reveals the need for individuals to know that it is normal and therefore "okay" to be mixed.

According to Walters (2006, p. 52), the TCK narrative normalizes a person's transnational upbringing, which they may have hitherto considered pathological because their experiences seemed different from and incomprehensible to others. One of Walters' (2006, p. 98) interviewees who had a transnational upbringing described how she felt after reading a book on TCKs:

...and when I read that book I was like, "oh wow", I was in tears a lot just because it was like oh that was that explains why...why you know I acted certain ways in the past...like there are reasons for my weird, why I was always different.

As an emic term "Third Culture Kid" serves to normalize experiences of repeated geographic and cultural displacement and situate them in a larger narrative of a globalizing world. 


\section{Mutual intelligibility}

"Third Culture Kids" alludes to the sense of mutual intelligibility stemming from a shared transnational upbringing. A recurring theme on an online TCK forum is the difficulty faced by TCKs in expressing their feelings and sharing their transnational experiences with those who had not had a transnational upbringing. In contrast, they feel they do not have to explain themselves in detail to be understood when speaking to fellow TCKs. David Morley (2000, p. 48) writes,

a person is "at home" in the rhetoric of those with whom they share a mutual understanding of life, such that interaction is not dependent on long explanations but can proceed on the taken-for-granted premises of a set of shared assumptions. Home is where you can be recognised (as the particular person you are and as one of the category of normal persons) by others.

A Korean alumnus of The International School (TIS) where I did my fieldwork said it was "healing" to return for a visit almost two decades after she had graduated and to also meet up with a former teacher. Eun Joo explained in a Facebook message to me,

[E]verything about [TIS] made sense...I fit in like that piece of puzzle that's been missing for years...I didn't have to explain anything to anybody...Mr [Salamon] just "got $i t^{\prime \prime}$.

As in the case of Nathan, the international school environment helped normalize Eun Joo's experiences through meeting someone who could understand her. While Mr Salamon did not self-identify as a "TCK", he was the child of European migrants to the United States and had taught at TIS for over two decades, during which time he lived as an expatriate, which meant that he was familiar with the transnational experiences of his students.

While transnational youth come from diverse backgrounds, their shared experience of mobility and cultural displacement offers a platform for mutual intelligibility to the extent that their differences become momentarily suspended. Borrowing from Edward Sapir, Bashkow (2004, p. 452) argues that, 
...people's perception of a commonality of culture is founded more on relations of mutual comprehension than on actual sameness or identity. What is required is only that people can understand one another, if only partially and imperfectly...

According to Bashkow (2004, p. 452), individuals of diverse backgrounds can negotiate differences to create "an exaggerated impression of mutual understanding" that enables them to feel as though they share a culture. Richard Jenkins $(1997$, p. 10) similarly argues, "mutual intelligibility of the behaviour of others' is a fundamental prerequisite for any group." Thus, the sense of belonging that TCKs arguably feel in relation to each other arises from what Barth (1994, p. 15) describes in his conceptualization of ethnic groups as an assumption that members of a group are "fundamentally 'playing the same game"' (see also Bourdieu, 1990).

"Third Culture Kid" is a heuristic device for talking about the difference between those who have a transnational upbringing and those who do not. It describes a particular ethnoscape (Appadurai, 1996, p. 48). It must be noted, however, that the term seemed to carry more significance, in the existing research and in my own, among adults who had had a transnational upbringing than among those who were still dependents. I suggest that this is because the young participants in my research were still immersed in the international school environment among peers who shared their transnational experiences. The term resonates more after they leave the comfort of their peers and experience dissonance in the cultural milieu of their passport country where they expect to have a sense of mutual intelligibility but discover that they do not.

However, this thesis argues that this sense of mutual intelligibility is situational. The diversity of experiences among transnational youth means that they may be playing the same game in relation to those who have not had a transnational upbringing, but they may not always be playing the same game in relation to each other. Factors such as cultural background, race, class, and gender do not become irrelevant as the literature would suggest (for example, see Fail, 2002)-rather they continue to affect their experiences. I return to Nathan as an example before turning to my own experiences in the next chapter. 


\section{A shared sense of place: "I needed to know that story"}

Nathan's story shows that there are many layers to the experiences of transnational youth. These layers determine the points at which mutual intelligibility occurs or not among transnational youth, which I explain using Bourdieu's concept of habitus. In addition to being a TCK, Nathan is also of mixed heritage. Nathan's parents are both American but his father is a native American from the "high plains Sappony tribe in North Carolina" while his mother is a "blonde-hair blue-eyed hippie." They were married in the 1960s at a time when they "were told they were not allowed to date by the university they were going to" and cross-cultural marriages were "pretty frowned upon." His parents moved to France partly to escape the racial politics of the time.

Nathan returned to live in the U.S. several times prior to Jakarta and during one of those times he completed a doctorate in education for which he had received a scholarship designed for native Americans. He explained how he then came to work as a school principal on a Navajo reservation for a few years.

I...kind of thought that immediately we (Nathan and his wife) would head back overseas-we were applying to schools all over the world-and get back in the game...And I got this phone call from a guy working on a school in New Mexico on the Navajo reservation saying, "I want you to come and take a look at our school." It really kind of caught us by surprise, but they wanted us to come down and visit the school. And there's a part of me that's like, "Hey working with native American kids, how many native American men are there with doctorates in education?" You know? "Well let me just at least take a look at it."

As soon as we showed up in this rinky dink reservation school, we knew we had to do it. We had this...an overwhelming sense of calling, and needing to give back, and needing to...maybe it was a little bit of guilt, maybe it was a little bit of intrigue. I just received my doctora[te] because of my native American heritage and yet I know very little about my native American heritage. I'm half native American growing up in France. (Laughs) I know more about French wine than I do about native American traditions. So there was a part of me that said maybe this is an opportunity to explore that side of who I am and to give back. 
I asked Nathan whether his native American background prompted the school to contact him. He said,

Yes, absolutely, absolutely. The school had been in existence for a hundred years, and I was the first native American administrator there they ever hired in a hundred years. The story of Indian education in America is just heartbreaking. There are some recent movies that [have] been done on that. Some of the stories [are] of the American Indian boarding school, and the treatment of kids, and the way they had been just literally raped of their native identity to become white-enculturated and stripped of their language and identity and pride...So it was just all a part of a very, very sad story.

And I needed to know that story. I needed to understand... who I am. I needed to understand that. And to be honest, it was the first time that I ever felt at home in America. Being on the reservation, being a part of this subculture of misfits who don't quite belong, who don't fit into the mainstream-all of the sudden...not only do I start...can I start understanding my grandparents, my father, me...but I just truly felt at home there, and just loved it, absolutely loved it...

...It's a sad story but it's also, there is hope. It's a beautiful story as well...

The stories that we tell of ourselves as members of a group have a deep emotional significance. Rapport and Dawson (1998, p. 29) suggest, the stories people "tell of themselves and others are determined by the grammar of their language, by the genres of their culture, by the fund of stories of their society, and by the stories others tell and have told of them." Therefore, although Nathan was not of Navajo descent like his students, the experience of being involved in their education and community exposed him to the collective narrative of native Americans.

Their "story" gave cultural meaning and socio-historical context to his own family's story-of his grandparents and father, of the social reception of his parents' marriage and his scholarship. Collective narratives define the relationships between individuals and society. They place the individual temporally in relation to history. Narratives are ubiquitous and can be verbally articulated through official national histories and concepts such as "Third Culture 
Kids", or carried within ourselves. Bottomley $(1992$, p. 38) writes,

To some extent, each of us carries with her the collective history of her group or class, the sense of one's place described by Bourdieu as habitus...This means that interpersonal relations are never merely individual-to-individual, as subjectivist accounts might suggest.

Nathan had carried within him the collective history of native Americans but it was not until he worked on the reservation that he encountered others who shared that "sense of place" as native Americans, which made him feel "at home". Being with a "subculture of misfits" in the American context also resonated with his general experience of not belonging due to his transnational upbringing. "Habitus" is the process through which a shared sense of metaphoric place facilitates mutual intelligibility or, in Bottomley's (1992, p. 122) words, "a commonsense understanding of the world, and especially of what is 'natural' or even imaginable."

Habitus is so natural, like the air we breathe, that we forget it exists. In Bourdieu's (1990, p. 56) words, habitus is "embodied history, internalized as a second nature and so forgotten as history." It is the social structures that individuals internalize, which then mediates between the objective structures of the external world and individuals' subjective worlds (Jenkins, 1992; Ortner, 2006). At the individual level, it is a "feel for the game" (Bourdieu, 1990, p. 66). According to Jenkins (1992, p. 75), habitus is a "'tendency', 'propensity' or 'inclination'" towards certain matters, behaviours, and ways of thinking rather than others. At the collective level, habitus facilitates a sense of mutual intelligibility through a shared set of dispositions.

I argue that transnational youth share a sense of place or habitus in some ways with each other, but not in all ways, at all times, with all transnational youth. It is analogous to how Italians may share a sense of place in some ways but not in all ways, at all times, with all Italians. Consequently, habitus impacts on the way transnational youth and other actors, such as parents and staff, interact with each other at TIS and the way they engage with the school's ideology of being "international". Most notably, I will show that students at TIS internalized the Eurocentric socio-cultural hierarchies that informed the school's ideology of being "international" (i.e. the rules of the game), but not all students had the cultural capital (i.e. the capacity) to play the game successfully. Some played along while others challenged it. Yet even when they did challenge the hierarchy, the ways in which they did so were constrained by the Eurocentric hierarchy they had internalized. As Bottomley (1992, p. 123) notes, "Habitus is not 
determining, but it is a powerful mediating construct that can predefine what is necessary or even imaginable." ${ }^{10}$ This thesis will show that despite the school's ideological commitment to nurturing a spirit of engagement with the Other on equal terms, the internalized Eurocentric structures (western habitus) remain powerful in mediating social interactions at TIS. A teacher referred to it as the "hidden curriculum" (see Chapter 6 (Snyder, 1970)).

\section{Embodied history: "It was a different experience"}

Thus, linguistic fluency alone does not guarantee mutual intelligibility for those who do not occupy what Bottomley (1992, p. 122) refers to as, "similar positions in social and historical space." Nathan related the way this played out on the reservation:

I have come to believe that a part of my responsibility...was to serve as a bridge between the two cultures. A bridge, a translation-I can interpret. Often in our school situation, most of our teachers were white, most of our students were Indian (i.e. native American). There's just not a lot of Indian teachers out there. So sometimes what was happening is the communication [that] was happening was simply...they both speak in English, but the native person speaking...completely different [from] the white teacher. And there's miscommunication. So my job was to say, "Okay here's what's going on here: You're speaking the same language, but you're completely missing each other."

Although both groups spoke English, there was a lack of mutual intelligibility. They were "completely missing each other" due to the different sense of place they inhabited. The ability to relate with another is as much about the unspoken as it is the spoken words because, Bottomley (1992, p. 13) explains, history and a sense of one's place in the world is "literally embodied, i.e. written on the body, in language and in particular ways of being-in-the-world."

I argue that the ability of actors at TIS to "feel" the game is largely dependent on what Bourdieu (1990, pp. 69-70) refers to as "bodily hexis", which is cultural capital in its embodied form. Bodily hexis encompasses the way a person moves, sits, speaks (e.g. accents), etc. It tells a story of where we have been and where we are going. A shared bodily hexis contributes to a sense of mutual intelligibility. Bodies express history, as Jenkins (1992, p. 75) writes, through

\footnotetext{
${ }^{10}$ See (Baldassar, 1999) for an example.
} 
"the manner and style in which actors 'carry themselves': stance, gait, gesture, etc." In Nathan's words:

I called it walking in two worlds. Not only do we have to become multilingual, bilingual, you have to become multicultural, bicultural so that you can understand who you're speaking to. Now if I'm speaking to you, I would...I'm speaking very differently than if I was sitting with a native American elder in my office. I would have a completely different facial expression, demeanour, posture...When I'm speaking with my Indian grandparents and when I'm speaking with my white grandparents, I spoke incredibly differently with both of them. It was a different experience.

The "facial expression, demeanour, posture" all mark a person's ability to play the game, so to speak, to draw on a shared interpretation of the world, and thus signify a shared sense of social place. The mediating ability of cultural capital in its embodied form is so powerful that "[i]t was a different experience" (emphasis mine), in fact, "walking in two worlds".

Bourdieu's notion of capital has extensive application in this thesis for analysing social interactions among actors at the school and the way they engaged with the ideology of being "international". Bourdieu (1986, p. 241) offers four forms of capital, which he also refers to as "accumulated labor": cultural capital, symbolic capital, social capital, economic capital. Most pertinent to this thesis is cultural capital in its embodied state in "the form of long-lasting dispositions of the mind and body" as discussed above (Bourdieu, 1986, p. 243). It encompasses language, accents, and taste for "clothes, types of food, drinks, sports, friends" (Bourdieu, 1989, p. 19) and the way a person carries themselves. It can be transmitted through educational institutions as well as socialization within the family.

Closely related to cultural capital is symbolic capital, which Jenkins (1992, p. 85) summarizes as "prestige and honour". Symbolic capital gives recognition to economic and cultural capital as a sense of distinction. If cultural capital is "primarily legitimate knowledge of one kind or another," then symbolic capital produces "common sense" and determines what can be considered legitimate (Bourdieu, 1989, p. 21; Jenkins, 1992, p. 85). At TIS, those with EuroAmerican capital, including the ability to speak native English, are constructed as culturally superior and authentically "international” (e.g. Chapter 5 and 7). 
Social capital refers to "membership in a group" or a "durable network of more or less institutionalized relationships of mutual acquaintance and recognition" (Bourdieu, 1986, p. 248). I will show that social capital and the ability of students to mobilize their social capital (by drawing on their cultural capital) influences their relationship to each other and the staff, and thereby the way they practise cosmopolitanism.

The notion of economic capital is relevant because the experiences of transnational youth are classed. Education was considered a necessity for escaping poverty at the reservation where Nathan used to work, providing a stark contrast to the affluent students at TIS.

...So after 4 years, even though it was an amazingly rich and deep experience for all of us... And for me, educationally here (i.e. at TIS) I've been working in international schools and with kids who are, have everything, affluent, and education is a luxury, you know, but ultimately they're gonna take over daddy's company and it really didn't matter whether they're going to school or not. That whole thing with education is...[it's] their (i.e. native Americans) only way of getting off the reservation. It's the only guarantee of getting a job, of breaking the cycle of poverty, etc, etc. Where every day that sixteen-year-old girl shows up to school, it's a success because she's choosing to go to school rather than give up and quit because she's pregnant. I mean, to see education at that level changed me as an educator and had a profound, profound impact on who I am as an educator.

Economic capital marks the collective privilege of those at TIS. At the same time, Nathan was alluding to the Indonesian students who were marked as elite relative to other actors at TIS. They "have everything" and attend an international school in a country where such schools are considered a "luxury". However, even among a privileged cohort, some are more privileged than others in different ways. This prompted some parents to use the education offered by TIS to convert their own economic capital into cultural capital for their children (Chapter 7). The notion of economic capital is also relevant in that it is convertible into cultural capital and can be used to challenge others' cultural capital.

The ability and disposition of transnational youth to engage with the school's ideology of being "international" and practise one form of cosmopolitanism over others varies with the capital they possess and habitus in which they operate. With this in mind, I explore how the "third 
space" created by the TCK literature is constructed as a bastion of cosmopolitanism that includes or excludes various types of transnational youth.

\section{Whose cosmopolitan third space $?^{11}$}

Third Culture Kids are constructed as cosmopolitan vanguards both in the literature and at TIS (Fail, 2002; Fail et al., 2004; Ferstad, 2002; Schaetti, 2000; Walters, 2006; Wurgaft, 2006). Schaetti (2000) argues that TCKs who have reached an achieved multicultural identity stage are capable of transcending ethnic, national, and racial constructions of identity. In her dissertation, Leah R. Frederick (1996, p. 282) goes so far as to write, "As this research began, I was convinced TCKs were special. As it concludes, I am even more convinced of their specialness..." in reference to their ability to transcend differences. Helen Fail's (2002) study of TCKs who are non-native speakers of English corroborates this argument but none of her interview questions allowed for the participant to discuss the impact that language, ethnicity, culture, or gender may have had on their experiences. It is commonplace for the literature to assume that transnational spaces are neutral and that transnational experiences by default produce internationally-minded cosmopolitans. I argue otherwise. As Clifford (1986, p. 22) notes, "Cultural analysis is always enmeshed in global movements of difference and power."

Some research does show that young people do not automatically transcend difference by virtue of their transnational upbringing, but these works are few and far between. Ayako Konno's (2005) study found that there is no significant difference between the ethnic identity of Asian TCK students in the United States (those who spent at least 36 months outside their passport country before going to the US) and Asian international students in the US (those who had not spent time outside their passport country before going to the US). Similarly, Michael Allan (2004, p. 91) argues that the dominant culture of international schools can be a "determinant factor in the process of intercultural interaction." He notes two examples of failed intercultural learning in his study of TCKs at an English-medium based international school in Japan: a student from Texas in the United States had no problems fitting in with the school culture, while a student from Taiwan did. According to Allan (2004, p. 96), "Intercultural learning has not taken place in either case, firstly because of the lack of cultural dissonance, and secondly because of too much." Lisa M. Sparrow's (2000, p. 181) work on intercultural

\footnotetext{
${ }^{11}$ Bhabha (1990)
} 
competence revealed that "only members of dominant paradigms can have the luxurious illusion of objectivity or a self which is free of social realities" even among those who are otherwise multicultural. ${ }^{12}$ Roger Goodman's (1990) work on kikokushijo in turn embeds the experiences of transnational youth with Japanese passports within Japan's class structures, while Peterson (2011) argues that the cosmopolitanism of young Egyptian elites attending international schools reveals the intersections of national and transnational class structures. Furthermore, Schaetti (2000, p. 74) acknowledged that "issues of power and cultural dominance in international microcultures" need to be addressed in research. Nevertheless, the notion that TCKs can, as vanguards of cosmopolitanism, rise above these structures persists both in the TCK/global nomad and international school literature, as well as the field site.

Consequently, this ethnographic research on transnational youth takes into account "relations of power and meaning" to reveal a more nuanced, complex picture of the impact of inequality in transnational spaces on the experiences of young people in international schools and the situational nature of cosmopolitan practices (Smith, 2001, p. 139). I show, through the use of concepts such as habitus and capital, that the experiences of transnational youth are embedded within historical colonial discourses and contemporary economic and cultural structures. The dominant form of cosmopolitanism at TIS, which is articulated as being "international", privileges Euro-American capital. This is not to imply that colonial discourses have remained unchanged. Rather, I argue that there are continuities from the colonial era: Eurocentrism dominates transnational spaces even as its influence shifts and adjusts in relation to contemporary capitalist discourses to create complex hierarchies (Pennycook, 1998).

\section{Conclusion}

This chapter has provided an overview of the TCK literature through which I have shown that "Third Culture Kid" is important as an emic (insider) concept because it narrates transnational belonging for those who have experienced multiple geographic and cultural displacements. Although the term was coined as a sociological concept, it is analytically lacking in the same way that "Italy" or "Indonesia" represent (geographical and) emotional homelands but are insufficient as anthropological concepts. The TCK is constructed as an identity that is hybrid,

\footnotetext{
${ }^{12}$ Participants in Sparrow's study included those with a transnational upbringing though she does not use the term "Third Culture Kid".
} 
cosmopolitan, and rootless in contrast to supposedly normative identities that are constructed as singular, parochial, and rooted. The main thrust of the literature is to circumvent the dominant paradigm of imagined communities based on the nation-state by creating a cosmopolitan third space for those who do not neatly fit into this paradigm. In this thesis, I abandon the use of "Third Culture Kid" as an analytical concept due to its reliance on categorical binaries and its focus on the individual.

At TIS, as I will show, those who operated through different habitus felt unable to "connect", to put it in their words, with each other, despite speaking the same language and having in common the experience of growing up transnationally. Not being able to "connect" significantly influenced social interactions and the formation of social groups on campus. However, the dynamics surrounding the sense of disconnection that occurs among transnational youth have been overlooked in the literature due to its focus on the individual TCK and the limited attention given to social dynamics that occur between TCKs. Nathan spoke of "the beauty of being a TCK" as the way in which "our differences are actually the thing that unites us". This thesis explores these differences and how differences are constructed in order to further understand how mutual intelligibility can be facilitated. Jenkins $(1997$, p. 50) exhorts us to problematize "how difference is socially constructed, or the relative salience of difference from one context to another" rather than "difference in itself." In the next chapter I use my own story to elaborate how factors such as cultural background, language, race, and class affect transnational experiences differently despite a shared transnational upbringing. I thus introduce some of the themes that will recur in subsequent chapters. 


\section{Chapter 3}

\section{Situating the researcher and fieldwork}

"What makes you angry?" asked a visiting professor as we stood in the hallway of the university's limestone buildings. I had casually told her that I had been mulling over a possible topic for my Ph.D. for three years. It took a split second for me to respond to her, "The question, 'Where are you from?'” One gut reaction to a simple question set the course for the next few years of my life. A trusted friend from my undergraduate years once remarked, "You talk about 'identity' ad nauseam." This was because, like Anne-Sophie Bolon in Chapter 1, my answer to the question was never straightforward and rarely left unchallenged. I could personally relate to much of the literature on Third Culture Kids, though not all. My own experience of a transnational upbringing and international schools is an example of how those with a transnational upbringing have experiences in common that can be understood through the "Third Culture Kid" framework, but also how there are differences in our experiences that are significant.

This chapter makes a case for reflexive ethnography as a suitable methodology for researching transnational identities and educational spaces. According to Hage (2005, p. 474), reflexive ethnography engages in the double gaze that is

capable of capturing both descriptively the lived cultures with all their subtleties and analytically the global which structures them, both people's experiences and the social environment in which this experience is grounded, both the experiential surrounding that people are aware of and the macro-global structures that are well beyond their reach.

I therefore reflect on my own transnational upbringing as integral to the process of ethnographic research because my experiences affect the research focus, access to data, and interpretive lens. The telling of my own story both situates the researcher in the field and helps introduce the main themes of the data chapters. The ambiguity of the researcher's status as both insider and outsider, and the tension it produces in the data collection and analysis processes, are a recurring theme in these discussions. 


\section{The researcher's story}

I was born in Canada to a Chinese Indonesian father and a Japanese mother. ${ }^{13}$ I had lived in four countries by the time I was eighteen and six countries by age twenty. I currently hold dual Canadian and Australian citizenship, and speak four languages. I mostly attended international schools in Indonesia and Singapore, though I also attended local schools in Indonesia and Japan for a year each. However, the transnationality of my story did not begin with me. It began at least three generations ago with my great grandfather. As Bourdieu (1986) posits, a disposition for cosmopolitan engagement was transmitted to me through my family.

\section{Hereditary cosmopolitanism}

My father was the eleventh of twelve siblings, making me one of the younger of my paternal grandparents' 50 plus grandchildren. According to family stories, my Chinese grandfather's father had worked as a body guard on a ship and died in Kalimantan, ${ }^{14}$ where the ship had stopped over for trading. My grandfather's mother also died some time later. At nineteen, my grandfather boarded a boat for the Dutch East Indies, now Indonesia. He was part of the exodus of Chinese emigrants of the early 1900s. They headed for various European colonies as indentured workers to escape impoverishment in a country torn by political turmoil. In the Dutch East Indies, he worked to pay off his passage and help his fiancée (they had been betrothed as infants) and younger brother to join him from China. My grandparents then saved money to begin street-side peddling in markets, which eventually grew into several successful businesses.

By the time my father was born in the mid-1950s, his parents spoke fluent Indonesian and were financially comfortable. Grandfather had only studied to the second grade, but was able to read and write Chinese, and became fluent and literate in Indonesian through self-study. Dad was sent to an elementary school in Jakarta where the language of instruction was Mandarin. When Dad was in fourth grade, the school was closed down along with other Chinese schools across Indonesia, as part of the aftermath of the attempted coup of 1965, allegedly by Communists. The Chinese were used as political scapegoats during the purge that saw Suharto rise to power. Public use of Chinese languages was subsequently discouraged,

\footnotetext{
${ }^{13}$ Some parts of this section were first published as a chapter in Writing Out of Limbo: International Childhoods, Global Nomads and Third Culture Kids (Bell-Villada \& Sichel, 2011). Reproduced with permission from Cambridge Scholars Publishing.

${ }^{14} \mathrm{An}$ island that was previously known as 'Borneo' and now a part of Indonesia.
} 
importation of printed materials in Chinese prohibited, and diplomatic ties with the People's Republic of China frozen (Hoon, 2008). Sino-Indonesian diplomatic relations were gradually restored in the early 1990s, but the ban on Chinese printed material was only lifted in 2001, three years after Suharto's downfall in 1998.

When his Chinese school was closed down, Dad moved to an elementary school where the language of instruction was Indonesian. After this he was sent to Singapore with some of his siblings to study in a school whose language of instruction was English. Sending children overseas to study in a more developed country is still a common practice among middle- and upper-middle class (Chinese) Indonesians as a means to provide them with high quality education (Yeo, 2010). Today Dad speaks English fluently with a general "Asian" accent whose specific origins are unidentifiable; he prefers to read books on certain topics in English; he feels most comfortable speaking Indonesian; he spoke Mandarin to Mom when they first met because that was their only common language at the time; and he is now fluent enough in my mother's native language to crack jokes in Japanese.

My mother's story also illustrates that the acquisition of cultural capital, including a cosmopolitan disposition, is a generational project. Mom was the sixth of six siblings, grew up in the immediate aftermath of Japan's defeat in the war, and came of age during Japan's rapid economic growth. Both of my maternal grandparents were from a village and had elementary school education. My grandmother worked in a factory in Tokyo for several years before returning to the village for an arranged marriage. My grandfather was a carpenter who built work boats for the Shinano river. My grandfather's father had died from frostbite when Grandfather was young, leaving him with the care of his younger siblings. Impoverished, he and his younger brother became known around the village as the hardworking brothers.

While their lives were not luxurious by any means, my mother remembers that her family lived more comfortably than some of her poorer neighbours by the time she was in elementary school. My grandmother did not want her children to experience poverty the way she and her husband had, and therefore enrolled Mom in ballet, Japanese traditional dances, tea ceremony, and other classes - the kind that could add cultural capital for women in those days and enable women to become upwardly mobile. Mom enjoyed some of them, but not, for example, ballet classes, because she did not have the cultural capital to fit in with the city girls who dressed differently from her. Grandmother also liked to try new, foreign things (perhaps 
due to her exposure to Tokyo during her youth), such as introducing meat to the family diet, introducing my mother to the western tradition of Santa Claus, and serving (diluted) coffee ${ }^{15}$ to guests. Mom later became the first woman in her village to attend university (to the disapproval of some neighbours who thought it unbecoming of a woman) in Tokyo where she studied Japanese and Chinese literature. After completing university and working for several years, Mom left for Singapore to study Mandarin.

My parents met in Singapore in the 1970s. They were later married in Canada. Both my parents have since moved countries multiple times with their children with just a couple of suitcases. Though my father does not self-identify as a Third Culture Kid, he fits the profile. If nothing else, he became what I like to jokingly call a "serial migrant".

It is evident that my own transnational experiences are a result of the transnational engagements that began in previous generations in my family. A similar pattern emerges in the data-the transnational engagements of previous generations in research participants' families facilitated their own cosmopolitan dispositions. For example, parents made conscious decisions to increase their child's exposure to cosmopolitan cultural capital (sometimes at great financial cost) such as to English-medium education (Chapters 5 and 7). My parents' transnational exposure and financial capability (they were penniless for a while but my father's business eventually succeeded) ensured that both my sister and I learnt to speak fluent English. This secured our privileged position in the changing linguistic landscape of Indonesia where the upper-middle classes are increasingly using English in daily speech and business communications, much like the elite who spoke Dutch during colonial times. I explore these intersections of national and cosmopolitan cultural capital in Chapters 5 and 7.

\section{Like a second generation immigrant}

I had more than enough cultural capital to be "international". I am a native speaker of English, Japanese, and Indonesian, and conversational in Mandarin. Everyone in my immediate family speaks these four languages to different levels of fluency, largely determined by our schooling. My parents and I left Canada and went "back" to Indonesia when I was about three years old. My younger sister was born in Japan during a temporary visit. I spent a year at a local school in Indonesia before my parents moved me to an international school where I did most of my

\footnotetext{
${ }^{15}$ It was diluted to the colour of tea because it was expensive and my grandmother did not know how to prepare it properly.
} 
schooling to prepare me for our intended to return to Canada (we never did).

However, my hybridity did not automatically translate into cultural capital in the international school context. The international school I attended used English as its main language of instruction and prided itself on the myriad nationalities that were represented on campus, but culturally speaking it was predominantly North American. In elementary school I was puzzled that it was considered normal to have mothers who knew how to bake brownies while mine made sushi and that my schoolmates had American snacks and "Cabbage Patch" dolls, ${ }^{16}$ which I had never seen in the local shops of Jakarta in the 1980s. (Their parents purchased them on furloughs home to the United States or in stores and country clubs frequented by expatriate workers.) I experienced a sense of cultural dissonance vis-à-vis the dominant school culture. I felt like a second generation Asian immigrant in a western industrialized country (Foner \& Kasinitz, 2007). Nancy Foner's (2002) research on second-generation Americans indicates that their experience of transnational engagement is increasingly overlapping with that of mine and the cohort I studied.

The literature focus on the cultural dissonance that TCKs experience upon repatriation, but I experienced dissonance at the international school, as did many of the students at TIS. International schools are not neutral social spaces, which is a theme that this thesis explores.

\section{English and linguistic imperialism ${ }^{17}$}

While growing up I felt a sense of superiority for speaking English. In my teens, I had an argument with my mother when I switched from Japanese to English in mid-argument. I spoke fast, using English expressions that were too difficult for my Japanese mother to understand due to her limited English. She asked me to speak in Japanese. I talked back, telling her something to the effect that English was my first language and she was just going to have to deal with it. My outburst was a combination of genuine frustration at not being able to express myself in Japanese as well as I could in English, and arrogance at being able to speak English better than her. My mother became furious. She threatened to withdraw me from the international school. Mom said, "I would rather have an uneducated child who has a good heart than an educated child who lets their education ruin them on the inside!" I eventually apologized after she started throwing my thick, heavy American textbooks away. It was one of

\footnotetext{
${ }^{16} \mathrm{~A}$ brand of dolls that became highly popular in North America in the 1980s.

${ }^{17}$ Robert Phillipson (1992)
} 
the best lessons she taught me.

I had used my English language ability as a source of power. Burck (2005) writes that language issues among migrant families can disrupt relations of power in families. Both colonial and capitalist discourses have imbued English with such power that even a child can use it as cultural capital to maintain or challenge relations of power with adults. Issues of language and cultural retention are a recurring theme in this thesis (Chapter 5 and 9).

\section{School as a site of cultural reproduction}

The international school was a site for western cultural reproduction, which is evident when I compare my own cultural orientation to that of my sister. My sister is an Indonesian citizen who grew up and went to an Indonesian school for the most part, and speaks Indonesian as her first language. Although we have much in common-she also speaks English fluently, I grew up mostly in Indonesia like her, and we made similar international moves-we are different in that I was educated mainly at an international school and speak English as my first language. Within the family, we share similar values and can culturally relate to one another. Cultural differences become apparent when our varied levels of language ability and acculturation affect the way we relate to others. Also, I struggled greatly with my sense of identity while my sister did not. This was partly due to differences in personality, but not entirely. Her educational milieu corresponded to the cultural context of the country we were living in, while mine did not. My international school was Americanized. I learnt how to count American coins (the penny, nickel, dime, quarter, etc) in elementary school long before I ever visited the United States. In high school, they set up a television set outside the high school office that aired CNN's daily reports on the presidential election between Clinton and Bush. Consequent to being in this environment, I subconsciously thought of myself as American until my mid-twenties.

Educational milieus have a profound influence on a person's sense of identity and are sites of cultural reproduction (Levinson \& Holland, 1996; Willis, 1977). This thesis analyses the role of TIS in the cultural reproduction of national and transnational class structures that privilege a Euro-American way of being international. 


\section{Mobility and (cultural) displacement}

My family moved to Japan for a year when I was due to start sixth grade at about twelve years of age. The different academic calendar meant I had to redo fifth grade at a Japanese public school. I had a rudimentary grasp of written Japanese at the time and failed most of my kanji (Chinese/Japanese character) tests. This did not bother me much, owing perhaps to the fact that I could speak English-I was aware that English was an internationally valued language and thus felt emotionally compensated for my failed tests, at least temporarily.

However, I did not fit in well in my new social environment owing to my gender and different cultural upbringing. I was neither able nor willing to participate in the hierarchical relations prevalent among my female classmates. (In Chapter 6, I cite Chaitan, who echoes this sentiment of being unwilling to choose his place in the school social hierarchy, which resulted in his social marginalization.) My male classmates had a less defined sense of hierarchy that seemed to almost disappear once they hit the soccer field. I longed to join them as I was a tomboy and usually played with the boys, but it seemed taboo to engage in mixed gendered play at the new school.

There was another girl in my class who similarly did not belong to any social group and was sometimes bullied (particularly by the girls). Though I kept my distance from her at school (for fear of stigmatization by association), I engaged with her on our walk home from school on a regular basis. Hierarchical relations and gender restrictions were less pronounced outside of school.

I spent a year having no friends at school (though I had plenty of friends at church) and began to develop symptoms of tôkôkyohi $i^{18}$ or "school phobia" by the end our stay in Japan (Yoneyama, 2000, p. 77). I spent many recesses walking slowly up and down the school hallways while looking over the soccer field. This sense of isolation and silence subconsciously remained with me until I came across the literature on Third Culture Kids, which provided me with a narrative to make sense of the displacement I had experienced in Japan.

When we returned to Indonesia to my old international school, I thought things would return

\footnotetext{
${ }^{18}$ Tokokyohi, wherein school-aged children develop psychosomatic symptoms that prevent them from attending school, was identified as a social problem in Japan. For example, I met a Japanese teenager who had lived in Sweden for several years during elementary school, who found it difficult to fit in when he returned to Japan and subsequently developed tôkôkyohi-one morning he woke up and was physically unable to walk.
} 
to 'normal'. On the contrary, I experienced cultural displacement again. I had become "too Japanese". I dressed awkwardly-different to my Americanized classmates back at the international school. I no longer knew how to relate to my old friends and, I presume, vice versa. I found new friends of various backgrounds, a few of whom were Dutch. I also made Japanese friends.

My link to the on-campus Japanese community was initially established and partially maintained due to my mother's links with my Japanese friends' mothers. As my research reveals, social networks on campus are partially facilitated by off-campus networks between parents, i.e. hereditary social capital (Bourdieu, 1986). My parents had no links to any of the other language communities. But I was not completely immersed in this community. I did not have the cultural capital to fully engage in the Japanese social group and had I tried to do so, I felt that I would have had to play the cultural chameleon and consciously perform and accentuate my "Japaneseness" at the expense of playing down my other cultural influences. Nor was I keen on being fully identified with a group that was considered "ESOL", i.e. many of them were enrolled in classes designed for those who spoke English as a second language. ESOL students were perceived as inferior and invisible to the mainstream Anglophone ${ }^{19}$ students. For example, one Anglophone Indian graduate, with whom I later got in touch, could not even recall the presence of a large contingent of ESOL students at our former school.

However, as middle school turned into high school and high school progressed, my nonJapanese friends moved away one by one. I indirectly experienced the effects of mobility through the transient nature of the student body-an experience shared by the participants who remained at TIS for an extended period of time (Chapter 9). Around this time, student cliques became increasingly defined by language and cultural orientation-a pattern that I did not notice about my own experience until after I began this research. My Dutch friends thus increasingly hung out with other Dutch students, likewise my Indian friends with other Indians, and my Korean friends with other Koreans. It became more difficult each year to replace my social network.

I found myself shifting in and out of a few language groups without feeling at home in any. This was not surprising with regard to the Korean and Dutch groups, considering that I could not understand anything beyond a few swear words. But I was neither at home in the English nor

\footnotetext{
${ }^{19}$ I use the term "Anglophone" and "English-speaking" interchangeably to refer to those who have acquired a natural command of English regardless of their family's linguistic background.
} 
Japanese speaking groups though I was fluent in both languages, partly because my social skills did not develop as fast as those of my peers, nor were they accompanied by the appropriate cultural capital. At the end of $9^{\text {th }}$ grade, the number of Japanese students grew when students from the Jakarta Japanese School moved en masse to my school. I befriended many of them because by this time I had become more interested in Japan myself. However, I was still unable to fully relate to the Japanese students. The influence of cultural capital upon the formation of social groups and campus dynamics features prominently in this thesis.

Then at sixteen I moved. I moved ten times over the next eleven years between seven cities in six countries for various reasons, sometimes with the family and sometimes without. Many envied me for having lived "overseas" (an elusive place whose location changed in relation to where the speaker was from), being multilingual, and able to move fluidly between different cultural milieus (Pollock \& Van Reken, 2009[2001]). I was fully aware that it was a great privilege and adventure to live in so many countries at a young age. Nevertheless, I was emotionally exhausted by the end. I experienced many of the symptoms that characterize Third Culture Kids-rootless, restless, and unable to reconcile my fragmented identities. I felt as though nobody knew who I was as I had to re-establish myself with each move. I also felt I had to perform different identities to suit the cultural contexts in order to accommodate the fact that others could only relate to certain fragments of my identity-North American, Japanese, Indonesian, etc. (Ang, 2001; Hall, 1996b). But considering the privileges that came with a transnational upbringing, I assumed I was making a big deal out of nothing.

This changed when I began my doctoral research in 2008. I read about Third Culture Kids and a range of other topics relating to identity, from migration to mixed-race children. To my naïve surprise, "identity" was a major issue for many. The dissertations and academic articles that I read-the kind of writing that is usually considered dry and boring-often conjured up emotional responses in me. The term helped me begin to narrate my own story (Chapter 2). But I still had qualms about the term Third Culture Kids because it appeared to me like a term reserved for the "western expat kids" with whom I had gone to the international school and to whom I could not relate. 
Between local and expat, Asian and western

The "western expat kids" represented my own (folk) category that I used to describe members of the dominant culture at my international school. I often visited Jakarta as an adult and drove past the campus on numerous occasions. Each time, I experienced a fleeting, strange and unsettled feeling. More than a decade after I had left the school, I broached the topic with my parents and finally came to understand why I felt the way I did. All my classmates had been foreign nationals, making me a local who was acculturated into a non-local, mainly western expatriate culture. I was trained to see Indonesia through foreign eyes, a perception that ran contrary to my family's close affiliation with the country. Perceiving Indonesia through both foreign and local eyes conjured within me what W.E.B. Du Bois (2007[1903], p. 8) describes as the "peculiar sensation" of "double-consciousness, this sense of always looking at one's self through the eyes of others, of measuring one's soul by the tape of a world that looks on in amused contempt and pity."

I occasionally saw Indonesia through western expatriate eyes when my classmates spoke about Indonesians or Asians in a condescending way, though this rarely happened at a school that did not condone overt racism. It was the less obvious but systemic omission of Indonesia from campus life that trained my gaze. Indonesia, and the entire world outside of western civilization for that matter, was almost absent from our textbooks. The non-western world appeared only in tokenistic or traditional forms like the Saharan desert in geography class or the Egyptian pyramids and Great Wall of China in ancient history class. Modern history was western history, literature was western literature, mythology was Greek mythology, and science was invented by westerners. The rest of the world was invisible and exotic (Said, 1985[1978]).

Indonesia was inferior to the West. The Indonesian staff was mostly in support positions (e.g. teaching assistants, library assistants, clerical staff, cleaners, security guards) while the teaching positions and other positions of authority were almost always filled by foreign staff, who were mostly white. Apart from my first grade teacher who was Indonesian, the compulsory Indonesian language, society, and history classes were the only classes taught by Indonesians. But by the time I reached high school, my former first grade teacher was also teaching Indonesia related subjects. 
Even as students, some of us were aware (through the adult conversations that we overheard) that multinational companies, international organizations, and international schools used a three-tiered pay scale. We were aware that Indonesian teachers occupied the bottom rank of the three-tiered pay scale for teachers. The middle rank was for the locally hired foreign teachers, like my Japanese teacher who openly complained about the system in class. She was not happy that she was paid less than other teachers, even though she was Japanese, and not a local. As students, we were unsure of how to respond to a teacher's outburst against the school, so we listened. The top rank was for foreign teachers who were hired overseas. The pay scale system was similar at The International School (TIS) where I did my fieldwork, and the locally hired foreign teachers who I interviewed were most critical about it. The system treated "local" as automatically of less economic value, which had implications for how the "local" was perceived socially and culturally. I internalized these hierarchies. For a long time I perceived Indonesia as inferior and was ashamed of all things Indonesian.

Even positive words spoken about Indonesia at times constructed it as "Other". My white North American teacher once said, "I love Indonesian culture, it's beautiful." I reasoned that I should be happy she had said something nice about Indonesia. But she spoke as an outsider about a "culture" that to her was exotic and to be tasted like the ethnic cuisines in a multicultural society. Seeing Indonesia as an exotic Other induced a strange, unsettling feeling of double-consciousness in me. I was partly a local, but I was complicit in Othering Indonesia by virtue of participating in the school.

I also saw white people through Indonesian eyes. In fifth grade our teacher took us to an orphanage to deliver second-hand books in an act of charity. A group of us, from what was one of the most expensive schools in the archipelago, were bussed to the main road near a maze of Jakarta alleyways. We got off and walked a little in our branded sports shoes and casual wear on an unmaintained, decrepit lane to reach the classroom where the Indonesian students were waiting in their red and white uniforms. ${ }^{20}$ It was a tiny, non-air-conditioned classroom ventilated only by the half-opened slats of the louvre windows facing the dusty lane. The host teacher welcomed our teacher and they spoke in front of the classroom as we sat on the wooden chairs watching. I only have a vague recollection of our visit, but what impressed me was that the host teacher, who looked as though she had put in a lot of effort to dress well, spoke to our white teacher, who towered over her, with awe, as though she had been visited

\footnotetext{
${ }^{20}$ The designated uniform for elementary school children in Indonesia is a white top and red skirt for girls and shorts for boys. These are the two colours of the Indonesian flag: white in the top half and red in the bottom half.
} 
by semi-royalty. I watched with that peculiar feeling of double-consciousness. Though I was economically far more privileged than the Indonesian teacher, I found myself in between two vastly unequal worlds, unsure where to locate myself in the relationship between local and expatriate (Fechter, 2007; Fechter \& Walsh, 2010; Leggett, 2003).

My experiences reflect the hybridity Bhabha (1994) writes about. I had a strong desire to become like and to be perceived as "western", while never quite achieving it (Bhabha, 1984). My mother did a great job of reprimanding me for overtly using English to exert power, but battling the hidden desire to do so continued long after. I internalized the cultural hierarchies that privileged the West. Writing this dissertation helped deconstruct my internalized racism through the process of identifying the discourses that inform cultural inequalities in transnational spaces. The themes of double-consciousness and internalization of racist hierarchies that recur in my autobiography are pertinent to the data.

\section{Self-identifying as a Third Culture Kid}

In 2008, despite some reservations, I signed up for the mailing list of the largest online community for Third Culture Kids, "TCKid.com". Brice Royer, whose father is VietnameseFrench and mother is Ethiopian and himself lived in seven countries before the age of eighteen, created the site to provide a space for TCKs to connect with each other. At the time, I had just started my dissertation and was struggling with issues of identity and a sense of not being able to "integrate" into Australian society, where I was living. I soon received a short essay entitled, "TCK Relationships and Grief" via the mailing list (Van Reken, n.d.). It was written by Ruth Van Reken, a white American who was raised for thirteen years in Nigeria, about the emotional impact of being repeatedly uprooted through multiple international moves while growing up. Her writing resonated deeply with me.

When I realized that her words described my own experience, it brought a profound sense of healing (Fail, 2002; Schaetti, 2000; Walters, 2006). It broke the silence that had been cast upon a part of my life by providing it with a narrative (Laub, 2005). I subsequently immersed myself in the literature and the online community, and actively sought out other self-identifying TCKs in my city. Schaetti (2000) identifies this process as the "reference group orientation (RGO) exploration" stage, during which the individual immerses themselves to some degree in matters relating to Third Culture Kids or, using her preferred term, "global nomads." The 
process "offers individuals a way to normalize and integrate their experiences of both dominant and marginal paradigms" (Schaetti, 2000, p. 223). Members of ethnic minority groups typically go through similar immersion processes as they explore their identity (Phinney, 1990; Schaetti, 2000). "Third Culture Kids" helped me understand my experiences (Van Reken, n.d., p. 9).

\section{Situating the researcher}

My own experiences influence the way I relate to the field (the participants and transnational social spaces) and the gaps I notice in the research. Nearly a century has passed since Malinowski (1922) wrote of himself as a white researcher arriving on the shores of a native beach to start his ethnographic work, thus cementing a "radical separation between 'home' and the 'field'" as well as the researcher Self and the native Other (Bunzl, 2004, p. 435). Much has since been said of the changing nature of the ethnographer's role in a postcolonial world as the lines between outsider and insider researcher increasingly blur (e.g. Amit, 2000; Narayan, 1993). Nevertheless, anthropology is traditionally the study of the Other from an outsider perspective and, as Bunzl (2004, pp. 338-339) argues, even critiques of fieldwork approaches based on "a Malinowskian fetishization of cultural alterity" have scarcely overcome the entrenched "epistemological separation" between the ethnographic Self and native Other. This separation requires the researcher to locate with precision their position in the complex grid of relations of power and meaning.

The separation is problematic because relations of power and meaning are situational. Instead of defining cultures as fixed entities to which one does or does not belong, I treat culture as a sense of mutual intelligibility based on shared experiences that offers a framework for interpreting those experiences. This sense of mutual intelligibility is momentary and shifts depending on the socio-historical context. In this sense, I share a sense of mutual intelligibility with different participants to varying degrees, as they do with each other. To some, I am an insider, to others I am an outsider, and to others I may be both. This thesis will make clear that the insider/outsider status is situational, especially in transnational spaces.

My experiences and the anthropological lens together suggest that the existing research on Third Culture Kids is valuable, but lacking in analyses of relations of power. It addresses well 
the impact of mobility and multiple cultural exposure on individuals, and the nature of TCK relations with the dominant paradigm of singular identities. However, there is much to be said about relations of power that occur among transnational youth that I bring to light using a postcolonial approach. I am mindful, however, of Hage's exhortation (2009) that it is important to capture power relations, but "what is bad is when you think you have captured the relation because the relation is more than the power relation." He argues that relations are multilayered and always more than just the economic or political: "there is always an excess" (Hage, 2009). Similarly, David Linger (2005, p. 11) critiques studies which treat the individual as "not unique, not psychologically complex, not the product of a developmental process, and, it would appear, not even conscious." The individual is more than the mere subject of social construction. An anthropological lens coupled with my emic perspective will enable me to critically analyse the power relations that influence transnational youth without losing sight of their individual subjectivities.

The ambiguity of the researcher's status as insider and/or outsider featured in the data collection process as I will discuss below after I have situated the fieldwork.

\section{Why do a school ethnography?}

As I explained in Chapter 1, this dissertation is an ethnography of transnational youth - both the children of expatriate workers and locals - who congregate at the transnational space of an international school in Indonesia. A school-based ethnography is appropriate for this study because transnational youth spend much of their waking hours on the school grounds, including after hours and weekends. The campus represents a locus for activities especially for children of expatriate workers who have few social ties in the host country (Chapter 6). Although students also frequented nightclubs, this applied only to a limited segment of the student body. Similarly, malls were a common place for TIS students to socialize, but mostly among their own social groups. There was limited interaction between the many different social groups outside the confined, gated space of the school campus. Thus, the international school represented the most strategic location for observing interactions among transnational youth and unpacking the resulting intercultural dynamics. The field site is strategic for moving the analysis beyond the methodological nationalism common to studies that focus on specific nationality, linguistic or regional groups of people leading transnational lives. 
Furthermore, this dissertation departs from most school ethnographies that commonly focus on data gathered in classrooms. While a substantial proportion of the fieldwork time was spent in classrooms, I chose instead to focus on the observations made outside the controlled environment of the classrooms because they yielded richer data. Even the school acknowledges that its ideology of being "international" is better learnt through the experience of immersion in an international environment than in the classroom (Chapter 4), thus making the social life of the students on campus important in understanding this process.

\section{Fieldwork}

I spent two semesters at TIS during fieldwork and two weeks at a smaller international school in Jakarta. Gaining access to TIS and social circles within TIS was relatively easy because I had attended international schools myself. The principal was very supportive of my research because he self-identified as a TCK and could personally relate to the struggles and benefits of a transnational upbringing. His family was friends with David Pollock, the co-author of the popular book, Third Culture Kids: Growing up among worlds. However, my status shifted constantly as I conducted participant observation among a diversity of research participants, due to both my cultural background and age.

\section{Participant observation}

On my first official day at TIS, the principal encouraged me to attend the casual, weekly, ten minute teacher meeting and asked me to introduce myself. This was to ensure that the teachers were aware of my presence as a researcher in order to ease my access into classrooms. "I'll be going to classrooms and hanging out with students during recess and other times-basically, I'm 'going native'," I jokingly said as I made double quotation marks in the air and some of the teachers laughed. I explained that I was researching "people who grow up moving around from country to country, otherwise known as Third Culture Kids." I assured the teachers that I was not researching pedagogy and therefore would not be assessing teaching methods. Afterwards, the vice principal showed me the class schedules, and I randomly chose classes to attend and observe. I tended to attend social science and humanities classes because they involved more classroom discussions. That was how my data collection through participant observation began. 
Over the course of a year, or two semesters, I "hung out" with students on campus, and sometimes off campus. A typical day entailed going to classes with students, hanging out with them during recess, and attending extra-curricular activities. At times I would follow a particular student around for a day with their permission. This gave me insight into their immediate friendship circles, and the social groups and parts of the campus that featured most in their lives. I found that some students hardly crossed paths with students from certain groups, depending on with whom and where they hung out. The main groups among the juniors and seniors were the English-speaking, Indonesian-speaking, Korean-speaking, and Japanese-speaking groups. I also frequented the staff lunchroom, as well as parent gatherings, in order to understand the adult influences in students' lives. During the weekends, I sometimes unintentionally hung out in social circles that included people with a transnational upbringing because my own upbringing meant that I was naturally drawn to them. This resulted in data that emerged from impromptu interviews and discussions about my research.

My insider status also facilitated access to social groups on campus. When students and teachers spoke with me, there was a sense of mutual intelligibility-that I understood their transnational experiences. However, my specific background and linguistic ability added nuance to this insider status. Some student groups were easier than others to approach because I had a "feel for the game" (Bourdieu, 1990, p. 66). I approached the Korean-speaking group last because I felt they would be easy to approach. I spoke English and Japanese, languages that were dominant internationally and regionally, respectively, which made it easy to gain their interest. Being an adult was an advantage too because Korean students were quite respectful of adults (though some treated me more like a friend after a while).

I gained instant access to the Japanese group as soon as they found out I was a native speaker of Japanese. They acted as though they had found an ally in me who was capable of acting as a "cultural broker" between the English and Japanese speaking worlds for them (Geertz, 1960, p. 228). Being a cultural broker by virtue of being fluent in both the dominant and minority culture of a given social space is a theme that recurs in this thesis through the experiences of the participants and my own as a researcher (Irvine, 1989, p. 57). Over the year, the Japanese hangout area became my default resting place where I would go after I had expended my energy hanging out with other students. Another group I could relate to well was made up almost exclusively of students of Asian descent who were fluent and comfortable in English, 
but were not as westernized as some of the other Asian students who hung out in the more dominant English-speaking groups.

I was surprised that the Indonesian group was not as easy as the Japanese group to approach. I attribute this to the fact that they did not need me as a cultural broker because they were capable of using their economic capital to gain status in the school social hierarchy. At least one Indonesian-speaking student (Dae Sik) tried to suss out my family's socio-economic status in Indonesia to see where I stood on his social grid. It was, however, the dominant Englishspeaking groups that took some courage on my part to approach, though I was not conscious of this potential difficulty during the first three weeks of fieldwork.

Initially, the students all appeared very young to me. I could not tell who was more or less fashionable, or who seemed more or less popular because they were all "just kids" in my eyes. A majority of the students were of Asian descent. I had lived in Australia for several years and so the North American(ized) accent (or the "international school accent" as some teachers called it) that many of the students spoke grated against my ears because I was unused to it. But after about three weeks, their accent started to neutralize in my ears, and my eyes adjusted. Soon, I could distinguish between the students who more westernized and those who were not, between the popular ones and those who were not, etc. Their fashion styles were different and I wondered how I had not been able to notice it initially.

It was around this time that I began to feel intimidated by the students who were considered more popular by others. The power relations that I noticed in the field and remembered from my own high school experience were influencing my perception of where I stood with the students. Although I was an adult researcher, I felt like a teenager mired in the social hierarchy of the school. I reminded myself that my eyes were deceptive and that as an adult and researcher I could exempt myself from the power relations at play among the students. I moved at regular intervals between student groups in order to see the campus from different perspectives without locking myself into any particular group. In this way I also prevented the social hierarchies among students from dictating my emotions, which would have affected my confidence in approaching some of the groups. It also ensured that I did not appear partial to any particular group.

Being a researcher who was culturally fluid also meant that participants sometimes forgot my 
ethnic or cultural background and divulged their prejudices against certain groups of which I would otherwise be considered a member (Chapter 7). Even though I was an "insider" based on my own transnational upbringing and experience of international schools, my status as an insider or outsider within the transnational space was not fixed. It shifted in relation to different social groups because transnational spaces are complex.

One of the main activities involved in conducting participant observation among young people is "hanging out". In my case this happened mostly on campus. Some of my colleagues who have also researched schools found this difficult to do, and preferred to work with adults (e.g. teachers and parents). Others, including me, found it easy because we genuinely enjoy talking to young people. In my case, I believe it can be attributed to my personality, background, and physical appearance, which enabled me to "pass" as a student. I found it a luxury to spend time in a transnational space where most were bilingual, many trilingual, and some quadrilingual. I enjoyed meeting students who could speak a combination of at least three of the languages I spoke, which was rare outside the international school setting. Hearing students switch accents and languages at will made me realize how much I had missed being in a transnational environment. There was a sense of mutual intelligibility that I had not experienced in a long time. In a way, it felt like "home".

My youthful look made it easy to blend in with the students. I dressed neat and casual-not as neat as the teachers, but not as casual as the students-in order to fit in with both milieus. Teachers and students mistook me for a student, often a senior, on almost a weekly basis. I made sure students were aware that I was a researcher for ethical reasons and convenienceit was easier to gain their attention by telling them I was a researcher who was "writing a book" about them. It made them feel special. On a couple of instances, a $9^{\text {th }}$ grade student asked if I was in $9^{\text {th }}$ grade. Needless to say, I was stumped. I was already in my thirties. In these instances, the student lost all interest in me when I told them that I was an adult. They were simply trying to establish whether I was "one of them". For the most part, however, students seemed to think that being an adult made me cool because it meant I was more mature, experienced, and knowledgeable. But I soon discovered, from the topics they broached with me or discussed in my presence, that for some "mature" simply meant that I was supposed to be experienced with sex, drugs, and alcohol. In contrast, when I attended parent gatherings (almost exclusively attended by mothers), I was regularly asked what grade my children were in. I went from being perceived as a teenager to a mother of two children within the span of a 
few minutes. I attribute this to not only my ambiguous physical appearance, but also the constructed nature of social spaces (Lefebvre, 1991).

The senior prom ${ }^{21}$ night drew attention to my peculiar relationship with the field site and participants, particularly as an adult researcher among teenagers. The atmosphere was very different from a regular school day. The air-conditioned gym was unrecognizable in its transformation into a Hollywood themed ballroom-the floors were carpeted, the walls and ceiling were hidden from view and refurbished with black cloth set up like a tent, the lighting was done up, and a live Indonesian band played on stage. Nothing was left to the imagination. The students, teaching staff and I were in ball dresses and suits. The student-teacher dynamic was different that night.

"Feeling awkward are we?" teased the principal, who stood nearby as I lingered near the entrance unprepared for the new setting. I was unsure with whom I should be standing and talking-students or teachers? It was as though I was back at square one in finding that elusive comfortable space for the semi-adult-researcher-friend. Teachers were extra vigilant and the rules were strictly: no students were allowed in or out of the building between 9:30 p.m. and midnight. The principal explained that this was to ensure that students could not tell their parents they were coming to the prom and then steal away to nightclubs. The strict rules caused tension in some cases: a few students were locked out because they were late, making the student-teacher relationship more dichotomous than it usually was and my liminal position more precarious. Some of the teachers felt equally uncomfortable in their temporary role as chaperones. I eventually managed to alternate between hanging out with students and teachers, but the night highlighted that social relations, including those between the researcher and participants, are situational and social spaces are socially produced (Lefebvre, 1991).

\section{Ethnographic interviewing}

I collected ethnographic interview data by using an open interview method. I often began the interviews by telling the participants that I was researching "people who grow up moving from country to country or go to international schools". I asked them to tell me their "story" starting from where they think it begins. This usually prompted them to narrate their life or

${ }^{21}$ A North American term referring to a senior end-of-year ball. 
experience of the international school for the next hour, with minimal encouragement or questions from me. The objective was to let them control the story and tell me what they felt was important for me to know. In the analysis stage, I looked for recurring patterns and key themes in the interviews. Some were clear, while others were subtle. These were triangulated across various categories of interviewees (students, parents, teachers, and alumni) and with data from participant observation.

In total, I conducted 145 in-depth interviews with 149 participants. Four of the interviews involved two interviewees each. In these cases, both interviewees shared their personal stories, but the interviews at times sounded like something between an interview and a focus group discussion. Among those from TIS, I interviewed 90 students, 23 staff (teachers, school administrators, psychologist, etc), five parents (all mothers), and 25 adults who had an internationally mobile childhood (of which five are TIS alumni). I also interviewed six students from the smaller international school that I visited for two weeks. However, these figures do not give a complete picture as some of them fit into more than one category: at least three of the staff members interviewed are parents of children enrolled at TIS as high school students and others have children enrolled in the lower grades or at other international schools; at least six of the staff members had internationally mobile childhoods themselves and one of them is an alumnus of TIS. Most of the interviews were conducted on campus. Students mostly chose to speak to me in shared spaces such as the library, cafeteria, and other hangout places where their friends generally left us alone but were able to come and chat with us should they choose to do so. Occasionally their friends joined our conversations, which then turned into group discussions. Only one pair of students who did their interviews together chose to do it in an enclosed room, which I indicate in the thesis. Staff members generally spoke to me in their offices, some of which were shared, or in their classrooms when it was empty. One staff chose to be interviewed while he smoked in a place that was out of sight from passers-by except for another staff who joined him for a smoke near the end our interview. I generally interviewed parents and adults who had had an internationally mobile upbringing in cafés, restaurants, their homes, their office, university campuses, and on Skype.

I sought a diverse set of interviewees in terms of ethnic, national, linguistic, and cultural background, gender, and age. ${ }^{22}$ Data saturation was reached at different times for different

\footnotetext{
${ }^{22}$ I focused on $11^{\text {th }}$ and $12^{\text {th }}$ grade students, but sought diversity in terms of age among teachers. In terms of official nationality, of the 90 students from TIS there were 14 Indonesians, 13 Japanese, 17 South Koreans, 20 from Anglophone countries (US, UK, Australia and Canada), and 26 of other nationalities (Argentina, Denmark, Fiji,
} 
groups, which highlighted a massive research gap that this thesis attempts to fill. After having interviewed a mere two or three white American students, I noticed that the stories that they told of themselves sounded new and interesting on an individual level, but felt strangely familiar thematically. This was because the key themes in their stories had been repeatedly covered in the existing research, which I had read over the course of nine months during the pre-fieldwork stage. This attested to the validity of the existing research, most of which had been conducted on white Americans. In contrast, the interviews with Asian students and students of mixed heritage offered new themes and patterns hitherto unseen in the literature. Their patterns of socialization have not been discussed before. There is a large group of transnational youth who have remained almost invisible, silent in the literature. This verifies the originality of this research.

The recurring themes and patterns are evidence that my findings are solid. Mainly, the findings show that transnational spaces are produced through social relations that are unequal in power. Young people experience transnational spaces and global mobility in different ways, which in turn has diverse impacts on the way they practise cosmopolitanism.

\section{Ethnographic writing}

I have used several ethnographic conventions in writing up the data analyses. I have used pseudonyms for the school and all participants in order to protect their anonymity. I have also used vague descriptions in cases where naming the specific national, ethnic, linguistic, or cultural background of the participant (usually of a school member of staff) in combination with their marital status or other information would reveal their identity to those who have been associated with the school. For example, instead of "Chinese Jamaican", I might say, "Asian Caribbean". In one or two cases, I have used two pseudonyms for the same person in different sections when a substantial amount of personal information is divulged.

Interviews are reproduced verbatim as edited quotes and indicated with the interview date. Unless otherwise indicated, conversations that I heard during participant observation are reconstructed from field notes. Finally, I use the term "school administrators" to refer to the principal, vice principals, activities director, academic director, and sports director of TIS; and

Germany, India, Jordan, Malaysia, Myanmar, Netherlands, Philippines, Papua New Guinea, Russia, Spain, and Taiwan). However, using their nationalities to indicate numbers can be misleading as many of them either have more than one nationality or do not identify with their passport countries. 
"participants" to refer to those who participated in this research either through explicit consent in the case of interviews or by being present at the school, which gave me permission to do fieldwork on their campus.

\section{Conclusion}

This thesis is an analysis of some of the major themes and patterns that emerged in the data. In this chapter, I related my own experiences of a transnational upbringing as a means to introduce some of the themes that emerged in the data and situate myself as a researcher in relation to the field. I then discussed how my experiences and appearance affected the way I was perceived during fieldwork, while emphasizing that transnational spaces are a social product. The way my age and status as an insider or outsider was perceived changed with the social milieu. In particular, whether I was perceived as a student or parent depended on whom I was with. I was perceived as being the same as those around me. The way social relations produce social spaces and vice versa affected the experiences of transnational youth at TIS as they did mine.

While "Third Culture Kid" was useful as an emic concept in understanding my own experiences, many aspects of my experiences have not been discussed in the literature. The literature's Eurocentric bias assumes that transnational spaces are neutral and therefore overlooks the way relations of power influence transnational experiences in complex ways. I explore these complexities in this thesis. I do so by interrogating the ideology of being "international" that is prevalent in both the literature and the field site. In the next chapter, I will introduce the field site, including its local and global contexts, and outline the key characteristics of the ideology of being "international" before unpacking its Eurocentric nature in subsequent chapters. 


\section{Chapter 4}

\section{Being "international": the field site and its context}

The International School (TIS) was chosen as the main field site because it was an international school that had a diverse student body (in terms of nationality and the cultural background of the students) and actively engaged with notions of cosmopolitanism through their ideology of being "international". It used an international curriculum, which contrasts with schools that may include the term "international" in their school names but whose curriculum is based largely on a national curriculum imported from outside of Indonesia, and whose student body is more or less homogeneous in terms of nationality. This chapter introduces TIS and its ideology of being "international". I define the ideology of being "international" as a Eurocentric set of ideas and practices of peaceably engaging with those considered different. This chapter identifies and contextualizes the key characteristics and practices pertaining to the ideology of being "international" using the data from the field site and the literature on international schools. This will set the scene for subsequent data chapters in which I interrogate the ideology of being "international" and argue that it is Eurocentric. It is important to interrogate this ideology as it will reveal the complexities of a transnational upbringing.

I begin by describing the school, its local context, and the ways in which the school articulates its ideology of being "international". I then contextualize the school within a global trend towards the internationalization of education (Amit, 2010; Dolby \& Rahman, 2008). This discussion locates the role of international schools in the cultural reproduction of national and transnational class structures through the promotion of a Eurocentric form of cosmopolitanism. The discussion highlights the tension between what the school believes is an ideal way of being "international" and the cultural hierarchies that continue to influence social interaction on campus. In order to analyse this productive tension in subsequent chapters, I propose in this chapter that the international school be conceived as a transnational (educational) space where multiple national and transnational discourses converge. Recognizing that the transnational field site is physically located within the nation-state of Indonesia is pertinent to a nuanced analysis of the social relations occurring within this space. 


\section{The International School (TIS) and Jakarta}

Living in Indonesia: A site for expatriates lists 32 "international schools" (Expat Web Site Association Jakarta, 2013)..$^{23}$ Inside the security gates of one such school lies a well-maintained, green oasis-like campus that belies the bustle and smog that characterize Jakarta, the capital city of Indonesia. TIS is different from local schools in many important ways: its original purpose, curricula, student and staff body, architecture, resources and landscaping.

TIS is a coeducational school that was established after World War II in a newly independent Indonesia to service the children of United Nations and diplomatic staff stationed in Jakarta. It was founded by a few embassies, but later turned into an international school and run as a not-for-profit organization that is overseen by a board of trustees. Until 2003, it accepted students of all nationalities (with priority given to those from the founding embassies) except Indonesian nationals due to Indonesian government regulations that prevented its citizens from enrolling in international schools. Indonesian students used to attend the school in its early days but the government prohibited its citizens from enrolling in international schools in 1960 to ensure they were educated as Indonesians in Indonesian schools. ${ }^{24}$ A school DVD on TIS's history suggests that the government's prohibition was "a major upheaval for everyone, because the culture was then removed from us and the school took on a different tone after that."

TIS has survived several socio-political upheavals in Indonesia and continues to thrive in their aftermath. The latest occurred on the heel of the Asian financial crisis when riots swept through Jakarta and other major cities and triggered the end of Suharto's 32-year rule in May 1998. Foreign nationals and Chinese Indonesians nationals who could afford to fled the country. TIS was "locked down" as staff and students tried to make their way home and to the airport (Interview with a teacher, 25 August 2009). Chinese Indonesians were targeted during the riots due to their particular minority status. Many Chinese Indonesian students I interviewed were enrolled in local elementary schools at the time, but spent the few years immediately after the riots living overseas, mainly in Singapore. The following academic year saw TIS's student body reduced by about a quarter because many foreign expatriate workers

\footnotetext{
${ }^{23}$ It is difficult to define international schools as I explain later.

${ }^{24}$ The prohibition was enforced based on the Government Regulation in Lieu of Law (Peraturan Pemerintah Pengganti Undang-Undang) or Perpu No. 48 Year 1960 regarding the Supervision of Foreign Education and Teaching (Pengawasan Pendidikan dan Pengajaran Asing).
} 
and their families who had fled Indonesia did not return, or returned but left their family behind in their home countries.

Around this time, changes in patterns of education for the Indonesian middle and uppermiddle classes began to reflect the global trend towards the internationalization of education, which I discuss below. In the 1990s, the Indonesian Department of Education and Culture (now Ministry of National Education or MONE) opened opportunities for schools to develop an international standard of education. Using the Living in Indonesia website I cited earlier, Kustulasari (2009, p. 95) also lists over 60 "international schools" across Indonesia, 32 of which were established in the $1990 \mathrm{~s}^{25}$ Those listed range from schools that use a national curriculum from overseas (e.g. the Japanese curriculum) to English-medium schools that use internationally recognized curricula (e.g. International Baccalaureate) ${ }^{26}$ Private "national plus" schools that claimed to have an "international" dimension to their curricula were also established during this time and continue to grow in number (Mayall, 2010). ${ }^{27}$ Today, these national plus schools generally offer a national curriculum supplemented by a focus on English and/or Mandarin language development, and/or use English as a medium of instruction in some or all subjects. ${ }^{28}$

The end of Suharto's centralized New Order regime was followed by an era of reformasi (reformation) that saw a move towards the decentralization of many aspects of state governance, including education. In 2003 MONE issued a law commonly referred to as the "National Education Policy" ${ }^{29}$ which states the importance of English language education for "pergaulan global (global interaction)". ${ }^{30}$ This has been cited as the impetus for the continued growth of national plus and international schools (Kustulasari, 2009; Mayall, 2010). The government also relaxed the restrictions it had placed on Indonesian nationals enrolling in international schools.

\footnotetext{
${ }^{25}$ Thirty one of these "international schools" were established prior to the 1998 upheaval. Although the definition of "international schools" is contested, Kustulasari (2009) classifies these 31 schools as "international" because they offered international curricula or were founded by foreign foundations.

${ }^{26}$ The incredibly diverse range of "international schools" listed indicate both a lack of clarity with regard to the definition of "international schools" and the eagerness with which schools advertise themselves as "international" (Hayden, 2011; Hayden \& Thompson, 1995; Hayden, Thompson, \& Walker, 2002).

27 Like international schools, many national plus schools are very liberal in the way they define "plus" in the education service they provide.

${ }^{28}$ Adding a Mandarin Chinese language component became popular after 1998 when the government ban on Chinese language material was lifted.

${ }^{29}$ The full title is "Law of the Republic of Indonesia No. 20, 2003 on the National Education System (Undang-undang Republik Indonesia nomor 20 tahun 2003 tentang system pendidikan nasional)".

${ }^{30}$ Chapter 37, Article 1
} 
Consequently, the number of Indonesian nationals from elite and upper-middle class families enrolled at TIS rapidly increased from 2003. The large number of Indonesian students altered the student demographic mix and the school's social dynamics. "Indonesia" became more present on campus. However, Indonesian students were also of concern to the school due to their perceived lack of integration into the dominant school culture and weak academic commitment. This thesis explores the tension arising from these concerns in a bid to understand the students' engagement with the school's ideology of being "international" which privileges Euro-American capital.

At the time of fieldwork, TIS had about 800 high school students who represented 50 nationalities, with the majority being from South Korea (approximately 25 per cent), Indonesia (approximately 20 per cent), the United States (approximately 15 per cent), Australia and Canada. $^{31}$ The high number of Korean nationals reflects the rapid growth of Korean communities (both migrant and expatriate) in Indonesia and elsewhere since the 1990s. The number of students from Anglophone countries had declined around the time of the 1998 riots. Most students, including Indonesians, spend some or all of their time growing up outside their passport country (or countries, for those who have more than one citizenship), and often they live in several countries before completing high school. The majority were of Asian descent, though many were also of mixed ethnicity.

The high school administrators and teaching staff represented about 20 nationalities, though they were predominantly from white-dominant Anglophone countries such as the United States, Canada, the United Kingdom, Australia, and New Zealand. The teaching assistants, administrative support staff, and other support staff (e.g. cleaners, gardeners, and security guards) were almost all Indonesian, but tended to be invisible in the students' social world, except to the Indonesian students, who had an easy-going relationship with many of the security guards. ${ }^{32}$

Located in an affluent neighbourhood, TIS was an enclave for the privileged, as are many other private (international) schools in Indonesia. It was often featured in local English-language magazines and newspapers catering for the city's expatriate and middle- and upper-class

\footnotetext{
${ }^{31}$ Only approximate figures have been used throughout this thesis to ensure the anonymity of the school. Also, there are over sixty nationalities represented in the student body for K-12 (Chapter 1).

${ }^{32}$ Some of the other support staff, such as security guards, were contracted from private companies that provide such services.
} 
population as a celebrated symbol of high quality education and a "cosmopolitan" lifestyle. Some of the campus facilities, such as the multiple gyms, pools, and sports grounds built across the elementary, middle, and high school campuses, compared favourably with those in elite universities in industrialized countries. Every classroom I entered was air-conditioned and fitted with electronic boards.

In Indonesia, TIS was perceived as a western educational institution, which had implications for its sense of security in a largely Muslim country. In 2002, terrorists (suicide bombers) linked to Jemaah Islamiyah bombed two nightclubs in Bali, killing 202 people most of whom were westerners. This was followed by similar attacks in Jakarta and Bali that targeted western interests, though most of the victims were Indonesians: the Marriott Hotel bombing in 2003, Australian embassy bombing in 2004, second Bali bombings in 2005, and the hotel bombings which occurred in 2009 during my fieldwork. Security checks (though mostly superficial) at entrances became a permanent fixture at major hotels, malls, business skyscrapers, and apartment buildings in Jakarta and other major cities. In November 2003 newspapers reported that international schools were allegedly included in a terrorist target list. This prompted TIS to upgrade its security, such that the entrance looked more like a military barricade to the lay eye, both in terms of the physical structure as well as the ten or so guards securing the entrance and ordering traffic. Every weekday morning and afternoon, the street in front of TIS was jammed with traffic created by chauffeured private cars dropping off and picking up students. Private traffic spilled over onto the public road as though they were entitled to do so. On the $17^{\text {th }}$ of July, 2009, during TIS's two-and-a-half-month "summer" break (sic), and midway through my fieldwork, two luxury hotels in Jakarta's business district of Mega Kuningan were attacked by suicide bombers. Six of the seven victims were westerners. In ensuing months, a bright orange police $\mathrm{car}^{33}$ was continually parked at the front gates of TIS's high school campus.

While the car and imposing security gates were installed based on real security threats, they were also symbolic markers of the school's separateness from its local environment in terms of class and culture. An alumnus who had studied at TIS before the security upgrades, remarked of TIS, "It was like a completely independent country or something" that created "an immediate bond" among fellow students and alumni based on a shared experience of the world within the gates (Interview, 25 July 2009). At TIS, the sense of being "international" was

\footnotetext{
${ }^{33}$ This was an unusual colour for a police car. I presume it was chosen because it serves as a conspicuous sign to signal that TIS is protected by the state apparatus.
} 
enhanced through its separateness from the local and the dominance of Euro-American culture, though these were never left unchallenged. Various discourses flowed in and out of the symbolic gates to contest it. Being "international" is dependent on the way difference is discursively constructed within the context of colonial continuity and contemporary capitalist structures. The next section shows how the school administrators and teaching staff articulated being "international".

\section{Articulating internationalism: "Being the best for the world"}

TIS is a school that offers high quality education (at a cost), providing its students with opportunities to study at leading universities in the world. ${ }^{34}$ It is also a school that proclaims noble intentions towards the world. These intentions are epitomized in the school motto which was changed around the time of my fieldwork from "Best in the World" to "Best for the World" (emphasis in original). Its sense of connection to the global, its sense of being "international", and its celebration of diversity permeated TIS's everyday life. The ideology of being "international" was a driving force for the school. Mission statements, symbols, rituals, and curricula that supported this ideology were present both physically and discursively together with the contradictions inherent in these.

Mission: educating "responsible world citizens"

TIS's 2009 promotional documents reflect its visions. TIS states that they are committed to nurturing "life skills which define our international community and global perspective." Among their many educational goals is their aim of educating "responsible world citizens who make healthy and ethical choices, appreciate cultural diversity, participate in community service, engage in positive relationships with host countries, show compassion and empathy, [and] communicate in more than one language[.]" The term "responsible world citizens" appear in several documents as do terms like "international mindedness" and the notion of educating students regarding "issues of global significance" and "world issues". These emphases are common to international schools (Hayden, 2011; Hayden \& Thompson, 1995). TIS purposes to instil a sense of "pride" in their students regarding their own cultural backgrounds while complementing this with the ability to consider "multiple perspectives". In other words, one of

\footnotetext{
${ }^{34}$ Among the 2009 graduates, 98 per cent entered college or university -55 per cent of them in the U.S., followed by Australia, Canada, U.K., Korea, and Japan.
} 
TIS's central aims is to nurture in their students the ability to engage peaceably across difference.

To this end, TIS claimed to offer learning experiences that are "international in their design and highlight the commonalities of the human experience." These learning experiences are gained through the international curriculum as well as immersion in a diverse transnational space. One of TIS's more recent 2013 documents states, "The school helps you realize that the only way to really become a 'responsible world citizen' is through immersion. Your teachers will offer perspectives from twenty nationalities and your friends, from sixty." When a local magazine requested to feature TIS as part of the special edition on all things American in Jakarta, TIS refused. The staff in charge of public relations said they had told the magazine, "No, that's not our edition. We are not an American school." She believed that TIS was the "true" international school. Accordingly, it was important for the school administrators that students mixed with each other in ways that reflected a sense of internationalism and openness to difference. It was of concern to the school administrators that some students appeared to self-segregate into groups based on nationality.

\section{Curriculum: the International Baccalaureate program}

TIS uses English as the main language of instruction and draws on international and North American curricula, offering the International Baccalaureate (IB) diploma and Advanced Placement courses in addition to the regular TIS diploma. The IB curriculum in particular is highly sought after by parents because it offers strong academic training and the qualification necessary to apply to many universities around the world. National as well as international schools are increasingly adopting the IB curriculum as the internationalization of education continues (International Baccalaureate Organization, 2013b). The International Baccalaureate Organization was founded in Geneva, Switzerland in 1968 and its program was initially designed to prepare internationally mobile students for university. The program seeks "to provide students with a truly international education"(International Baccalaureate Organization, 2013a). The IB mission statement says that it aims to develop "young people who help to create a better and more peaceful world through intercultural understanding and respect" and "who understand that other people, with their differences, can also be right" (International Baccalaureate Organization, 2013c). 
Rituals: for global citizenship

Early in my fieldwork I noticed that "global citizenship" was the buzz term floating around campus, particularly among the staff. The East Asia Regional Council of Schools (EARCOS), through whom the Global Citizenship Award is organized, describes a global citizen as one who is:

a proud representative of his/her nation while respectful of the diversity of other nations, has an open mind, is well informed, aware and empathetic, concerned and caring for others[,] encouraging a sense of community and strongly committed to engagement and action to make the world a better place. Finally, this student is able to interact and communicate effectively with people from all walks of life while having a sense of collective responsibility for all who inhabit the globe (EARCOS, 2010).

TIS offered activities that were designed to fulfil their aim of raising global citizens. Students participated in activities that emulated organizations whose aims are to tackle global issues.

The Model United Nations (MUN) club is a classic example. Typically, students learn to debate and deliberate over international issues as mock delegates from certain countries (which do not usually correspond to their own nationalities). The MUN club activities culminated in students traveling overseas to a regional MUN conference with students from other international schools in Southeast Asia.

Another example is the Global Issues Network (GIN) conference held in Beijing in 2008 (organized by EARCOS). It inspired some of the students who had attended in Beijing to host a local conference in Jakarta during my fieldwork. The main aim was to raise awareness about global issues pertaining mainly to the environment and poverty, as well as to inspire young people to become part of the solution and raise funds for the cause. There were students from other schools ranging from international, to Taiwanese, national plus, and (Indonesian) state schools.

An ethos of noblesse oblige underpinned the effort. An invited speaker, orphanage supporter, and alumnus of TIS said, "We come from a very privileged background, so we need to spread 
the word." His aim was to encourage as many young people as possible to be involved in similar efforts. At the end of the academic year, the student organizer of the local conference for the GIN was presented with the "Global Citizenship Award".

It seemed ironic, however, that the school whose students possibly use the most amount of energy per capita in the country had organized a conference to raise awareness of environmental issues. For example, one student noted on another day after her environmental issues class that they had calculated she would need several planets like earth to support her lifestyle if everyone was to live like her. My field notes are filled with comments I made about the cold air-conditioning inside the buildings. Students (and I) often wore sweatshirts or cardigans in the classrooms to keep warm. While it appeared like noble intentions, the global outlook that was being nurtured at TIS presupposed economic privilege.

Imagined communities: a global international school community

TIS had well-established ties with other major international schools across Southeast Asia. These ties were fostered through regular regional competitions and meetings for the school sports, dance, music, and MUN teams. There was a lot of publicity surrounding these regional meetings. They were usually preceded with pep rallies ${ }^{35}$ to support the school teams. Students involved in these activities travelled overseas or hosted students from other international schools in the region when TIS hosted the meetings. Again, being "international" required a degree of economic privilege.

Although TIS's current website indicates that there may be a move towards establishing stronger links with communities in Indonesia, TIS students were mainly socialized with other international school students into a transnational lifestyle (O'Reilly, 2009). The alumni who I met and who were living in Indonesia at the time explained that they mainly interacted socially with graduates of TIS and other international schools. This suggests that a specific type of cosmopolitan engagement with a specific type of Other was being fostered at TIS.

Symbols: nationalities, flags, and Obama

It was common practice to foreground the number of nationalities represented in the student

\footnotetext{
${ }^{35}$ A North American term that was used at TIS to refer to gatherings held to boost moral support and get people "hyped up" about sports and other competitive events.
} 
body and teaching staff in the school's promotional material. As one former staff put it, “...what we wanted was for people not to be insular, not to feel as if their way of life was the only way. And what a perfect set up for that when you had 55, 60 different nationalities" (DVD on TIS's history). The school administrators believed that the diversity of background represented at the school, as signified by the number of nationalities, promoted openness to difference. It was therefore a selling point that they felt more than justified their claim to be an "international" school.

Students were encouraged to flaunt their nationalities as part of the school's celebration of diversity. Peering through classroom windows, it was difficult not to notice the posters hanging on the walls with pictures of national flags and other national symbols that students had drawn. Many of these posters had not one, but symbols of two or three or more countries drawn on the one poster to represent the student's sense of identity. Some of these countries represented the students' nationalities, others of the parents' nationalities or ethnicities, and yet others of where students had lived. Students typically told me about how mixed or "international" their friendship groups were by counting the number of nationalities they represented. One of the main prisms used to identify difference was nationality. Being "international" presupposed the national.

The school's celebration of diversity was also apparent in the way Barrack Obama's election was a hot topic on campus. The start of my fieldwork coincided with the 2009 U.S. presidential inauguration. As a bi-racial child to a Kenyan father and white American mother, who had spent part of his childhood outside of his passport country in Indonesia, Obama was the new poster boy for TIS. In one classroom, the teacher displayed a pull-up banner of Obama for several months. During the first weekly meeting for teaching staff that I attended, the principal announced there would be a live screening of the inauguration ceremony that night at the school. He said, "...today is momentous. A TCK, multiracial president has been elected. It is a great day. It is a historic moment." During the ensuing days, Obama was popular among teachers as material for class discussions. In one social studies class, Mr Salamon showed a video clip from the inauguration in his class, and discussed how multi-racial Obama's family was as he drew our attention to the new president's bi-racial sister and her Asian Canadian husband. The excitement over Obama was a celebration of diversity in its visually apparent, mixed-"race" form, and the way in which it crossed national boundaries. Being a TCK presupposed the nation-state and "race" (Chapter 8). 
More rituals: United Nations Day

There was a United Nations flag hoisted on a flagpole on the campus. Much of the school's ideological commitment to global well-being was expressed through activities relating to international organizations like the United Nations. United Nations Day was the school's most emblematic ritual for expressing its ideology of internationalism. The main event in the morning included a colourful procession of flags that represented the nationalities of the high school student population. The flags were carried into the theatre by students, most of whom were dressed in the corresponding national costumes (or their interpretation of it). This was complemented with performances by the dance teams, choir, band, and strings groups. Another highlight of the morning was the music and dance performances by the Chinese, Indian, Indonesian, Japanese, Korean, and French clubs. ${ }^{36}$ At lunch time everyone filed out of the theatre for an afternoon of international cuisine tasting as the high school campus was turned into a vibrant market place of food stalls, many of which were attended to by the mothers of the students.

Students and staff came dressed in traditional outfits. Most preferred to wear outfits that they felt represented their cultural, ethnic or national background, while others wore outfits from countries other than their own. One pair of students with whom I chatted wore outfits that represented each other's country. An Indian teacher came dressed in a Manchurian outfit complete with the round hat and cue. Others tried to have some fun by wearing costumes that represented their country in a less conventional manner. For example, some male Chinesespeaking students came dressed in Hawaiian shirts and boxer shorts, cheekily claiming to be imitating Taiwanese "gangsters". A few male students who were western nationals painted their national flags on their bodies and faces. It was a lively festival with a kaleidoscopic display of costumes, food, and performances. The school indeed had reason to celebrate diversity. However, I propose in Chapter 11 that the celebration of United Nations Day revealed a Eurocentric performance of diversity that emphasizes visible difference, which is often defined by "race".

\footnotetext{
${ }^{36}$ There were various clubs in which students could participate as part of their extracurricular activities. Some were based on common interests, such as the magic club or dance club, while others were oriented towards community service. There were also clubs that took on the names of various countries and were designed specifically for putting on performances on United Nations Day. The French club was made up primarily of students of different backgrounds who were learning French; the Korean club was made up of Koreans; while the Chinese, Indian, Indonesian, and Japanese groups were mixed.
} 


\section{Students: Being "international"}

Having immersed myself for one year in TIS's campus life, I sensed the school's commitment to nurturing internationalism. Extra-curricular activities encouraged students to engage with each other and the host country through charity work, such as raising funds and visiting orphanages. I also observed classroom discussions that challenged students to consider views different from their own. In one $9^{\text {th }}$ grade Asian Studies class, the atmosphere became a little tense as they discussed religion. The teacher showed a documentary about a few Muslim individuals from culturally diverse backgrounds, including a white Texan convert, going for the Haj pilgrimage to Mecca. During the discussion, there was a student who was atheist and another who was a committed Christian and each seemed to feel uncomfortable with the other's view. At one point the atheist student said, "I don't think we need God," before adding for just in case, "I don't want to offend anyone." The Christian student tried to defend her beliefs, but I could feel that she was offended, and so was the atheist student. A third student asked, "How different would the world be without religion?" The atheist student responded, "Religion makes people feel comfortable. If there was no religion then there'd be no chaos." The teacher himself used to be Christian but later decided not to be. He ended the class discussion with, "I have to say this. Whatever religion changes your heart is good. To make you think about justice, equality, etc. It's the heart that is important." Later, some of the more senior students explained that they usually became better able to accept differing views as they matured in age.

One student noted that those who make obviously racist comments may be ostracized by their peers until they learn to guard their mouth. Sometimes this was done in jest, and at other times not. My observations confirmed this strong stance against prejudice. One male student, Levi, whose father was white American and mother was Indonesian, was known to make racist remarks, particularly against Indonesia. When he did this, his friends "exiled" Levi, in jest, by banning him from entering their hangout area for either a few minutes or a whole recess break. Levi continued to engage in conversation with his friends while walking around the periphery of the hangout area. On another occasion, Levi conveyed his strong dislike of Indonesia to me in such a way that another student, Maya, who was listening to our conversation, explicitly called him out for making racist statements, abruptly stood up, and left the scene to express her disapproval (see Chapter 11). 
Finally, many descriptive phrases used in a poetry reading from a past UN Day performance, which I watched on a DVD that I had borrowed, summarized what I collectively refer to as the school's ideology of being "international" that was imbued with notions of being international, global citizenship, and TCKness. Thirteen students took turns reading lines such as, "I am a stranger," "I am the mix of colours," "I am the misplaced foreigner," "I am the expatriate," "They thought I only spoke English," "I am the diverse sister," "But I won't care...I will not be treated as an outsider," "The wall will slowly crumble," "They will see I'm human too," and "Living in both worlds." The reading culminated in all the students declaring in unison, "(And they will accept), I too, I too, I too...am a citizen of the world." The notion of belonging nowhere and everywhere at the same time, of visible diversity, of being third cultured, of being a citizen of the world permeated the discourse of internationalism at TIS.

Overall, TIS was a model school in the way it managed diversity among its (economically privileged) students. The school's strategy of nurturing internationalism through close encounters with the other in a transnational space appeared effective. However, Daniel, who was the student council president during the first half of my field work, argued to the contrary. While Daniel believed that schools like TIS offered "significant exposure [to] other cultures and other people" and valued this exposure, he also argued, "I just don't think it's fool proof. I think there needs to be other elements." Next I explore why the school's ideology and approach to being "international" is not "fool proof".

\section{It's American. It's European. It's western. It's Asian. It's international?}

TIS's ideology of internationalism is premised on the assumption that transnational educational spaces are neutral when they are not. I asked students, staff, and parents at TIS what they thought was the dominant culture of the school or had the most influence on campus. They gave diverging responses. A male Japanese student in $12^{\text {th }}$ grade said, "Definitely American, I mean, they've got proms." British and German students concurred, and cited the pep rallies TIS held, as well as the Advanced Placement classes, which were taken from the American curriculum. A Dutch mother agreed, saying that in the Netherlands schools do not organize big sports events as they do at TIS. But when I asked an American student the same question, he did not think the dominant influence was American. Rather, he cited the International Baccalaureate program as evidence that it was more British, because it was 
modelled after the British university preparatory program. In contrast, Shane, whose father was British and mother was Indonesian, very confidently declared that the dominant culture was "Indonesian". He hung out almost exclusively with the Indonesian-speaking groups, and held a competitive attitude towards the male English-speaking students. Meanwhile, a Japanese mother, who was married to an American man, said that the school was too Asian, with a slightly disapproving tone to suggest she would have preferred if it was less Asian. It was as though the strong Asian presence made the school less "international".

Most were least aware of the influence of their own cultures on the transnational space and most aware of how it was different from what they were familiar with. Transnational spaces are often defined by the Other. As my fieldwork unfolded, it became clear to me that the school administrators, teaching staff, and some parents felt that although TIS was supposed to be the "true" international school, its mission was compromised by the excessive presence of Korean students, mainly, and Indonesian students. These two Asian groups were perceived to be ethnocentric and unwilling to become international because they appeared to always hang out among themselves, even though this was not always true. The Japanese group was also perceived as ethnocentric but were less conspicuous due to their smaller size. Friendship circles were assumed to be a matter of mere choice, with little consideration given to relations of power present in transnational spaces that may have affected their choices. In order to interrogate these assumptions, I need to first describe the social relations of students, since this formed a major part of their social lives on campus.

\section{Mapping student cliques}

On my first day at TIS, one of the teachers showed me an article in TIS's student magazine entitled, "The great divide". The student article contended that while the school "provides the ideal setting for internationalism," students still practise "self-segregation based on characteristics ranging from nationality and religion, to even sexuality and extra-curricular activities." ${ }^{37}$ While some degree of social grouping is expected, the existence of "Korean", "Indonesian", and "Japanese" student hangout areas was a particularly sore point for the school administrators. In this thesis, I focus on the $12^{\text {th }}$ grade hangout areas, although the Japanese hangout area for $12^{\text {th }}$ graders tended to include $11^{\text {th }}$ grade students. These groups

\footnotetext{
${ }^{37}$ The name of the student magazine shall not be cited here to maintain the anonymity of the school.
} 
appeared to be large, entrenched, nationality-based groups that were perceived by teachers and students as ethnocentric and self-segregating. But I argue that these groups were not cohesive wholes with indisputable boundaries. They are better described as Indonesianspeaking, Korean-speaking and Japanese-speaking groups, based on their strong preference for these languages over others, to account for the (national and ethnic) diversity found in each group. I argue in Chapters 9 that there is slippage among language, culture, nationality, and "race" that constructs these groups as homogenous, ethnocentric and self-segregating.

Meanwhile, there were student groups that represented, for the school, ideal "international" groups. These were the English-speaking groups that were racially (in the colonial sense of the term) diverse, and whose members were often referred to as "everyone" even though they only represented about a third of the student body. Generally, the English-speaking groups commonly referred to themselves using labels that described their smaller sub-cliques, such as "white kids", "stoners", "gossip girls", "Dutch boys", etc. Of these, "white kids" was a rather ambiguous designation because it sometimes referred to small high-status cliques among the English-speaking groups, and at other times to the English-speaking groups as a whole, depending on who was using the term-an insider or outsider to the English-speaking groups.

Although I have categorized the student cliques quite simply above, I adapted many of these categorizations from those used by the participants and am employing them as a starting point for discussion. It is important to remember that there were many other smaller cliques and much interaction between members of various groups. In the upper grades, there was a noticeable mixed-grade Mandarin-speaking group and a male Indian group, among others. There were some who regularly floated in and out of two or more groups and were not "rooted" in any because their network of friends spanned different groups. Some students, such as those who may have been friends when they were younger, hung out with different sets of friends outside of school but were rarely seen together on campus. Thus, if cliques appeared distinct at TIS, it is because the campus environment reinforced boundaries that were more easily crossed or blurred outside the structured school grounds. The following chapters provide more nuanced analyses of the simplistic categorizations, and interrogate the structures that reinforce them.

My yearlong fieldwork from January to December of 2009 spanned two academic years. The $12^{\text {th }}$ grade students whom I observed during the first half of my fieldwork graduated in 
May/June of 2009. Those who were in $11^{\text {th }}$ grade during this time returned after a threemonth "summer" break (June to August) as $12^{\text {th }}$ graders for the second half of my fieldwork. There was concern among the staff about the impact of the larger groups, which dominated the hangout areas, on student social dynamics. One staff commented that it was intimidating even as an adult to walk past some of the larger cliques, let alone as a fellow student. She noted that a parent had asked the school administrators to make architectural changes to the hangout areas to reduce the cliquishness. Tearing down the main outdoor hangout areas was not an option at the time.

But over the summer break, the school installed ten sets of wooden tables and benches in the main senior hangout area to see if it would break the larger groups into smaller cliques. The same staff apologetically said to me that she hoped the new tables did not disrupt my data. As it turned out, the new tables made it easier for me to identify some of the smaller cliques because it caused the English-speaking and Indonesian-speaking groups among the new $12^{\text {th }}$ graders to hang out in smaller groups at different tables. The locations they chose to sit at reflected their status as will be discussed in further detail in Chapter 8. Although the larger linguistically-defined student groupings were observable in all grades, their distinct hangout areas were most apparent in the upper-grades. The pattern indicates that cultural socialization plays a greater role in determining in-groups and out-groups as children become older, which I discuss in Chapter 9.

Student groups that appeared to form based on nationality presented a picture of TIS that was less-than-integrated. These were basically groups other than the ones that use English as their main mode of communication. The concern over the large number of students from particular nationalities led the school administrators to consider placing a cap on the enrolled number of students of each nationality-except those with citizenship to countries represented by the founding embassies, all of which were western. This decision appears reasonable on the surface as a measure to ensure the school has the right mix of students. However, closer analysis reveals that the very notion that certain mixes are acceptable and others unacceptable means there are gatekeepers determining who is or is not being "international". 


\section{The gatekeepers for being "international”}

One example of how relations of power manifest in practices of cosmopolitanism is the way self-appointed gatekeepers believe they can decide who is or is not international, TCK, or interculturally competent, i.e. cosmopolitan. The teaching staff and school administrators often took on the role of gatekeeping. Upon hearing about my research, it was not unusual to have teachers assure me that I had come to the right place as most of the students were "TCKs". However, some added that, for example, the Koreans are "not really TCKs" because they only hangout with other Koreans. ${ }^{38}$ Hanging out with those from the same ethnic group was taken as evidence of their inability to practise being "international".

On another occasion, a teacher remarked over a casual chat that the Koreans tended to be "monocultural". This was despite the fact that almost all the Korean students were bilingual (Korean and English) and some trilingual (e.g. Indonesian), in contrast to the many in the English-speaking groups who were monolingual and had never attempted to hang out with the Koreans. According to this teacher, some stayed very much within the Korean community and did not "assimilate", while others branched out. The use of the word "assimilate" presupposes a normative culture that students are expected to assimilate into, as opposed to a mutual, interactive process wherein members of different cultural groups move towards one another.

The same argument was applied to the students in the Indonesian-speaking groups. During a senior graduation breakfast, a teacher remarked to another person and me that the Indonesian students tend to separate themselves from the others as he pointed to the table where the Indonesian students were sitting. The Indonesian students had arrived late. They chose to sit at the empty table closest to the other students and furthest away from the teachers (where I was also sitting). By the time they arrived, the other students had already sat in their groups at the other tables. Nevertheless, it was the Indonesian students who were perceived as self-segregating. The teacher added that the Japanese students also separate themselves as he pointed to another table and said, "See the Japanese boys sitting over there?" He explained that the Koreans students were similar, although some of them do mingle with others. The teacher also suggested that the Indonesian students perhaps have a tendency to stick with themselves because they come from wealthier families compared to the other students and are therefore from a different socio-economic class, a theme to which I will

\footnotetext{
${ }^{38}$ The conversations in this paragraph have been reconstructed from field notes.
} 
return in Chapter 7.

The English-speaking groups were not perceived as self-segregating due to the visible diversity of their groups, as I will explicate in Chapter 11, even though they also sat in their own groups. Self-segregation was a practice that was mainly associated with the non-English speaking groups. The onus for integration was placed upon students who are not part of the normative English-speaking group(s). The Korean-, Japanese-, and Indonesian-speaking groups were perceived as self-segregating partly due to the racial discourse on diversity that renders them more homogenous than they are, particularly the latter two. The staff reinforced the cosmopolitan norm by differentiating between students who were considered "international" or a "Third Culture Kid" and those who self-segregated.

I argue that not all students were able to be "international" in the way the school envisioned because to be "international" they needed Euro-American capital. There is a productive tension between the transnational identities that the young people at TIS shared and the differences in the way they were able to practise being "international". In order to understand these tensions, it is important to analyse the data within its socio-historical context. In the next section, I contextualize international schools and international education within a global trend towards the internationalization of education.

\section{The internationalization of education}

According to Dolby and Rahman (2008), research on international education emerged 125 years ago and evolved with changing historical circumstances. Research had been sparse until the recent turn of the century when interest in international education and the number of international schools proliferated because "the pressure to 'be international' and to 'internationalize' dramatically intensified in all aspects of education" (Dolby \& Rahman, 2008, p. 679). However, research on the role of international schools in shaping cosmopolitan subjectivities is still lacking despite growing scholarly recognition of its importance (Dolby \& Rahman, 2008; Hayden, 2011; Hayden \& Thompson, 1995; Matthews \& Sidhu, 2005; Mitchell, 2003; Rizvi, 2009).

International schools are a context for international education. While the origins and 
definitions of international schools are contested, their growth reflects global developments (Hayden, 2011; Hayden et al., 2002). According to Hayden (2011, p. 214) the periods following the First and Second World War saw the first growth spurts:

Schools such as the International School of Geneva and the Yokohama International School, both originating in 1924 (Knight 1999; Stanworth 1996), were founded largely as a means of catering for the children of expatriate diplomats and employees of transnational organisations who followed their parents' globally mobile professions around the world, and for whom education provided locally - perhaps because of language or a mismatch with university entrance requirements in the home country was deemed unsuitable.

Decades later, teachers from the Geneva school designed the International Baccalaureate program after realizing that the cultural diversity within international schools required a pedagogical approach that fosters open-mindedness and accommodates the "multiplicity of views" present in the classrooms (Hill, 2007, p. 253; International Baccalaureate Organization, 2013a).

Existing research has hitherto made distinctions between national and international schools by assessing their purposes and outcomes. National curricula and schools, which in the twentieth century were used for nation-building, were concerned with turning "subjects to citizens" (Parker, 2003; see also Rizvi, 2009). National schools are perceived as a site for the cultural reproduction of national class structures. In contrast, international education prepares "young people to cope with life in an increasingly interdependent world" (Hayden \& Thompson, 1995, p. 328). It arguably turns national citizens into "global citizens" suited for a globalizing world (Phillips, 2002; Resnik, 2008).

More recently, Hayden (2011, p. 215) argues that earlier categorizations of international schools have been "overtaken by events" and calls for new research approaches which recognize that national and international education may be merging (see also Hill, 2007). Economic globalization have led to the growth of the transnational capitalist class (Sklair, 2001), and the increased need for national elites and upwardly mobile classes to acquire cosmopolitan capital (e.g. Peterson, 2011). These groups are converging with greater intensity in educational contexts. The "post-colonial elite" of host countries are increasingly opting for 
international education (Hayden, 2011, p. 217). Rizvi (2009) notes that national educational spaces are also becoming more diverse and transnational as the internationalization of education continues. Hayden (2011, p. 220) summarizes,

On the one hand, national education systems are introducing international elements... On the other hand, international education in the form of international schools has rapidly emerged as a means of catering not only for the globally mobile professional classes, but also for the socio-economically advantaged national elites for whom an English-medium form of education is perceived to bestow further advantage.

International education is a highly sought-after commodity. As providers of international education, private national schools that incorporate international elements and international schools that cater mainly to the children of expatriate professionals can cost as much as approximately USD 33,000 per year at the high school level. ${ }^{39}$

International schools reproduce social and cultural capital that is increasingly defining both the transnational capitalist class and national elites. Weenink (2008, p. 1091) refers to this social and cultural capital as "cosmopolitan capital", which he defines as "a propensity to engage in globalizing social arenas" and "bodily and mental predispositions and competencies (savoir faire) which help to engage confidently in such arenas." Peterson (2011, p. 7), in his study of Egyptian upper classes, conceives cosmopolitanism as a "set of practices (Bourdieu 1977, 1984) through which the Egyptian upper classes and those with upwardly mobile aspirations construct themselves as transnational elites." Cosmopolitan capital includes western education, fluency in English, international mobility, global social networks, familiarity with global popular culture, and certain ways of carrying oneself.

Nevertheless, studies of international schools have continued to use the nation-state as their analytical starting point, which I earlier explained as "methodological nationalism" (Wimmer \& Glick Schiller, 2002). Methodological nationalism is inadequate for the study of social relations at international schools. It focuses on binaries which contrast international education with national education and international schools with national schools (e.g. Hayden \& Thompson, 1995; Lallo, 2008; Wylie, 2008). It constructs difference as national difference, and thus the

\footnotetext{
${ }^{39}$ This figure is an approximation of the tuition fee quoted by the International School of Geneva. In Jakarta, tuition fees for international schools range from approximately USD 8,000 to USD 22,600, not including mandatory facilities and re-enrollment fees, which can add up to USD 5,500 to the cost annually per student. All fees quoted are for the academic year 2012-2013.
} 
research often implies that international schools are better than national schools because they help students transcend national differences. Therefore, when students are perceived as unable to overcome national differences, they are seen as parochial and having failed to be "international". Methodological nationalism is unable to conceive of cosmopolitan practices as diverse because its analytical framework is dependent on binaries such as nationalinternational and parochial-cosmopolitan.

Furthermore, methodological nationalism is unable to conceive class structures as transnational. Consequently, it overlooks the role of international schools in reproducing the cosmopolitan capital of the transnational capitalist class. Instead, the literature differentiates between schools that are ideologically-driven or market-driven (see Hayden, 2011). Some scholars argue that international education promotes international mindedness, which in turn produces responsible global citizens (Gellar, 2002; Phillips, 2002, p. 178). Failure to do so is not attributed to any flaw in international education, but to the narrow-mindedness of students and parents (e.g. Tamatea, 2008). This interpretation exempts the ideology of being "international" from critique. These same assumptions which attribute failure to the individual were reflected at TIS.

Brown and Lauder (2009, p. 144) argue that we need "a far more nuanced account of education and social class" which considers the "mosaic of global power and privilege that is part nationally based and part transnationally based". The ability to engage with those who are different, as implied in the notion of being "international", is nurtured within this mosaic of power. As Rizvi (2009, p. 284) notes,

...identities are forged in histories of differentially constituted relations of power; that is, knowledges, subjectivities, and social practices, including practices of cultural negotiation, are established within asymmetrical and often incommensurate cultural spaces, even more so in transnational spaces.

Therefore I use an anthropological approach in order to empirically test the ideological basis of international schools by addressing the complex ways in which knowledge is produced and reproduced. I conceptualize The International School (TIS) as a transnational (educational) space located within the national territory of Indonesia and treat national and transnational as mutually constitutive (Smith, 2001). It is a transnational space in which diverse national and 
transnational structures converge within a local setting. Conceptualizing TIS in this way helps tease out the nuances produced when discourses intersect to influence the social dynamics on campus. As mentioned in Chapter 1, I use methodological cosmopolitanism as a means to use the transnational as my analytical point of departure. By assuming cosmopolitanism as the norm at TIS, I am able to focus on exploring the diverse ways in which people engage in cosmopolitan practices.

\section{Conclusion}

The globalizing marketplace has made class structures increasingly transnational. Education is internationalizing to accommodate this change. This thesis studies the social realities of an international school in Indonesia within these global trends. I argue that the convergence of a diverse set of young people who are in pursuit of the same cosmopolitan capital produces diverse ways of practicing cosmopolitanism. However, the ideology of being "international" has yet to recognize that cosmopolitan practices are diverse. This thesis explores the tension that emerges out of this mismatch by using methodological cosmopolitanism.

Using a postcolonial lens, I problematize the international school as a transnational site of cultural production where colonial and capitalist discourses intersect. This thesis will make visible the Eurocentrism of the dominant form of cosmopolitanism and denaturalizes its universality. I argue that international schools reproduce the transnational capitalist class and national elites by maintaining cultural hierarchies that privilege Euro-American cosmopolitan capital. In the next chapter, I illustrate the overarching importance of language in shaping cosmopolitan subjectivities. English in particular is a powerful form of cultural capital that enables transnational youth to practise cosmopolitanism as defined by TIS's ideology of being "international". 


\section{Chapter 5}

\section{English: the language of power and cosmopolitanism}

One the most obvious markers of being "international" at TIS was fluency in English, preferably native fluency, and preferably with the "right" accent. English language ability has a profound role in shaping cosmopolitan ideologies, practices, and subjectivities. It give access to power and shapes identities and subjectivities (Burck, 2005). On the one hand, we speak languagewe use it as an instrumental tool, for example, to assert (racialized) identities or to gain competitive advantage in a globalized marketplace. On the other hand, language constructs us as cultural beings. Each language carries within itself cultural meanings that provide coherence to (disjointed) life experiences and situate individuals who speak (or do not speak) it within their socio-historical context. The language we speak and the accent we speak it with tell a story of where we have been and where we are going.

This chapter highlights the way speaking English is conflated with being international at TIS, and how high status is accorded to the ability to speak English. This deeply impacts the subjectivities of transnational youth and their relations with others, including family members and each other. I critically analyse the way colonial and contemporary capitalist discourses imbue English with power. I focus on language in this chapter because languages play a significant role in defining social relations at TIS.

\section{Becoming “international” by speaking English}

The role of English as a marker of cosmopolitan capital at TIS was most visible to those who did not speak it at home. Over the years, Jenny had hung out with Korean-speaking and Englishspeaking groups at different times. In describing her changing friendship circles, Jenny said, "In high school...the Koreans divided more, [so] I hung out with this one Korean group... who were really, like, "international", sort of." She made double quotation marks in the air with her hands as she said, "international". I asked her what made this Korean group "international" and she responded, "They spoke English". It is likely that they had more in common than simply their language preference, but what is pertinent is that Jenny automatically associated speaking English with being "international". It is this association that contributes to the way 
using other languages, such as Indonesian and Korean, as the main mode of communication is associated with being simply Indonesian or Korean, and not being international.

Likewise, Kairi associated speaking English with being international, which in Japanese is referred to as kokusaiteki. Kairi explained that her parents enrolled her at TIS instead of the Japanese school, as is customary for Japanese expatriate children in Indonesia, because they wanted her to be international: "For starters, both my parents say that they wanted me to be kokusaiteki. And my name is 'Kairi' because 'Kairi' is something that's easy for foreigners to pronounce...right? That's why I got the name "Kairi'." Kairi followed this explanation with an elaborate account of her relationship with the English language.

So I attended TIS and...the Japanese kids who I knew, like when there was a [social] gathering for all the families at [dad's] company, the Japanese kids-the ones who were my age-all went to the Japanese school. And I never felt down at all about this for being different from the others. In fact, it made me happy. I was fascinated in the sense that, "Oh, so I can speak English," or "I have a different world from these people" - fascinated as in like...l've always liked the feeling of having something that others don't.

For Kairi, speaking English and attending an international school gave her a sense of distinction that set her apart from the others (Bourdieu, 1984).

This sense of distinction remained even when she returned to Japan for several years. When she told her classmates in Japan that she was a kikokushijo or returnee student (Goodman, 1990), she said,

They would say to me, "Can you read the English writing on this mug out loud?" I was in third grade and I'd say "Blah, blah, blah, blah" in English, and they would all be like, "Wooooowwwwwww!" So then I was really happy 'cause I thought, "Cool, I'm different. Yeah, I'm different because I speak English."

Fluency in English accorded Kairi privileged status within the Japanese community both in Indonesia and Japan. It acts as cosmopolitan cultural capital. 


\section{"English is the power language"}

English gives the speaker status in various contexts, and children internalize this at a young age. Rick, a North American teacher, saw the impact that English had on his children from both his previous and current marriages to Indonesian women.

RICK: English is the power language. I mean, I know from my background as a teacher, it's the power language. Even within families, children quite early sense which is the power language, and they go to the power language...There's research that backs me up on this, and I know from my own children as well-English has power.

DT: Even though they've been at a local (Indonesian) school the whole time?

RICK: Yeah, and their mother's [an] Indonesian speaker and so on. That's why now-I've got with my new wife, we've got a daughter, two years old-we're trying to do everything we can to get her to speak good Indonesian, but English is the power language. When I say power language, it's the dominant language of the...it's perceived as the dominant language...by everybody. So that even on television, you know... watching Indonesian television, I do all the time, even a gossip program-the celebrities break into English. The people being interviewed on the news will use English and they appear, I think, somehow to the general population as wiser or more educated or more trendy, whatever. Whatever they're gonna call it, it's perceived as a good thing. So to use formal correct Indonesian is almost laughed at now. But to use English, oooh, that's good, impressive. And kids pick up on that. They don't realize it, but they gravitate towards the language that has the power. So it's hard to get in the bilingual family, and I think it's hard to get the children to speak the...the weaker language.

Despite raising his children with his Indonesian wife in Indonesia, it requires effort to encourage them to speak the local language. It is counterintuitive for his children to speak "the weaker language" because cultural hierarchies are intimately tied with language.

As I show in the next section, the global social hierarchy, in which English predominates, reinforces the lingering taste of colonial discourses on culture, language, and "race" to shape the subjectivities of transnational young people. Discursive relations between the language of 
the colonizer and colonized, whereby the former is constructed as superior to the latter, endure to the present day, though they have shifted to accommodate the hegemony of English as the most powerful of all colonial languages.

\section{The coloniality and globality of English}

As Norma Field (1996) comments, "The spread of a language has historically been tied to military conquest and economic domination, and the primacy of English is inseparable from the history of the British Empire and postwar American global domination." English language teaching was central to the British colonial project (Pennycook, 1998), including the cultivation of native populations who were "British in taste". Homi Bhabha (1984, p. 126) writes that "mimicry" of the colonizer's language by the colonized "emerges as one of the most elusive and effective strategies of colonial power and knowledge". It was effective because mimicry was never perfect, rendering the colonial subject forever inadequate-"almost the same, but not quite" (Bhabha, 1984, emphasis in original). Speaking the colonizer's language and being educated in their ways came to signify a sense of social distinction that colonial subjects continually desired and pursued, thus consolidating the colonizer's dominant position (Bourdieu, 1986, p. 243).

In Indonesia, it was fluency in Dutch that signified elite status during colonial times. In Java, the traditional priyayi nobility and others drew on their exposure to Dutch education, particularly their mastery of the languages spoken by those in power during colonial times, to reconstruct themselves as modern elites (Gerke, 2000). According to Selosoemardjan (1962, p. 129),

The rise of the intelligentsia to the upper class was recognised by other classes, which tried to acquire the external symbols of this new class by wearing Western-style dress and walking around with a dispatch case in one hand and a fountain pen showing in the upper pocket of the jacket. But by far the most distinguishing symbol of the new upper class was the use of foreign languages, namely Dutch or English.

These markers of distinction remain relevant today. The legacy of Dutch colonialism on local subjectivities emerges in the data from TIS, albeit subtly. Participants who identified as Indonesian in one way or another commonly mentioned that one of their grandparents or 
great grandparents were of European (usually Dutch, sometimes German or Portuguese) descent, or that one or more of their grandparents speak Dutch because they had been educated in Dutch-medium schools. ${ }^{40}$ These references to a European connection imply a sense of distinction, that they were different from the general population.

Two Indonesian university students, Dina (who grew up in Indonesia, France, Norway, and Chile) and her friend Camellia, perceived a very clear hierarchy of languages among the colonial (Dutch), national (Indonesian), and regional (Javanese) languages in the way they are used. Both of their grandparents were Dutch educated and their parents and relatives grew up speaking Dutch. Dina and Camellia, who can only understand a few words of Dutch, believe that the elders in their families speak Dutch for two reasons: "when they have secrets", such as when they talk about financial matters, and as a mark of distinction.

DINA: Arrogance. Arrogance...they have this attitude when they talk in Dutch. Different when they talk in, it's different, I sense it when they're talking in Indonesian or in English, and then suddenly they switched to Dutch, it's different. It's the attitude.

CAMELIA: Yeah me too.

DINA: The attitude is, it's like they feel like more "aristocratical".

CAMELIA: Yeah because...

DINA: They got the um (puts her chin up in the air) attitude.

CAMELIA: No, no, because like this (puts on a facial expression of conceit that out-does Dina).

DINA: They have the attitude for being, "We are more important." I think it's because of the colonial stuff, because they always consider that.

CAMELIA: It's true.

\footnotetext{
${ }^{40}$ Apart from the Dutch, usually only the local elite attended Dutch-medium schools prior to the Japanese invasion of 1942 (Mysbergh, 1957).
} 
DINA: Because only the Dutch educated are considered more, like, well-known, educated and, like, hail the Dutch.

CAMELIA: My grandmother she only speaks Javanese with the, how do you say it...

DINA: Maids.

CAMELIA: ...my housemaids or house servants. And they speak Dutch with her family, with her siblings, or with my mom, or with...or with some important people. But not with the grandchildren and not with other people.

DINA: So you see there are languages that separate us.

CAMELIA: Just make them, like, they are exclusive or something.

DINA: Yes. Dutch is for the exclusive part, Indonesian is like for us, for the kids, and then the dialect is like for the maids. (Interview, 13 November 2009)

Language is tied to class and status. The former colonizer's language had the highest status as the language used with the elders in the family and "important people". By speaking Dutch, the speaker is able to draw on the cultural capital that they inherited through their historical connections to the Dutch educated elites of colonial times. The national language occupies the middle status, while "dialect" (regional languages) are perceived as low status and associated with lower-class workers. While Dina's reference to Javanese as a "dialect" is partly due to limitations in her English skills, it also suggests the tendency to see regional languages as inferior and not even worthy to be called a language.

In more recent times, the shift from a colonial to a capitalist economic order dominated by the United States saw (American) English replace Dutch as the main non-indigenous language that marks status and privilege. B. Kumaravadivelu (2006, p. 13) observes, "If the coloniality of the English language is undeniable, so is its globality." English dominates scholastic, linguistic, cultural and economic realms. Robert Phillipson (1992, p. 2) metaphorically says, "whereas once Britannia ruled the waves, now it is English which rules them. The British empire has given way to the empire of English." This has implications for the study of transnational youth 
and the way language influences their subjectivities. A sense of distinction can be derived from having fluency in English, attending English-medium schools such as international schools, and/or having partial European descent (including e.g. white American). Fluency in English is associated with elite education and having access to the wealth and opportunities found in the international market (Imam, 2005), and thereby with cosmopolitan cultural capital.

English as a marker of privilege is sometimes desired at the expense of the national language. Some Indonesian parents and grandparents take pride in their children's inability to speak fluent Indonesian despite being raised in Indonesia. One couple explained that their eldest elementary school-aged grandchild sometimes gets the word order wrong when speaking Indonesian. "When she speaks Indonesian, she has a bule $e^{41}$ accent," added the grandfather with a chuckle. Far from being concerned by this, he seemed to delight in it. Syeda Rumnaz Imam (2005, p. 478) writes of a similar situation in Bangladesh, where the English-educated are illiterate in the national language and "tend to look down on" those educated in the national language.

As educational institutions, English-medium international schools like TIS are in a position to shape subjectivities in ways that reflect "cultural constructions of colonialism" due to the symbolic meaning of power and privilege vested in the English language (Pennycook, 1998, p. 19). Bill Ashcroft (2001, p. 39) writes,

...when we consider the pedagogic formation of the colonized child in attending colonial schools and learning the colonial language, we see a process in which hegemony, ideology, interpellation and language all come together in a powerful instance of subject formation.

Similarly, international schools interpellate, or "bring into being or give identity to" (Oxford Dictionaries), young people, by promoting ways of being "international" that privilege EuroAmerican capital, such as the English language. The data in the remainder of this chapter reveal "powerful instances of subject formation" continuing to occur among transnational youth in international school contexts.

\footnotetext{
41 "Bule" literally means "faded" in Indonesian but is used as slang for "white people". It can be used with a derogatory inflection, but it more often carries a positive connotation relating to white privilege.
} 


\section{"When I Spoke English I Felt Smart!"}

Language, particularly English, emerged in Lianne's story (to her own surprise) as a significant influence on her subjectivity due to its symbolic power (Interview, 25 July 2009). Lianne is an alumnus of TIS and speaks English with what sounds to most like a general American accent. According to her passport, however, she is Singaporean. Her father is Singaporean and her mother is Indonesian. Lianne grew up in Indonesia, but completed most of her study at TIS. While she now speaks English with native fluency and considers it her strongest language, when she first attended TIS in kindergarten, she spoke Indonesian more than English and was placed in an ESOL class.

We sat at Lianne's kitchen counter as I interviewed her. The morning sun, or at least the rays that made it through the smog, shone through the glass windows of the air-conditioned Jakarta condominium. Ten minutes into the interview I asked her what it had been like to learn English as a second language when she first started going to an international school in Indonesia in kindergarten. Thereafter, "language" dominated her narrative. She said, "It was fun, you know, because I loved languages and I still do. And I think it was fun because I was becoming smarter." Lianne straightened her back on her kitchen stool, held her head up and pointed her nose into the air-all to illustrate, in a playful manner, the uppity attitude she used to have with regard to her ability to speak English-as she continued, "When I spoke English I felt smart!" Lianne laughed. She then explained why it made her feel smart as she talked about her relationship with her mother. True to her attractive, charismatic nature, she was very expressive and spoke animatedly throughout by manipulating the intonation, volume, and speed of her speech.

'Cause my mom spoke to me in Bahasa. ${ }^{42}$ My mom speaks great English. She speaks very well, she's able to communicate, but she prefers to speak in her native tongue. So that later on I find out, when I'm eighteen or whatever...she didn't want me to lose my native tongue. That's why she kept talking to me in Bahasa. But, you know, the more I learned more English, the more I was able to talk back to her in English. And it made me feel smart, you know, so it was fun.

\footnotetext{
42 "Bahasa" is short for "Bahasa Indonesia" which means "the Indonesian language". Foreigners (and sometimes Indonesians when speaking in English) often refer to the Indonesian national language as "Bahasa Indonesia" or simply "Bahasa." The latter results in grammatically incorrect usages such as "I speak Bahasa" which means "I speak language". In this thesis I will use "Indonesian" to refer to the national language as the preferred translation of the Indonesian term "bahasa Indonesia" unless I am quoting my informants.
} 
Lianne spat out the word "smart" with gusto and accompanied her speech with lots of facial and hand gestures to emphasize her spoken words. When I noted this, she laughed and explained,

Yeah, that's...that's another thing, you know. I remember coming home from school, and I picked up facial and hand gestures. (Again, she says the italicized words with gusto.) And, and my mom was like, "Huuuhhh?" I don't think that Indonesians speak with their face...or they speak with their hands...I think it's mostly through words. And so that was another one that I completely, you know, was oblivious to until my mom was like (Lianne changes her voice to sound like a theatrical version of a frustrated mother), "Stop raising your, your hands, they're everywhere." She would tell me to stop (slowing down her speech and softening her voice almost to a whisper), but I would never, because it would, like I told you, it made me feel smart (picking up speed again and rapidly rattling off the italicized words), so much more clever than my mom. (Laughs)

So symbolically powerful is the English language that even as a child Lianne was able to use it to challenge her mother's authority (Burck, 2005). The more her English improved, the more she was able to "talk back" to her mother. While Lianne's mother had a good command of English, she did not have native fluency and found herself on the less powerful end of the nonnative-native dichotomy compared to her own daughter. Lianne had gained a natural, native command of English, including the embodied language of gestures, through her educational environment. TIS moulded Lianne's embodied sense of place or habitus in a way that gave her access to the symbolic power embedded in the English language (Bourdieu \& Thompson, 1991).

Lianne's account of her relationship with English also demonstrates that the postcolonial context of Indonesia magnifies the symbolic power of the English language. The vast economic inequality between the majority of Indonesians and those in the expatriate community reinforces the value of cultural capital associated with the ability to speak English, which is conflated with high status. I asked Lianne how she felt about Indonesians who do not speak English very well, and she was forthcoming about it:

If now, no, I don't care. Before, oh my god, when I was a little kid I would've been a 
snob about it. Yeah, I would've been a complete snob about it because it means I'm much more superior. Oh, come on, you know, like, there are some things that's like, passed on to you because of [TIS].

I laughed as Lianne said this because I could empathize with her. Knowing that I had gone to a similar school to hers, Lianne understood why I was laughing and continued,

You should know this. It's like some stool. All of a sudden you're on like a pedestal...I can't really explain it. But there was a feeling of superiority, definitely, because of the affiliation, because of the command of language, because of people you hang out with, because of the extra-curricular activities that were like, you know, bountiful, the subject we studied, like, come on...You know that it was much more advanced, if not interesting, than the local schools. And so, back then...if the person I was communicating with is not up to my standard, like, forget it. Complete snob.

The inequality between the international and local school environments amplified the sense of cultural superiority associated with speaking English. It was like being placed on a "pedestal". Lianne explained that the feeling of superiority started to wear off when she became older and her conflation of being Indonesian with being inferior was challenged.

... High school...maybe towards $10^{\text {th }}, 11^{\text {th }}$ grade. Because, what changed was...back in the day, when all of a sudden you're going out and you're meeting people from the German school, the French school...And then, uh, for me it was also church because I got...my first communion, I had to take lessons with a whole bunch of Indonesians who actually were very cool people (laughs), you know. It changed. It was humbling....because I think I realized, "Oh there was a world outside of [TIS] that could have been equally as interesting and equally as awesome."

Because this girl [Mira], she opened up my eyes. She went to school in Oklahoma, I think, and she's Indonesian, and just interacting with her helped me to understand that it was okay, you know, there's a whole different world. And of course by then you were studying world economics, and world studies or whatever it is..., and, "Oh, the world is beyond" (laughs), you know...And I had a girl friend whose boyfriend was, like, a rich Indonesian boy and...when we hung out with him, it's like, "Aaah (putting on a 
surprised look), ohhh, okay," yeah, like, oh my god, there's a whole different world of interesting and awesome and privilege and...yeah, and money.

Lianne also explained that the "very cool" Indonesians spoke English. Meeting Indonesians who were financially privileged and had Euro-American cultural capital (e.g. speaking English and going to school in Oklahoma) was "humbling" for Lianne because it disrupted the construction of "Indonesian" as inferior. However, there remains a sense of equating coolness (status) with financial privilege and exposure to the West. Euro-American cultural capital is conflated with cultural and economic status. In contrast, Indonesian cultural capital is perceived as inferior.

There were differing attitudes towards speaking Indonesian among those at TIS who were not Indonesian by nationality and were part of the mainstream English-speaking groups. I also observed a wide range of abilities among students who had spent most of their lives growing up in Indonesia. Some like Rajesh, an Indian national, Stephan, a French national, and Vlad, a Russian national, had native fluency in Indonesian. Rajesh's American friend Tom, however, only had a mediocre command of the language. When I met him, Tom was in $11^{\text {th }}$ grade and was taking private lessons to improve his Indonesian. Tom started taking lessons after he realized he would be returning to the United States for college soon and had very little to show for the years that he had spent in Indonesia. There were also many students who could hardly string a sentence together in Indonesian. At the extreme end was Darren, who was of mixed Indian and Australian background. Darren said that if he got in a taxi and the driver could not speak English, he would get out. He explained that when he came to Indonesia at about age six, he had as much interest in Indonesian as he did "in a cockroach". Such negative expressions were rarely used, but it did reflect Rajesh's belief that his classmates' inability to speak Indonesian had much to do with their lack of interest in Indonesia. The lack of interest was precipitated by Indonesia's status as a economically and culturally inferior country (Chapter 6).

Cultural hierarchies deeply impact upon the subjectivities of transnational youth. Many internalize the structure and learn to distance themselves from the inferior (e.g. Indonesia) and align themselves with the superior (e.g. the West). In Chapter 7, I illustrate how the slippage among status, class, and culture creates even more tension in subject formation when "race" is factored in. 


\section{Speaking "without" an accent}

Accents are also markers of privilege and belonging. Within English, there are distinctions between acceptable and not so acceptable accents that are indexed according to a global linguistic order led by the United States and Britain. ${ }^{43}$ These distinctions create varying responses among those who engage with the Anglophone world. At TIS, South Asian students were particularly adept at switching between accents. When the bell rang at lunch break on a typical day, male South Asian students (predominantly Indian with one Pakistani) dashed out of their classrooms speaking with a general "American" accent. One by one, they found each other as they started walking towards the cafeteria, and eventually merged into one group somewhere down the hallway, by which time they were speaking with a distinct South Asian accent. Their practice of switching accents illustrates the complex ways in which "hegemony, ideology, interpellation and language" come together to shape cosmopolitan subjectivities (Ashcroft, 2001, p. 39).

Speaking in a not so acceptable accent has negative implications. Akshat was the sole Indian male in his grade who could speak English only with an Indian accent. According to his friend, Devraj, people "don't take him seriously". ${ }^{44}$ Devraj noted that an Australian teacher had praised Akshat for speaking English well when in fact it is common for the educated in India to speak English well, but their Indian accent leads people to assume otherwise. Not being fluent in English or being perceived as not fluent in English due to one's accent can lead to feelings of insecurity. Marco, a student from the Philippines, explained that there is a term in Tagalog which, translated literally, means "nose bleed". It refers to how those who do not speak English well feel intimidated when faced with a native speaker of English.

...That's the Filipino term if you're like Filipino and you can't speak English properly...We call it nose bleed if you can't say anything perfect in English...Sometimes they even say like, “Don't English me, I'm panic." (We laugh.) You're confused, intimidated and lost for words, I guess, in one single word. (Interview, 14 December 2009)

While the term can be applied to other languages, Marco said, "the term is usually used more for non-English speaking Filipinos" because it is assumed with English that "you're supposed to

\footnotetext{
${ }^{43}$ Jan Blommaert (2010) writes of the commodification of language that sells accents together with the ideological package they carry.

${ }^{44}$ Conversations with Askat, Devraj, and Mandeep are reconstructed from field notes.
} 
know it...that's the pre-conceived notion for English. That's why you feel nose bleed for English." It is not surprising then that such feelings of intimidation would either lead to reluctance to engage with native English speakers and/or a desire to mimic them.

The politics of accents is intertwined with the colonial discourse on language. It reveals the tension between being "fascinated and lured by power and the Western way of life" and attempting to resist assimilation (N. Krishnaswamy \& Burde, 2004[1998], p. 57). Mandeep, whose family was originally from India but had taken up Singaporean citizenship, said that he used to have a "proper" Indian accent when he was younger. But he learnt to put on an American accent when he moved to the Philippines and enrolled in the international school there. Mandeep insisted that he did so because he was being "stupid". After some time he realized this and quit speaking with an American accent. Mandeep spoke with a hybrid accent that seemed like a softened version of an American accent mixed with an Indian inflection, which became slightly stronger when he spoke to his mother on the phone. However, Mandeep was unable to switch between two distinct accents at will the way most of his Indian friends at TIS did.

Devraj explained that Indian students switched accents because in India they get teased and laughed at if they speak with an American accent. "It means that you've lost yourself," he said. Devraj had strong opinions about this. For Devraj, it seemed that mimicry without the ability to retain bicultural/bi-linguistic skills is the equivalent of giving oneself over to the lure of the dominant culture while remaining incomplete subjects who are "almost the same, but not white" (Bhabha, 1984, p. 130). Switching accents is a strategy that enables one to access the privileges that come with the use of English, while resisting complete interpellation. Krishnaswamy and Burde (2004[1998], p. 155) argue that Indians practise an everyday form of subversion in coping with pluralistic situations and they "have always compartmentalized life and created space in the form of pigeon-holes to accommodate various waves that come to influence their life to keep their feet firmly on the ground."

Switching accents is a tactic for resisting the power of English as well as maintaining boundaries that define a sense of belonging. Devraj spoke with an American accent to me and said, "I speak to you like this. I switch." He implied that he switched to the American accent for my sake because I was an outsider. According to Devraj, the switch comes naturally to them: “You don't think about it. It's, like, when you switch from one language to another, do you 
think about it? No. Well, it's the same." Devraj was didactic. When I chatted with Devraj and his friends, they spoke to me, a non-South Asian, with an American accent, then switched to a South Asian accent a split second later as they turned to address one of their mates (even if it was just to utter one word), and switched back to an American accent as they turned back to me. ${ }^{45}$ It was the same in large group settings. As the president of the Indian club, Devraj switched accents while speaking from behind a podium depending on which group in the audience he was addressing, the South Asians or non-South Asians. Accents were used as markers of cultural boundaries between insiders (South Asian) and outsiders (non-South Asian).

Even though they spoke the language of the former colonizer, an "outsider", the Indian boys differentiated between the colonizing and indigenous accents, so to speak. By being selective with whom they spoke in an Indian (insider) accent and an American (outsider) accent they reclaimed the power to draw the boundaries between insider and outsider, and thereby positioned themselves as insiders. There is symbolic power in the ability to act as gatekeepers to an insider status.

\section{Linguistic and cultural boundaries within the family}

Instead of compartmentalizing her use of language to create boundaries within herself, as the South Asian boys did, Lianne created boundaries between herself and her mother. I asked Lianne how her mother had responded when she started talking back and feeling "more clever" than she. As an adult, Lianne described her relationship with her mother with a deeper understanding of the cultural challenges that her mother may have faced:

At the time, I wasn't aware of [my mother's] reaction, or how she may feel. But later on in life, after my dad passed away and I settled in Indonesia, I realized that it was a challenge for her because she really wanted to teach me the values her parents taught her. She wanted me to grow up Indonesian.

\footnotetext{
${ }^{45}$ It was only after I had known them for several months that on one instance did one of them seem to forget to switch out of the South Asian accent and into the "American" accent to speak to me. This made me rather happy because it indicated that they were comfortable enough with me to not have to make the distinction between insider and outsider.
} 
Lianne's father was a peranakan Chinese ${ }^{46}$ who had received his education in English during the British colonial rule of Singapore. Lianne explains that she was educated at TIS because her father wanted to take advantage of his company's policy of paying for his children's high tuition fees at the international school.

He wanted to take every advantage of that for his children, and I think he won that education battle with my mom. So, I think, during those days, it was repressed for her. She didn't have much influence in our lives in terms of education or culture or whatever...But it wasn't really until I settled down (in Indonesia as an adult) and had this job and my dad passed away did she really open up about how she fe[lt]-her lack of influence.

Although Lianne grew up in Indonesia, she did not "grow up Indonesian" in the way her mother had wished. The cultural influence of the international school environment overshadowed that of her mother and host country. I asked Lianne how it made her feel to hear her mother's views and she responded,

As an adult? Oh, I still rebelled...this is me thinking, you let dad make the decision, live with it, you know. This is who I am. Deal with it.

Tensions may arise when unequal gender relations intersect with linguistic and cultural hierarchies within a marriage. As a wife whose first language (Indonesian) was considered internationally less important than her husband's first language (English), Lianne's mother's desires for her children became subordinate to those of her husband.

Lianne gave more recent examples from her wedding, at which I was present, where she and the groom had acted in ways that were not considered Indonesian:

It helped that dad was also himself pretty much, you know, not fully Asian or whatever. So, I think it...helped mom to warm up to what her kids would be. But I don't think that she expected us to be so off the charts because we were still growing up in Indonesia, she was still talking to us in Bahasa, we still went to visit her family. But it just didn't stick because all we knew was what [TIS] taught us, and what [TIS] taught us was very

\footnotetext{
${ }^{46}$ The term peranakan refers to descendants of the Chinese who settled in the Malay peninsula and what is now Indonesia and intermarried with the indigenous population.
} 
American, very westernized. The friends that we made were always the oil kids. I had a lot of friends from Mobile Oil, Schlum..., Schlumberger, you know, all these big oil companies. And...those guys are pretty much Texan, right? (Laughs)

So I think it was a losing battle for her. She still tries to get her way, but her kids, we don't...I don't want to, you know, conform. This is who I am and it's very different, but I love it because it's me. And she has to accept it.

The school environment silenced the influence of her mother and Indonesia through the absences: the absence of Indonesia in the curriculum, and the absence of Indonesians in the teaching staff and student body. Lianne's westernized cultural makeup attests to the power of educational institutions to reproduce culture (Levinson \& Holland, 1996). Ortner (2006, p. 109) explains,

For Bourdieu the subject internalizes the structures of the external world, both culturally defined and objectively real. These internalized structures form a habitus, a system of dispositions that incline actors to act, think, and feel in ways consistent with the limits of structure.

Lianne believes a cultural hierarchy was in operation at TIS, which students internalized. It was, in order from the top, "western" with "American" followed by "European" and then "eastern" which includes "half-Indonesians" followed by "Koreans or the Japanese". The curriculum, she argued, shaped the hierarchy because it privileged American knowledge:

I think because our teachers are mostly Americans, I think that a lot of our study material was based out of the States, I mean I learnt what a penny was....before I learned about the rupiah! $!^{47}$ And, and, social studies was always about American history before world history. And then I go to [university] and it's like, you know, I go to Melbourne...it's like, ooh, colonization, hmm, how come I didn't study that at school? Duh, we were being colonized at that school! (Laughs.) I honestly think that it was just the system. It was the operating system of the school: the workbook, the teachers, and then most of the kids were of course American kids. It's the oil kids, Mobile Oil, Castrol, right? Whatever, whatever.

\footnotetext{
${ }^{47}$ Indonesian currency
} 
Lianne's discussion gives insight into the hidden curriculum at TIS and its ability to shape student subjectivities. The power of educational institutions and the environment they provide to reproduce the hegemonic culture cannot be overstated. The school environment shaped the way Lianne spoke, acted, and thought.

In fact, the environment outside the school gave credence to the privileged status of the culture reproduced by the school. Lianne elaborates,

I had a really excellent education. I was not unaware of the opportunity or the privilege it was to attend $[T I S] \ldots .$. Because when I go home and when I hang out with my mom's friends' kids...you know, they went to this normal SD, ${ }^{48}$ and at that time no one spoke English. There was not many language schools, so it was an advantage to be able to be speaking...and...going to school where, "Hey, my third boyfriend is the second whatever in charge of the Australian embassy," you know. It's like a privilege to be surrounded by people who are from different designations or whatever it is. It was just the knowledge of it that made me know I was very privileged to be able to go to this school.

Lianne acquired social capital at TIS due to the connections she established with persons of "different designations". The environment outside and inside TIS worked together to reinforce and maintain the distinction attached to the school's dominant culture, thereby giving further credence to the school's authority to reproduce said culture in its students.

There are invisible benefits and costs that come with an international school education. Parents find international schools attractive due to the global opportunities they offer students who master English and gain an international education. However, it can create cultural gaps within familial relationships. As a child, Lianne quickly internalized the structure that accorded high status to English and the cultural capital associated with it, thus placing her at odds with her mother's cultural values and position in their relationship. As an adult, Lianne has a reflective understanding of the conflicting dynamics that were at work in her parents' desire for quality education for their offspring. Yet, this understanding does little, if anything, to change Lianne's cultural makeup: the language she speaks, the way she carries herself, her understanding of the world-all betray the influences of her westernized educational

${ }^{48}$ An acronym for "sekolah dasar", which means "elementary school" in Indonesian. 
background. She still enjoys socializing with other TIS graduates, some of whom she met after she had returned to Indonesia as an adult, due to the sense of connection she feels with them as a result of their shared international schooling.

Lianne now speaks Indonesian fluently, especially since she began to use it for work, and is married to an Indonesian man. The sense of superiority she once held has passed, but there remains a certain degree of cultural gap to be reckoned with. On the one hand, as a child, she chose to draw from the privileges associated with English. On the other hand, she was socialized into a Euro-American school culture-a process that she had little control over. International moves may have featured in her childhood only in an indirect way as someone who stayed at an international school and watched her friends come and go. Nevertheless, the experience of being educated at an international school still meant that she had to straddle multiple cultural worlds-home culture and school culture-while growing up.

Further, Lianne's mixed upbringing is derived from several generations of transnational engagement. She claims that her Singaporean father is not "fully Asian", and that this helped her Indonesian mother "warm up" to her and her sibling's ways (Interview, 25 July 2009). Her father had been "brought up British" in a "British education system in Singapore" and "his English is very British." This influenced the choices he made for his daughters' names and education: he attempted to balance the culture of the colonizer and colonized. He had an English name, John, but Lianne said that for his daughters "he wanted to have a Chinese name that was acceptable," i.e. Anglicized. Hence, her name is "Lianne", which sounds like the Chinese name "Li-an". For her education, he chose an international school due to its English language instruction and reputation as a provider of high quality education.

The colonial imprint on the previous generation is not unique to her father's life. Lianne's mother's family and cultural background can also be traced back to Indonesia's colonial past. Her mother is "from Manado, ${ }^{49}$ but she's very much Dutch" due to both her Dutch education and mixed indigenous, Dutch and German heritage. "My great, great grandfather is an Indonesian Dutch hero," claims Lianne, "so he was, like, a warrior in World War One, I guess, and he's honoured in some Dutch museums. And so they (the family) [are] very proud of that inheritance." While Lianne described her mother's background as a matter of fact, it was

\footnotetext{
${ }^{49}$ Manado is a major city on Sulawesi island. It is also one of the wealthiest and most-Christianized places in Indonesia that has one of the longest history of European colonization (by the Portuguese, Spanish and then Dutch) and a tradition of good education.
} 
common for other informants from former colonies to make references to their colonial link either through descent or education as a sign of distinction. Euro-American cultural capital is inherited through the generations (Bourdieu, 1986). Not only did her parents' inherited British and Dutch cultural capital give Lianne access to the cultural capital reproduced at TIS, it also facilitated her the ability to internalize it. Hereditary cultural capital has significant implications for the variable propensity of students to internalize the school's ideology of being “international" (Chapter 9, 10, and 11).

\section{Associating English and "expat" with high status}

I will provide two more examples of the deep impact that English and its symbolic power has on cosmopolitan subjectivities. Afra's story sheds light on the importance of having a "natural" command of English. Afra was an Algerian national who had studied at international schools in several countries (though not Indonesia). He spoke eight languages, including English, which he spoke with a distinct American accent when I interviewed (2 March 2009) him on Skype. He said of English, "I wanted to keep up, you know, maintain my English 'cause wherever you go in non-English speaking countries, speaking in English is, like, a big plus." Later Afra elaborated, "I think English, especially American English, is the language of the privileged." He explained that others perceived him in a better light when he was able to demonstrate his fluency in English.

The use of English as a status marker was driven home when I hung out with Olivia during her visit to Jakarta from another city in Indonesia. Olivia self-identified as a Third Culture Kid due to her transnational upbringing. Her parents are Chinese Indonesians, but she left Indonesia in her early teens and lived in Singapore, Canada, and China before returning to Indonesia as an adult. She was fluent in English, but I also knew that she was a native speaker of Indonesian. As I was used to code-switching ${ }^{50}$ with anyone who was fluent in two or more of the languages I spoke, I repeatedly tried to use both Indonesian and English when speaking to her. I was puzzled when she spoke nothing but English back to me. Olivia had her reasons, which I recorded in my field notes:

By the end of the day I gave up with Olivia and spoke in full English to her. But I actually

\footnotetext{
${ }^{50}$ Alternating between two or more languages in speech.
} 
found it a bit tiring speaking nothing but English with someone who is also a native speaker of Indonesian. After the interview she told me that she [had] learnt during her TESOL $^{51}$ program that code-switching is something you do to go downward to meet the other person at their lower level. When I mentioned that I do it to make an emotional connection...She said that speaking Indonesian doesn't do that for her. (Field notes, 3 April 2009)

Olivia refused to follow my suit to switch to Indonesian because she thought it would relegate her to a lower status than me.

As we were exploring the mall earlier that day, I had noticed that Olivia spoke to the shop attendants in English in the first instance and switched to Indonesian only when it became clear that the other party could not understand English. Olivia later commented that she was humbled by how I had used Indonesian to speak with the shop attendants. This puzzled me as it seemed perfectly normal to me that I would, as someone who was partly Indonesian and fluent in Indonesian, speak in Indonesian to a fellow Indonesian whilst in Indonesia. Olivia explained that she feels the need to speak English to everyone when she visits Jakarta even though she does not do that in her hometown, a much smaller and more modest city than Jakarta. She used English as a marker of privilege to establish her status as superior to those of the shop attendants who were of a lower socio-economic background. Olivia's actions were partly driven by the need to prove herself capable in English in other situations, such as at her workplace, where many of her colleagues were expatriate workers from Anglophone countries and her employment was dependent on her ability to speak English. It was also due to the power of the discursive constructions of English and English speakers as superior. My use of Indonesian in public spaces appeared to Olivia as an act that required humility because I had to relinquish access to the sense of privilege that comes with using English. Alastair Pennycook (1998, p. 217) suggests that colonial and postcolonial discourses surrounding English are "powerful indeed, and replayed in many contexts."

Having links with the "expat" community in Jakarta (i.e. social capital) also gives access to cultural capital. Olivia was surprised when I explained that despite attending international schools, I did not share a sense of affinity with the western "expat" communities. I had internalized the structures myself and did not feel sufficiently equipped with the necessary

\footnotetext{
${ }^{51}$ Teaching English to Speakers of Other Languages
} 
cultural know-how (capital) to participate in these communities (at least that is how I felt at the time, though not anymore). In her view, I had no reason to feel intimidated on account of the cultural hierarchy that I had internalized since, as one who was "half an expat", I was positionally higher than her. "Half an expat" was a reference to my mother who, being Japanese, elevated my position through the links I had with the Japanese expatriate community in Indonesia and with Japan itself, a country that is more economically advanced than Indonesia. My positionality shifted, depending on who served as the point of reference, Olivia or myself, because, as Ashcroft (2001, p. 51) suggests, "The colonized subject may also be the colonizing subject depending on his or her location in the rhizome."

More than a year later, Olivia went through an emotionally involved process to reckon with the power of these discourses and decolonize herself, so to speak, from the structures that she had internalized. I went through a similar process while writing this dissertation. Global economic structures intersect with the legacy of colonial discourses to inform the cultural hierarchies that are then internalized to form habitus.

\section{"Natural" English: the native-non-native speaker dichotomy}

Parents and governments go to great lengths to help their children and nationals acquire English language fluency. It was no different at TIS. Some parents desired not just communicative fluency in English for their children, but native fluency. Parents invested much time and money to enrol their children at TIS early, to expose them to an English-speaking environment, including teachers and classmates who were native speakers of English. Some simultaneously ensured that this did not compromise their children's fluency in the parents' native language. Parents wanted their children to acquire the linguistic and cultural capital necessary to participate successfully in the global system without losing the cultural capital required to operate in their own national system.

Mee Yon was one such parent. Mee Yon had studied at a Korean university majoring in English literature, and had a good command of English though she had a distinct Korean accent. I interviewed her over lunch at a popular sushi restaurant in a prominent South Jakarta mall. Mee Yon was dressed well, as always, with her earrings, necklace and hair neatly in place. 
Mee Yon had used different strategies with her two children to equip them with the appropriate language skills. Both children had gone to Korean schools before enrolling at TIS. Sam was moved to TIS in grade seven, while Jenny was moved at a younger age, in grade two. Mee Yon explained why she changed strategies with her second child:

When I came here (Jakarta), I put him (Sam) at a Korean school to let him get Korean language and Chinese character. Chinese character is the basic language for the Korean and for Japanese. So I had to wait until he gets all language skills, and then move him to [TIS]. While he was at Korean school I send him to English academy and his English skill was very high already. So he just join the... he took a test, and school asked him to join the mainstream, not the ESOL. So he got...he can get....he could get a kind of advanced courses, and that's why he could get a Ivy League university.

But my little one, she join the [TIS] at the second grade. 'Cause I felt that my son has still Korean accent, and in terms of natural English, he doesn't feel comfortable. So academic English is very high. He took an MBA; in English exam, he got top one per cent. So his English is almost perfect, but still feel not like a native language. Still he doesn't feel like using it like a native. So I put my little one in second grade and spend lots of money now for a long time because I'm owner payer.

"I'm owner payer" refers to the fact that she and her husband paid for their children's tuition fees out of their own pockets. This often represented a considerable financial sacrifice (and investment) compared to those where one spouse was employed by a company that paid their children's tuition fees as part of an "expat package". Even so, Mee Yon decided to send Jenny to TIS from as early as grade two to ensure that Jenny acquired "natural English". As academically successful as her son was, it did not diminish the perceived importance of the ability to speak English in such a way that it comes naturally to the speaker and is untainted by a Korean accent. A Chinese Indonesian mother echoed this concern. She had enrolled her children at a young age at TIS because she wanted them to have a good command of English such that it would come naturally to them and they would not have to think about what they were saying. However, equally important to Mee Yon was her children's retention of Korean, an issue I discuss in depth in Chapter 7. The non-native-native speaker dichotomy and issue of parental language retention influences parental school choice, which in turn influences the ways in which cosmopolitan subjectivities are shaped. 


\section{Conclusion}

As cultural capital, the language a person speaks tells a story of where they have been and where they can go. Language ability (or lack thereof) and accents are instrumental in positioning oneself vis-à-vis others. English in particular can narrate social belonging as well as act as symbolic power. In some cases, like that of the Indian students, it is possible to reclaim the power to draw boundaries of belonging through the selective use of accents.

The dominance of English at TIS can be traced to colonial times and its link with contemporary capitalist discourses, as can its impact on the subjectivities of those educated at a school like TIS. English is constructed as an "international" language and is a marker of cosmopolitan cultural capital. Subsequent chapters show that fluency in English thus affected students' ability to participate in the form of cosmopolitanism promoted by the school's ideology of being "international", and this had implications for social relations at TIS. The currency of English as cosmopolitan cultural capital attests to the fact that cosmopolitan practices are embedded within national and transnational structures and their socio-historical context. The next chapter will show that, in addition to speaking English, being "international" is also constructed as being distant from the local. 


\section{Chapter 6}

\section{Living in Disneyland: uneasy relations with the local}

The Sudan was the backdrop to our story; it provided the terrain of difference that marked us as cosmopolitan. But we didn't have to be there, and the Sudan wasn't really about us.

-Craig Calhoun (2008, p. 113)

The International School's ideology of being "international" endorses a form of cosmopolitanism that draws on Orientalist discourses (Said, 1985[1978]). Through these discourses, the local is constructed as an exotic, dangerous Other and purged from transnational enclaves, except in superficial forms. The local is necessary in a non-intrusive form to ensure that these enclaves feel "international" by virtue of their cultural distance from the local. Calhoun $(2008$, p. 106) refers to this form of cosmopolitanism as "felt cosmopolitanism", whereby one feels cosmopolitan through frequent traveling and the local is present as a backdrop to mark the privileged as cosmopolitan.

In this chapter, I show that the school constructed its "international" community as "western" by reinforcing the distance between a western "us" and an unfamiliar Indonesia. The colonial imagination enables the western "us" to construct the exotic, dangerous Rest of "them" (Said, 1985[1978]). I illustrate that the economic structure, as symbolized in the school's pay scale, substantiates this construction. It substantiates a hidden curriculum (Snyder, 1970) that privileges being "western" and "white" and shapes student subjectivities. The hidden curriculum, as a set of discourses that permeates the students' social lives on campus, reinforces Euro-American capital as dominant in transnational spaces.

\section{A "western" expatriate community}

TIS is both an educational institution and a transnational space, but one that is physically situated within the Indonesian nation-state. The security-obsessed architecture of the gated campus suggests that it is a community marked by its separateness from the local 
environment. It reflects Fechter's (2007, p. vii) work on expatriate communities in Jakarta, which she argues was an "expatriate bubble" characterized by the "pervasive importance of boundaries." Likewise, as a school that caters to the expatriate population, TIS is a transnational bubble. However it is analytically useful to remember that "transnational" presupposes the "nation-state" in much the same way that "anti-racism" presupposes "race" (Smith, 2001). The transnational bubble does not make the Indonesian nation-state disappear; rather, its existence is dependent on the availability of Indonesia to serve as a "backdrop" to throw the cosmopolitanism of the transnational bubble into relief. In his work on corporate expatriates in Jakarta, William Leggett (2005, p. 272) argues that, "Through the colonial imagination a union is forged between western populations and a divide created between East and West as transnational economic processes become situated within a genealogy of empire." In TIS, the Indonesian postcolonial backdrop is pertinent in constructing the students, staff, and parents as raced, classed, gendered cosmopolitans. Those who practise "cosmopolitanism of the above" draw on colonial and capitalist discourses to fashion themselves as cosmopolitan in contrast to the local Other (Hall \& Werbner, 2008, p. 346). However, the educational function of TIS and the presence of the local Indonesian Other (as well as others without Euro-American capital) as students who are equal targets of TIS's project of producing "global citizens" complicate the divide as I show in subsequent chapters.

TIS's diverse student body makes it difficult to determine who is an expatriate and who is a local. The main types of students at TIS consist of foreign nationals, who consider Indonesia as a temporary place of residence; foreign nationals, who have spent most of their lives in Indonesia but still consider it as a temporary place of residence because they expect to repatriate eventually; "local" Indonesians, many of whom used to live overseas; Korean nationals, who may or may not remain in Indonesia but are part of the growing Korean population that is increasingly becoming a permanent fixture in Indonesia; and children of mixed marriages, namely between expatriate men, mostly western, and Indonesian women. Despite the analytical difficulty in labelling these groups as expatriate or local, visiting speakers like Vera Trewin and TIS's staff members who identified as western engaged in constructing a union among "western populations" and a divide between "East and West" through a colonial imagination that was supported by the global economic structure. 


\title{
Constructing the host country as "Disneyland"
}

\author{
The "wonders of Disneyland"
}

Vera Trewin visited TIS to give talks to parents and teachers at TIS about Third Culture Kids and life as "expats". The flyer that advertised her talks described her as an "expat expert" who had lived around the world as a "diplomatic spouse" with her husband and children. During her talk, she showed the following quote on her PowerPoint presentation as she explained the reverse culture shock expatriates experience upon returning to their country of origin,

Repatriation can be like visiting a small town museum when you have just seen the wonders of Disneyland.

It was unclear whether the above were her own words or she had quoted someone else. Nevertheless, the quote offers a succinct description of how repatriation leaves the "expat" feeling as though the most interesting part of their life is over. Expatriate life, particularly outside the former colonial metropolitan centres, is represented as a visit to Disneyland where ordinary people are transformed into princesses and princes residing in castles with maids and drivers, travelling in exotic places, with lives that are sometimes punctuated by the adventures of narrowly escaping local social and political crises. Kathleen A. F. Jordan (1981, p. 154) writes that the experience of transnational youth repatriating to the United States for college involves "a loss of privilege in terms of life-style, a loss of specialness...a loss of mobility...[and] a forfeiture of the fantasies allowed by overseas life and exotic experiences." When I asked students about their living arrangements in Jakarta, a student said, "They're pretty much all the same. You know, like these fancy dream houses that you probably would never get anywhere else." The "expat" life enables middle class people to live out fantasies of the bygone era of colonialism as a modern day transnational capitalist class of cosmopolitans. "Disneyland" evokes an Orientalist discourse that constructs host countries as exotic, fantastical, adventurous playgrounds (Said, 1985[1978]). Transnational life is viewed through a contemporary reincarnation of the colonial gaze that places host country localities in the spatially removed and temporally displaced peripheries of the former colonial metropolitan centres (Leggett, 2005).

The "wonders of Disneyland" come to life when juxtaposed against the "small town museum". 
Although the Orient is not merely "a creation with no corresponding reality," Said posits that the discourse is about the "relationship of power, of domination, of varying degrees of a complex hegemony" between the Occident and the Orient (1985[1978], p. 5). The "small town" may seem ordinary and mundane, but it is also the norm. Although the former metropolitan centres are seen as ordinary and mundane, the West remains positionally superior because the wonders of Disneyland come to life only in so far as there is an outsider who will visit and taste of it. Identity is inherently relational and positions of superiority cannot exist without an inferior Other. The wonders of Disneyland serve to enrich the lives of the temporary participant-spectator who maintains their superiority by never becoming a part of that world, by always looking upon it as "Other" (Hage, 1998).

Claudia, a parent of a TIS student who was Central American and married to a US American man, had attended Vera's talk and felt that the talk seemed very "American" (Interview, 15 May 2009). Vera had described the expatriate lifestyle as different from their normal lifestyle back home in North America. But because some of what Vera described as unusual was part of Claudia's everyday experience in her home country, it appeared to Claudia as though Vera exoticized the Other.

She was speaking from a perspective that life is this way-we have our kids and we don't have household help, and we don't have poverty that we see, staring at us right outside the door, and we don't have exotic foods...For Indonesians some of the western food can be exotic, if you look at it the other way. It was sort of the perspective that everything is exotic.

By using North America as a point of reference, Vera constructed North America as the norm and the host countries (she seemed to have in mind developing countries like Indonesia) as different, exotic Others, thus participating in and creating an Orientalist discourse. Claudia continued to explain that Vera was only representing one perspective to the expatriate experience.

It would be nice to see...if someone like [Vera Trewin] could step beyond her own little world, her own little perception. 'Cause she's just really giving advice to Northern hemisphere people...I mean...There's a lot of things that she said that's very valuable that I totally endorse...But...if somehow, if she could put herself in somebody else's 
shoes, you know, like a Japanese person. Or if there's someone that is actually [a] little more diverse...could probably do a better, a more inclusive job.

Claudia explained using other examples that not all the families of TIS students fit the western "expat" paradigm that Vera had in mind. While Vera assumed in her talk that the norm is for fathers to travel to work from home, Claudia points out that in some societies it is commonplace for fathers to be away from home for long periods of time. Or while TIS assumes that it is commonplace for parents to volunteer at school, many parents of European and Asian backgrounds find this concept foreign to what they are used to.

So...there might be some things there [in Vera's talk] that's not very useful to other people...The majority probably wouldn't mean anything to a Korean family...It's not something that helps them, you know. That's my guess.

Although Vera presented it as though it applied to all who had lived as expatriates, in reality her talk only represented one perspective-a western one. It appealed to audiences who felt socially distant from the host country and therefore can treat it as a backdrop.

This distance from the host country was made clearer during a chat over a drink with Vera and three mothers who helped organize the talks. The three mothers were active volunteers at TIS, and all had at least one child in high school. Nora was a Dutch woman who took me under her wing whenever I attended parent coffee mornings, was supportive of my research, and had been the one who invited me to join them for drinks that day. I found her easy to talk to. Having lived outside of the Netherlands since she married her husband over two decades ago, Nora said that she found herself crying as she read and was able to relate to some of the Third Culture Kid literature about changing culturally through living overseas. Then there was Truc, a Vietnamese woman married to an American man. When Vera asked where she was from, Truc replied, "Boston". The rest of us laughed and teased her for responding in the true American fashion of assuming that everyone knows the names of American cities. The third mother was a Canadian of South Asian background married to a German man.

We wanted to go to a café for drinks between Vera's talks, but the nearest place we could get to was a pub in a hotel near TIS. It was within walking distance from TIS, but we took a taxi because it was drizzling. Upon reaching the entrance gate to the hotel, the security guards 
conducted their routine check. It had become standard procedure to do security checks on all incoming vehicles at major malls, hotels, high-end apartments and business skyscrapers since the 2002 Bali bombings. For the most part, such security checks were lax and superficial. One of the guards opened the back seat door where Truc was sitting. He had opened the taxi door by about twenty centimetres, still had his hand on the outside handle of the door and was about to peer inside the car when Truc shouted, "If you open it more I'll fall!" and pulled the door shut. She said it in fast paced English without expecting the guard to understand. The rest of the party in the car laughed and laughed at Truc's reaction. Vera commented, "Oh, you obviously know how to handle them, eh." She said this in reference to Truc's longstanding experience of living in Indonesia. Truc had the license to react in the abrupt way that she did because she was superior to the guards in terms of class. Vera's use of the phrase "handle them" to describe Truc's treatment of the guards exemplifies Truc's more powerful position since only those in subordinate positions such as children and animals are "handled", but not equals. Needless to say, treating lower class Indonesians poorly or rudely is not unique to foreigners, and common also to middle and upper-middle class Indonesians. But it was in moments like these that class (as patrons of an upper-class hotel) intersected with EuroAmerican capital (using English). The distinction between "them" (the locals) and "us" (expatriates) was made possible by socio-economic inequalities.

The exotic Other

The Orientalist discourse romanticizes the Other (Said, 1985[1978]). This was made apparent at a regional conference for schools using the International Baccalaureate program held in Singapore in March 2010. One of the plenary speakers was "articulate to the nth degree" according to my field notes. The slide show that formed the backdrop to his speech was filled with richly coloured photographs of various peoples from non-urban areas whom he had studied as an anthropologist at an Ivy League university. In my field notes (25 March 2010) I wrote,

The essence of his message was that there is very deep wisdom that is carried by all these seemingly primitive cultures. Very deep. He shared that wisdom with us. Mesmerized us with it. How the fishermen of the Pacific islands can calculate the distances while at sea by looking at the ripples in the waters. He also spoke of the Inuit who knew the glaciers were melting just by looking at it, while it takes scientists lots of 
calculations to say the same things. By the end of it, we were convinced that these seemingly primitive cultures were indeed full of wisdom that we had to heed. That we could not discount. They knew how to live with nature, we didn't. When he finished, fully mesmerized, we gave him a standing ovation. The clapping filled the room; it was a dense kind of clap that filled the room. It went on for a while.

It appeared as though the speaker was promoting cosmopolitan engagement with those who are different by encouraging the audience to value the wisdom produced by the Other. But in a private conversation with my colleague and me, another speaker expressed her discomfort with the speech. She was a white American raised in Nigeria and was active in helping TCKs understand their own experiences. She asked us, "Were there any white people in the slide show?" There was not. That proved her point. The absence of white people in the slide show reinforced the perception that the Other are "primitive", and that there was a divide between the West and the Rest (Said, 1985[1978]). According to Hage (1998), the exotic, romanticized Other is valued in so far as they enrich the cosmopolitanism of the dominant culture. The power to ascribe value to the Other rested with the observer who feels cosmopolitan through the act of ascribing that value.

"I miss the riots"

Like the parents, self-identified TCKs participate in the Orientalist discourse. Afra, an Algerian national who had grown up in several countries (though not Indonesia), noticed that some TCKs speak of developing countries as though their poor economic conditions or socio-political unrest were like adventure rides. He was living in Korea at the time I interviewed him on Skype (2 March 2009). I first came across Afra through an online Third Culture Kid community, where he posted comments that expressed his frustration at the way others wrote about conditions in developing countries. When I interviewed him later he said (with a distinct American accent),

Well I can relate to the people saying they have unresolved grief or, you know, feel like they had a hard time moving from one country to another. I've experienced that too. But I can't relate to people telling me, "I lived in Africa and everything was anarchic and disorganized and...I had no sanitation or no running water," or whatever. I mean that's something I've been through in Algeria, not having water running in the sink. And that's 
a horrible thing to go to. That means you can't take your shower like other people do [in] the US, and that was no fun for me. Let me tell you, I had very long hair at that time, and it was horrible to wash with a...with a basket, you know, instead of running water. So that's not something fun to go through...and I feel almost offended by people who say, "I miss walking barefoot."...Anything that's a sign from an undeveloped country, you know, like, "I miss the riots," or...the war...not the war, people don't say "I miss war." But they say, "I miss the riots 'cause thanks to riots I couldn't go to school." There have been riots in Algeria when I was there and we couldn't go to school. But we had that tear gas in our balcony and that wasn't fun, you know. So I can't relate to that...People say it was good times not to have running water, or to have an earthquake somewhere. I don't think that's something you should miss.

Even if "I miss the riots" was said with knowing humour, Afra sounds frustrated with the way developing countries are perceived by transnational youth who have the privilege to leave those countries in tough times-a privilege that was not always available to him as an Algerian national. While the lack of modern facilities and outbreaks of social upheavals represent a oneoff incident (whether they are considered traumatic or adventurous) for some, for Afra they remain a reality from which he cannot completely separate himself as long as his only passport is from a developing country. Maintaining a distance from the host country requires cultural capital that not all transnational youth are able to access.

\section{An unfamiliar, dangerous Other}

Social distance from the host nation-state was maintained by forging a sense of community among western expatriates and constructing the host country as an unfamiliar, dangerous place that was different from the West. In advising parents on how to protect their children from social ills, the school administrators normalized state-society relations as they are in the West. At a general meeting of parents and the school administrators, the principal, vice principal and several other officers spoke on various aspects of the school that they thought were relevant to the parents. The vice principal's talk was of particular interest. A couple of weeks earlier, the vice principal had alerted parents through an email about a private party that had been organized mainly for $9^{\text {th }}$ graders. The school administrators had found out that alcohol would be served at the party and expressed their concern in the email. At the meeting, he called for "expat" parents to be vigilant of their children's behaviour with regard to alcohol. 
However, in doing so he invoked a sense of community among "expat" parents against the backdrop of an unfamiliar host country where under-age drinking is not regulated:

The next thing I just want to talk about is...the partnership between you and the school in relation to your kids. You may have heard about an email I sent out to you...a couple of weeks ago, alerting about an organized party that was...includ[ed] alcohol...That's the sort of things that we really value-that the challenge for us as mostly expat parents is that we're in a society that doesn't have the same situation as home. Even though it's a [...] Muslim country, if I'm a westerner here in Jakarta-and I've noticed with my own kids: my thirteen, fourteen year old boy could walk into a bar and be served a drink. No ID needed, no questions asked. You can go to a supermarket and buy vodka mixed cans. My daughter did this. She won't mind me telling you this, she's ashamed of it. She and her friends in eighth grade: straight after school, "Let's just have fun," off to Hero ${ }^{52}$, box of mixed...(laughs), got totally drunk and sick, came home feeling horrible, "I'm never gonna do that again." But me, I had no control over that. I had no idea they could just walk in a supermarket and buy this...you know. So what we're trying to do is go beyond just our own little resource[s] and try and work together on this.

The vice principal's comments contain assumptions regarding the expected role of the state in protecting children in public spaces from exposure to the dangers of substance abuse based on his experience of "home". The absence of law enforcement with regard to under-age drinking is constructed as being out of the ordinary, even by local standards. He presumed that a Muslim country should strong enforceable sanctions against alcohol consumption. As a visible minority in Indonesia, the white vice principal interpreted his daughter and her friend's experience at Hero, a local supermarket chain, through a racial lens. He attributed their easy access to alcohol to being "a westerner here in Jakarta". In reality, easy access to alcohol by minors is not particular to westerners. Indonesian children can also buy alcohol without any form of identification. The practice of showing identification when purchasing goods is barely known. This applies not only to countries like Indonesia, but also developed countries like Japan where alcohol is available to all, even from automatic vending machines, though machines fitted with identity card readers began to replace older machines in 2001 . There was a disjuncture between the vice principal's expectations of the state's involvement in preventing alcohol consumption among young people and the reality of the state's lack of

52 "Hero" is the name of a local supermarket chain. 
involvement.

The world outside is constructed as an unfamiliar, dangerous space of the Other over which the "international" (western) community has "no control" and from which children need protection. Racialized terms such as "Muslim" and "western" are used to construct difference between the school community and the host country, when the main issue is the disjunction in the school's expectations regarding the role of the state in child protection and the local reality that applies irrespective of the values held by parents, school administrators, and Indonesian society at large. While he recognized that not all parents are "expats", he conflates the "mostly (emphasis mine) expat parents" with "us" and "we" who he assumes have a similar EuroAmerican background and understanding of "home" as he does. He calls for a "partnership" between parents and the school so they can go beyond their "little resource[s]" to gain back control in an unfamiliar setting. This is the "challenge" that the school and wider (expatriate) community face-creating the familiar within an unfamiliar space.

The sense of "challenge", of having to contend with the an unfamiliar, foreign environment accentuates the sense of cosmopolitanism felt by the school community (Calhoun, 2008). Indonesians and non-western expatriates are not necessarily included in the "we" and "us" that represent the western, expatriate school community, which is conflated with the transnational through a distinction from the local. When the local becomes too familiar, as it does for foreigners who have lived in Indonesia for longer, speak fluent Indonesian, or are married to Indonesians, their ascribed identity shifts from being cosmopolitan to "gone local" (Fechter, 2007, p. 100).

\section{International schools as the centre of student life}

The construction of the western expatriate community as "us" affects the way the school perceives its students. The lives of western expatriate families in Jakarta provide the model for "normal" engagement with the school. This model assumes that expatriate families arrive with little or no ties with the local community and locates the international school as the main, if not sole, centre of student life in the foreign city. It is within this campus, physically marked as separate from the rest of Jakarta by its heavily guarded gates, that students are expected to find a community servicing most of their needs in addition to that of education, whether it be 
sports, music, or family activities. One alumnus said in a video about TIS's history that, "School was in many ways the centre of activity for the expat community, and especially for the kids who went to school. We'd spend hours here." However, students come from diverse backgrounds, which means that they have diverse sets of ties and access to various communities in Jakarta-local, expatriate, diasporic, etc. Some students are involved in and contribute to communities outside the school, but these are largely invisible to the school. As a result, the contributions made by students who focus mostly on activities organized by the school are most visible, making these students appear most engaged as members of the school community.

Anaya provides an example. She was a senior in the first semester of my fieldwork, and I often saw her hanging out with the mainstream English-speaking group during recess. She was of Indian descent, and had lived in Indonesia for most of her life. She was born in Spain and had a Spanish passport, though she had only lived there for one year-the year after the 1998 riots, when she moved to Spain due to the unstable socio-political situation in Indonesia. Anaya had an Americanized accent when she spoke English, her first language. She had moved from the Indian international school and seemed integrated in the English-speaking group when I met her.

Anaya was critical of the school staff for assuming that TIS was her only source of community life. Anaya had commitments involving the Indian Indonesian community outside of school. She did not have the time to participate in school activities as much as she would have liked to (Interview, 27 April 2009):

It's just really, really difficult, honestly...trying to balanc[e] school with my outside of school life, because they demand so much. Like, school demands so much, and the community... Not even academically. But time, you know. They don't realize that you have a life outside school.

According to Anaya, the school places expectations on her time in the name of "school spirit". Whether it was to come and watch the school team compete in a sports game with other schools, or to fulfil her role as stage manager for the school drama team, she sometimes felt that they required "ridiculous amounts of time" which did not take into account the fact that she was also involved in the community outside the school. Anaya cited the school's 
normalization of the expatriate community as reason for assuming that the school is the centre of student life:

Because it's an international school, they feel like...so they feel like, you have nothing else to do outside of school. Yeah, because everyone's an expat, they don't have their family, their extended family, here.

Although Anaya's family had a "transnational resume", so to speak, her family's long-term engagement with the host country diverged from the traditional "expat" pattern. Her transnational engagement was a mixture of the patterns followed by "expats", diasporas, and migrants. Anaya cited examples of her engagement with the community outside TIS-teaching young children at a Hindu temple and fulfilling duties towards her extended family and friends from the local Indian community, such as visiting her grandmother at the hospital or attending weddings of family friends. Anaya was involved in multiple communities. Her more local engagement diminished her potential to contribute to the school's "international" community.

Anaya's complaints, though exaggerated in an adolescent kind of way at times, were valid but nuanced. I told Anaya that her experiences sounded similar to those of Indonesian students. Indonesian students were involved in activities in local communities (e.g. taking martial arts lessons not offered at TIS) and were therefore perceived by TIS as apathetic because their contributions to community life were invisible to the school. Anaya immediately backtracked on her complaints, saying that students should still contribute to school life. It appeared that she either did not want me to defend the actions of the Indonesian students who were negatively perceived by the school or did not want to be placed in the same category as the local students. Anaya had previously been critical of her Indian Indonesian friends who, like her, had moved from the Indian international school to TIS and had not integrated into the English-speaking groups. She felt that they could have had they tried harder. In light of this, I suggest that Anaya had a strong desire to become "international" and thereby identify with the dominant, western culture of the school. In order to do this, she placed a distance between herself and the more local Indonesian-speaking students, including the Indian Indonesians, while also justifying her inability to participate in school life as much as the others in the English-speaking groups.

Similarly, Korean students were involved in activities that took place within the Korean 
community outside the school. As a result, Korean students' heavy involvement in off-campus afterschool activities was perceived as lying outside the school norm, such that the school administration felt that some of the Korean students perhaps did not belong at TIS. Some felt the Koreans were merely using the international school as a stepping-stone to go to universities in the United States. The acceptable level of involvement in school life was measured by the norm represented by western expatriate families.

\section{Propped up by an economic structure: the pay scale}

The discursive construction of distance between the expatriate community and the host society is propped up by an economic structure (Bourdieu, 1986, p. 252). The pay scale at TIS reflected the global economic structure and generally rewards employees who were able to demonstrate distance from the host country. There are essentially three main tiers to the pay scale for the teaching staff. The highest paid tier consists of foreigners who are hired overseas and made up a majority of the teachers and administrators (hereafter "overseas hired foreign staff"). They are usually paid a base salary that was supplemented by what is popularly referred to as the "expat package" (Fechter, 2007; Leggett, 2003). At TIS, the package pays for rent, petrol, comprehensive medical insurance and return airfare to visit their home country once a year for the employee and dependents. ${ }^{53}$ The middle tier consists of foreigners who are hired locally as teachers and support staff (hereafter "locally hired foreign staff"). They usually receive the base salary without the package, though in recent years their salary was supplemented with medical insurance for the employee. The lowest tier consists of the Indonesian nationals who are hired mostly as Indonesian program teachers and support administrative staff (hereafter "local staff"). A locally hired foreign staff commented,

So if you look at the package, some friends, an Irish friend of mine here, he was local hire and had a couple of kids, he figured it out. He said, it's a difference of about, for him and his wife who are both local hire and the kids, it works out to about forty thousand dollars ${ }^{54}$ a year difference. It ends up doubling, in effect, doubling your income if you're an overseas hire, or your disposable income.

The three-tiered pay scale impacted upon the lifestyles available to each group. On the surface

\footnotetext{
${ }^{53}$ From TIS's “Expatriate Personnel Regulations 2009/2010"

${ }^{54}$ American dollars
} 
this had little bearing on the social interactions between staff at the school on a day-to-day basis, but the instances where the pay scale did influence interactions shaped the subjectivities of various actors.

Locally hired foreign staff seemed the most aware and vocal about the impact of the threetiered pay scale. Roger, a North American, gave a detailed description below of the instances when the pay scale intrudes upon social interactions with his colleagues who were overseas hired:

I could say that it's partly my fault, but it's not entirely my fault... My personality is such that, I'm quite happy on my own and I don't sort of easily form friendships with other colleagues. I mean on campus yes, but weekends I'm pretty much on my own with my family doing family related things. So I don't build up my way to sort of build [CHECK], you know, sort of relationship with my colleagues out of work. That part is my fault. But having said that, it is true that when you're on a different social economic scale, it does influences your choices of activities.

And, you know, it, it really hits home when you, every year...it's gotten better rather than worse, but the first few years I was here, there was that...the worst periods were the end of the year and the beginning of the year. Because the last week of June, everybody's talking about wonderful plans they have for the summer. And what I was doing? I was staying here. Right? Whereas they were going off to..."Oh we're gonna go trekking in," you know, "in Nepal and then we're gonna fly to Europe for a couple of weeks" or...and I'm staying in Jakarta. Might get a week in Bali, might go to Jogjakarta, might do something local, but otherwise, not anything very wonderfully exciting or something like that, or unique or different.

And then the week when the class started in August, well everybody's followed up about their stories, "What did you do?" "Where did you go?" And there's always sort of that deflating moment when somebody says, "Oh what did you do this summer?" And, "Oh I just stayed here." (In a deflating tone) "Oh." There's always that awkward pause, you know, "Ooh, okay" (with an awkward, disappointed look). 'Cause you don't have a great story...You don't have a great sort of experience that somehow matches or even supersedes their experience. It's all very, "Ooh, okay" (puts on a disappointed look 
again). So, "Well, it was nice talking you. Bye." They don't say it that directly, but sometimes at these parties, the first week back or something, there's a party at somebody's house, it's always that awkward moment. And so, that influences things. Also, people making choices to suddenly jet off to Bali for a weekend or something like that...just for an ordinary weekend or a long weekend. I can't afford to do that.

Instead of creating social conviviality, opportunities to share positive experiences turn into moments when socio-economic fault lines are highlighted and reinforced. An Indonesian teacher recounted similar experiences.

The pay scale reinforced social boundaries. Roger described situations in which his limited economic capability relative to his overseas hired colleagues meant that he could not involve his family in socializing with them, thus creating an unequal relationship.

ROGER: So as I said, you get into this situations where...oh, well this is very personal, but I don't mind...Our department used to have these big deals when somebody left, at the time it was back in around 2000 or so, and they chose for us to go to Darmawangsa. Have you ever eaten in the Darmawangsa? It's very, very expensive. And so the deal was, it's the end of year thing, the person's leaving, so it's a farewell party for this person. So that person and his or her spouse are invited, and we pay all expenses for them too. So we have a nice sit down meal. You're waited on by the waiters, and so on at the Darmawangsa. But it ends up being about a million (rupiah, i.e. approx. AUD $195)^{55}$ per person. And this is 2000 . It's probably about a million half, two million (rupiah, i.e. approx. AUD180, AUD240) ${ }^{56}$ now if you went back and tried to do it. So if I was to bring my wife to join this outing, that would be two million for one meal for the two of us. So what I would do is I'd go alone so I only have to pay for myself, right? To pay for myself, but everybody else would have their spouses there, something like that, and because they're all...you know, what's another, you know, what's another million here or there, because they don't have to pay for their house, they don't have to pay for their...you know? It just... when you've got a limited, much more limited budget, you make choices based on that budget. So I found that it does interfere with socializing.

\section{DT: With your colleagues?}

\footnotetext{
${ }^{55}$ Based on the June 2000 exchange rate.

${ }^{56}$ Based on the August 2009 exchange rate when the interview took place.
} 
ROGER: Yeah, yeah. Or they're going scuba diving, or they're going doing this, doing that. Well, I really have to weigh the costs, the benefits of this. Well, that's interesting, but I would prefer to save the money for my kids, children's college education, you know (laughs). Or, if we have to move house or we have to fix our car. That's our priority.

Due to his limited financial capability, Roger needed to compartmentalize parts of his life out of his colleagues' view, in this case his spouse, in order to maintain his social ties with them. Such social ties were also maintained by reciprocal gift giving, and the inability to reciprocate due to limited economic capital creates an unequal relationship. Roger explained,

It does make you a little bit more lonely, I suppose. Because there would have been, I think, a little more natural engagement with the other colleagues, or on the weekend, and so on. That would've sort of, would've been easier to forge friendships 'cause you're sort of living on a more of similar level. You know, "You wanna come to our house and use our pool this weekend while we hang around the barbeques?" Or "Do you wanna just come over?"...If you're the one who always have to say, "Well gee, can I come," you always sort of feel beholden to others, or a sense that you are. Yeah, you have to be, yeah, you have to be sort of invited, you can't offer the...extend the same kind of offer to them. Right? I can't say, come [over] and use our pool, 'cause I don't have a pool, right? That sort of thing. Whereas I'd have to wait for you to invite me. You see what I mean? It's different, it's different.

Roger lacked the economic capital that he could convert into social capital to facilitate a "natural engagement" with his overseas hired colleagues.

Roger explained that he tended to gravitate towards other foreigners in similar situations, as well as host country nationals.

DT: Do you feel as though you can relate more or get along with certain groups of people?

ROGER: Yes, definitely yes. Indonesians, Indonesians. 


\section{DT: Indonesians?}

ROGER: Yeah, Indonesians. Yeah, and people who are the local hires-especially if they're men, and their wives are Indonesians or their wives don't have much salary, so they're in a similar economic bracket, if you like, to me. Because then, we get each other, we understand each other- "Let's do this activity," 'cause we know it doesn't...it's within our budgets and we agree to do that, right?

Social circles are often predetermined by the individual's economic capital, rather than purely a factor of personalities (Ortner, 2002, 2003). While he could relate to his colleagues who were overseas hire at a professional level, Roger's lower economic status created for him a greater sense of affinity with other local hire foreigners and Indonesians who were in a similar economic situation.

Spouses also influence one's access to social circles. Roger's first wife was an Indonesian who grew up in several countries and was fluent in English. But at the time I interviewed him, Roger was married to his second wife who was also Indonesian and of whom he said:

My current wife doesn't speak really good English. She can, but she's very shy to use English among a large group of people. So it makes it hard for me to bring her to events that are very busy, you know, rame, ${ }^{57}$ because she's...unless she...unless I know that she'll go there and see people she knows already. And it's very interesting when we do go because, you know, I do take her to some things and she'll sort of be quiet and then suddenly she'll see another Indonesian woman and it's like, boy, she goes over immediately and then will spend the rest of the evening talking to that woman in Indonesian. So she's much more comfortable socializing in Indonesian. So it does limit again, 'cause I don't want to just, you know, completely separate from her when we're at parties, so I end up sort of joining her for a while. But it does...it's just different, it's a different interaction. We don't interact as a couple so easily with couples here [at TIS] who are both expats.

Social interactions in transnational spaces are racialized, gendered, and classed. The transnational space that the couple had to navigate is a Euro-American transnational space

\footnotetext{
${ }^{57}$ The colloquial version of the Indonesian word "ramai" which means "lively", "crowded", or "busy".
} 
that placed Roger, a North American man, in a better position to navigate it. Fechter (2007, p. 113) depicts a similar scene from a German expatriate gathering in Indonesia and says of the Indonesian wives of expatriate men, "Clutching their handbags, some of them seemed rather uncomfortable, clinging to their partner while manoeuvring their way through the crowd." Similarly, Roger's wife lacked the Euro-American cultural capital, including linguistic capital, to feel comfortable in transnational spaces, let alone seamlessly engage with his colleagues. On his own, he was accepted, but as soon as Roger associated with his wife during these social gatherings, it limited his capacity to participate in a transnational setting (Stoler, 1995). According to Bourdieu (1986, p. 249), social capital "exerts a multiplier effect on the capital [an agent] possesses in his own right." Roger's connection with his wife exerted a negative multiplier effect on him. The non-neutrality of the transnational space made it appear as though the (western) cosmopolitan man was brought down by his local, parochial (Indonesian) wife.

Economic structures, like the pay scale, provide scaffolding for social boundaries. Individually, awkward moments during office small talk after a holiday season or at social gatherings seem insignificant. Collectively, they remind actors who lack capital that the socially constructed boundaries that appear to blur amid celebrations of internationalism, indeed still exist. Students at TIS are by no means immune to the effects of these discourses. They shape the way young people experience and interpret transnational educational spaces.

\section{Hidden curriculum: "It's our daily experience here"}

Spoken and unspoken social constructions forge cosmopolitan subjectivities, and at times the latter were more salient. They permeated the hidden curriculum - the unintended lessonsthat often ran contrary to the educational mission that was premised upon the notion of being "international". The significant socio-economic distance between the international school students and teachers and the majority of the host country nationals gave credence to the hidden curriculum. Students internalized this curriculum. Nick, another local hire foreign staff married to an Indonesian woman, believed in TIS's good intentions. But he was concerned about the powerful effects of TIS's hidden curriculum on his children's identity.

I just don't want them to look down on their mother because they go to school in this 
environment. I think there's institutionalised racism at this school. And I think it's hard to escape that. I can see that that is part of the culture that my daughters are growing up in and that concerns me. Because of Indonesians being very clearly second-hand (i.e. second rate) citizens...l still don't think we've broken through in terms of classified staff, ${ }^{58}$ and even the Indonesian teachers I don't think are treated with the same level of respect as other teachers are...They're not paid the same. I'm not, I'm not saying that that's why they're not respected as much, but it's symptomatic...I don't know what percentage it would be but...for certainly, the vast majority of our students, they see Indonesians in subservient positions-primarily drivers, nannies, maids, gardeners, secretaries, electricians, and what have you. How many Indonesians do they see in positions of power? They don't, right?

And this is that whole idea of the hidden curriculum. It's what we say we teach, which I believe we believe in and we're trying to do, but by the very make up of the institution, we are teaching this hidden agenda...It's not like anybody's setting out to try to teach it, but it's being taught because it's our daily experience here. This is the dark underbelly...There's no other school I wanna send my children to, I do really believe in the school and I really believe that it's an incredible [education] that we're offering....and the multiculturalism and all of those aspects that are powerful and good. But, there is this dark underbelly that isn't being addressed there. I think it poisons the system to some degree.

While I cannot ascertain whether students were aware of the pay structure (it is likely that they were), the fact that the Indonesian staff was in positions lower than the foreign staff was clear for all to see. When the social structure is pegged to an economic structure, it becomes "part of the culture" and "daily experience" of actors at TIS-it shapes their attitudes, interactions, and subjectivities. Its influence is, as Nick said, "hard to escape."

The hidden curriculum is seen in the lack of interest in Indonesia and the Indonesian language on both personal and institutional levels. Another teacher, Rick, echoed Nick's concerns about TIS's relationship with the host country.

I think we're in a neo-colonial situation here. It's, I think, disgusting in some ways. The

${ }^{58}$ Administrative support staff 
lack of knowledge of Indonesia is, I think, deplorable. It's shameful, and that's been fairly consistent...the lack of knowledge of the language even though they (i.e. past school managers, principals, etc.) had spent many, many, many years here. I mean the principals, out of the high school principals...maybe Nathan (i.e. the current principal) is the most likely to have acquired some Indonesian and he's the one who's been here the least amount of time. Because he has some other...linguistic background, I think. He's only in his third year now, but I think he's planning on, in fact, I know he's starting to take Indonesian lessons, and he'll probably acquire sort of a pretty good practical knowledge of the language.

Whereas, I don't wanna mention names, but others that have been here much longerten we're talking about, or sometimes even twenty years plus-speak practically no Indonesian. I find that shameful. I mean, if I was in...[the] Czech Republic or if I was in Chile or whatever, I would acquire at least a kind of functioning use of the language where you could sort of go out and shop in the language a little bit, you know? You may never get to a fluency of a level of conversation but at least be able to get by. And I don't think they feel the need to do that here and they don't certainly don't go out of their way to learn it.

My own observations of teachers and students confirmed Rick's observations that while many learn to speak the language, there were also many who had lived in Indonesia for more than a decade or two and were barely able to ask a simple question such as, "Where are we going," to the bus driver while on a school field trip. Rick argued that the lack of interest in learning the language of the host country on the part of TIS'S decision makers contributed to the institutionalization of racism. Their attitudes were reflected in the way the Indonesian studies program was perceived. Rick related,

The school's treatment of [the] Indonesian program, again that I found shameful. I think it is not given the proper attention...There's a very clear situation happened last year that was...it was really abysmal what they did to cover the program for the students. They had a teacher leaving because of pregnancy...The person they hired (i.e. as replacement) was through me, but against my recommendation because she herself didn't really feel she was the right person. I wasn't saying, "Oh I don't like her, we should get another teacher." She herself felt that it wasn't the best position for her, but they 
gave it to her because they hadn't gone out to look for somebody else. They hadn't done the legwork, they hadn't put in the time and that's simply because it was perceived as unimportant. Had it been a Science class or a Math class or English class, they would've gone overseas, they would've spent money, they would've done something. But this was considered as just Indonesian, I'm sure. Maybe they didn't say it overtly, but it was there-it's just Indonesian, just a stopgap measure, it doesn't matter, as long as nobody complains.

So I think the administration doesn't give enough respect to the Indonesian studies program, it's the same with the way they treat the language-it's only, you know, it's only Indonesian. It's the same people making the decisions that don't learn the language.

"Indonesia", the local, occupied an inferior position not only in terms of the staff pay scale, but also in the "international" curriculum. The school administrators could afford to pay scant attention to the language and knowledge of the host country both as individuals and as decisions makers of an educational institution because they and the school formed part of the privileged transnational capitalist class. It evokes Said's (1994, p. 41) words, "One can see in the story, I think, the power to give or withhold attention, a power utterly essential to interpretation and to politics."

The "power to give or withhold attention" in relation to the study of Indonesian language at TIS also appeared in the story that Jesse told. Jesse was an alumnus who had been at TIS for two years, and had gone on to major in Indonesian studies at a university in Australia. During his university course, he went on a language exchange program to Jogjakarta and Malang and eventually became fluent in Indonesian. Jesse then visited TIS to see his former teachers. When he started speaking Indonesian to his former Indonesian teacher, she cried. According to Jesse, she was touched because none of her other students had taken the study of Indonesian seriously. Jesse described the Indonesian program as "a joke". While there are other international schools, even within Indonesia, which put more effort into teaching the language of the host country to their students, negative attitudes towards developing countries and their language pervade the hidden curriculum.

Neither the lack of interest in the local language, nor the lesser significance attached to the 
Indonesian studies program is accidental. Colonial discourses on cultural hierarchies continue to construct what Pennycook (1998, p. 19) refers to as "European/Western images of the Self and Other" and notions of "Superiority and Inferiority". These discourses are supported by contemporary capitalist economic hierarchies. Pennycook (1998, p. 23) writes that "colonialism should not be seen as a forgotten era in the past but rather as the context in which current ideas were framed" (see also Phillipson, 1992). I am by no means suggesting that there is a colonial agenda in operation at TIS, but that the discursive forces set in motion during the colonial era continue to provide context for present day perceptions of cultural hierarchies that are structurally embedded in institutions like TIS. Discourses are certainly not immutable, but they are remarkably resilient over time (Said, 1985[1978]).

\section{Internalizing hierarchies}

The discourses embedded in TIS's structural makeup do not work in isolation. They are powerful because they form the social fabric both inside and outside the campus gates to shape subjectivities. Colonial and capitalist discourses intersect to reinforce racialized, classed, and gendered social structures, which transnational youth then internalize. Nick and Rick were intimately aware of the impact that these discourses had on young people through observation of their own children.

Nick candidly shared his observations of his daughter's desire to identify as white like her father instead of Indonesian like her mother.

...And [Lara] (older daughter) for example, doesn't really like going to [lka's] (wife) village. Because, I mean...it's weird 'cause [Lara's] actually a little bit of a racist. She really, she really...kinda looks down on Indonesians, you know? And, and it's not...I mean, I remember when I went to dinner and it was just the family and me and the girls and so on. And uh, I made some sort of a self-deprecating joke about being the only bule, ${ }^{59}$ and [Lara's] like, "No, I'm a bule." I'm like, "No honey, you're campur. ${ }^{60}$ You're a mix." "No, no, no, I'm a bule," you know? And really, we explained this and, no, she's a bule. That's the way she sees herself.

\footnotetext{
${ }^{59}$ An Indonesian slang for "white people."

${ }^{60}$ An Indonesian wording meaning "mix."
} 
Fechter (2007, p. 80) posits that even "using bule in such a casual, self-deprecating manner represents a power move: through re-appropriating the term, expatriates limit the unwanted connotations that Indonesians' usage of the term might have, thus linguistically regaining a dominant position." Lara recognized, even as a seven year old, that she could gain a dominant position by identifying with her white father. Dominance was racialized, gendered, and classed. It was marked as white, male, urban and rich like her father, in contrast to Indonesian, female, poor villager like her mother. For Lara, her father's physical presence marked whiteness as superior and Indonesianness as inferior. Nick observed,

And we noticed that when [Lara] goes to the village and I don't go, if just [Ika] and the girls go, "Totally different," [lka] says. Then she (Lara) plays with the other Indonesians kids, she just totally mixes in. But if I go, she stays with me. And we stay, you know, more separate.

Lara stayed physically close to her father to indicate that she identified with her father's whiteness. Physical distance reinforces social boundaries that are constructed through embodied racial markers. Nick could relate to his daughter. As a child of European migrants growing up in North America, he had not wanted to identify with his parents' heritage in his desire to assimilate into the dominant culture, though he later grew out of this as an adult. Nick thus suggested that Lara's attitudes might also be part of a phase in her identity development.

So, how that's gonna play out over time...it's, it's hard to say, it's hard to know...maybe [Lara] will come to it eventually too 'cause I didn't like being [European]. So she doesn't like being Indonesian.

Transnational youth are not immune to social discourses. They internalize the social discourses conveyed by the hidden curriculum in school and reinforced by the society outside the school.

\section{Conclusion}

At TIS, the international school community is constructed as western and juxtaposed with the host society. Ironically, to feel "international", one needs to maintain a distance from the local 
by constructing it as a fantastical, unfamiliar Other. The presence of an unfamiliar host society that needs to be "handled" accentuates the sense of being "international". The distance between the "international" and "local" is reinforced by the pay scale. The pay scale rewards overseas hired staff based on their initial lack of ties with the host society.

Social boundaries between those considered international and local are racialized, classed, and gendered. Those who occupy a liminal space are acutely aware of the processes of boundary making, rendering them methodologically interesting subjects. Ann Stoler (1992, p. 550), in writing about colonial concerns about the "métissage", argues that they "straddled and disrupted cleanly marked social divides" and their "diverse membership exposed the arbitrary logic by which the categories of control were made." The local hire foreign teachers and their children, who are able to shift in and out of both the transnational and Indonesian contexts, feel the effects of the boundaries precisely because their own positional ambiguity requires them to constantly negotiate these boundaries.

Attempts to maintain the boundaries even as they were blurred created dissonance among different parties at TIS, which the subsequent chapters explore. The next chapter continues the discussion of how "we" and "they" are constructed in ways that privilege Euro-American capital, which in turn reinforces the dominance of a Eurocentric ideology of being "international". 


\section{Chapter 7}

\section{In pursuit of cosmopolitan capital}

For the international cosmopolitan class, equipped with the best passports that money can buy, and a habitus that allows them to feel at home in most international cities, the world is their turf.

-Ghassan Hage (2005, p. 470)

In chapter 4, I showed that TIS's vision is to educate students to become "international". However, I argue that TIS's efforts to promote being "international" are frustrated by the national and transnational socio-economic hierarchies in which cosmopolitan practices are embedded. TIS's ideology of being "international" requires cosmopolitan cultural capital, which overlaps with Euro-American cultural capital. Therefore students' abilities to practise this dominant form of cosmopolitanism vary depending on their cultural background. This chapter explores the tension between the school's expectations of its students and the differing ways in which students and parents engage with the school's ideology of being "international". In doing so, I demonstrate that Euro-American cultural capital dominates the transnational space of TIS's campus.

I show that parents value cosmopolitan capital and chose to enrol their children at TIS to enable their children to acquire this capital. However, those who are not familiar with the Euro-American habitus, especially those who do not speak English, experience dissonance when they navigate through TIS's transnational educational space. The school constructs those unfamiliar with the dominant Euro-American habitus as "Other" in contrast to the western "us" that I detailed in Chapter 6. The varying access that students have to (Euro-American) cosmopolitan capital mediates the authenticity of their claim to be at TIS.

\section{Parent gatherings: the dominance of Euro-American cultural capital}

Students at TIS had different starting points in their pursuit of cosmopolitan capital and ability to practise being "international" due to their varying family backgrounds. These socio-cultural differences remained hidden because most students spoke English to some degree or another 
and their youth meant that they were expected to be malleable and equally capable of acquiring cosmopolitan capital regardless of their cultural background. In contrast, parent gatherings made apparent the ease with which those who had Euro-American cultural capital navigate the transnational social space of the international school, and the difficulty for those who did not.

I attended parent gatherings that ranged from monthly coffee mornings organized by parents around discussion topics that interested parents to meetings between parent groups and the high school administrators, college information sessions, and open house nights. Generally, expatriate families of international school children relocated based on the father's employment, which meant that mothers rarely had official employment. Therefore, both fathers and mothers attended gatherings that took place in the evenings, but those who attended gatherings that took place during the day were almost exclusively mothers. Many of the mothers who attended parent gatherings were mostly highly educated women (e.g. one whom I interviewed was a former Fulbright scholar), some of whom had given up their professional careers (e.g. as doctors, engineers, etc.) to become "trailing spouses" for the sake of their husbands' careers (Coles \& Fechter, 2008). A couple of mothers I interviewed commented that they missed the intellectual stimulation that came with the interview, revealing their predicament as "trailing spouses". Mothers who attended the parent coffee mornings or were involved in the main Parent Teacher Association (PTA) had a good command of English.

\section{Parent coffee mornings and a Third Culture Kid information evening}

When I walked into the monthly parent coffee mornings for the first time, I immediately noticed the visible and audible contrast between the parent group and the larger student body. The parent group was made up of roughly 20 women who were predominantly of European descent. It thus only represented a handful of all parents. The few mothers of Asian descent who were present were commonly either married to a western man (often Anglophone) or fluent in English because they had been educated in an Anglophone country. Further, while the English-speaking students, for the most part, had an American or Americanized accent, many of the mothers spoke with a distinct non-native speaker accent. This pattern, particularly the fact that the attendees were predominantly white, was repeated at various other parent gatherings. 
It was the same at the international school I visited in Singapore in March 2010. I spent a day following Ruth Van Reken (2009[2001]) around as she gave several talks to students at an international school about Third Culture Kids, followed by an evening talk for parents. The audience for the daytime talks was mostly students of Asian descent, while the audience for the evening talk was mostly parents (both fathers and mothers) of European descent. The only visible non-white group present at the evening talk in Singapore was the group of selfidentified adult Third Culture Kids with whom I was sitting.

At both schools, the demographic contrast between the parents and students was stark. While there may have been multiple reasons why Asian parents generally did not attend the gatherings, one possible reason is the cultural (including linguistic) dissonance between the school and Asian parents. It appears that the transnational space of these international schools provided a more comfortable space for those with Euro-American cultural capital.

\section{Open house night}

The currency of Euro-American cultural capital at TIS was obvious when non-English speaking parents were faced with the prospect of navigating the transnational social space. At TIS's open house night, parents unfamiliar with the dominant culture of the school felt uncomfortable or intimidated. All parents were invited to attend an opening ceremony for the night, before visiting their children's different classes by following their children's daily schedule. Each "class" lasted for about ten minutes during which the teachers briefly explained about the class. The parents were then given an opportunity to ask questions.

I introduced myself to some of the Japanese parents before the ceremony started as the parents gathered in the main theatre foyer for nibbles and drinks. One Japanese mother confessed that she was intimidated by the cultural gap between the school staff and herself. Her poor English was a sore point for her. Her shy and submissive mannerisms corroborated her confession. Even her nail polish looked distinctly Japanese. When I asked her whether I could follow her around that evening for my research, she seemed grateful I had asked. Even though she was with her husband who was competent in English, my presence meant that she would have someone who was female and fluent, not only linguistically but also culturally, in both the dominant Euro-American school culture and Japanese culture. I became the cultural 
buffer that shielded her from the unfamiliar Anglophone setting. For the remainder of the evening, I felt as though she clung to me, metaphorically speaking. Given the level of dissonance some parents felt in relation to the dominant Euro-American school culture, it was not surprising that they did not attend many of the parent gatherings.

\section{Korean parents' meeting: miraculous encounters}

Cultural dissonance between those with and without Euro-American capital was apparent at the annual meeting held between Korean parents and the school administrators. In October 2009, the principal, vice principal, activities officer, academic counsellor, and sports officer, who were mostly men, met with Korean parents, who were mostly female, in the school's small theatre. Roughly 70 Korean mothers attended the day-time meeting. A volunteer interpreter was present at all times, attesting to the linguistic handicap that Korean parents faced in an Anglophone environment. The five staff took turns speaking in English and as the mothers asked questions in Korean. The interpreter stood next to the speakers as she interpreted both ways between English and Korean. She interpreted consecutively-the speaker would speak for a little while and then let her interpret before speaking again. Some mothers laughed or whispered comments to each other before the interpreter conveyed the principal's message (which were at times humorous) from English into Korean, indicating that they understood English. However, many also responded in identical manner only after they had heard the interpreter's version in Korean, indicating that they did not understand English. There was a linguistic gap between the staff who represented the school's dominant culture and the Korean mothers who exemplified a large proportion of the parent body.

At the end of the meeting, I spoke to the interpreter, So Young, to ask whether I could interview her. She clarified that she was a parent of a child enrolled in primary school at TIS, not the high school cohort that I was studying. There were high school parents who were fluent in English and capable of interpreting, but they had solicited her help to ensure that all the high school parents could sit and listen to the staff speak. I then asked So Young whether there was someone among the high school parents who spoke English, as I wanted to interview them and I do not speak Korean. She suggested that I approach Mee Yon. She pointed towards the centre of the theatre where some of the mothers had congregated by then. "The one wearing the tiger print," she said. I looked and thought I had spotted the person who So Young was pointing at. I thanked her and off I went, trotting down the stairs 
with an out-to-accomplish-a-mission strut. I had no time to waste in finding contacts among the Korean parents that day as I had another interview appointment to rush to soon after.

By the time I walked across the theatre to talk to the lady in the tiger print, the staff had left and I was the sole non-Korean person in the room apart from the Indonesian cleaners who were standing-invisibly-on the sidelines waiting to clean up the theatre. While walking hurriedly across the theatre full of Korean women, I became painfully aware that my body language, the way I carried myself and moved across space, was out of synch with theirs. The Korean parents seemed to move their bodies independently but in harmony with each other, like a symphonic concert of "miraculous encounter[s]" that occur when one's embodied language matches the general cultural flow (Bourdieu, 1990, p. 66). The Korean bodies by then were huddled in conversation in small groups scattered across the theatre. Some were standing and others sitting, most of them chatting away in Korean. Some groups seemed serious and others jovial, but all were in synch with the dominant cultural music that was inaudible to me. El-Zein writes that migrants "survive by growing new body parts" (2002, p. 239). In this sense, I did not have the cultural "limbs" (Wise, 2010, p. 935) nor the time to acquire what Malinowski $(1922$, p. 8) refers to as "the feeling" for etiquette or atmosphere in the room.

I sat down on the chair closest to the "tiger print" mother. Another person was sitting between us, so I arched over to speak to her. The second I opened my mouth and uttered some English words, a look of horror came over her as though she had seen...well, a roaring tiger. I immediately stopped explaining about my research and stupidly used English to ask the question, "Do you speak English?" She shook her head, shifted in her seat, and leaned back (away from me) as much as the available space behind her would allow. She pulled so far back that her chin dug into her neck. I instantly recognized her reaction-she was scared of English and the proposition that she engage with it.

I had the wrong person. As I looked around, the Korean parents quickly accommodated my presence. I heard someone speaking in Korean to another as though explaining what I wanted. Though I do not speak Korean, I gathered this much from context and the few English or Korean words that I did pick up. Soon, someone directed me to another person who had a tiger print top underneath her cardigan, which explained why I did not notice her earlier. She was still in conversation with another, but nodded to me to indicate that she knew that I 
needed to talk to her. This was Mee Yon, who was fluent in English. Although I had possibly been rude to the Korean parents with my abruptness and awkwardness due to my lack of Korean cultural capital, they did not seem offended. I experienced the power of speaking fluent English. I had the power to intimidate some of them, regardless of my intentions, by doing nothing more than speaking a few words in English. I had the privilege of having my cultural ignorance forgiven and my wishes instantly accommodated without having to ask.

Euro-American capital was privileged even in a space dominated by Koreans. Embodied capital influences the level of comfort and privilege we feel in navigating social spaces. In this instance, I felt the foreignness of my body in a space where "Koreanness" dominated, despite the fact that I look physically indistinguishable from Koreans (and was often mistaken for a Korean during my stay in Jakarta). It follows that many would have experienced a sense of dissonance while navigating the transnational space of TIS where "westernness" predominated. When this cultural dissonance is overlooked, it creates the illusion that those with Euro-American capital are collectively more "international" than others because they "fit in". I show that those with Euro-American capital appear more authentically "international" than those without.

\section{Ideal cosmopolitanism meets pragmatic cosmopolitanism}

Clearly, language was an issue for the Korean parents, and the interpreter's presence was essential for the meeting. Given the large number of Korean students enrolled, a separate meeting for Korean parents made practical sense for keeping them informed of their children's schooling. However, the school administrators thought otherwise because, as I argue, the lack of Euro-American capital (especially English language fluency) was conflated with not having cosmopolitan capital. At the meeting described above, the principal said to the Korean parents: "What is happening in here-the fact that there is a separate meeting for Korean parents-symbolizes what is happening out there." The principal pointed in the general direction of the high school area of the campus. He later reiterated the symbolic link between the two while expressing his concern with the Korean students' tendency to self-segregate. It was constructed as a matter of choice and their choice, it was implied, was the result of Korean ethnocentrism. The existence of a separate meeting for the large number of Korean parents was perceived not as a language issue but as a refusal to participate in the 
internationalism the school was trying to promote. The principal called on the Korean parents to instil more "international" values in their children that are congruent with the school's values. The onus was placed on the Koreans.

The principal and the vice principal further expressed concern that Korean parents were overly demanding of their children in terms of academic achievement. The mothers in the audience laughed a little at this as though acknowledging that it was true. The principal listed the external pressures placed on Korean students, such as private tutoring, music lessons, and having to attend Korean schools in addition to their regular schooling at TIS. The school believed that students were not getting enough sleep as a result, leading them to sleep in class and cut classes. The principal went as far as to suggest that if parents were sending students to two schools-TIS and the Korean school-then parents might need to reassess their children's schooling needs. "Perhaps this is not the right school for you," he said. The reasons underlying parental school choice seemed at odds with TIS's purported goals of educating "global citizens". Their children's failure to become "international" in the way the school conceived it made their desire for cosmopolitan capital for their children inauthentic and their presence problematic.

The failure of Korean students to integrate with the English-speaking students and the Korean parents' efforts to ensure their children retained Korean cultural capital were seen as failure to be "international". Parents from non-Euro-American backgrounds who sought to produce cosmopolitan capital in their children were perceived as un-dedicated to the school's ideology of being "international". Parent gatherings amplified the sense that westernness predominated the school culture, which provided the benchmark for measuring the authenticity of being "international".

\section{"We can't all expect to live the same way"}

The school's perception that some students did not fulfil their expectations for an ideal student was affected by the way student contribution to the school community was measured in ways that privileged Euro-American capital. Cultural dominance is not "automatic", but it is, as Hall (1996a, p. 424) puts it, "actively constructed and positively maintained." Students with Euro-American cultural capital are affirmed in myriad subtle, unintentional ways. The 
dominant culture exercises symbolic power through the type of sports they offer, the recognition of certain types of extracurricular activities over others, and through the modelling of the culture practised by the staff (Bottomley, 1992; Bourdieu \& Thompson, 1991).

\section{Measuring student involvement}

Students with Euro-American capital (westernized) were relatively well represented in sportsrelated activities, while Asian students dominated music-related activities. When a slide show of pictures taken during various school events over the semester was presented during a general assembly that involved all high school students, there was a heavy emphasis on sports activities, and less emphasis on music activities. This was partly because the staff in charge of posting photographs of extracurricular activities at the time was Dr Davies who was sports oriented. He was well liked by students of a diversity of cultural backgrounds, but seemed to have an especially good rapport with the westernized male students who often hung out in $\mathrm{Dr}$ Davies' classroom playing mini basketball. Dr Davies' preference for sports activities over others inadvertently affirmed the involvement of westernized students over that of Asian students in school activities and regional competitions. I regularly saw Asian students perform in the evenings and on weekends, sometimes just to play or sing one song as entertainment for school events that they were not a part of as individuals. These activities were not as spectacular or visible as sports activities, and therefore Asian students were at times perceived by others, and themselves, as apathetic.

\section{Internalizing negative views}

Korean students were academically oriented, gave impressive performances on United Nations Day, and were actively involved in music activities, such as the school band and strings group. Despite all this, Dong Gun, a Korean student who was fluent in English, believed the Korean students had a bad reputation among the teaching staff because they were perceived as focusing solely on academic pursuits and did not contribute much to the school in other ways. Dong Gun said:

Yeah, I mean, who's gonna like a group of students who study only? Who don't do much extracurricular activities, don't really benefit...don't really, like, have any benefit for the school...contribute to the school, I guess? Who don't, who always travel 
together in their same culture everyday. Never speak English, they speak Korean. Even if teachers just say "You have to speak in English." They always speak Korean. Who would like them, right?

Dong Gun said this with a mixture of frustration over his fellow Korean students who he believed did not contribute to the school community and over the teaching staff for not accepting that Korean students were different from western students.

But, you know, it's not their (Korean students') fault, really. It's just the culture that's like that... You have to accept it. But there's a huge racism thing, I guess, and teachers are not really fond of them because they're not like everyone else. I think I can say the same thing for Indos because they basically do the same thing, except for the studying part. (We both laughed because the Indonesian students were reputed to party more than study.) But basically we're the same, that's why I think we got along. The Indo, me and the other Indo, we got along together because, you know, we're the same, we're similar but we just go different paths. They (teachers) have to understand that Asians, especially Indos and Koreans, compared to westerners are different. We think differently. We can't all expect to live the same way and even if we're in the same place, same society right? So yeah.

Dong Gun took issue with teacher attitudes toward Korean students and called it a "huge racism thing". Dong Gun's choice of word may appear careless considering the school's success in managing diversity, but it did express the sense of frustration and resignation that many of the Korean students felt about the way they were perceived at the school.

Even then, Dong Gun accepted as legitimate the perception that Korean students did not contribute to the school. It had not registered in his mind that Korean students were heavily represented in extracurricular activities relating to music. Dong Gun submitted to the symbolic power to which he was subject (Bourdieu \& Thompson, 1991). As Hall (1996a) argues, cultural hegemony requires the consent of those who are dominated. Student involvement in the school community was measured in such a way that the contributions made by those with Euro-American capital were more visible than the contributions made by those without EuroAmerican capital. 


\section{Moving to "a higher social class"}

About a month before interviewing Dong Gun, I had observed him and two or three of his male Korean friends at a loss for words in the face of their teacher's inability to comprehend their perspective on Korea's mandatory military service for men. They were having a casual chat in between classes and my field notes (31 March 2009) say,

The topic of the military came up. Mr [Bailey] asked, "Well, can't you live so that you don't have to go back to Korea? I mean, in this day and age of globalization..." The Koreans tried to explain, but $\mathrm{Mr}$ [Bailey] doesn't get it. [Dong Gun] tried to say, "It's out of a sense of..." For some reason he couldn't find the word "duty". He said, "A sense of..." a few times, but it ended there. The other boys then tried to explain about losing their citizenship. I piped in, "You'll be stateless." Then they explained how the parents have to sign a paper saying they will serve in some sort of public service if their son doesn't serve in the army.

Short of changing nationalities, avoiding the twenty plus months of mandatory military service was rarely an option for Korean men. Whether it was about the military or other issues, it was sometimes difficult for teachers to grasp that the conditions for participating in the processes of globalization were different for TIS graduates depending on their background and nationality.

Dong Gun explained in his interview that teachers generally did not understand the Korean socio-economic context that drove Korean students in a seemingly single-minded pursuit of academic achievement.

...[It's] the only way we can, in our Korean society, we can go out of our social class, like move on to a higher social class, to go to a better college, to seek better education. It's the only way. That's the only way to live a better life than your parents did. Otherwise you're just a nobody, you're just a nobody. But once you make that jump, you become this really special person, and that's the only way you can do it. That's why they study for hours, you know, even after school...

According to Dong Gun, there was a clash between what TIS thought was good for the 
students and what he claims is the reality that Korean students face upon repatriation to Korea. This clash, I believe, in part led the principal to suggest that the Korean parents reconsider whether or not TIS was the right school for their children. In the next section, I provide some context to this difference in opinion and argue that it is an example of the dissonance that occurs when national and transnational class structures converge in a transnational space.

\section{School choices in national and transnational contexts}

Both the school and the parents believed that TIS offered something of transnational value that was worth reproducing in the students. However they diverged in the meaning they attached to that something. TIS was a popular school with more applications for enrolment than the available student intake. A staff working in the office that handled the school's accounts said she was impressed by the Korean parents' persistence in trying to enrol their children at TIS. She recounted a story of how one such parent came to the office with a bag of cash pleading for them to let her child enrol. The staff had to repeatedly explain to the parent that no cash payment was accepted for tuition fees and that student acceptance at the school was not determined by the form or the amount of payment. This unusual incident symbolizes the strong desire of Korean (and other) parents without Euro-American cultural capital to convert their economic capital into (Euro-American) cosmopolitan capital by paying for their children's international education. Their pursuit of cosmopolitan capital is a "generational project" (Peterson, 2011, p. 33). TIS offered an environment for reproducing cultural capital in their children that these parents cannot provide at home.

As an international school, TIS played an important role in fulfilling both national and global expectations of their students. In the eyes of Koreans and Japanese, for example, TIS offered high quality education and an internationally recognized university preparation program. Students, without fail, spoke highly of TIS's pedagogical approach that emphasized critical thinking. There is a Korean high school in Jakarta, but parents believed that TIS offered better quality education. There is also a Japanese school in Jakarta established by the Japanese government. But it only provides compulsory schooling, which ends at grade 9. Japanese families commonly followed one of the following paths when their children reached the end of grade 9: the breadwinner, usually fathers, would ask their employer to relocate them back to 
Japan with their whole families, or to Singapore, where there was a locally established private Japanese high school; if the employer did not transfer the father, then the mother and children returned to Japan or relocated to Singapore while the father remained in Indonesia; or they enrolled their children at an international school in Jakarta. Choices like these were made depending on circumstance and financial capabilities. International education also provides students with the opportunity to compete for places in world-class universities in Anglophone countries. Thus, its high educational quality, internationally recognized programs, and location (i.e. families could remain together in Jakarta) made TIS an attractive and prestigious school choice.

Moreover, international schools enable some to gain a competitive edge in national education systems in their passport country. In the case of Koreans, the pathway to employment is dictated by a highly competitive educational system. The prestige of the university they attend affects their future employment opportunities. Koreans living overseas are given opportunities by higher education institutions in Korea to circumvent some of the competition through the special university entrance requirements set up for overseas returnee students. According to TIS's Korean students, these requirements vary depending on whether they have been overseas for three, six, or nine years to accommodate the student's lack of exposure to the Korean curriculum and acknowledge the potential contributions they can make to the university with their international experience. Japan follows a similar, though less regimented, system. Schools and universities have designed separate entrance requirements for kikokushijo or returnee children to take their international experience into consideration. Goodman (1990) argues that the special consideration given to kikokushijos serves to reproduce class structures that enable children of professionals who were sent overseas by multinational corporations and government agencies to return to Japan and enter prestigious universities.

Returnee students need to maintain some knowledge of what is taught in their own national curriculum. Korean students in particular utilize off-campus Korean tutorial schools for this purpose. Though they grow up transnationally, young people need to remain competitive in their passport country as that is where they are likely to go to university and work in the future. The social and economic structures of students' passport countries have a transnational reach. 


\section{Managing cultural identity in national and transnational contexts}

Parents were often faced with the need to balance their effort to expose their children to cosmopolitan cultural capital with maintaining fluency in the culture of the parents' or passport country. This was partly to help maintain their children's sense of identification with the parents' country and partly for pragmatic reasons-to help them acculturate into the workforce in their passport country in the future.

Parents had a significant role in constructing their children's identity through school choice and influencing their children's cultural orientation in these schools-whether towards the school culture (in this case mainly Euro-American) or home culture (assuming both parents are from the same country). Dae Hyun said, "My mom told me to be international, so I avoided the Koreans and hung out with the others. But then she started worrying that I was not Korean enough. So she told me to go hang out with the Koreans. So I did." At the time of my fieldwork, Dae Hyun hung out mostly with an English-speaking group made up of students of Asian descent.

Kairi

Kairi's story illustrates that employment considerations are intertwined with cultural orientation. When her father was due to be re-posted in Jakarta, he initially intended to take up the posting as a tanshin funin ${ }^{61}$ while the rest of the family stayed behind in Japan so Kairi could complete her high school there. But Kairi asked to come along because she wanted to reexperience the international environment of TIS that she had once experienced during her father's first posting in Jakarta about a decade earlier. In convincing her parents, she promised to attend university in Japan where she would have a greater chance of being accepted by "a good university" as she would be eligible to apply as a kikokushijo. A good university, her parents believed, would shape her into a "rippa na ningen", which can be translated as a "worthy" or "respectable person".

According to Kairi, her parents did not want her to attend university in, for example, the United States. She explained: "They said that for one thing it will cost too much money. Plus, they reckon that if I were to work in a Japanese firm, then I would definitely have a better

\footnotetext{
${ }^{61}$ The term refers to the common practice of Japanese male heads of households living away from the family for extended periods of time as a result of work-related postings.
} 
chance of getting hired by going to a good Japanese university than an unknown university in the United States." This statement contains two assumptions regarding the successful use of cultural capital. First, her parents seemed to believe that her language fluency and educational background would present different opportunities in university applications. Kairi's capital may work as a competitive advantage relative to that of other Japanese applicants in Japan, lending her opportunities to be accepted in a "good Japanese university"; or it may prove a disadvantage if she has to compete with Americans and other English speakers in the United States, where she would find herself in an "unknown university". Cultural capital can mediate university choices. Second, they assume that the successful use of cultural capital in university choice will translate into cultural capital in the job market in Japan or "a better chance of getting hired." Being successful in the job market in the future is linked to the acquisition of the right balance of (Euro-American) cosmopolitan cultural capital and national Japanese cultural capital.

Kairi argued that being grounded in a singular identity is important even in the midst of her pursuit of "internationalism" to avoid being "chuutohanpa" or "half-baked". "My younger sister often mixes in English [when speaking Japanese], but I tell her to stick to speaking Japanese at home. And that's because...I don't think it's good to mix English and Japanese. Because, if you're chuutohanpa...so if you're chuutohanpa in both languages then-and Kubota sensei (Kairi's Japanese teacher) is of this school of thought too-you need to have one foundation. If you don't have a definitive foundation, then it'll make life difficult in various ways. For example, if you're chuutohanpa in both, then you might end up not reading or not being able to speak in either language." The use of the label "half-baked" pathologizes $\mathrm{bi} /$ multiligualism and hybridity. Nevertheless, cultural fluency that accommodates singular notions of identity and conforms to the dominant culture of national contexts remains salient in mapping out career and life trajectories.

Yae

Similarly, Yae's parents insisted that she attend a university in Japan, her passport country, to ensure her enculturation in Japan. They argued that it would determine her future success. At the time of interview, Yae had graduated from TIS the previous year and was visiting from Japan where she was an undergraduate student. Yae had initially wanted to study in the United States for university, but her parents were adamantly against it because she had 
neither a clear idea of what she wanted to study in the U.S. nor the desire to live there indefinitely. She said her parents felt that "going with a 'half-baked (chuutohanpa na)' determination will be useless." Yae explained:

They told me, "Do you know what will be most frightening for you in the future? You...you're passport says that you are Japanese, but not having a Japanese identity, losing it, do you know how frightening that is? There are a lot of people like that in this world. People like that won't succeed. How can they, when they don't know their own identity? You're gonna end up like that too. Besides, even if you go, you won't learn anything in America right now when you're so chuutohanpa. So if you want to go to America, you should first learn jyoshiki in Japan, you need to build something up first as a Japanese, then study abroad in America for graduate studies or the like...There's no point going to America with such a chuutohanpa sense of determination when you're not even planning to live there indefinitely."

Her parents equated cultural hybridity with "losing" her "Japanese identity", which is something to be feared because in their eyes it offered no future. These fears about cultural hybrids are similar to colonial discourses of European-native mixed bloods in the Dutch East Indies and elsewhere. Ann Stoler (1992, pp. 549-550) writes that these historical discourses "encode metissage as a political danger predicated on the psychological liminality, mental instability, and economic vulnerability of culturally hybrid minorities."

Yae's parents were also expressing pragmatic concerns for their daughter's future competitiveness in the market place. Their concern about Yae's imperfect English ability and desire for her to have a solid grounding in Japanese jyoshiki indicate that her parents were aware of the importance of cultural capital in both Anglophone and Japanese contexts. Since her partial enculturation into Anglophone culture would be a disadvantage in Anglophone contexts, they insisted on the importance of nurturing her ability to navigate through a Japanese work environment. Yae wanted to eventually work for a multinational corporation in Japan, and her parents explained that it would be easier to find a job in Japan as a graduate of a Japanese university. Even if English were used in multinational corporations, Japanese would still be necessary. They said that Yae's limited knowledge of formal Japanese and kanji (Japanese/Chinese characters) would disadvantage her. Even though she insisted that she would study kanji while in the U.S., "All things considered, you know too little about things 
which you can only learn by living in Japan, such as the Japanese atmosphere (funiki), or culture, starting with the Japanese feel for common sense, the jyoushiki that comes with being Japanese. These are things you can't learn through a book in America." That's what they told me," she said. Yae believed it had turned out well because she was now taking an English based course popular among kikokushijos at a Japanese university where she could use both languages.

\section{David}

Jeong Tak, who went by the name David, said that his parents wanted an international education for him due to "all the advantages" that would equip him in an increasingly globalized world. David said of his father's views:

He wants me to speak English. He wants me to have a broader scope, broader mind, but he doesn't want me to be an American...So, he wants me to have all the advantages, I guess, about the broader scope, international friends, and English, all that. In education here, he can really see, for example in science. In Korea, science is like memorizing rather than understanding concepts and do experiments. Well, they do experiments, but not as much as they do here. Here is sort of like a discussion education, where the teachers ask questions and they're sort of like, "Isn't it this? Isn't it this?" Give idea and we understand later. And the teachers analyse it, "Blah, blah, blah, blah." In Korea, it's not like that. So I guess my dad wanted me to get more, like, a creative science, I guess, of education.

David's parents wanted David to have the educational and cultural capital that TIS offered, such as "broader scope, international friends, and English." However, they also wanted him to retain his Korean identity.

I'm open-minded, but I'm still more to the Korean thoughts, and beliefs, and so on... I think they [my parents] educated me sort of like that. "You're a Korean, you're a Korean. Although you're going to an international school, you're a Korean." I think that's part of the reason.

In addition to retaining his Korean identity, David explained that his father impressed upon 
him that Korean cultural capital was important for his future economic success:

It's not that swinging [on a] chair is really bad, or American beliefs are bad, but then it's just different from Korean beliefs. Since he wants me, and I want it too, to work in Korea, live in Korea for the rest of my life, it's better to have Korean beliefs rather than American beliefs...

[B]eing educated in American school, be part of American teachers, international students, I think he [dad] was...not scared, but he was worried that I'll have those American sort of system of thought, international beliefs, which I don't think they're bad, I just think they're different.

David's parents felt that it was a combination of "international" and "Korean" capital that would help David "work in Korea".

Significantly, David conflated educational advantages with "international" or "international beliefs", which he in turn conflated with "American" or "American sort of system of thought". This conflation makes evident that international schools are seen as providers of high quality education that reproduces cosmopolitan capital in their students, but also that cosmopolitan capital overlaps with Euro-American capital. For David, becoming "international" ran the risk of becoming "American". As a result, his father was concerned about his Korean cultural retention.

He wanted it (international education), [but] he doesn't want me to be American, have American thoughts and everything, American beliefs and everything. So at home...I think my dad and mom...sort of put it into the back of my mind "You're Korean, you're Korean." Like that...

David also explained about his fluctuating language ability over the years and his mother's efforts in ensuring his fluency in Korean:

In middle school I thought English/Korean is about the same. My teacher told me that I was-I didn't know what that meant at the time, but then...he told me that-I was a bilingual. So I was as proficient in English as I was in Korean. But then...from, like, third 
grade my mother started to get scared because I was dreaming in English. I was talking in English in my sleep, instead of Korean. So it was...it meant to her that I was becoming more and more...lean to the English side rather than the Korean side. So she thought that I might forget Korean.

So she started educating me...at home. She bought these textbooks that the kids in my grade would do in Korea, and then she started working on the textbooks with me... all throughout...until sixth grade, no, until eighth grade I was working on the...things...middle school and elementary school, I was working on...Every year she bought these new textbooks for my grade...So my Korean education was pretty much settled, I think. So I didn't lose my Korean, I didn't lose my English. But then in high school, Korean education stopped 'cause I was starting to get really busy.

His parents wanted David to retain his Korean language skills because they knew that he would need them in the future.

Cultural capital, whether cosmopolitan, American, Japanese or Korean, does not exist in a vacuum of an idealized world. It is embedded in national and transnational socio-economic structures. Parents see TIS as a site for reproducing the necessary cultural capital (education, language, access to universities, etc.) in their children to ensure their future success. Parents are dedicated to seeing that their children acquire the "right mix" of national and cosmopolitan capital. This mixture varies depending on where they want or can afford to send their children to study for university. Some parents may perceive their child's hybridity as an advantage, while others may not.

Whether students and parents perceived the school's ideal cosmopolitan practices as "international", "western" or "American" depended on their distance to Euro-American capital. At times, parents' best intentions for their children ran contrary to TIS's goal of producing "global citizens" who by default are westernized to some degree or another. As a result, those who did not practise the dominant form of cosmopolitanism were deemed to be inauthentic cosmopolitans. This perception of inauthenticity was particularly strong with regard to the way the Indonesian students were perceived, as I discuss next. 


\section{Postcolonial elites meets the transnational middle-class}

The Indonesians, they're filthy rich. They pay the school fees, but then the school pays a lot of taxes on that, and ninety per cent of the taxes go back into their [parents'] pockets.

-Aaron, $11^{\text {th }}$ grade American student (Reconstructed)

Aaron told me this as we sat in the cafeteria with two of his friends within the first couple of weeks into my fieldwork. He and his friends were interested in my research and were offering information about the campus. The hyperbole of his words aside, "filthy rich" was a common description used by non-Indonesian students to refer to the socio-economic background of Indonesian students at TIS. Sometimes it was said matter-of-factly, and other times mockingly. "Filthy rich" was contrasted with the assumed middle class normality of the other students. Aaron's friend Catie, for example, explained that while she may be better off than the average Indonesian outside TIS, back in the United States her family is just part of the regular middle class. "Filthy" also suggests that the financial status of the Indonesian students was perceived as lying outside the norm and was gained through unlawful means. While this echoes the political discourse in Indonesia relating to its chronic corruption issues, I argue that it also reflects the unease that emerges when socially constructed class or cultural boundaries are transgressed. According to colonial discourses, Indonesians should be poor as befits a Third World country, while middle class western expatriates are normal. Wealthy Indonesians disrupt this structure.

Given the expensive tuition fees, only the elite and upper-middle classes among the local population in Third World countries are able to access international schools. By enrolling their children in international schools, they thereby convert their economic capital into cultural capital. International schools become a site where different classes of people with varying senses of entitlement to cosmopolitan capital converge-the middle class from overseas meets the upper classes from the local Indonesian population. The former generally consist of children of professionals working in transnational companies and organizations, while the latter are often children of large business owners and government ministers. The middle classes from developed countries are better positioned to access the cosmopolitan capital necessary to operate in a transnational context than the middle class of developing countries 
due to the economic hierarchy. Those with western cultural capital are particularly well positioned because they have a "natural" claim to cosmopolitan capital.

Peterson (2011, p. 89) describes a similar dynamic in his study of the Egyptian elite in an American school in Cairo whereby economic capital and cultural capital do not overlap.

For Americans, the primary purpose of the school is to provide an American education such that their children's acquisition of educational capital is not impaired by their parents' relocation to Egypt. For Egyptians, a primary purpose of the school is to provide students with a "quality" education far removed from the Egyptian system. These purposes combine to create a system in which middle-class Americans set social standards for Egyptians of the highest elite class...

Likewise, Euro-American cultural capital has been and still is important in constructing the upper classes in Indonesia since the later part of the Dutch era, as discussed in Chapter 5.

In Indonesia, the upper classes and upwardly mobile top-end middle classes pursue EuroAmerican cosmopolitan capital in the form of "transnational goods" and "Western educations" (Peterson, 2011, p. 7). It is common practice for the upper classes to send their children overseas for higher education, especially to the United States and other Anglophone countries. In order to facilitate the transition into higher education in the West, Indonesian parents choose one of a few options for secondary education for their children including: a local "national plus" private school (which may be supplemented by an extra year or two at a transitional institution at the destination country), a local school which offers international education and internationally recognized accreditation, the local international school, or English-language based education in Singapore or the destination country. Western higher education can also be attained through private institutions established locally or through international joint ventures that offer western accreditations. Many education options are available, but the more "authentic" they are as sites of Euro-American cultural production, the higher the status. Both locals and foreigners engage with this discourse of authenticity.

I met a British woman at a conference. At the time, Sarah was living in Spain with her family, where her children went to a British international school. Sarah commented that the Spanish locals sent their children to the school because it was perceived as elite, whereas the British 
did the same because it was the normal thing to do. She spoke of it as though it was curious, possibly laughable, that the locals considered elite what in her mind was merely "normal". There was a disjuncture between Sarah's and the local elite's perception of the school due to their different positionality vis-à-vis cosmopolitan capital. The school represented high quality education and a site for acquiring cosmopolitan capital for the local elite. It was something out of the ordinary. For the British, it represented an educational quality comparable to that back in the U.K. and a site for the reproduction of British capital. The overlapping nature of British (and by extension western) cultural capital and cosmopolitan cultural capital normalizes its pursuit among the British, like Sarah. Similarly, for those who consider Euro-American culture as part of their identity, TIS would appear to be a natural choice for their children's education. Because the dominant school culture greatly overlaps with their own, it normalizes their choice and renders their pursuit of cosmopolitan capital invisible. It does not make them appear like overdressed "new money".

This normalized pursuit becomes visible, however, when parents are asked whether they are willing to relinquish access to Euro-American cultural capital that is reproduced through educational institutions. I asked Vianny, a mother of one of the students at TIS and an Indonesian woman married to a white American man, about her children's education. I asked whether it was important for her children (U.S. citizens of mixed heritage) to attend university in the U.S., and would she consider Indonesian universities as an option. She was in clear favour of the United States: "They have a good education there [in the United States] and their father is American. It's better opportunity to tell the truth, right? Just being realistic about it. Much better opportunity for them. So...right?" Because her children were American citizens by descent, it made the choice of sending them to an English language based international school appear normal. Those with a western background can choose to place their children in international schools as though it were the most natural choice, while in effect reproducing cosmopolitan capital.

In contrast, those for whom western cultural capital is not a part of their everyday family life appeared to transgress social boundaries in their pursuit of the same cosmopolitan capital for their children. The pursuit of cosmopolitan capital by Indonesians and Koreans at TIS was at times interpreted by members of the dominant culture as (mis)using the school to acquire western cultural capital that is not a "natural" part of their makeup. One staff said in passing, "They just want to get into American universities," as though suggesting that their motivations 
were not genuine, i.e. not committed to becoming "international". They were constructed as "wannabes": ambitious upstarts. The pursuit of cosmopolitan capital was seen as authentic for some and inauthentic for others.

Students participated in this discourse. I heard rumours from non-Indonesian students like Aaron who constructed Indonesian students as inauthentically ambitious and "filthy rich". Non-Indonesian students alleged that the Indonesian students gained entry into TIS because their parents had paid a lot of money in addition to the regular tuition fees, i.e. they had bought their way into TIS using what was assumed to be unlawful economic capital. Indonesian students, particularly the Chinese Indonesian students, were cast as illegitimate students in these (exaggerated) rumours. ${ }^{62}$ Although it is difficult to determine the motives for non-Indonesian students in spreading these rumours, what is significant is that they chose to draw on a discourse that naturalized their own claim to cosmopolitan capital, and thus reinforced the school's ideology of being "international" that privileged Euro-American capital.

Authenticity was partly constructed based on the identity of the person or body which paid the tuition fees. A large portion of non-Indonesian students had their tuition fees paid for by their parents' employer-the government agency, multinational company, or transnational organization (e.g. diplomatic agency, Nike, or the Red Cross) that had relocated the family to Indonesia. The employers paid for the tuition fees to ensure that the education of their employee's children was not compromised by the relocation. These parents did not make significant financial sacrifices to enrol their children in TIS. Some of their employers also provided high-end apartments or houses with pools to live in. But such luxuries were not constructed as "filthy" or "rich" because they were provided for by their employers and therefore considered "lawful" and their life would return to middle-class normality when they returned to their passport countries. Some students had their tuition fees paid for out of their parents' own pockets. Although these students were from a diverse range of nationalities, Indonesians were among the most conspicuous of this group because many were from wealthy families. For these students, enrolling at TIS required the effort of converting economic capital into cultural capital. This (economic) effort, or lack thereof, acted as a measure for constructing authenticity.

\footnotetext{
${ }^{62}$ After I had heard the rumour from several students, I headed to the office that handled the school accounts. I asked an Indonesian administrative officer (who incidentally grew up transnationally herself as a child of an Indonesian diplomat) about them. I met a half-hour-long, excruciatingly detailed explanation of the payment process as evidence of the impossibility of bribery.
} 
Some of the students who hung out in the English-speaking groups were from wealthy families, but the term "filthy rich" was reserved for Indonesians who hung out in the Indonesian-speaking groups. The Indonesian students were particularly conspicuous partly due to their visible markers of wealth. A teacher commented that her non-Indonesian students said the Indonesian students were "glamor-loving" in reference to, for example, the designer clothes and bags that Indonesian-speaking students sported. Also, talk of Indonesian students having bodyguards peppered the conversations I had with students. While I did not observe any students with bodyguards on or near the campus, I did see a number of men who appeared to be bodyguards congregating near the entrance of a beer garden, which I discuss in Chapter 10. One Indonesian student, whose father was a high-ranking government official, said that his father used to assign a bodyguard to follow him around when he was off campus, but he did not like it and managed to convince his father to stop. Meanwhile, students also hired bodyguards on occasion for show. Dae Sik, a Korean student who hung out with Indonesians and at times identified as Indonesian, spoke of hiring bodyguards when he went clubbing. Bodyguards served as a symbolic marker of wealth and power. Indonesians and nonIndonesians alike used such markers to construct the Indonesian students as different from mainstream students.

More specifically, most of the Indonesian-speaking students who were considered "filthy rich" were Chinese Indonesians, and often referred to as "Chindo(s)", a term that was not in popular use outside the school. Although "Chindo" did not carry a derogatory connotation, it did indicate that the Chinese Indonesian students were singled out as different from other Indonesian students. Staff and alumni sometimes blamed Indonesian students as a whole for having negatively changed the culture of the school and giving the school a bad reputation with their lack of academic diligence and tendency to go clubbing and partying. This was despite the fact that many other students, especially students from the English-speaking groups, went clubbing too. Sometimes the blame was placed more specifically on Chinese Indonesian students rather than Indonesians as a whole. One teacher specifically differentiated between the behaviour of indigenous and Chinese Indonesians. She believed the former studied hard, while the latter did not.

It is not the purpose here to determine whether or not a particular group of students did or did not behave in certain ways. The more significant point is that discourses about the inauthenticity of cosmopolitan pursuits by Chinese Indonesian students reflected local 
discourses about the inauthenticity of the ethnic Chinese minority as Indonesians (Hoon, 2008). In Indonesia, the ethnic Chinese were legally differentiated from the indigenous population under the colonial Dutch administration, and subsequently under Suharto's New Order regime. They were allowed to flourish economically, but not politically. Often, they became targets of political scapegoating during times of crisis (most recently in the 1998 riots) as a result of their collective wealth and foreignness. This racializing discourse regarding Chinese Indonesians that was present in the national space of Indonesia flowed into the transnational space of TIS.

When national and transnational structures intersect, they challenge the neatly constructed boundaries because one's economic capital does not always reflect one's cultural capital. It is similar to how "new money" transgress class boundaries by using economic capital to compensate for their lack of distinction, or how the "fallen nobility" feel uncomfortable when they are lumped together with the lower class as a result of their lack of economic capital. At TIS, children of expatriates who would otherwise be considered middle class in their passport countries experience an upward shift as their status is elevated to being culturally equal to or higher than that of the local Indonesian elite. In contrast, the local elite, despite their economic capital, experience a downward shift as they are culturally placed on the same or lower level than the middle class from overseas due to their lack of a "natural" claim to (EuroAmerican) cosmopolitan capital. The Indonesian students were generally financially better endowed than the western expatriate students.

These positional shifts created a sense of dissonance. Those who identified with the dominant culture of the school expressed this dissonance by undermining the authenticity of Indonesian students' wealth and right to be at TIS. Dissonance also appeared in the form of competition (particularly amongst the male students) for the top position in the school social hierarchy, as I discuss in more detail in Chapter 10.

\section{In pursuit of "international” passports}

The pursuit of (Euro-American) cosmopolitan capital takes on a tangible form when concerns the pursuit of western passports. Research participants from developed countries never spoke about passport issues because they had a "natural" claim to desirable passports. In contrast, 
participants who were or whose parents were from developing countries were well aware that passports are pragmatic assets.

Anaya

Anaya's maternal and paternal grandparents migrated out of India but they maintained their connections to India and returned at various times. Her mother was born in Spain and partly raised there, while her father was born in India and partly raised in Malaysia (Malacca) and Indonesia. In addition to describing her family's transnational engagement over three generations, Anaya emphasized the importance of her mother's Spanish passport due to the advantage it provides for her family:

I was born in Spain...My parents realized at that time that they had a very big advantage of getting, of making me be born in Spain considering my mom was born there-that we'd all get European passports. And if you think about it, that's kind of a really, really big advantage. And in the Spanish community you always go with the mother. So my mom has Spanish passport and my dad is really into this, like, "passports", "immigration" (Anaya makes quotation marks in the air with her fingers), and, like, airport stuff, and ticketing...So he knows a lot about it, and so he just thought that it would be a big advantage to our future if we all had European passport[s].

So...my brother was born here (Jakarta), but he followed my mom and got a Spanish passport. After five years my dad got a Spanish passport as well. And because I was born there (Spain) I automatically got one. It actually is working to our benefit, 'cause now I'm going to university and I have to pay a quarter of the fees that everyone else (who do not have a European passport) has to pay.

Anaya's father strategically sought to acquire Spanish citizenship for his family through his wife's connection to Spain.

Anaya's preference for England for university studies, as opposed to the U.S. like many of her peers, was not just influenced by the lower tuition fees that she would be expected to pay as a member of the European Union. Anaya also had family ties in England and has had a preference for England "instilled" in her: 
Because my brother's there, and because I have cousins there. And because of my European passport. And because I've always wanted to go there. Because my mom is, like, my mom is very pro-Europe, and she's very...like, she's always had like this attraction to England. So, it's been instilled, I guess, in me.

It is unclear whether her mother encouraged Anaya to go to the UK mainly due to her mother's own ties with Europe, family ties in the UK, or financial considerations. However, it illustrates that even though issues of citizenship may seem like a practical matter, they affected Anaya's emotional preference for university destination (Bourdieu, 1986).

Anaya usually hung out in the English-speaking groups that were perceived by the school as "international". Therefore it could appear as though Anaya's practice of being "international" was a matter of individual choice. However, Anaya's family's transnational engagement, including with Europe, began a couple of generations prior to her own. It follows that she was predisposed to engage with the dominant culture of the school. As Bourdieu (1986) writes, "the transmission of cultural capital is no doubt the best hidden form of transmission of hereditary capital, and it therefore receives proportionately greater weight in the system of reproduction strategies..." I want to highlight that cosmopolitan cultural capital is hereditary.

\section{Afra}

Afra similarly frames his discussion about passports in terms of tangible benefits. Afra is an Algerian national who was born in the United States. He was living in Korea at the time of our Skype interview, but he grew up in the U.S., Mozambique, Turkey, and Algeria. Because his father was a diplomat, he was ineligible for American citizenship despite being born there. Afra explained that the principle of jus soli ${ }^{63}$ does not apply to children of diplomats like him. As he told his story about growing up in several countries, he said that at times he would let his friends think he was American, though he felt "guilty" for doing so:

My parents, you know, drew me away from everything Algerian 'cause there was a civil war there and they didn't want me to know those things. So they tried to maintain a house that had no citizenship issues. So we never talked about Algeria or anything. And

\footnotetext{
${ }^{63}$ A principle that states that a child's citizenship is determined by the child's place of birth.
} 
then I went to Algeria, [and I] never tried to be Algerian. But now I realize I have this passport and it's a country I don't know...And I might have to go back to one day, and the only things that I know about the country or I've seen about the country are not good things. So it made me sort of guilty if I told people I'm American, but I'm an Algerian. I'm actually an Algerian citizen. It's like someone saying, "I have a million dollars," but he has a hundred bucks in his bank account. So it's a bit [of a] hard feeling, you know.

Afra compares having citizenship in a developing country, Algeria, with having "a hundred bucks," while citizenship in a developed country, the United States, is the equivalent of having "a million dollars". Passports are a form of social capital, i.e. membership of a network. I have kept in regular contact with Afra since I interviewed him in 2009. Our communication has often been about his efforts to enrol in a university graduate program in a developed Anglophone country which would enable him to apply for permanent residency, and eventually citizenship.

\section{Deborah}

It was the same with Deborah, a Ghanaian national. Deborah was born in Ghana, but moved with her family to Japan, where she studied at an international primary school. She then moved with her mother and sister to the U.S., where she finished her schooling and undergraduate years. Her father remained in Japan and her mother later returned to Japan. Deborah is fluent in English and Japanese. When I interviewed her over Skype, Deborah was working in China as an English teacher. Not long after the interview, her visa to China expired and within two days Deborah had to fly back to Ghana-a country she left to live overseas when she was two years old and had only visited once when she was six.

In Ghana, she found a job at a Japanese firm on a local salary. Had she had an American passport, her educational qualifications and cultural capital would have earned her a higher salary. Deborah's salary was not enough to pay for the college debt that she had accrued during her studies in the U.S. I was in regular contact with her during her three years in Ghana. It was evident that she had difficulty adjusting to life in Ghana and regularly spoke of finding ways to re-join her family in Japan or, like Afra, applying for graduate school in an Anglophone country. Her visa application to Japan was rejected, and she eventually moved to the UK to further her studies with the financial support of her relatives. 
In contrast, interviews with those who had acquired citizenship of developed countries as a matter of descent that spanned several generations did not reveal the same kind of concern for passports. They did not perceive its importance as capital because it was "normal" in the same way that enrolling at an international school while overseas was "normal" for those with Euro-American cultural capital. To those like Anaya, Afra, and Deborah who have to expend effort to acquire citizenship of developed countries, however, the importance of passports was plainly visible.

\section{Conclusion}

Research shows that parents cite varying reasons for choosing an international or internationalized education: e.g. English language education, access to university and/or work opportunities abroad, and an international outlook (Amit, 2010; Hayden, 2006; Weenink, 2008). Weenink (2008, p. 1099) found in his study of international education in the Netherlands that parents "wanted to prepare their children for a future in a globalizing world and to stimulate them to engage in globalizing social arenas." Engaging in these globalizing arenas require cosmopolitan cultural capital, which overlaps with Euro-American cultural capital. Thus, preparing for a globalizing world means different things to different actors depending on their background and positionality.

TIS offered an education that promised future economic and professional success in both expanding transnational contexts and transnationalizing national contexts. For both contexts, students need to acquire cosmopolitan capital. Furthermore, for the latter case, students need both cosmopolitan and national cultural capital. Peterson's (2011) research shows that the elite of postcolonial Egypt see a need to immerse their children in transnational educational settings, like the American international school in Cairo, to acquire cosmopolitan capital that will reproduce their elite status within the national context of Egypt. The same applies to TIS's Indonesian students who come from the local elite classes. A similar, though less pronounced, dynamic applies to the Korean and Japanese students.

The pursuit of cosmopolitan capital by those who were differently positioned due to their cultural background at TIS created a sense of dissonance. TIS wanted to produce "dedicated 
cosmopolitans" who could successfully navigate transnational contexts, whether they be the international school campus or the world beyond (Weenink, 2008, p. 1094). For those who the "best passports that money can buy", the pursuit of capital to become part of the "international cosmopolitan class" appeared natural, dedicated, and authentic (Hage, 2005, p. 470). For those who did not, the pursuit of cosmopolitan capital was constructed as inauthentic. They appeared to be too pragmatic and failed to fulfil the school's expectations that they become "international". The dissonance arose from the differing expectations that various actors had of the school and the shifting class positions that resulted from the convergence of national and transnational class structures. It is easier for those who already have Euro-American cultural capital to participate in transnational contexts. The next chapter will continue to demonstrate that being "international" required Euro-American capital within the context of a Euro-American school culture, but I shift the focus to student social relations. 


\section{Chapter 8}

\section{Becoming white: the politics of hanging out and school belonging}

Choosing where and with whom to hang out is an important part of school life for young people (Cillessen \& Mayeux, 2007; Kinney, 1993; Lease, Musgrove, \& Axelrod, 2002). Contrary to popular belief, social groups at schools are not formed based on interests or personalities alone (Ortner, 2003). Class and cultural background influence friendships and social groups which appear to be forged by chance, as well as whether or not students even feel they have a choice in the matter. In this chapter, I argue that colonial and capitalist discourses intersect at TIS to inform the school social hierarchy and youth practices of hanging out. Students draw on different forms of capital, at times in contradictory ways, as they position themselves in the social hierarchy and determine with whom they prefer to hang out while coping with the effects of mobility on their friendship circles.

Students compete to become "international" as a means to climb the social hierarchy. In this chapter, I show that students become "international" in part by acquiring Euro-American cultural capital, which in their words is expressed as becoming "white", "normal", or "western". Becoming "international" involves becoming dominant within the social hierarchy by drawing on their cultural capital. This chapter interrogates the processes that produce student cliques that appear to be "nationality-based", thus providing a less-than-integrated picture of international schools. I analyse the ways students navigate through and racialize social geographies of power at TIS. I illustrate that Euro-American capital is privileged in many aspects of the school, including student popularity, use of space, perception of the Other, participation in school activities, and student perception of staff. English-speaking groups, particularly the high-status ones, are racialized as "white" (Dyer, 1997; Frankenberg, 1997). Students who are not part of the mainstream English-speaking groups are perceived as a nameless, faceless "Other". Furthermore, students are more connected with the school when they share a sense of mutual intelligibility with members of the teaching staff. The privileging of Euro-American capital impacts upon students' sense of school belonging.

In his application of Gramsci's concept of hegemony on ethnicity, race, and racism, Hall (1996a, p. 424) writes that it has a "multi-dimensional, multi-arena character". I argue that the dominant culture of TIS and the way it reinforces the ideology of being "international" is 
similarly multi-dimensional and complex. It does not merely impose itself on the dominated. Hegemony is naturalized and the dominated are complicit. As Paul Willis $(1977$, p. 171) writes, "macro determinants need to pass through the cultural milieu to reproduce themselves at all." This chapter shows that racial categories are ambiguous and shifting in transnational settings depending on the positionality of actors in relation to each other (Lindegaard, 2009).

\section{Racializing status and student cliques}

Students employed descriptive language that racialized social groups. Students referred to the English-speaking groups as "western", "white", "bule", "everyone", or "normal" (or the "fountain people" in the case of the $12^{\text {th }}$ graders because they hung out near the school fountain). The other main groups, as mentioned in Chapter 4, were referred to as the "Indonesians" or "Indos"64 (and often "Chindos"), "Koreans", and "Japanese". The terms they used sometimes ran contrary to the diversity of physical appearances or home culture background represented in these groups. Instead, the terms emphasized the cultural capital that students had in common. English-speaking students, particularly those in the high-status group(s), were racialized as "white" in reference to their Euro-American capital.

"The white kids...are popular"

During one of the breaks, I chatted to a couple of senior students about cliques and popularity. "So, who are the popular kids?" I asked as we sat in the main outdoors hangout area that had just enough shade for our comfort. It was a sunny, tropical day on the well-landscaped campus whose lawns were covered with broadleaf carpet grass, fairly typical of the limited green spaces in Jakarta.

"Well, popularity isn't such a big deal here," Melinda contended. Her answer was typical of the senior students in the main English-speaking groups because their own dominant status was hidden from them. "But I suppose the white kids who like to sit over there are considered popular," Melinda continued as she pointed at the benches near the campus shop. "The "white kids'?" I inquired suspiciously, as I was sure they were not all "white" in the Oxford English Dictionary sense of the term. "Yeah, the white kids," repeated Melinda.

\footnotetext{
${ }^{64}$ Atlhough historically, the term 'Indos' referred to those who were of mixed European, often Dutch, and indigenous descent, in the TIS context it was merely short for 'Indonesians'.
} 
I later took a closer look at the group to which she was referring. Indeed, many of them appeared to be white, but there were also those who appeared to be black, Asian, or of mixed descent. All were highly westernized in their mannerisms. "White kids", then, did not refer to physical appearance, but rather cultural competence (Twine, 1997). There were also many sports bags with the school logo lying on and around the benches, indicating that many of the "white kids" were highly involved in extracurricular school activities.

On another occasion, a couple of male students from the group that Melinda had referred to as the "white kids" helped a few male Korean students set up a tent during a senior sleepover held at school. As they were doing this, one of their friends came over and said, "Hey, the white kids are helping the Korean kids!" There was a pause in the air as we all tried to digest that statement. One of the "white kids" broke the silence, "Dude, I'm Pakistani." The other "white kid" added, as he held on to the tip of the tent he was working on, "Yeah, and I'm Asian. My mom is Chinese...and, you're half Japanese." Upon hearing this, the first student chuckled and walked away as his friends busied themselves again with the tent.

Student cliques that were perceived as popular were made up of students who were highly westernized in their mannerisms and dispositions. Though many tended to be of European or part European descent, students were often perceived as white regardless of their physical attributes because whiteness is not always about skin colour (Hage, 1998). Being "white" was conflated with having Euro-American capital and high social status. Student groups and behaviour were thus racialized.

"You mean...the normal people?"

English-speaking groups, though dominant, were not homogenous. If high status students among the English-speaking groups were referred to as "white", then words such as "normal" or "everyone" were used to refer to other students who represented the majority of the English-speaking students. Jenny referred to them as the "normal people" as she recounted her experience when she first enrolled at TIS: “Um, I did have [a] class with, like, the normal people, but I had, like, a special class with the ESOL people. So I made friends there" (Interview, 23 October 2009). The most obvious marker of normality was fluency in English. Jenny's use of the word "normal" reflects how the Euro-American capital was made invisible as 
a marker of distinction among members of the dominant culture, and all others were measured against this normality (Dyer, 1997).

By the time I interviewed Jenny, she was one of the "normal people". Jenny detailed the social hierarchy by differentiating between the "popular" students, "normal people", and the others.

JENNY: Oh, well there are these kids who go out every night and do drugs and stuff. They're popular people, quote, quote (laughs). And people who do sports, like, who are in, like, basically in every season...sports. And (pauses) that's about it. Or (pauses) yeah, yeah that's about it.

DT: And the not popular ones?

JENNY: ...You mean, like, the normal people?

DT: The normal people? Are there people [who are] other than normal?

JENNY: Yaaah (laughs). The normal people, they're occasionally in [sports teams]...They go out once in a while. They (pause), oh, and they're normal-looking. Like, not goodlooking, not ugly-looking. I really sound superficial, saying all this (laughs).

DT: (Laughs) [It's] high school

JENNY: Um, and then the not normal people...They're just, they're quiet. They don't go out at all, like Koreans. They, like, [nobody knows like the mass and individuals], right? They don't really talk that much...to foreigners (i.e. non-Koreans). ${ }^{65}$...Oh, uhm there's this Indo group, they're considered popular, like, dominant because um (pause]...like, first of all they're rich, and like, they're like, in my opinion they're like rebels. 'Cause they go out every night like, they go out and do like rebel, like things...

DT: What about the other ones? [Do] they tend to be of particular countries or...

JENNY: Oh, the sporty ones, they're mostly like Australians or like white people.

\footnotetext{
${ }^{65}$ By "foreigner", Jenny means people who are not Korean.
} 
(Pause) So if you're white and good at sports, that's like the very high chance you go out with the popular people group. And (pause) and then the rest is like spread out.

DT: Spread out? Like, mix?

JENNY: Yeah

DT: What about the...quiet ones?

JENNY: Yeah...they're mixed too but rarely any white people, I think.

Jenny associated high-status students with going out, doing sports, and being mostly Australian or white.

Even the types of sports students choose to get involved in contributed to the racialization of popularity. Sports such as rugby, soccer and basketball are considered high status, while sports such as badminton are considered low status. Jenny commented, "If you're a guy and you're good at sports and you like to go out, you fall into the popular people group. But then it really depends on the sport really." Jenny chuckled as she continued, "Like, if you're [in] basketball or soccer or rugby, I guess you'll fall into-and if you like to go out a lot-the popular people. But if you're something like badminton, swimming or cross-country, and you don't like to go out a lot and you're white...I don't think you'll..." I asked her whether some sports are considered better than others, to which Jenny responded, "Yeah, I guess so. 'Cause no one like...falls for varsity badminton." She was suggesting that female students are not attracted to badminton players even if the players make it to the school team because it is not considered high status. ${ }^{66}$ As badminton is popular mostly among the students of Asian descent while other sports have a much higher proportion of students of European descent, its low status has implications for the racialization of the campus whereby "whiteness" is associated with high status and attractiveness, and "Asianness" with low status and unattractiveness.

Indonesians were also considered popular for being wealthy and for going out at night. Indonesians' economic capital made up for their lack of Euro-American cultural capital. Jenny referred to the mainstream English-speaking group(s), of which she was a part, as the "normal

\footnotetext{
${ }^{66}$ I will discuss the impact of gender on the social hierarchy later in the chapter and in Chapter 10.
} 
people" who did some sports, went out sometimes, and were supposedly average looking. These students were perceived to be diverse. Finally, low-status groups, such as the Koreans and even groups that were mixed, were perceived as quiet because they did not go out clubbing, and were rarely included among the "white people". High status was associated with either Euro-American capital or wealth, while low-status was associated with a lack of EuroAmerican capital.

They seem mixed, but are basically white

Students who had native fluency in English and spoke it as their main language of communication at school generally hung out with each other despite their different national, ethnic, and racial backgrounds. Students in these groups were westernized in their mannerisms. The way they sit, walk, talk, move, dress, and wear makeup all betray the western influences in their lives (Bourdieu, 1990). Many of them also exude confidence and a sense of entitlement to social spaces (Burck, 2005, p. 103). These students tended to win the tacit approval of the school as the best practitioners of being "international" due to the visible diversity of the groups. They were the standard that others were encouraged to emulate and by which others were measured. These students shared a sense of mutual intelligibility with each other based on their Euro-American, especially Anglophone, capital. However, the shared cultural language embedded within their practice of being "international" was invisible to them and the staff because, as Hall (Hall \& Werbner, 2008, p. 353) argues, "this is exactly one of the limitations of liberalism. It's never understood culture. In particular, it's never understood its own culture."

On the contrary, the mutual intelligibility shared by those who had the Euro-American cultural capital to be "international" was obvious to those who did not. A Japanese female student, Kairi, said, "They may seem mixed, but they've basically built a wall around themselves based on being white." The cultural sameness of those in the dominant groups was most visible to those who were positionally marginal to them, and struggled to join these groups. Kairi said that when she enrolled at TIS as an $11^{\text {th }}$ grader, she tried to join the English-speaking groups by sitting in their hangout area. But she gave up after about one week. Kairi found that their values and the way they interacted with each other were vastly different from what she was used to. "I tried to do the over-the-top-reaction thing like an American," she explained in Japanese. Kairi demonstrated what she meant by switching into English and expressively 
saying, "That's great! It's beautiful!" as she flung her arms out for effect. "But I wasn't being myself," she reverted back to Japanese. "I thought to myself, "Why do I have to be the one acting like an American? It's so tiring, I don't like it.' So I quit because school isn't supposed to be a place where you go to get tired." Kairi felt as though the onus was on her to make all the cultural adjustments. On another day, I casually said to her in English, "Hey Kairi, how's it going," as we passed each other. To my surprise, she spontaneously sighed a big sigh and said in Japanese, "I don't get how I'm supposed to respond to that. What are you supposed to say when people say that to you?" She seemed frustrated. There is no equivalent greeting in Japanese. For Kairi, the seemingly simple greeting, "How's it going" represented yet another cultural difference that required her to exert effort to understand and adjust. The question leaves her wondering whether she is supposed to describe to the asker her real state of mind, or say something else.

Kairi had not been trained to respond in a way that creates what Bourdieu refers to as the almost "miraculous encounter" between her bodily hexis, habitus, and the Euro-American transnational environment or field, as Bourdieu (1990, p. 66) calls it. Drawing on Bourdieu, Amanda Wise (2010, p. 923) says, "when one encounters a similarly habituated body or bodies they more often than not respond in certain magical or miraculous ways to interactions with our own bodies in given situations." This could be a simple "Hi," a slight change in facial expression, or the process of slightly leaning your body towards someone, being able to almost perfectly anticipate the other body responding by leaning towards you, to which you respond by leaning forward a bit more, and it all ending seamlessly with a kiss or two on the cheeks. Wise (2010, p. 922) explains, "It is precisely because of their embodied nature that habitus and hexis have the capacity to induce in us affective responses to inter-subjective encounters with those around us and to interactions with our environment." When this magical, miraculous encounter does not happen, then one experiences what the Indonesian students refers to as "nggak nyambung", or "can't feel connected". Many cited this as their reason for not hanging out in the English-speaking groups.

As a researcher unfamiliar with teenage slang, I experienced a similar sense of dissonance to Kairi when I was casually asked by students, "Hey Danau, 'sup? (i.e. What's up?)" Male students, in particular, greeted me in this manner. Each time, I noticed that they walked past me without waiting for my answer. When they did stop to listen to me detailing my schedule for the day, it felt awkward. I decided to ask a male student whether there was a standard 
answer to the question. He told me that it is simply: "Nothing much." I was an adult trying to adjust to a particular type of Anglophone teenage lingo. Those who are not a part of the dominant culture have to exert effort to understand and adjust to it even with the simplest of greetings. These efforts are invisible to members of the dominant culture.

Whether the English-speaking groups were considered "white" or "normal" shifted depending on the positionality of the speaker vis-à-vis the dominant school culture. Ruth Frankenberg (1997, p. 1) views whiteness "as ensembles of local phenomena complexly embedded in socioeconomic, sociocultural, and psychic interrelations. Whiteness emerges as a process, not a 'thing,' as plural rather than singular in nature." Although outsiders are able to differentiate between subgroups within the English-speaking groups, outsiders racialized the students in the English-speaking groups as "white" based on the Euro-American cultural sameness that they shared. English-speaking students "became white". In contrast, among the English-speaking groups, only those who were considered high-status in relation to the majority of the Englishspeakers were labelled "white". Insiders to these groups and staff with Euro-American capital perceived the students in the English-speaking groups as the "international" norm.

\section{Spatial practices: Reproducing status through hangout areas}

The use of campus space reflected the way groups and status were racialized and gendered. Lefebvre (1991, pp. 27-28) argues that "space embodies social relationships," and it is neither neutral nor "innocent". Rather, Lefebvre (1991, p. 26) contends that,

(Social) space is a (social) product...the space thus produced also serves as a tool of thought and of action; ...in addition to being a means of production it is also a means of control, and hence of domination, of power; yet...it escapes in part from those who would make use of it.

At TIS, this meant that students hang out in various areas following patterns that reflected their social relations. During the common recess time, student cliques congregated in the same area day after day. There were hangout areas that were considered cool and others that were not, reflecting the power relations between groups-relations that reflected the slippage between language, culture, "race", and gender. 
Reproducing racialized spaces

Jenny, who was an $11^{\text {th }}$ grader at the time, recounted her changing friendship circles through middle and high school in a way that highlights the link between the racialization of popularity and the use of social spaces. She was Mee Yon's second child (see Chapter 5) and a Korean national who moved to Indonesia with her family at age two. Jenny attended TIS for most of her schooling. When she first enrolled at the school as a $2^{\text {nd }}$ grader, she took classes catering to speakers of English as a second language. But by the time I met her, she considered English her strongest language. She initially hung out with Korean students but she felt "bullied" by them for being different. Jenny explains, "They just moved from the Korean schools, they had different standards. Like, I don't know the latest fashion or, like, the latest celebrities or anything like that. So they didn't really like me." In response, Jenny left the Korean group and joined another. "I hung out with the Koreans in $6^{\text {th }}$ grade, and then these people who hang out in the cafeteria," she said, as she gestured with her hand to indicate "these people". I asked whom she meant by it. "You know, like, quiet people who don't really, like...exist that much," she explained. We both took to laughing at her peculiar choice of words as she apologetically added, "I don't mean it that way." Jenny also mentioned that they were mostly of Asian descent and hung out in the cafeteria, a social space that was frequented by all to purchase and eat food, but not considered a choice hangout area for the long-term. She continued to explain, "They liked me, they really liked me. But then I felt like, I feel really bad saying this, but 'I could do better than this,' you know? So I went to hang out with the white people."

Jenny's ascendancy in the social hierarchy had its challenges. While the "white people" she hung out with were nice, she said,

I couldn't...I didn't really feel open enough. I felt like I always had to hide myself a bit. I was basically the only Asian in that group, other than one Indonesian girl. So I felt like, if I opened up too much they might not like me, or something like that. I was very insecure. Like...I couldn't...like...act crazy or anything, do anything that stands out that much like...do nothing that seems to make me look like...like, you know (laugh)...like a...loser.

I asked what made people seem like a "loser", and she explained, 
Like, if I liked someone and if I say, "Oh, she's kinda...." and everyone's like, "She's so weird." And yeah, if I say, "Actually she's not that weird, she used to hang out with me in the cafeteria." And if I say something like that, they'd be like, "Oh, oookay"...I think they thought, like, "Oh then why is she hanging out with us now," kinda way.

To justify her membership in the group, she felt the need to take on their views as her own and place a distance between herself and the lower-status cafeteria group. When describing the school social hierarchy, Jenny repeatedly expressed her discomfort at making what she felt were "cheap" and "superficial" observations. Yet, as a teenager, her perception of reality at the time was such that she made friendship choices according to these dubious criteria. Cultural capital mattered, popularity was racialized, and spatial practices reflected this predicament.

Spatial use of the campus was reproduced from one generation of students to the next. The relatively low status attached to the cafeteria as a hangout area held true for Marco and Ernest's grade, which was a year above Jenny's. During the first half of my fieldwork, I often saw Marco and Ernest, who were still in grade 11 at the time, hang out in the cafeteria during recess. Most students in their group were of Asian descent, though there was at least one female student of Pacific Islander descent and one male student of mixed (white) American and Asian descent who hung out in the group. The male student was not as westernized as those who hung out in the (high-status) "white kids" group or the "normal" groups-e.g. his accent sounded slightly Indonesian at times when he spoke English. Marco and Ernest recounted that they used to hang out in the cafeteria when they were in grades 9 and 10. Then, at the beginning of grade 11 , the group hung out near the main $11^{\text {th }}$ grade hangout area. However, the area was usually full of the other English-speaking groups, so their group ended up sitting on the benches that lined the hallway adjacent to the main hangout area. They said that they lasted one week there. They felt intimidated and there was not enough space, so they moved back to the cafeteria. This is where I initially often found them and their friends. When I asked Marco and Ernest whether or not the cafeteria was considered a cool place to hang out, one of them replied, "I don't think so, we're just known as the Caf people, right?" (Interview, 14 December 2009) 
When they became $12^{\text {th }}$ graders in the second half of my fieldwork, they moved to one of the new tables and benches that were set up in the main $12^{\text {th }}$ grade hangout area. This time, there was enough room for them to hang out near the other English-speaking groups. They called this the "Caf upgrade", which was successful following their failed attempt the year before. The "upgrade" referred to their move from the lower-status cafeteria hangout area to the higher-status main hangout area of their grade. This is where they often hung out during the second half of my fieldwork.

There were a few other groups that hung out in the cafeteria regularly from different grades, and each seemed to have a similar racial-makeup and appeared to be of similar statuses in their respective grades. At least one was a mixed-grade Mandarin-speaking group, but others were English-speaking groups made up of students of Asian descent of various nationalities like Marco and Ernest's group. Social groups that were similarly positioned in their respective grades hung out in similar social spaces.

Towards the end of the 2008-2009 academic year (around May 2009), I saw Andre, an $11^{\text {th }}$ grader, visiting the hangout area for the 12th grade "white kids" group, i.e. the benches that Melinda had pointed to previously. Andre was a male student of mixed European and Asian descent with a tanned complexion and sportsman build, who was also a member of the $11^{\text {th }}$ grade "white boys" group. It was as though he was staking out territory for his posse, establishing their entitlement to that hangout area through his association with the older highstatus "white kids". The following academic year (August 2009), Andre and his friends took over those benches when they became $12^{\text {th }}$ graders. Similarly, in the new academic year the Indonesian-, Korean-, and Japanese-speaking groups of each grade, especially in grades 11 and 12 , occupied the same hangout area that their upperclassmen had used in the previous year and had vacated. Social relations reproduce social spaces, which in turn reinforce those social relations (Lefebvre, 1991).

The relationship between spatial practices and the racialization of status was apparent during the assemblies when students met separately according to their grades once every month or two. The assemblies were held at the same time, but the different grades rotated between four main venues (cafeteria, library, and the two theatres). Students were free to sit where they liked, but they chose to follow a particular seating pattern. Typically, the "normal" English-speaking students tended to cluster around the front centre area, with the high-status 
group nearby. As a result, one could see more students of European descent with light collared hair sitting closer to the stage. This pattern was more obvious in the higher grades, which is reflective of the greater influence that culture has with age. The other groups, such as the Indonesian-, Korean-, Japanese-, and Chinese-speaking students, tended to sit in different places each time, but never in the front centre area as shown in the diagram. When I asked a Japanese student whether or not she would sit in the front centre area had she arrived the venue earlier than the others, she said no because she felt as though it was not her place.

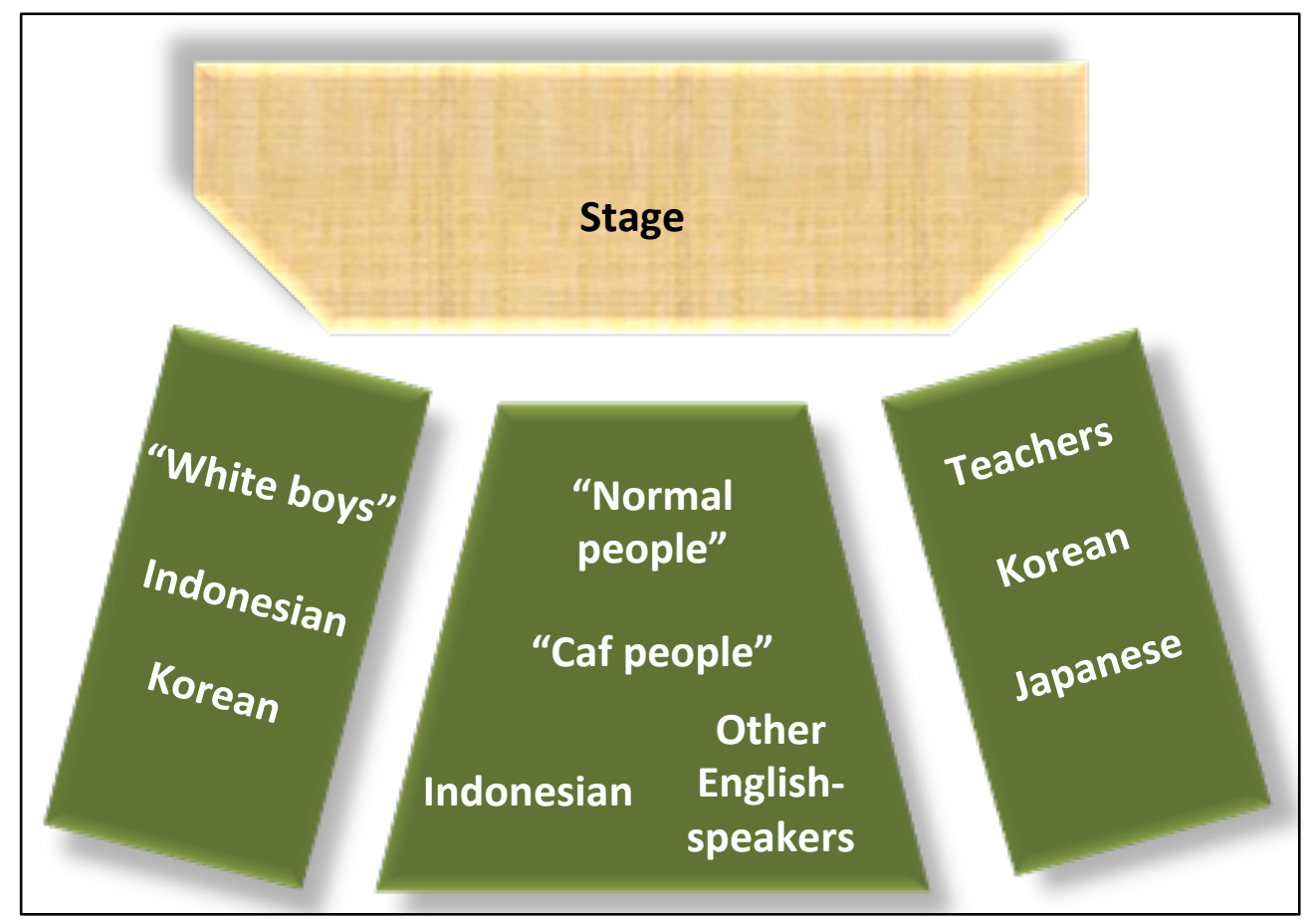

Figure 2: An example of seating during assemblies.

The spatial proximity of the students with Euro-American capital to the stage symbolizes their cultural proximity to the dominant culture of the school administrators and teaching staff. Cultural affinity with the dominant school culture gave some students a sense of "cultural entitlement", which allowed them to be "spatially dominant" while reinforcing the "spatial exclusion" of those who do not share that same level of affinity with the dominant culture (Hage, 1998, pp. 48-49).

\section{Gendered spaces}

The way students used social spaces also indicated that status was gendered. At various levels of the social hierarchy, boys were more dominant than girls in the same group, and some of 
the all-girl groups seemed like satellites to the core group of their level.

During the first semester of fieldwork, the senior (Class of 2009) English-speaking students hung out in three spots in the main hangout area. The "white kids" consisted of both boys and girls, and sat at benches that were placed in a slightly elevated area compared to the others nearby. The largest group is indicated in Figure 3 as "Normal" to borrow Jenny's labels. This group was diverse (in terms of nationality), and mixed gendered.

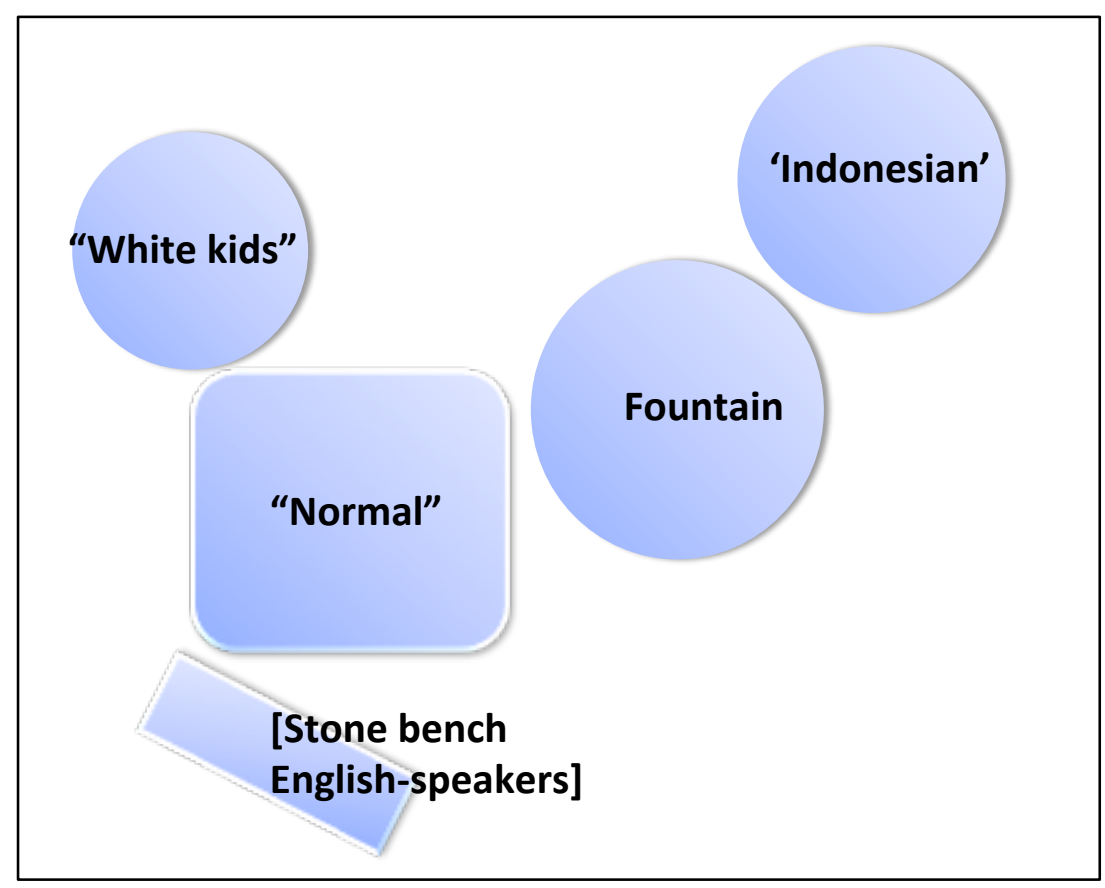

Figure 3: Main senior hangout area for Class of 2009.

Although there were smaller friendship circles within this group, they hung out together in the same general area. The president of the student council hung out in this group. Some Englishspeaking students preferred to sit at a stone bench located a meter or two away from and on the periphery of the larger group, partly because there was not enough space in the main area. Those who hung around the stone bench were made up mostly of girls apart from two boysone of whom was gay and the other was the boyfriend of one of the female students. These three groups, while they hung out in separate areas, had crossover friendships between the groups. Though separate, they also had crossover friendships with those who hung out in the Indonesian group. In fact, two core male figures from the Indonesian group were dating Indonesian girls who were part of the main English-speaking group (both girls had native command of English and I rarely heard them speak Indonesian). The "Indonesian" group was also mixed-gendered and culturally diverse but was defined by their use of the Indonesian 
language.

The school administrators introduced small tables to the main senior hangout area the following semester in a bid to break up the large groupings (see Chapter 4). As a result, the new seniors (Class of 2010) hung out in smaller groups that better fitted the tables. These smaller groups sat roughly according to their social status, as in Figure 4 below.

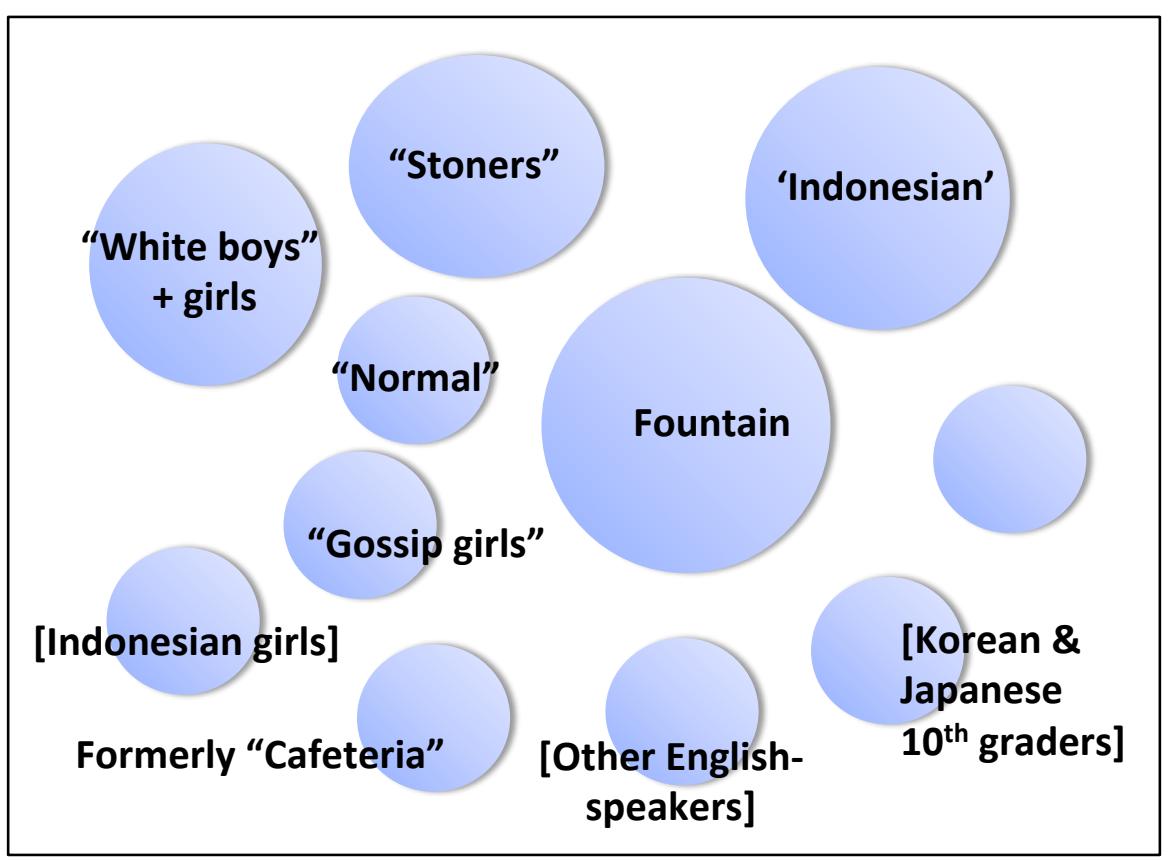

Figure 4: Main senior hangout area for Class of 2010.

The groups that projected a dominant image were the "white boys", "stoners", and "Indonesian" groups. However, "white boys" was an ambiguous term. At least one boy had an Indonesian parent and a Dutch parent. Nor were the girls "white" according to my conversation with Gary who hung out with the "stoners" (Field notes, 15 October 2009):

"Those guys, are the white boys." "White boys?" I asked. "Yeah, they're the white boys." ...l looked at the bench along the [campus shop] wall. There were eight to ten girls with dark hair (brown and what not)...There were only about two "white boys". I asked, "What do you mean by 'white boys'? I mean, look." [Gary] turned around. "Where are the white boys?" I asked. He said, "Yeah, well, the boys are white boys.

Although the girls hung out with the "white boys", their presence was irrelevant. It was as though they were omitted from a census. They were relevant only as accessories to mark the 
dominant boys as dominant (Field notes, 15 October 2009):

"See those," he continues (referring to the girls), "they care too much about who they're seen with. So they hang out there." He says this same thing two or three times in different ways to emphasize it to me. "They want to be seen with the popular ones...They hang out with us outside of school, but in school they're there because care a lot about what other people say and think."

The girls' popularity was dependent on the boys with whom they hung out. But the girls' choice also affected the boys' status. "We're rivals," Gary said of his posse's relationship with the white boys as though to amuse the researcher-since many in the two groups were also good friends with each other.

The group Gary hung out with were labelled "stoners", but they also called themselves the "Black Label". ${ }^{67}$ It was an exclusively boys group, though they occasionally had female visitors. They set themselves apart by installing speakers in their hangout area and playing loud music from their smartphones during recess; they projected an image of being tough party-goers. Gary said with a smile, "And those guys (white boys), they call us the 'stoners'." However, according to some of the girls in the other groups, these boys were not as tough when on their own. "Divide and conquer," laughed one girl as she explained that they were more approachable individually. There is power in the ability to form groups.

The "normal" group was the largest of English-speaking groups. It was mix-gendered. Significantly, the president of the student council of the new academic year (class of 2010) hung out as in the previous year with the English-speaking group. Both elected presidents, Daniel and Rajesh, were culturally versatile and had a nuanced understanding of the sociocultural dynamics among their peers.

Next to that group and further away from the three high-status groups was a table that was dominated by girls. Similar to the girls who had hung out at the stone bench in the previous year, they were friends with those who hung out in the main group. Next to that was an allgirls Indonesian group who generally did not hang out with the main mixed gendered

\footnotetext{
${ }^{67}$ There were other subgroups that used the names of hard liquor to label themselves, e.g. "Absolut". These group names often came to the fore when they organized parties where the group hired out a club and charged a cover cost in an attempt to make a profit.
} 
Indonesian-speaking group. The main difference was possibly that these girls did not go clubbing as much and had more crossover friendships with the "Cafeteria" group that sat next to them. Finally, there was an all white, mixed gendered English-speaking group that sat apart from the others. With both batches of seniors, there was a general impression that girls' groups were like satellites to the main mixed-gendered groups of their status. Boys in the higher status groups projected a sense of dominance.

Status was also sexualized. It came to the staff's attention that some of the $9^{\text {th }}$ graders in the two major mixed-gendered hangout areas of their grade were being territorial by refusing other students entry into their area. I heard that the more popular students had called the other hangout area the "loser hut", and students in the latter had called the other the "slut hut". Teachers took these incidents seriously, though students claimed that the teachers were overreacting. Nevertheless, the way students constructed each other bears analysis. The term "loser" is more gender neutral and could mean that this group was perceived to be less sexually desirable or even asexual. In contrast, "slut" is a gendered term used to describe female behaviour, though more imagined than real in this case. While it is a denigrating term, it also connotes the sexual desirability of both the male and female members of the group. Sexual desirability accompanied status. In Chapter 11, I argue that in some ways EuroAmerican cultural capital enhanced perceived sexual desirability.

\section{Social capital: the power to make groups}

There were English speakers who are not shown in Figure 3 above-boys who hung out mainly in the library and a few girls who hung out elsewhere. These students hung out in places that were out of view of the others. Most did not seem comfortable hanging out with their peers from the main English-speaking groups. One exception was Chaitan, whose parents were Indian, but by the time I met him in Indonesia he had lived in three cities in India, as well as Sri Lanka, Singapore, and China. In China he attended an American school where he believed he had picked up an American accent. "Surprisingly, my gang was all white kids and I was the only Asian," he explained. (I later found out that Chaitan's friends were not "all white". At least one boy was of mixed white and Asian descent, thus evincing the ambiguity of racial categories.) As I sat and listened to Chaitan, it became obvious to me that his style of speaking and his bodily hexis were such that they would have enabled him to join the main English-speaking groups with ease. But Chaitan claims he had made a conscious decision not to do that when he was 
forced to choose between friends in $8^{\text {th }}$ grade.

I was friends with everyone, sort of. [Matt] and [Troy] (who were in the main Englishspeaking group during my fieldwork) and they're like, "Dude, you're cool and stuff, and you can hang with us. But you gotta stop hanging with them." That was quite a moment, mindset change you know. I was the guy in middle school, and here I'm like, wowww, I don't wanna be with these people.

Their directness took Chaitan by surprise. "I mean, really direct. Boom. (Laughs)...It just came to me as a shock: choose your friends," he continued. Later, Chaitan had to make a similar decision in $10^{\text {th }}$ grade. He was getting close to the Indonesian students, who were considered high status, but felt that he had to abandon his other friends (who he was with when I met him) in order to be fully accepted even though this time they did not tell him directly. Chaitan said, "There was a feeling that, like you know, 'You can hang with us, but they can't."' "They" referred to "the guys in the library" (to borrow Chaitan's description), with some of whom he was already friends from middle school. Chaitan was instrumental in bringing them together with a few others who had been on their own. Chaitan's explanation of how the group came to be suggests that most of them were lacking in what Bourdieu $(1989$, p. 23) refers to as symbolic power, "whose form par excellence is the power to make groups."

Members of the dominant groups are often unaware of their own dominance. While Chaitan reckons that students were not as cliquey at the American school that he had previously attended in China, he also recognized he may be biased because he was part of the dominant group there. He recalled,

Maybe because I was on top there, the top dog or whatever, so I didn't feel it as much. Maybe there were equally as many cliques...I'm not sure. I wanna believe it wasn't like that. But the thing is, I feel that when you're at the top, you want to make it like everything is happy and stuff.

Chaitan's observation echoes the claims that were made by many in the "normal" and highstatus English-speaking groups about how popularity was not really an issue at TIS. It was common for them to say, "We're just friends." But when I told students like Marco and Ernest about these claims, they looked at me with disbelief and promptly dismissed them. Those 
outside the dominant groups were acutely aware of the social hierarchy because it negatively impacted upon their comfort level in various social spaces on campus. For example, Marco joined an extra-curricular club that was made up of students learning Spanish who wanted to prepare a performance for United Nations Day. During practice, Dirk, a tall Dutch boy from the main English-speaking groups, would end up in the middle of the room, while Marco ended up squished on the sidelines. Marco's body language indicated that he lacked the confidence to claim entitlement to space.

Although Chaitan's friends were culturally diverse (Italian, Dutch, Indonesian, Indian, etc.), his group mainly consisted of male students. There were female students with whom some were friends, but in contrast to the all-boys "stoners" group, the boys who hung out in the library collectively projected an asexual image while at TIS. ${ }^{68}$ In contrast, the non-English speaking groups shielded themselves from being relegated to a low status by removing themselves entirely from the English-speaking social hierarchy, as I discuss in Chapter 9, and retaining the ability to form a mixed-gender group.

Euro-American capital acted as a measure of normalcy. It was also racialized as "white". Popularity and the use of space was also racialized and gendered. Thus, a sense of openness to the Other is not sufficient for being "international". In order to become "international", students need to also become "white" and dominant. Those who did not felt marginalized.

\section{School belonging}

The cultural hierarchy discourages those who are marginalized from participating in activities that promote school belonging. This was particularly obvious when the activities required participants to make a fool of themselves in jest. The student council organized an annual School Spirit Week for which each day of the week was assigned a theme, such as Gangster Day, Superhero/Nerd Day, Cross-dress Day, and Twin Day, and students were encouraged to dress up accordingly for fun. The week culminated on a Friday with a Senior Slave Day when a few $12^{\text {th }}$ graders were "auctioned" to students. Typically, a group of students (often the friends of those auctioned) pooled some money to "purchase" one senior, make them dress in embarrassing outfits, and order them around for a day. In one case, a male senior "slave" was

\footnotetext{
${ }^{68}$ This image did not last into college, according to Chaitan, with whom I caught up about six months after he graduated from TIS.
} 
made to shave his head (by his friends who had "purchased" him), albeit with his permission. The money from the trade was donated to charity.

The $12^{\text {th }}$ graders who volunteered to be auctioned as slaves were from the English-speaking and Indonesian-speaking groups, the two groups that competed for status within the school social hierarchy. Only members of these groups volunteered because activities that involve spectacular displays of self-deprecating behaviour require the participants to be in a position of power for it to be humorous to both the audience and participants. For those purchasing the slaves, the activity is humorous only if the slaves are from positions of power and purchasing them offers an opportunity to reverse the hierarchy and poke fun at power. The slaves were of interest to the purchasers because they were popular seniors ( $12^{\text {th }}$ graders) from high-status groups as opposed to, say, unknown freshmen ( $9^{\text {th }}$ graders) from low-status groups. Students who are popular can risk being auctioned knowing that they will fetch a reasonable price. Being a prized purchase attests to their popularity, while a low price indicates lack of interest in the person being auctioned. Therefore, it was easier for members of the English-speaking and Indonesian-speaking groups to participate in this activity as slaves because they did not risk losing face.

Cross-dress Day also involved self-deprecating behaviour, particularly for males who had to put their masculinity at risk in a hetero-normative environment. Only those from the Englishspeaking groups participated, as described in my field notes:

It was cross-dress day. A lot of people from the (mainstream) fountain group were cross-dressed. In the morning, as I sat on a bench near the campus shop with [Thea, John, and Michael], [Priya] came up. Apparently he had a bra on underneath his shirt. Nobody noticed. He took the [black] shirt off and put on a tight-fitting cheerleader shirt. But then [Thea] told him to wear the black dress, so he did. Then [Monica and Jurgen] compared waist sizes by putting their bums together back to back. Then they went away and changed into each other's outfits. [Craig] and some girl were also wearing each other's outfits. [Shivani] had come totally prepared. She even drew a beard on her chin with a marker, and was sporting a red baseball hat to go with her "sexy" boy look. A few others were also cross-dressed. None of the Japanese were cross-dressed. In fact, I didn't notice any others cross-dressed from outside the fountain group except [Joon] (a male Korean student). I saw him as he pas[sed] the 
library when I was interviewing [Maki]. He was wearing a kemben (strapless) outfit with a big bow in the middle (where the cleavage is supposed to be). I smiled at him, and he noticed me too and acknowledged me smiling at him. But later I saw him as I was walking somewhere, and he was dressed normally. I asked why. "I was too embarrassed," he said. (1 April 2009)

In contrast to the English-speaking groups, in which female and male students were casually swapping clothes and enjoying Cross-dress Day, Joon tried to participate in it but felt uncomfortable enough to quit halfway through the day. Joon did not have the cultural capital necessary in the TIS context to engage in self-deprecating behaviour without the risk of embarrassing himself. In an interview, Koichi explained this dynamic: "If someone who is always quiet says something that doesn't suite their style, then it just seems totally out of place." The English-speaking groups were sufficiently distant from being a "loser" that they could break the rules without being perceived as a "loser". Participating in Cross-dress Day reinforced their dominance.

The different uptake of the other three days also reflected the social hierarchy. Like Senior Slave Day, Gangster Day was popular among the English-speaking and Indonesian-speaking groups. Many came dressed like tough rap singers donning a baseball cap tilted to the side and large golden chains around their necks. Gangster Day was about looking tough and dominant. Meanwhile, Twin Day, which was more about being cute, was popular among the Korean and Japanese female students. Superhero/Nerd Day was unpopular. I only spotted three seniors who dressed up for it. Dong Gun went all the way and dressed like a nerd from America circa 1950-large, black-rimmed glasses, white shirt, bow tie, trousers pulled up high up his waist and not long enough to cover his ankles, and shiny black leather shoes. One of Dong Gun's many friends dressed up as Superman. She was an Indian girl who generally hung out in areas that were out of sight from the main hangout areas. Finally, a Korean boy painted his face like the Joker from the Batman movie "The Dark Knight". None of the students who identified with the dominant groups participated in Superhero/Nerd Day. "School Spirit Week" is not innocent. Students perform the events in ways that reflect relations of power. 


\section{Cultural affinity with staff}

Cultural affinity with the teaching staff and school administrators plays an important role in campus dynamics because it provides students with access to social capital (Bourdieu, 1986). As authority figures, the mostly Anglophone teachers are in an influential position to reinforce the dominance of Euro-American capital, particularly in classrooms (Hall, 1996; Lears, 1985).

\section{Discomfort at "being preferred"}

Although Dong Gun complained about teacher attitudes towards Korean students (Chapter 7), he was not the target of the teaching staff's frustration himself because he spoke fluent English, was more westernized than the majority of Korean students, and had friends in almost every major group. By his own admission Dong Gun said,

I have no personal experience because the teachers don't think that I'm a Korean enough. (Laughs) Like, they never see me as a stereotypical Korean just because I don't hang around with them. When they [teachers] go around, they never see me there [where the Koreans hang out] and stuff because I'm always around with different culture people. So I'm not a part of that issue. These are the things that I hear. Even in class you know, they're just...[pause]...I don't know, I can't explain it. It's just a feeling. A feeling that you have when you see what's going on.

Dong Gun exemplified the school's ideal of internationalism. Early on in my fieldwork, a staff singled Dong Gun out to me as a student who had a typical K-pop ${ }^{69}$ look (mainly in reference to his slightly dyed, permed hair), but was well integrated into the larger school communityunlike other Korean students. Dong Gun was a "floater" who did not hang out with the Korean groups or any other particular group for long. Instead, he moved fluidly among them.

Other students who, like Dong Gun, had the cultural capital that made it easier for them to move between English- and non-English-speaking groups articulated similar sentiments of feeling uncomfortable with being preferred by members of the dominant culture, particularly teachers. Young Sik, another male Korean student who spoke fluent English, said:

\footnotetext{
${ }^{69}$ Korean pop.
} 
YOUNG SIK: Teachers...I just feel it, like...They're more for Americans, more for the white guys or the guys who speak better with them...If you ask Koreans, they would offer a list...of people who are prejudice to them but as the, the more like international guy...I don't get as much as these guys (pointing to the 12th grade Korean hangout area)...I get less, yeah, yeah, I think so. (Pause) When teacher comes, like...I don't know, I feel like they're more, nicer to me than Koreans. Some people, there are also really good at English and can communicate well, but especially like these guys who are really struggling now. Yeah, they're, teachers kind of yeah, are not too nice.

DANAU: Okay, and do you feel like sometimes they're nicer to bules instead of you?

YOUNG SIK: Yeah, for sure. That's for sure.

Both Dong Gun and Young Sik were westernized and fluent in English, and therefore they were preferred by members of the dominant culture (e.g. Foley, 1996, p. 82).

Ben or Hyun Bin, another Korean student who spoke fluent English and went by his Anglicized name when interacting with non-Koreans, described similar experiences in relation to his western peers.

...There are people who almost can't speak English. It's like, really bad saying it, but who can't speak English as well...and have hard time speaking fluent English...and there [are those] who are really fluent speakers. And fluent speakers get along with westerners easy. But others, westerners kind of push them aside, that kind of thing...that kind of...like when you have to make groups in class...those more fluent speakers would be...would have easier time making groups with westerners. And if they have to make like a large group, then some Koreans would be left out, that kind of thing.

Ben articulated a sense of discomfort with the privileges that Euro-American cultural capital accorded him, which his Korean peers who spoke English as a second language were not able to access. Ben cited this as one of the reasons why he hangs out mainly with his Korean 
peers. $^{70}$

Some Koreans have...better English than others. So for those people...like if they hang out with English [speakers], the less fluent English speaker would get, like, a little secluded kind of thing...'Cause they'll feel like, "Oh there's so many English [speakers], they're hanging out with westerners,"... and then there'll be like division within Koreans.

Even though he felt comfortable speaking English, he chose to do most of his socializing in Korean with his Korean peers because he did not want to participate in making them feel marginalized. The dominant school culture is reinforced by affirming those who have EuroAmerican capital at the expense of those who do not.

\section{Rapport building for students with Euro-American capital}

It was easier for teachers and the administrators to build rapport with students who are westernized than with those who are not, due to the shared sense of mutual intelligibility. A white Australian teacher acknowledged that he found it easier to build rapport with western students. The rapport he was referring to was evident in some classrooms taught by other teachers. On my first day in one of the social studies class, Dr Davies, the teacher, held a lively discussion in which he used students to bounce off one another to keep the discussion going. Dr Davies constantly engaged with the westernized students who were sitting mostly in the front row, while he engaged the back row only on rare occasions, such as asking Aisha, a female Malaysian student, for clarification on an issue relating to Islam.

Aisha was called upon to represent her culture to the others and be an expert on Islam. This is a responsibility that is often placed upon members of minority groups. Aisha was the only female student among hundreds of high school students who wore a conspicuous religious headdress, the Muslim jilbab. ${ }^{71}$ Apart from her, there was a male student who wore a Sikh turban. Ironically, this made her a visible minority within the international school, though just outside its imposing security gates lay the world's largest Muslim country.

\footnotetext{
${ }^{70} \mathrm{I}$ discuss other reasons in Chapter 9.

${ }^{71}$ The jilbab, as it is commonly called in Indonesia, is a headdress typically worn by Muslim women in Southeast Asia and elsewhere. It is a cloth that covers the head, particularly the hair, but reveals the face and is often held in place with a pin, broach or needle. Some women wear it all the time, while others wear it on formal occasions. Aisha almost always wore a jilbab except on United Nations Day when she took it off to perform a dance as part of the Japanese club.
} 
When I sat in on Dr Davies' class on another day, he ran the class in a more subdued way, which created a different student dynamic where all students were equally engaged in the class discussions. It suggested that Dr Davies may have allowed the westernized students to dominate the discussion in the previous class because I was present and he wanted to perform an animated discussion for the outside observer. It still stands, however, that the ease with which students with Euro-American capital were able to relate to authority figures naturalized their position as culturally dominant within the school (W. Brown, 2006; Hage, 1998).

Students with Euro-American capital actively sought teacher attention, received it, and thereby asserted their dominance. Mr Sawyer's class was culturally diverse. Mr Sawyer appeared to have a good rapport with all of his students regardless of their background or English ability. Despite this, it was the four students from the mainstream English-speaking groups, all of whom were female, who were the loudest and demanded the most attention from Mr Sawyer.

My field notes focused on what the four girls looked like, sounded like, and did. Appearancewise, the use of eyeliners set them apart from their female classmates. Although on various occasions students told me that appearance did not matter at their school, girls who wore eyeliners almost invariably sat next to other girls who wore eyeliner in class. All four dressed in a way that I labelled "dressed up" and "girly" in my notes. Nadia was British and long, straight blond hair. She was wearing a colourful flower print top and black tights that came just below the knee. Lauren appeared to be African American and had straightened black hair. She had large round earrings, and wore a low V-neck top that showed her black bra most of the time except when she occasionally sat up with her back straight. Alyssa had an American accent, though Malaysian by nationality, and appeared to be of mixed descent (though she may not have been). She wore full makeup and a bra that was so brightly red that it showed through her opaque white top. The fourth girl generally spoke with an American accent but sometimes pronounced words in a way that indicated she was not a native speaker of English. She wore a tight pair of jeans, a flower print top, and flat, red shoes. The clothes the other girls in the class were wearing appeared plain in comparison. The bodily hexis of the four girls also set them apart (Field notes, 30 January 2009):

[The fourth girl] has legs on the bar underneath the desk in such a way that you can 
see her knee popping out [above] the desk...[Alyssa] has one leg straight on the bar underneath the desk, and one foot on the chair so that her knee also sticks out higher than the desk height. [Lauren's] knee is also sticking out because she has her legs crossed...Everyone else is sitting normally (i.e. with their legs below the desks). No. 3 is slumping on the desk.

The four girls embodied a spatial presence that was different from and, in this case, more dominant than their classmates.

The other students were relegated to the sidelines in my field notes partly because the four girls were closest to where I was sitting, but also because they were loud. While working on an exercise set by Mr Sawyer, Lauren yelled out, "Who's finished?" But she did not seem to care about getting an answer. She said it as though to seek attention. Nadia often joked with $\mathrm{Mr}$ Sawyer. My field notes say:

The teacher tells them to put their pencils down because he wants their full attention. [Nadia] says that girls can multitask. The teacher jokes and says, "Yeah, but boys can't. [Keisuke] can't." [Lauren] takes a long time to put her pencil down. So the teacher teases her and says, "Everyone is now looking at ya." Finally the teacher explains something for a few seconds. Students start getting lively again.

All four loved talking to the teacher, though Alyssa was not as loud and the fourth girl, as a non-native speaker of English, at times appeared as though she found it difficult keep up with the other three. This is not to say that the other students did not have a good rapport with $\mathrm{Mr}$ Sawyer. They did: Mr Sawyer joked with some of the other students too; Midori, a Japanese girl stood up and casually walked around while doing her work; Keisuke, a Japanese boy, approached Mr Sawyer to ask a question while listening to his iPod with one earphone; Mr Sawyer confiscated a mobile phone from one of the Korean girls who responded with a teasing, "Sooooo mean"; and two of the Korean girls played around with Mr Sawyer's computer after class and he did not seem to mind. Nevertheless, it was the four girls who dominated the classroom space by filling it with their voices and body language, and thereby reinforced their connection to the dominant school culture.

Cultural dominance inside the classroom feeds into a sense of "school belonging" outside the 
classroom. Student affinity with the teaching staff signifies social capital and access to power. Social capital represents what Bourdieu (1986, p. 248) refers to as "a durable network of more or less institutionalized relationships of mutual acquaintance and recognition" through which one is able to access the pool of capital possessed by others. Students who already have EuroAmerican cultural capital can enjoy a "multiplier effect" by drawing on the cultural capital that the teaching staff has (Bourdieu, 1986, p. 249). Their shared cultural capital reproduces social capital through an "unceasing effort of sociability, a continuous series of exchanges in which recognition is endlessly affirmed and reaffirmed" (Bourdieu, 1986, p. 250).

The cultural affinity between students with Euro-American capital and the teaching staff is evident in the way Kenji conflated his schoolmate's Euro-American capital with authority. I was following Kenji around one day (with his permission) to get an idea of what his school day was like and with whom he hung out. Kenji's father is Japanese and his mother is Indonesian. He is a native speaker of Japanese and Indonesian, and speaks English as a second language though he had a good command of it. At one point, we were in the computer room as Kenji worked on his homework and played computer games. There were a few students working behind Kenji. One of them was Darren, who was of mixed decent and hung out with the "fountain group". Darren said something in English to his friends while Kenji had his back to them. Immediately Kenji turned to me and asked in Indonesian, "Guru ya? (Is it a teacher?)" I told him no. Kenji then proceed to explain in his usual mixture of Indonesian and English, "Kadang bule kalo ngomong kayak guru (When the white guys talk, sometimes they sound like teachers), and I'll be like (Kenji turns around and acts surprised to find out instead that it was a student), anjing (damn)."${ }^{72}$ Kenji associated the speech patterns of native speakers of English with authority.

\section{Rapport building for students without Euro-American capital}

Studies on multicultural education conducted in the United States show that teachers from minority backgrounds serve as "cultural translators and cultural brokers" for minority students (Irvine, 1989, p. 57). These teachers help minority students "navigate the culture of the school, which is often contradictory and antithetical to their own cultures" (Villegas \& Irvine, 2010, p. 185). These teachers are able to act as mediators because they share a sense of mutual intelligibility with the minority students and, at the same time, can engage with the dominant school culture as authority figures. A similar line of argument can be applied to TIS where

\footnotetext{
${ }^{72}$ The term "anjing" literally means "dog" in Indonesian and is often used as a swear word. Male Indonesian students often used it casually on each other as well as others.
} 
teachers who do not come from western or Anglophone backgrounds serve as cultural brokers for students who are unable to identify with the dominant school culture.

Japanese students were quiet as a rock in the regular classes taught by western teachers, but became vocal and participative once they were in a class with a Japanese teacher who spoke their language and shared a sense of mutual intelligibility with them. The first time I sat in a $12^{\text {th }}$ grade Japanese class for native speakers, the students chatted and joked rather loudly. The Japanese teacher "Kubota sensei", ${ }^{73}$ as they called her, used the opportunity to welcome me to her class and facilitated a casual chat about the students' diverse cultural experiences. Kubota sensei was interested in my research and what I had to say about her Japanese students who were, in her eyes, Third Culture Kids. The way Kubota sensei perceived them ran contrary to the way western teachers perceived the Japanese students-as self-segregating.

After about 45 minutes, the fun and jokes culminated in four of the five male students going up to the front of the class to demonstrate, to great hilarity, the physical warm-up exercises they had been required to do in time to music at their former Japanese school. Then they went back to their seats to focus on the Japanese article they were reading for class. The students switched straight into serious study mode. Their behaviour in this class stood in stark contrast to their behaviour in the mainstream classes. When their cultural capital is not affirmed as "normal" in the classroom or other settings, they experience an absence of a sense of entitlement to not only physical, but also verbal space. Though it was unusual to spend 45 minutes of class time chatting, the relaxed atmosphere itself was similar to that in other Japanese classes for native speakers, as well as Chinese language classes where most of the students were of varying Asian backgrounds. The students who were silent in other classes were more at ease in classes where they had some degree of mutual intelligibility with the teacher. Similarly, an Indonesian teacher commented about her Indonesian students who had been at the international school since they were young that, "They relax in this class. Even though English is their language, it's still tiring for them [out there]. At least that's how I see it." The student feel as though they are part of the norm in Indonesian classes and do not have to exert effort to negotiate cultural dissonances. Cultural affinity facilitates student-teacher rapport, which in turn promotes a sense of being part of the norm, of belonging in that social space. But in the case of students who are not familiar with Euro-American capital or speak English as a second language, their sense of normalcy is confined to particular classrooms (or

\footnotetext{
73 "Kubota" is the teacher's surname and "sensei" means teacher in Japanese. In Japan teachers are called by their surname followed by "sensei".
} 
hangout areas). They lack the social capital that links them to the authority figures who hold the power to shape the dominant school culture.

There were times when some of the Japanese students turned to me, an adult, as a cultural broker. I had both the linguistic and cultural competence to communicate with Japanesespeaking students, English-speaking students, as well as the teachers. One of the first classes I observed was a college-prep English class for non-native speakers. The Japanese students were keen to speak to me once they found out that I was fluent in their language. In another class, Erina, a Japanese student, was similarly keen to talk to me. Erina was very quiet and at times tense during group work, when she seemed unable to voice her opinions freely due to her discomfort with the linguistic and cultural difference. However, Erina was by no means shy, considering that she later became the president of the Japanese club. I had introduced my research and personal background, including the fact that my mother was Japanese, at the beginning of Erina's class. When the bell rang to signal the end of class, the first thing Erina did was to turn around to me and ask whether I could speak Japanese. Once I said yes, she seemed relieved. "I was curious about that the whole time," she said. Japanese students relished finding an adult (i.e. someone who was in a position of power) who shared a sense of mutual intelligibility with them.

Likewise, Ali was one of the few students with a Middle Eastern background, and it was important for him that Dr Briones, who was from the same region in the Middle East, was there to ease his adjustment process when he first joined the school. Ali speaks of the fieldtrip he went on during the orientation program for new students (Interview, 25 November 2009):

I went to orientation before and I didn't really like it that much, didn't really connect. I felt like I tried, that actually I tried connecting, but somehow it took a lot of effort and there was no positive result. Like, I tried to talk to a person, like, "What are we doing," and "Why are we doing this?" And I tried to make a joke, but still, like, you know, it's really hard. I just didn't really connect well. I connected with a really good teacher, $\operatorname{Dr}$ [Briones]. You know him? He was there and I connected with him very, very well. We just talked over time and stuff. So he was my saviour in the trip.

"Connect" was a commonly used expression to describe a sense of mutual intelligibility. It 
included a shared sense of humour, as illustrated by Ali's reference to his failed attempt to use jokes to connect with his peers. Students frequently cited humour as crucial to establishing a sense of connection with others. Although Ali did not specifically refer to Dr Briones' cultural background, it is clear Dr Briones' presence was important for Ali. I suggest that Dr Briones acted as a cultural broker for Ali. Later, Ali hung out with the Indonesian-speaking group in his grade. He claimed that he shared their sense of humour.

It is also important to note that student-teacher rapport can cut across racial lines. Before my fieldwork began, Mrs Taylor's classroom used to be frequented by students who ate breakfast and lunch or just hung out there whenever she was not teaching. It was "quite a phenomenon" said Mrs Taylor, and her colleagues corroborated her statement. Later, a white Australian alumnus spoke fondly of Mrs Taylor, saying that she was a great teacher. While her classroom was not as popular during my fieldwork year, I still noticed that students of Asian descent liked to hang out in Mrs Taylor's classroom during recess, including Ernest and Marco who were in the English-speaking group that used to hang around in the cafeteria. "We feel comfortable with Mrs Taylor because she understands us and know what it's like to be a teenager," commented Ernest. They did not know that Mrs Taylor, who sounded American, looked like a white American and was an American, was raised in Hong Kong (when it was still a British territory). She confessed, "I feel safest when I am surrounded by Chinese [sic]. I feel least safe when surrounded by Americans." I suggest that while Mrs Taylor appealed to a diverse range of students, it was not just her personality that contributed to rapport building. I suggest that a shared sense of mutual intelligibility based on her transnational upbringing and familiarity with Asia also contributed to rapport building.

\section{Conclusion}

Transnational educational spaces are not neutral spaces. Students' sense of belonging is affected by the school culture. At TIS the school ideology of being international privileged Euro-American capital, making it easier for students who were westernized to integrate into the dominant groups. An analysis of student popularity reveals that Euro-American capital was normalized as seen in the use of the label "normal" to refer to the main English-speaking groups. Euro-American capital was also rendered high status and racialized as "white". Westernized students had an easier time building good rapport with teachers because of their 
sense of cultural affinity. Students who did not have sufficient Euro-American cultural capital to feel a part of the norm felt marginalized, as seen by their different behaviour in mainstream and language classes.

"There is no more powerful position than that of being "just' human," writes Richard Dyer (1997, p. 2). The normalcy of the English-speaking groups renders their whiteness invisible. There is power in this invisibility to construct being "white" or "western" as being "international" as will be revisited in Chapter 11. Consequently, "self-segregating" on the part of the non-English-speaking groups is not merely about students' unwillingness to be "international". It is an effect of the social hierarchies that privilege Euro-American capital. In the next chapter I show that students form separate language groups to ease their sense of marginalization. 


\section{Chapter 9}

\section{Becoming "Asian": Alternative processes of cosmopolitanization}

The process of becoming "international" is characterized by a sense of ambivalence inherent in hybrid identities. Cosmopolitanization is a social strategy that TIS students use to mediate their positionality within a transnational space. It is a process of negotiating boundaries, sometimes by blurring them and at other times by reinforcing them. I propose that becoming "western" and becoming "Asian" are both mutually constitutive with becoming "international" as they represent ways of practising cosmopolitanism that emerge out of the cultural inequalities embedded in transnational and national structures.

The previous chapter demonstrated that the students who were perceived to be "international" and therefore perceived to be practising cosmopolitanism had Euro-American capital. They were constructed as "normal". This chapter shows that students who did not acquire sufficient Euro-American capital were constructed as Other and homogenized. The different ways in which students experience a transnational space produces diverse ways of practising cosmopolitanism. Students respond to cultural hierarchies by reinforcing boundaries of difference to create home turfs into which they can retreat and find relief from feeling marginalized. Students form groups based on language as a response to losing their social network resulting from a high rate of student turnover. They also gravitate towards these groups as they mature due to the increasing importance of culture with age. I show that students who feel their transnational upbringing has led to a lack of exposure to their parents' home culture compensate for this lack by immersing themselves in the corresponding language-based groups. I argue that Asian students respond to processes of socialization, mobility, and blurring of boundaries by practising a form of cosmopolitanism characterized by a form of pan-Asian cultural competency and identity.

\section{Changing names, changing identities}

As discussed in Chapter 8, students from non-Anglophone backgrounds acquired EuroAmerican capital in order to integrate into the dominant school culture. Some students experienced this process of acculturation as a change of identity. Students cited name 
changing as a potent example of the process of accepting an identity change. Sometimes the students themselves initiated the name change, and sometimes it was imposed.

Jenny said that she used to go by her real name, "Hae Jin". But some of the non-Korean boys teased her by mispronouncing her name. Jenny explains, "I was in elementary school, in $6^{\text {th }}$ grade; they kept calling me [Hee Jin, Hee Jin]... intentionally, so I felt really bad." So she changed her name. Jenny laughingly explained, "I just told them I'm [Jenny] now, and they're like, 'Okay'." She had picked the name of her favourite character in a novel for herself. Another Korean student whose Korean name was "Jae Soo" went by the name "Jae (Jay)". When I asked how he got the name, he said that his $5^{\text {th }}$ grade teacher kept calling him "Jae", so he has been just "Jae" ever since.

A few female students shared similar stories. We had been sitting in the main senior hangout area one typically sunny day when a casual chat turned into an animated discussion about identity. There were two students who were Indian nationals, and were both named "Vandana". One of them joined the conversation after the rest of us had already been chatting for about half an hour. When she joined, I tried to double check with her whether I was pronouncing her name correctly, and this simple gesture triggered a discussion about the subtle ways in which the dominant culture requires its participants to assimilate.

"Vandana, is that how you pronounce..." I began to ask, as I pronounced it like I would "bandana" and stressed the second syllable.

Before I could finish my question, Vandana cut in with a firm, "Actually, no! That's a wonderful place to start! First of all, you pronounce my name Vandana." She stressed the first syllable, as it would be pronounced in Hindi.

"Vandana?" I repeated after her.

Once I pronounced it correctly, she said, "Yes, and that's...I mean, that's probably the basis of my confusion! Like, I have no idea where I come from. I honestly don't, 'cause I was born here. I've lived here my whole life, and I've gone to an international-based system...school since I was five." 
"So, kindie?" I asked.

"Huh...like prep senior, yeah, kindergarten," Vandana continued. "And when I walked into my classroom my teacher goes, 'Oh, so your name is Vandana?'” she said, as she imitated my initial pronunciation of her name. And I don't say anything! I'm like...'Yah.'" She put a blank look on her face. "That's meeee."

We all burst out laughing at her vivid narration as the other Vandana chimed in, "Oh my god, that's so true."

"Yeah, right! I knowww, like." The two Vandanas started to finish each others' sentences. They were caught up in the excitement of knowing that they could empathize with the other's experience.

"And then after that I started introducing myself as Vandana," continued the second Vandana while the first piped in to finish her own explanation, “...as, as Vandana!" Exactly! Total identity change, right there! It...it was crazy!"

Although the (mis)pronunciation of a name may appear trivial, it is symbolic of the power of the dominant culture to shape identities. As Vandana impressed upon me, even a change in the pronunciation of a name can result in an instant and "total" identity change. Both Jenny and Vandana hung out in the mainstream English-speaking groups, but even those who did not used name changes as a means to connect with the English-speaking world at TIS.

Names can serve as a gateway to another world, another fragment of a person. Daniel (Chapter 4 and 8), whose parents were Danish and American, gave an example of this when he spoke of his two Korean friends, with whom he hangs out a lot in class, but rarely outside of class. Outside of class he hangs out with the English-speaking groups while his Korean friends hang out with other Koreans. Daniel explained,

Another interesting thing is their names. I always call them [David] and [Lisa]. I've never gotten this impression that they seem to mind that. But if ever, like, "[Jeong Tak]" and "[Ye Ryun]" (their Korean names)-they sound so foreign. Those sound so foreign when I'm saying them, not the actual way they sound, but foreign to my 
tongue, that...I really don't associate it with the same person. It's like if all of a sudden I started calling [David] "[Jeong Tak]", I would have to like, meet him all over again, and it's really strange. (We both laugh.) But, 'cause I've often considered, you know, "Why do I always call him [David]?"-that's how he introduces himself to the teachers, but that's 'cause most teachers can't remember Korean names.

English names make it easier for other English-speakers to relate to Daniel's two Korean friends, but they also construct boundaries between Daniel and his friends. The Korean and English names compartmentalize the Korean-speaking and English-speaking cultural worlds that David and Lisa operate in, similar to the way Indian and American accents compartmentalized the cultural worlds that the South Asian boys operated in and demarcated the line between insiders and outsiders (Chapter 5).

Those who are not socialized into the dominant culture in the home environment can acquire the necessary cultural capital (including name changing) and learn to operate in the dominant culture. Some integrate into English-speaking groups and thus enrich the "international" appearance of these groups. The visible diversity that these students bring to the Englishspeaking groups renders the Euro-American cultural capital that they share invisible. Those who cannot or refuse to acquire the necessary cultural capital may separate themselves from the dominant English-speaking groups. This is often interpreted as ethnocentrism on the part of the non-English-speaking groups without regard for the complexity of factors that contribute to the formation of these social groups, such as the way they are constructed as a homogenized "Other".

\section{A nameless, faceless "Other"}

As discussed in the previous chapter, the students in the main English-speaking groups maintained their cultural dominance by defining who or what kind of behaviour was considered "normal", in the same way that the staff defined who was considered "international". The more normative a student's behaviour appeared, the more they were perceived and engaged with as individuals. The notion of "normal people" was reinforced through the presence of those who lie outside the norm. Those who fell outside the norm became part of a nameless, faceless Other in the eyes of students in the English-speaking 
groups.

One day, I followed the team sports class out onto the field, and was standing around watching them under the hot sun with my folded notebook in one hand. When it came time to select the team members, Oliver and Naomi, who were the team captains for the day started taking turns picking their team members. "Max," said Oliver. "Juan," said Naomi as she squinted in the sun. One by one the students went behind the team captains as their names were called out. Towards the end, only the Korean students, all of them male, were left. It was Kyu Sik, DJ (short for Dae Jeong), and Jay (short for Jae Sook). The names of the latter two had been Anglicized to make it easier for English-speakers to pronounce. But instead of calling them by their names, Naomi, hesitatingly, said, "You and...you," as she lifted both arms to point at each of the Korean students she was referring to. She could not remember even their Anglicized names and seemed slightly embarrassed about it. Kyu Sik, DJ, and Jay looked a bit unsure which one of them Naomi was referring to. "Yeah, you," Naomi added as she pointed again. While those who are part of the norm are recognized as individuals with names and personality, the "Other" becomes a nameless mass.

Naomi illustrates this point. Naomi is a Japanese national who speaks fluent English and hangs out with the English-speaking groups. She was a member of the UN Day Japanese club and she was quite vocal in criticizing the club leadership (Chapter 11). She complained that they were being insensitive towards the non-Japanese members by refusing to speak in English, the common language, and insisting on speaking in Japanese, which many of the members could not understand. In objecting to the leadership's Japanese-centric management of the club, Naomi aligned herself with the school's ideology of being "international". However, once she was outside the Japanese sub-context and in the larger context of the school, she unwittingly conformed to the Eurocentric view that marginalized the students who were not part of the English-speaking groups. Naomi was committed to engaging with difference in one situation, but reinforce cultural dominance in another. Cosmopolitan practices are situational.

This incident echoes what Jenny noted in her interview, "I don't think anybody outside the Korean group really knows the Korean[s] individually. So if one of them comes and, like, tries to hang out with the mainstream people, they would be nice and all but they wouldn't be friends." Later, I asked Fleur, a white American, and Anton, an Indonesian student who spoke English better than Indonesian, whether or not they knew the names of the Korean students. 
Fleur hardly knew any and was amazed when Anton rattled off the names of Korean students from their grade. I asked Anton why the others did not know the Korean students by name. Anton responded, "They don't try I guess."

Daniel gave a nuanced account of cultural racism. He argued that while growing up in a "third culture environment like [TIS]" would encourage people to be more "open to meeting other people and much more tolerant," it does not "cure people from having prejudices and stuff." He thought that many other factors, such as parenting, come into play in shaping our views. "I still see people who are, you know, I definitely wouldn't say racist, but prejudiced against certain people...stereotypes...," he said. Daniel then continued, "I mentioned that some of my friends happened not to really know any Koreans, but some of them, well some of the people I know at least, I feel...kinda...actually just don't want to meet them...'cause they're (i.e. the Koreans are) stereotyped as uninteresting people." The "Other" was constructed as devoid of individuality, "uninteresting", and therefore not worth knowing. For example, an alumnus I spoke to could not even remember the ESOL students from her grade even though there were many enrolled when she was a student.

The lack of interest in the "Other" hinders the development of free and easy social relations. Yoo Mi recounted that she found it difficult to make "foreign" friends when she first joined TIS as a $10^{\text {th }}$ grader. She explained (Interview, 28 April 2009),

It was frightening. I came here...I mean I had, like, blond friends when I was young, but when I first came here there was an outing (for orientation) and then I would see people with blond hair and blue eyes and I'll be like, "Oh my god. It's a foreigner there"...It was like...it was new...seem[ed] like I never been to international school before.

My English wasn't that fluent, 'cause I was spoken Korean, so my English wasn't that good, so...then...just play with my Korean friends I guess. And you know how, this school really doesn't like Koreans? You know how they, how they...the impression that Koreans always studying and...'cause Koreans never go parties, and they always study, they always good students...so the impression isn't that great.

Yoo Mi was racialized as "Korean" despite her experiences that were not typically Korean. 
Yoo Mi was born in Korea but moved to Kalimantan, a large Indonesian island, when she was five years old because her father worked for a mining company. They lived in a remote area in Kalimantan. "It was a forest. I would see orangutan," said Yoo Mi. After living there for two years, she relocated with her family to Surabaya, a large city on the densely populated island of Java, where she attended an international school. Yoo Mi did not know what "A,B,C" was but quickly learnt English and made friends who were from diverse backgrounds. Then the family repatriated to Korea where she studied at a local school from grade five to ten during which time she lost her fluency in English. These diverse experiences did not add much to her cultural capital when she moved to TIS in spite of its ideology being international. In the eyes of the dominant culture, Yoo Mi was simply "Korean".

Further, despite having had "blond friends" when she was younger, the adolescent years she spent in Korea imbued her with a sense of feeling intimidated (frightened) by westerners. Yoo Mi's perception reflects a racial construction of "white" as superior and, therefore, intimidating. Colonial discourses remain a powerful force that constructs racial imaginaries that are reinforced through contemporary global hierarchies. It perpetuates a gaze that sees the West as at once desirable and intimidating.

Yoo Mi felt that Koreans were not perceived in a positive light. She said,

(After school started) I approached some, some foreigners and I say hi blah, blah, blah but they, they didn't really welcoming 'cause I was new, and they didn't know me and I was Korean, and so...yeah. I mean, they say, "Hi", and say only...service talk, you know what I mean? Like...just like, "How's the weather"-not like deep, deep talk. So I couldn't join that group.

By "that group", Yoo Mi meant the mainstream English-speaking group(s). There was a lack of mutual intelligibility between her and students with Euro-American capital that could facilitate further connections. After two to three weeks of trying to join them, she gave up and started befriending other Korean students with whom she had a sense of mutual intelligibility.

After that, I realize that I started playing with my Korean friends, and I felt comfortable you know...how the language, it was much easier for me and...they understood me like 
how...you know how the western people don't understand, “How come you don't party and stuff," but then in Korea society (laughs), not partying [is] good.

I asked Yoo Mi to elaborate on the difference between conversing with a Korean and western student:

Asking school homework is the easiest thing...If I ask Korean friends, "Oh, what is the school homework," they tell you and they talk about other things: talk about teacher and how the other teachers that doesn't give this homework but our teacher does and blah, blah, blah...But if I go to the western people then they'll just tell me the homework, you know what I mean?...and finish that talk.

In addition to a lack of mutual intelligibility, Yoo Mi was implying that there is a lack of interest among the students in the mainstream groups towards the others, which negatively affects the flow of conversation and creates a sense of dissonance. The Other is perceived through stereotypical images. The Other is differentiated from each other by their nationality labels "Korean", "Japanese", "Indonesian", etc. Otherwise, the diversity within these groups is invisible. Cultural dominance is maintained by constructing the Other not as individuals, but as nameless, faceless, uninteresting, homogeneous groups.

\section{Invisible diversity}

The seniors who hung out in the Indonesian-speaking group during the first semester of my fieldwork were culturally and ethnically diverse. I regularly found two Filipinos, two Koreans, two Taiwanese, and a few others who were only partially of Indonesian descent in the Indonesian-speaking group. The Filipinos and one of the Korean students were not fluent in Indonesian, and admitted that they could not understand all that was said by their Indonesian friends. Nonetheless, they chose to hang out with the Indonesians. Those who were of part Indonesian decent were also part British, Japanese, or Thai. Even those who were Indonesian by nationality were of varied ethnic backgrounds. Most were ethnically Chinese, while some were native Indonesian or of Indian descent. ${ }^{74}$ Many of these students said that when they

\footnotetext{
${ }^{74}$ Most of the Indonesian nationals at TIS were of Chinese descent. Although they are a minority in Indonesia, their financial standing means many of them are better able to afford the expensive international school fees compared to the majority of the Indonesian population.
} 
were younger they hung out with peers who were of different nationalities, but their social groups changed as they got older. I discuss this later. Many factors contributed to the formation of a (diverse) Indonesian-speaking group, who just as equally use English in their conversations.

The Indonesian in-group diversity was invisible to the staff and many students from the dominant culture. A student from a high-status English-speaking group spoke of the "Indonesian" group as though it were made up exclusively of "Chindos" (i.e. ChineseIndonesians) even though when he spoke of individual members of that group, he was in fact aware that there were a handful of native Indonesians, Filipinos, Taiwanese, and Koreans. But when he thought of them as a group, their diversity became invisible. He racialized them as "Indonesian".

I pointed out to a staff member that the senior Indonesian-speaking group was also diverse. In response, she said that Indonesia was a diverse country anyway. She dismissed the diversity of the Indonesian group as nothing out of the ordinary. I said, "But it is not common to see native, Chinese, and Indian Indonesians form friendships with each other the way they do here." The effort the Indonesian-speaking students made to overcome their differences was not recognized as "international". It was simply seen as being "Indonesian". The diversity in the English-speaking group could have just as easily been dismissed as, "The United States (or the United Kingdom) is diverse anyway." But it was not. The diversity of the Indonesianspeaking group was second-class because it did not conform to the school's ideology of being "international", which emphasized racial diversity and Euro-American capital.

\section{Creating home turf}

Linguistic and culturally based groups that were separate from the English-speaking groups provided protection from dissonance for those who did not have Euro-American capital. For those who do not have the necessary cultural capital (e.g. speaking fluent English or a western bodily hexis), the Korean- and Japanese-speaking groups provide some degree of shelter from the discomfort of having to engage with the dominant culture. 


\section{"English infested society"}

Dong Gun, as previously mentioned, floated from group to group instead of being entrenched in the Korean speaking groups. But Dong Gun spoke at great length defending his Korean peers' choice to remain within the Korean-speaking groups.

"So it's natural and it feels more comfortable for Koreans to just be with Koreans in an English infested society, I guess, in [TIS]," Dong Gun chuckled at his own choice of the word "infested". He then continued to explain why the Korean students liked to hang out with other Koreans. "They try to survive, live through the day. They need it because they just need to belong somewhere. And if it's not with their culture, then with who, right? But the teachers who always argue that this is an international school, you have to speak English, you have to get along with the people. I mean, that's ideal, but Koreans are, what can you do when one doesn't feel comfortable in that way? So I feel very sad and sorry for the Koreans....because they're always getting the teachers' fingers pointing at them" (Interview, 20 April 2009). Dong Gun's comments suggest that some Korean students experience the dissonance due to their lack of fluency in English. Others are fluent in English, but their cultural capital is not sufficient for them to feel a sense of belonging within the larger school community due to a lack of mutual intelligibility.

David (Jeong Tak) described Koreans as "family". David had been at TIS since primary school, was fluent in English, and said that he used to have "international" friends. Even then he hung out almost exclusively with Koreans as he progressed through school. David says, "It's like all the Koreans are my family." He claimed to feel "way closer to Korean people." I argue that the sense of closeness is derived from a sense of mutual intelligibility of experiences that he shares with other Korean young people at TIS.

In Chapter 8, I explained that marginal English-speaking students remained marginal because they were unable to mobilize their social capital to form groups. Unlike the marginal Englishspeaking students, Korean students formed groups with clear linguistic boundaries that were separate from the dominant English-speaking groups. Like the South Asian boys in Chapter 5, choosing to speak in Korean enabled Korean students to reclaim the power to draw the boundaries between insider and outsider, and thereby position themselves as insiders. Although they were marginal vis-à-vis the dominant school culture, at least within these 


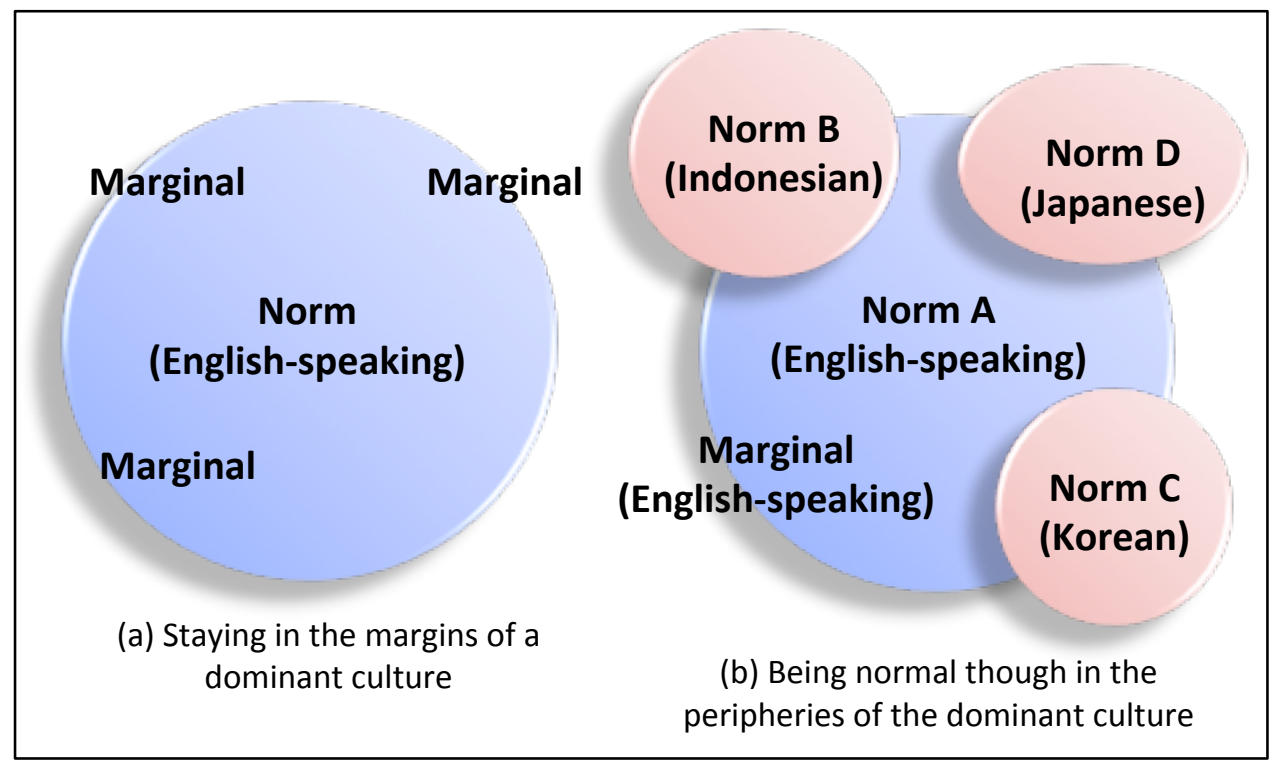

Figure 5: Creating home turf. (The diagram is not representative of relative group sizes.)

As in the diagram, I show in the next section that the situation was similar for the Japanesespeaking groups.

From cultural hybrid to becoming "Japanese"

Koichi or Shirasu-kun ${ }^{75}$, as he was commonly called by his Japanese peers, found that moving from the Japanese school to TIS negatively affected his social status. Koichi claimed that he used to be a central or popular figure among his schoolmates back at the Japanese school. His friends corroborated this claim. Moreover, Koichi was a cultural hybrid, but his hybridity was not recognized as being "international" at TIS since he hung out almost exclusively in the Japanese hangout area. Although both of his parents are Japanese, his family moved to Indonesia when he was in grade two and he grew up mostly in Indonesia. He was a native speaker of Japanese and near-native speaker of Indonesian. I have reproduced an extract of my interview with Koichi in the original languages accompanied by an English translation to make visible his hybridity to the reader. The part written in the English alphabet is in Indonesian and the other parts are in Japanese. Koichi switched between the two with ease in explaining how he learnt Indonesian at the Japanese school in Jakarta (Interview, 1 April 2009).

\footnotetext{
${ }^{75}$ It is common in Japan to use surnames or given names followed by kun to refer to someone, usually male or younger.
} 
Koichi:

俺の友達でも、俺より長いやつとか俺よりもできないやつもいるんだろうと思 うんだけど。(Even among my friends, I'm sure there are guys who have [lived here] longer than I have but can't speak as well as I can.)

DT: Kenapa? Kok bisa? (Why? How come?)

KOICHI:

インドネシア語ってこう、なんか面白いなって、「こういう風に色んなことが

あるんだ」って。で、だんだん興味持ち始めて、、、だから、[ケンジ]

みたいにインドネシア語話せるとこにも入っていくわけ、自分自ら、わかんな いけど最初は言葉、こいつは何言ってんの?って言って、、、(So, I thought, Indonesian is kinda interesting, like, "Oh, so it's got all sorts of stuff like this." And I gradually got interested...So, I actively, by my own choice, joined those who could speak Indonesian, like [Kenji]. I couldn't understand the language at first. It was like, "What's he saying?")

DT: Apa, maksudnya di sekolah, apa...? (Huh? You mean at school or...?)

KOICHI: ...Maksudnya di sekolah, and teman...Indonesia ngomong-ngomong...Ini tuch pikir, ini kayak bagus...belum keluar (kata-katanya) juga mau ngomong, gitu...Ya gitu, jadi, “Ini ngomong apa?" Jadi tanya-tanya. "Ini apa? Ini apa? Ini apa?” Gitu. それで、こういう意味だよ、こういう意味だよって言って、Oh, gitu, gini, gini. Ya udah...面白くなって。 (...I mean at school, and my Indonesian ...friends were chatting. I thought, this seems cool...so I couldn't say anything, but I wanted to talk. Yeah, that's how. So it was, "What are you saying?" So I kept asking. "What's this? What's this? What's this?" Like that. So then, [they] would say, "This is what it means. This is what it means." "Oh, is that right? Like this, like this." So yeah, I got interested.)

Koichi explained that he also learnt Indonesian from the maid and driver who worked for his family. ${ }^{76}$ He got along well with the maid when he was a child and learnt Indonesian so he could play with her as she spoke no Japanese. "I probably ended up like this because I spoke

\footnotetext{
${ }^{76}$ Expatriate families typically either employed a maid, driver, and sometimes gardener and/or security guard using their own salaries or were provided with one by their companies. TIS students often learnt Indonesian through these employees, particulary the maid and driver.
} 
Indonesian thinking that it's really fun to speak it," Koichi added in Japanese. Learning Indonesian was "fun". At the Japanese school, being Japanese meant that Koichi was part of the dominant culture and therefore positionally higher than his mixed Japanese-Indonesian schoolmates, making it easier for him to join them. Similarly, he was positionally higher than his adult Indonesian maid and driver in terms of both cultural and class hierarchies. He was also still young and impressionable.

At TIS, Koichi's social circle extended from the Japanese group to the Indonesian group. His interest in Indonesia and fluency in Indonesian was unusual for a Japanese who, according to the regional cultural hierarchy that reflects the economic structure, are positionally higher than Indonesians and generally not interested in Indonesia. Even the way he sat sometimes betrayed his Indonesian upbringing. Indonesians were interested in befriending him. Neither did he seem to have problems talking to Koreans, in fact he said he had dated one before. Koichi said he used to hang out in the Indonesian student hangout area when his older Japanese classmates all graduated together and the Japanese hangout area was left empty. But by the time I met Koichi in his senior year, Koichi's recess time was spent mostly at the Japanese hangout area while his Indonesian-speaking friends regularly visited him there and stayed to chat with him. The most regular of the these visitor friends were a Chinese Indonesian, a mixed Japanese-Indonesian, and a Korean and a Taiwanese who had grown up mostly in Indonesia. Koichi engaged with those who were different on a regular basis, but his cosmopolitan practice was not visible to the teachers and administrators because he did not engage with the "western" students. Inter-group interaction among the non-mainstream groups was common. However, these cosmopolitan practises remained largely unrecognized.

Although he was a dominant figure within the Japanese-speaking group, Koichi was not a popular figure within the school at large due to his lack of Euro-American cultural capital. Koichi confessed that he wished he could join the English-speaking groups, which he referred to as the "westerners" as he pointed towards the main senior hangout area:

KOICHI: I do want to join them. It's probably really fun to be friends with them all, I do think that. But there's still, like, a part of me that just can't go. It's because...it's sort of, like, umm...maybe there is still, like, a language barrier, maybe? I haven't tried, but I guess, to be honest about it, I still feel insecure about whether or not I have the English ability to keep up with the kind of conversations that Americans have. So, it's 
like, it's really hard to...break into that group, I guess.

DT: So, you can't join, but you also have a desire to join?

KOICHI: Yeah, I do, I do.

DT: Is it quite strong?

KOICHI: Well, I guess, quite...they look like fun, and I've got a few friends there. So...if my friends are there, I'Il drop by and stuff. When I watch the other friends talk, I think, yeah, it seems nice. I think, you know, it would be kind of cool to be among these western friends and kind of like, "Hey look, I'm the only Japanese person with them" (laughs)...but yeah, there's a part of me that just can't go there.

And it's like, I've got a normal life here (pointing to the Japanese hangout area that we were sitting in), so I guess I'm not in a desperate place. Yeah, I'm not desperate. So...it's like, I've got enough friends even without having to go there. On the one hand, there's a part of me that's, like, [trying to tell myself that] if I wanted to go there, I can go; and on the other hand, there's a part of me that wishes I could be someone who is able to go to that [hangout area] as well as this [hangout area]. But in a way, I'm not that desperate, so I probably don't try hard enough. ${ }^{77}$

As Koichi spoke of his desire to join the English-speaking groups, he gazed towards their hangout area in the same manner that I saw a few others-Korean-speaking, Indonesianspeaking and low-status English-speaking students-gaze at those groups. Their gaze carried a sense of longing for something unattainable. In Koichi's eyes these groups became "western", even "American", in the same way that he became "Japanese" in their eyes.

Those without Euro-American capital perceived being "international" as being "western" or "American". Similarly, students in the English-speaking groups and staff perceived the cosmopolitan practices of Asian students as being "Korean", "Indonesian", or "Japanese". Despite his desire, Koichi felt unable to join them because he feared marginalization. He thus remained within the Japanese group where his cultural capital enabled him to feel as though

\footnotetext{
${ }^{77}$ Translated mainly from Japanese.
} 
he belonged. Even though he was interculturally competent and practised cosmopolitanism with other Asian students, Koichi became Japanese at TIS. However, fear of marginalization was not the only reason students hung out in non-English-speaking groups. Neither were these groupings static. Language-based groups became more and more distinct as students got older, as I show in the next section.

\section{Changing friendship circles with age}

Asian students, particularly those who had been at TIS since primary school, noted a distinct pattern of change in student interaction whereby cultural background mattered more as they progressed from primary to middle to high school. In primary school, they interacted regardless of cultural background. In middle school there was a vague sense, at least retrospectively, that Asian students hung out more with other Asian students and western students with other western students. By high school, students groups became more distinctly based on nationality or language. Patterns of friendship change because having a sense of mutual intelligibility becomes increasingly important with age. It is also a result of student mobility as I will later explain.

Kumar joined TIS in the $3^{\text {rd }}$ grade and initially struggled due to his inability to speak English. But he remembered being friends with children of various cultural backgrounds. As he progressed to middle school, he was mostly friends with other Indian students but still retained friendships with non-Indian students. By the time I met him in his junior year of high school, he hung out almost exclusively with other Indian students.

David (Jeong Tak), who is Korean, had been at TIS since grade two and tells a similar story.

In middle school it's international kids that I was friends with. Well, I had friends from my ethnicity, but the ones that I usually hang out with. They were much less Korean. So it was really hard for me to have Korean friend or befriend with Korean because in middle school, it was so tiny per cent of the students...the level of Korean...the number of Korean. In middle school, I kinda have half American friends...not American, but international friends, and half Korean friends. Now in high school, it's like eighty precent Korean friends. 
By "international", David meant non-Koreans. Even though he found it hard to befriend Koreans when he was younger, he ended up hanging out with Koreans in high school.

Yun Shin, or Sam as he was known among non-Koreans, followed a similar trajectory in that he had more "international" friends when he was younger, but hung out mostly with Koreans by the time I met him. Sam had lived outside Korea since he was six weeks old. Initially he lived in Jakarta and attended a Korean school until the 1998 riots forced him to relocate temporarily when he was in $3^{\text {rd }}$ grade. He went with his mother to Brisbane, Australia where he attended a local school and learnt English. A year later he moved back to Indonesia to attend TIS. Sam had a transnational upbringing, but he hung out almost exclusively with other Korean students.

Sam cited mobility as one of the reasons that affected the changes in his friendship circles. Even for those who stayed at one international school, mobility featured significantly in their lives. Sometimes all their friends left at the same time, leading them to lose their whole social network with the turn of a single academic year. As his non-Korean friends left, Sam was unable to replace them with other non-Koreans. He eventually hung out more and more with other Koreans: "People come and go, come and go, most people are like that. All my Korean friends are quite stable here, so I have them as very stable friends." I suggest that as he grew older, it became easier for Sam to maintain friendships with other Koreans than to make new friends among non-Korean students because cultural capital weighs in more on relationships as a teen than as young child.

Another Korean, Seung Gi, makes this point more explicit. Seung Gi similarly cited mobility as a reason for the changes in his friendship circles. Seung Gi had friends of many different nationalities and, like Dong Gun, I often saw him shuttle among different groups of friends. However, he hung out mostly in the group labelled "Indonesian" as a senior. Unlike Sam, he preferred to hang out with Indonesians instead of Koreans despite being only able to understand 70 per cent of what was said when his friends spoke in Indonesian. Seung Gi used to have more "international" friends when he was younger. Many of them came and went. As he became older, Seung Gi found it increasingly difficult to befriend the new "international" (which was often conflated with "western") students and thus ended up hanging out mostly with the Indonesian students. He found that he could not "connect (nggak nyambung)" with the newcomers. As he grew older, not only did his social capital to access the "international" 
group diminish, but also he was unable to cultivate the Euro-American cultural capital necessary to relate to the incoming western students. Having a sense of mutual intelligibility with friends is more important as a teen than it is as a young child. As for his preference for hanging out with the Indonesian students over the Korean students, Seung Gi cited financial reasons-his family was generally better off than the other Korean families. Social, cultural, and economic capital all intersected to affect Seung Gi's friendships.

Ben, whose Korean name is Hyun Bin, moved from Korea to Canada, then back to Korea before moving to England, and then Indonesia. In Indonesia, he already had pre-existing family friends from the Korean community that helped him make friends among the Koreans at TIS when he joined in $9^{\text {th }}$ grade.

BEN: I have family friends here who are Korean. I hang out with them. I was automatically [in] the Korean group. I had several friends, because my dad would travel Indonesia and then Korea, Indonesia, Korea...Sometimes brings friends from Indonesia and they were Koreans here, in [TIS]. So we become very good friends.

DANAU: So you mean you knew them from before?

BEN: Yeah. Since, like, seven years old.

Ben's social capital facilitated his friendships with other Korean students. Ben reckons they were "welcoming" because they knew what it was like to be new at the school. "Yeah, cause they were all like...some time in their life they have...they came here, right? So they know how it feels to first come to see the different groups and stuff. So they were really welcoming and stuff."

Ben was one of the most westernized among the Korean seniors, but still he felt that a lack of social and cultural capital made it difficult for him to befriend the students in the Englishspeaking groups. Ben explained,

I don't have really many western friends because I wasn't here in middle school, elementary school. It's [Korean] people from middle school and elementary school have much more western friends...'Cause in elementary school, like, there's no cultural 
difference because they're so young and stuff. Even middle school, it's less...division. But as you go to high school, there's such a strict and vivid division...between cultures. It's so hard to make foreign friends. Like, if they're not in your class, it's like, almost impossible to just go up to them... and it's kind of like intruder...Like, western [hangout area], Korean guy...going in... just random [Korean] guy walking in...and talking to a random [western] person-it's kind of weird. But if I have a purpose, that kind of thing...[then] I can just talk to them.

Students were generally amicable to each other, and felt able to approach individuals in other groups if they had a specific purpose to do so (e.g. ask a classmate about homework). However, they found it difficult to just go and "hang out" in another group.

As Ben suggested, many of the students who had been at TIS since elementary or middle school used to be good friends with students who were, by high school, hanging out in different language-based groups. Students in all the major groups and who had been at TIS since elementary school agreed on this. The groups had distinct boundaries in high school, but the friendship trajectories that students had taken indicated that most of them used to practise cosmopolitanism according to the school's ideology being "international", i.e. friends with people across racial, cultural, and linguistic differences. As they grew older, however, social and cultural capital grew in influence over their sense of mutual intelligibility with each other, thus affecting their ability to maintain or make new friendships across these differences.

Initially, Ben wondered why students seemed to form the distinct groups, and attributed it to the different future trajectories they would be taking.

I kind of see why now. But when I first came here, I didn't quite see why [laughs]. I heard that in middle school it's better there. They would mix easily...more. But in high school, I don't see why people would divide up, that kind of stuff. But now I see, because what their ultimate goal, like, university and that kind of stuff, is different-how they study, like their parents and stuff-is different. So they wouldn't really get along [with] forei...other people.

According to Ben, their different home environment and their future plans for after they graduate influenced their choice of friends. This argument appears to run contrary to the fact 
that many students were interested in studying in the U.S. or U.K., including Koreans regardless of their cultural background. I argue, however, that while their destinations for university may be similar, the path they take to get there and their projected life trajectory after university are affected by their family culture, finances, and country of passport, which I discussed in Chapter 7.

Both those who stayed and moved found that their social, cultural, and economic capital had a greater influence on their ability to make friends with various groups of transnational youth as they grew older. Even among the high school students I observed, the boundaries based on language were more pronounced among the $12^{\text {th }}$ grade than $9^{\text {th }}$ grade students. In contrast, the cliques within the language-based groups diminished as they matured and popularity within the groups mattered less. It is too simplistic to dismiss the existence of non-Anglophone groups at the school as the result of "self-segregation" and failure to practise cosmopolitanism. Various factors intersect to influence the formation of these groups.

Significantly, it was mainly Asian students who cited the pattern. In contrast, students from English-speaking group(s), regardless of how long they had been at TIS, were mostly unaware of the pattern. Due to their dominant position, the English-speaking groups on campus were rarely aware that they were in a group that shared a sense of mutual intelligibility because it was perceived as normal as I argued in Chapter 8.

\section{Missing being “Korean”}

In addition to the impact of mobility, students commonly cited the transnationality of their upbringing as the very reason for being drawn to their Korean peers. All four Korean students mentioned above spent a considerable time, if not their whole lives, outside Korea. They are multilingual, have a "natural" command of English and, in most cases, are able to write better in English than in Korean, though some are more comfortable speaking Korean than English. However, apart from Seung Gi, who hung out with Indonesians, they (David, Sam, and Ben) claimed that they hung out with other Koreans at TIS precisely because they had limited experience with Korea and had a desire to know their parents' country. Some had no friends in Korea (not surprising, given that they had not been living there). However, each imagined Korea in a slightly different way that was reflected in their practise of cosmopolitanism. 
Imagining "Korea"

For Ben, who had extensive transnational experiences, hanging out with Koreans at TIS was a new experience. He had left Korea for Canada during primary school and spent grades 5 and 6 in a Canadian town at a school with only three Asian students-himself, his younger brother and a Canadian-born Chinese. He had gone to Canada on a study abroad program organized by his school in Korea. Ben and his brother home-stayed with a Canadian family during that time. He then returned to Korea for $7^{\text {th }}$ grade before moving to England to study at a boarding school. This time, his brother stayed behind in Korea and Ben was one of two Koreans at the school. Ben prefers to speak Korean as he can "express more feelings" in Korean than English, but he speaks English fluently with an accent that sounds mildly American.

During my fieldwork, however, I noticed that he hung out mostly with the Korean students. When I asked him whether he missed hanging out with non-Koreans, since he had spent some time almost exclusively with non-Koreans while in Canada and England, he responded:

But like, I had that experience so I like kind of having this experience (i.e. hanging out with Koreans) now. So when I go to college, I'll have a different experience. It's okay with me...It's a chance for me to have that experience.

But the bad thing is, since I have to move around so much, like, when I was about to get so close to the friends there as friends... When I made that kind of friends, I had to leave. It kinda...it's hard for me to leave those kinds of people and then settle in a new environment. But...yeah... that's kind of [the] bad part of it. But I can just contact them with MSN or...it's okay, yeah.

Ben only spoke in passing about his difficulty in leaving friends behind. But his experiences echo the existing research on Third Culture Kids. They learn to cope with repeated loss of friendships and social networks due to mobility, but these losses can lead to a sense of unresolved grief that resurfaces later in life (Pollock \& Van Reken, 2009[2001]).

Meanwhile, David spoke of Korea with a sense of longing for the "home" that has never been, apart from temporary visits home (Baldassar, 2001). He was a senior and said he would most likely go to Korea rather than the United States (his other choice) for university, partly due to 
the lower tuition fees in Korea and partly because he had missed out on living in Korea.

Since I've been overseas for a long time, I would like to go back to Korea, stay there, live there, work there, be educated there, and...For now, I don't really wanna travel around the world. I just want to stay and live in Korea. That's my home, so I just wanna...I've been away from home for such a long time, so I wanna go back and live there...That's home. I think I have enough international overseas experiences. And I have barely, you know, Korean experience...experience in Korea. Maybe, like, twenty years later I'll get sick of Korea and wanna live overseas, but for now I wanna stay...I really feel that I'm secluded from the "Korean experience" (he makes quotation marks in the air), like...that I was... that I'm kind of missing the Korean experience that normal Korean people should have. So yeah, I wanna go back to Korea.

David makes frequent references to Korea as "home" and his strong desire to return as he spoke to me in fluent English. His parents had played a major role in influencing his identity and orientating him towards Korea, as I discussed in Chapter 7.

It was common among transnational youth who had lived overseas for most of their lives to be curious about, and even infatuated with their parents' country precisely because they had very limited experience of living there. Furthermore, David's (as well as Sam's and Ben's below) desire to immerse himself in the lives of his Korean peers echoes an identity development stage common to migrant children as well as Third Culture Kids when they seek out a "reference group" with whom they share a sense of mutual intelligibility (see Schaetti, 2000).

\section{Using Korean "roots" to build international "routes"}

Sam claims that he hangs out with other Koreans because he wants to retain his connection to Korea. Sam articulates his interest in Korea as a need to know his "roots". Sam speaks English fluently, though his accent is not as native sounding as David's. He says that he hung out mostly with Koreans even in middle school and cites language retention as one reason.

SAM: 'Cause it's, well I...I didn't want my Korean...to forget my Korean. Nowadays my relatives say that my Korean is pretty good, but still it's shaky. 'Cause if I speak Korean, it seems fluent and all but-no pronunciation issue-but, yeah, some of the hard, like, 
words...yeah

DANAU: Why is Korean important to you? Like, speaking Korean?

SAM: It's a root. It's like, wherever I go, I won't be considered as...like, even though how good I am in English and all, my root is from Korea so I don't wanna lose that. 'Cause I've seen people get like... like, who miss their countries. I've also seen people who don't actually know how to speak Korean but they're Korean. So I don't, I don't want that to happen. 'Cause...I like my relatives (laughs). I wanna speak with my relatives.

Maintaining connection with relatives through language retention is important for Sam in establishing roots. This corroborates the TCK literature that argues that transnational youth find "home" in relationships (Pollock \& Van Reken, 2009[2001]). However, Sam said he did not mind changing his Korean passport to an American one if it meant he could avoid the compulsory Korean army service. For him, identity was not about nationality.

Sam believed that knowing his Korean "roots" enhanced his ability to be "international". The two are mutually constitutive because he became more aware that he was Korean when he was in an "international" space. This struck home for him when he joined a summer school program run by one of the top high schools in the United States which drew students from a diverse array of countries.

There were like people from all around the countries with like different accents, different sound talking, different faces, speaking and all. I think it was great, really great fun...People say if you live in foreign countries, they say if you go somewhere that is very international, people say that you become an international person. But I think it's more different. You actually become an international person, but your origin actually becomes stronger 'cause the fact that, the fact that...oh, how should I say...You seem to know that you are a Korean more in international society...It seems that you represent, 'cause you're in international place, in different countries, it seems...you represent more...

It's not that you lose your roots, but you become more aware of it. But at the same time you are becoming international...The fact that you are Korean speaking English, you still can speak Korean and you're speaking English, and then you are...intermingling with 
other countries -1 think that's what makes it international rather than a person who's actually born in foreign countries.

"A person who's born in foreign countries" is a reference to, for example, Korean Americans who are born and raised in the United States and can speak English but not Korean. In Sam's view, "they're just American" and "that's not showing diversity, that's showing America."

Sam articulates becoming "an international person" in terms of bilingualism and biculturalism whereby one has the ability to mediate between cultures. In order to do this, one needs to know their "root" or "basic" identity, and English is useful in so far as it is a tool to communicate that "root" with others, as opposed to it (English) becoming part of one's identity. Sam said, "you can share your basics to other countries in English so that, I think that's what international means." Sam's belief that he needs to speak Korean to be Korean and to establish Korean roots to become international appears to contradict research that argues that linguistic ability is not requisite for claims to identity (e.g. Ang, 2001). In light of Hall's (1996b, p. 4) words that it is "not the so-called return to roots but a coming-to-terms-with our 'routes'," it would appear as though Sam is unable to come to terms with his "routes".

However, I suggest that Sam, like David and Ben (in the previous and next sections), was critiquing the school's ideology of being "international", which did not acknowledge alternative practices of cosmopolitanism. Korean students were well aware of the way members of the dominant culture at TIS perceived them as deviating from the school's model of an ideal student who was "international". The dominant ideology made the cultural sameness shared by the English-speaking groups invisible, while it celebrated physical diversity. In contrast, for Sam intercultural interaction occurs in the presence of difference where difference is defined based on language as opposed to physical attributes such as "race" or ethnicity. Sam was arguing for a different way of practising cosmopolitanism-becoming international by first becoming Korean to make up for his transnational upbringing. For Sam, becoming "Korean" is mutually constitutive with becoming "international".

\section{Becoming "international" by becoming "Asian"}

Young people who experience a sense of ambivalence in transnational spaces negotiate 
cultural boundaries through varied practices of cosmopolitanism. In this section, I emphasize that becoming "western" and becoming "Asian" are mutually constitutive with each other for transnational youth of Asian descent. Asian students who did not hang out in the mainstream and high-status English-speaking groups but were more westernized than the other Asian peers they hung out with expressed greater identification with being "Asian", as contradictory as this may seem.

Ben explained that the reason his Korean friends do not hang out with the English-speaking groups is because they do not understand their culture, such as the practice of "egging" and "how they party" and "prom and that kind of stuff". Indeed, despite the large number of Koreans, only a handful attended the prom that year. However, because Ben feels " 40 per cent western and 60 per cent Korean," he is sympathetic to the various practices of western teenagers. As mentioned before, Ben appeared to me to be one of the most westernized senior Korean students. Even then, he had difficulty befriending the "western" students in the English-speaking groups.

In contrast, Ben described a sense of affinity with other Asians, in which the cultural boundaries are blurred. I asked him whether he also found it difficult to approach the Indonesian group. "Indo, ${ }^{78}$ I'm fine," Ben answered immediately and assertively. Then he continued,

BEN: There's like more...I don't know...I think it's easier to go into Indo group. 'Cause, like, it's still Asian...And their culture is a little bit more similar to ours than the western[ers]

DANAU: Do you know more Indo people?

BEN: Actually, I don't really know them much...But I have friends who are Indo, and friends who are Cantonese and...Italian. But people who are western, like Englishspeaking countries, it's harder to make friends with since they have their own group and stuff. I don't know. Even Italians...have different cultures from like States, and like English, and so it's easier to hang out with Italians. That's how I find it. I don't know why...still...

\footnotetext{
${ }^{78}$ Short for "Indonesian".
} 
Ben acknowledges the western influence on his cultural identity. His experiences in Canada and England had blurred the boundaries between Koreans and other minorities in Anglophone spaces. His sense of "we" includes other Asians and even Italians, and he considers those who are "western", i.e. students in the English-speaking groups, as "them". Ben is uneasy about not being able to define the boundaries of being "Asian", especially once he began to explain that he can also relate to Italians. This is because he becomes "Asian" through the sense of mutual intelligibility that comes with the shared the experience of being a minority in Anglophone spaces. Being "Asian” facilitates Ben's cosmopolitan engagement with others.

At TIS, Asian students seemed to share a sense of being "Asian" that was subsumed under the students' more specific national or ethnic identities. Yae's interview contained slippages between being "Japanese" and being "Asian". Yae, a recent graduate of TIS, was one of the few Japanese who had no qualms throwing in English words into her speech while speaking in Japanese. She was born in Japan from where she moved to Thailand, then back to Japan, before moving again to the Philippines, Malaysia, and then Indonesia where she finished high school. In Chapter 7, I discussed Yae's predicament with regards to her future. Her parents wanted her to attend university in Japan, her passport country, to establish her identity as a Japanese and ensure that she would not end up in a liminal cultural space. Yae agreed with this, but in explaining her reasons for returning to Japan, she conflated being "Japanese" with being "Asian".

For one thing, I don't have a feel for what is common sense (jyoshiki) in Japan because I've lived in Southeast Asia for so long. And my Japanese is nowhere near perfect...They (her parents) said I'm lacking in my Japanese identity. I got told, "You just don't have it in you. And it's not like you speak perfect English either." I totally agree with them, as much as I hated having to admit that. But, yeah, at the end of the day, I am more Japanese, [more] Asian after all. I'm Japanese, and up until now I've always hung around Asians. I am Asian after all. But I am lacking in my [knowledge] of history and jyoshiki as a Japanese.

Besides, she says, "Japan is fun, and it feels safe" and even if she did go to the U.S., "I probably would have ended up hanging out with Asians anyway." To capitalize on and consolidate her Asian identity, Yae feels the need to become more knowledgeable in Japanese history and 
competent in performing and understanding Japaneseness or "jyoshiki". Yae conflated being "Japanese" with being "Asian". She gives her tendency to have Asian friends as evidence of being "Asian after all." Yae's conflation of becoming "Japanese" with becoming "Asian" reflects the sense of ambivalence inherent in hybrid identities. Being "Asian" is an expression of her cosmopolitan engagement with others.

Becoming "Asian" suggests a sense of mutual intelligibility among Asian youth who have a transnational upbringing and share the experience of not being part of the dominant culture of a Euro-American transnational space. It is an expression of cosmopolitanism in the same way that the being "international" represents an ideological expression for the cosmopolitan practice that emerge out of the sense of mutual intelligibility shared among transnational youth with a certain degree of Euro-American capital.

\section{Conclusion}

Cosmopolitan practises are situational. In order to participate in cosmopolitan practices that conform to the school's ideology of being "international", students acquired Euro-American capital and accepted an identity change. Students who were unable or unwilling to do this were constructed as a nameless, racialized Other, making their cosmopolitan practices invisible. Although cosmopolitan practices which privilege Euro-American capital were conceived as being "international" by those who were able to participate in these practices, these same practices were conceived as being "western" or "American" by those who were unable to integrate into the dominant school culture. In turn, cosmopolitan practices that deviated from the school's ideology of being "international" were invisible to the dominant culture and conceived as being "Korean", "Japanese", or "Indonesian". Whether or not cosmopolitan practises are recognized as such depends on how difference is defined.

At TIS, Korean-, Japanese-, and Indonesian-speaking students chose to hang out in their language groups because they felt they could "connect" better with their peers and escape feeling marginalized. By creating separate groups, they went from being nameless to being the norm within these groups. The use of languages different from that used by the dominant group enabled them construct boundaries between insider and outsider, and in the process reclaim their status as insider, and the power to be gatekeepers. 
Some of the Asian students who were more westernized than their peers in the language groups articulated an ambiguous sense of being "Asian". Their sense of hybridity caused their identifications to slip between being Korean or Japanese and being Asian. Asian students shared a sense of mutual intelligibility as minorities within an Anglophone space. Being "Asian" is an expression of cosmopolitan practices that privilege Asian cultural capital in the same way that being "western" or "international" is an expression of cosmopolitan practices that privilege Euro-American capital. Being "Asian" facilitated alternative forms of cosmopolitanism. The next chapter continues to discuss the dominance of Euro-American capital in transnational spaces by focusing on (hetero)sexual attraction among transnational youth. 


\section{Chapter 10}

\section{Cosmopolitanizing intimate desire}

Intimate relations are apropos sites for exploring cosmopolitan engagement. They expose the intersections of race, class, and gender within prescribed social structures. Intimate relations blur social boundaries by transgressing them, while at the same time highlighting the boundaries as they are transgressed (Stoler, 1992). With a focus on heterosexual relations, ${ }^{79}$ । argue that colonial and capitalist discourses of sexual desirability and patterns of intimate relations outside the school gates privilege Euro-American capital and influence the perceptions of transnational youth regarding who they are attracted to and who they think is attracted to them. Discourses about sexual desirability affected social dynamics among students at TIS, which in turn was projected unto their cosmopolitan practices to reinforce the school's ideology of being "international”, which privileges Euro-American capital.

In this chapter, I begin by discussing the ways in which those with a transnational upbringing, both young people at TIS as well as young adults outside of TIS, racialized their discussions of sexual attraction as they consider various factors for a potential partner. Gender and cultural capital influence their openness to marrying outside their own ethnic groups. For some, whiteness in a partner is ideal while others shun it. Indonesian-speaking students took this a step further. They used their wealth to challenge the dominant status of "the West" at TIS by drawing on nationalistic, discourses of being "Indonesian", thus emphasizing my point that the national and transnational are mutually constitutive. Transnational youth and adults are conscious of the prevailing stereotypes about interracial couples. I show that relations between expatriate men and Indonesian women bring these discourses into relief. Some transnational youth and adults discussed how they avoid or are subjected to stereotyping. The ways in which transnational youth and adults articulate their own and others' sexual desirability and attitudes towards intimate relations demonstrate that their cosmopolitan engagement with the Other is embedded within existing social hierarchies.

\footnotetext{
${ }^{79}$ Data on other relations were insufficient.
} 


\section{Racializing beauty and attraction}

Transnational youth form perceptions of beauty and preferences regarding partners by drawing on the discourses that shape the social structures around them. Many racialize beauty and attraction by drawing on discourses of being "international", whiteness, and/or nationalism. This racialization is expressed either as desire for whiteness or rejection of whiteness. The data on South Asian students illustrate that the desire for whiteness influences them to perceive "white" as beautiful and natural. In turn, the data on Japanese students illustrate that their linguistic capital (or lack thereof) influences whether or not they reject whiteness in partners (Meerwald, 2002).

Indian girls like white guys, Indian boys like white girls

A group of male South Asian students made explicit their views on the desirability of whiteness. One day I was in the cafeteria chatting with Mandeep and his friends during one of their free periods. They were all male and South Asian. I spoke to about four of them, though not all four were present throughout the conversation. They were part of a usually larger group of six or seven male South Asian students. We talked about the opposite sex, partly because I directed the conversation towards that topic based on what I had seen the previous day when I attended a meeting of the Indian club. Devraj, the president of the club and a wellbuilt and handsome-looking senior, spoke to the group about the dance performance they were preparing to showcase on United Nations Day. The club members were made up mostly of students of South Asian descent, of various nationalities, with a few who were not of South Asian descent. As he spoke from behind the podium, Devraj switched accents depending on with whom in the audience he was engaging. I had noticed that there were not that many male students in the comparatively large club of about forty students. The senior boys in the front rows stood out. Most of them, including Mandeep, were good friends with Devraj, and were clearly physically more mature and better built than their younger counterparts. They carried a presence that comes with being atop the age and gender pecking order among a cohort of young people. They also seemed to attract the attention of a fair few of the younger female students.

I said to them, "There was what, eight to ten senior boys and a gazillion girls? Man, yesterday I wished I was a senior Indian boy!" I was suggesting that they may have been the centre of 
female attention, and they laughed as though feeling a little complimented. But they reckoned that it did not make a difference. Some said that they were interested in white girls, others in Indian girls or both. "But not the Indian girls at this school," said Devraj. Jagad explained that the "Indian girls are just full of themselves. They think they're all so beautiful." This seemed odd to me given that in my eyes some of the Indian girls were beautiful. But according to them, the Indian girls think they are as beautiful as the white girls, when in reality they are not. Jagad added that the white girls are more modest in their attitude.

Jagad continued to expound his view. Indian girls change to become someone else. They change their clothes, and they try to speak in a different accent. They think they are attractive, but they are not. They are not themselves. They are actually insulting themselves. Puzzled, I asked for examples. Jagad hesitated, and then named Ravi, who he said had completely changed since last year. Jagad felt uneasy and clarified that he was not trying to gossip about Ravi. He then offered Vandana as a contrasting example. I had noticed that while Ravi hung out with her Southeast Asian friends, Vandana was fully integrated into the mainstream English-speaking groups. Jagad felt that Vandana was being herself. She has been the way she is now for a long time. But Ravi tries to act different. At this point Akshat (the only one in the group who spoke with a distinct Indian accent) interjected with an explanation, "Like, he (pointing at Jagad) makes fun of my accent and I'm completely fine with it." Jagad then resumed his explanation saying that the only thing that has changed about Ravi is her clothes.

Like them, I had noticed the change in the way Ravi dressed during my year at TIS, but I had seen it as something positive. She had started to wear clothes that were more "feminine". While they did not comfortably fit her still somewhat bony frame, I had perceived it as a sign of her maturing and becoming more "womanly" in her still young, girly way. But Jagad and Akshat were digging at something else.

While Vandana's westernized disposition had been cultivated since she was young (she joined TIS when she was five years old), Ravi was only now trying to cultivate this by changing the way she dressed and spoke (i.e. accent). There was no significant difference between the way Vandana dressed and the way Ravi used to dress. Vandana generally dressed in casual shorts and tight fitting shirts that were not overly feminine. But she carried herself in a way that that made her appear comfortable with the Anglophone crowd, and with confidence. It came naturally to Vandana, while Ravi had to exert effort. In the boys' eyes, Ravi had transgressed 
the social boundary that defined her place. Ravi was guilty of mimicry that made her look inadequate (Bhabha, 1984).

Then I asked them, "And what do you think the Indian girls think of you?" "Oh, Indian girls, they're into white guys," Mandeep quipped. "Okay, so this is how it is," he said, as he stood up and acted it out for us in the cafeteria. "They see us, and they say (Mandeep puts on a limp voice), 'Oh...hi.'” He said this as he cast a lazy, reluctant sideways glance towards an imaginary Indian boy. As though uninterested and disappointed, he immediately looked at the floor and then away from the imaginary boy. Then he continued, "But when they see a white guy, suddenly it's (this time Mandeep put on a high pitched voice), 'Ohhhh, hiii!'” He giggled, raised one shoulder, tilted his chin down, and looked flirtatiously at the imaginary white boy. We laughed as some of the boys nodded in agreement with Mandeep. The boys felt that the Indian girls were more interested in white boys than they were in Indian boys.

Later that day, I saw Mandeep and Jagad enjoying the company of Jackie, who was of mixed white and Asian descent. She was one of the few non-South Asian students from the Englishspeaking group who had joined the Indian club. In the TIS context, Jackie was "white" because she had Euro-American capital through her descent and disposition. Mandeep and Jagad seemed to be giving her their full attention as they chatted in the cafeteria. The scene resembled what Mandeep had acted out earlier, except the genders were switched. True to their confession, the boys seemed more interested in white girls than they were in Indian girls. Although the interaction between the boys and Jackie appeared as though they were being international because they looked visibly diverse in terms of "race", it was an interaction that privileged Euro-American capital.

Notions of unassuming beauty signify the predominance of whiteness in the non-white psyche. Beauty is racialized within a framework of cultural hierarchies that reflect global economic structures. The western disposition of "white girls" was perceived as natural, becoming, and authentic. "White girls" seemed to include Indian girls who acquired the appropriate bodily hexis from childhood because being western was racialized as "white". In contrast, those who pursue it at a later stage in their life were perceived as "insulting themselves". The act of pursuing whiteness or Euro-American capital was seen as inauthentic because it involved effort and transgressed social boundaries. 
"She thinks we're just pebbles on the roadside"

A similar dynamic occurred among the Japanese students. When I began my fieldwork, Kairi was the only female Japanese student in her grade among five male Japanese students, all of whom had moved either from Japan or the Japanese school in Jakarta within the previous three years. As mentioned in Chapter 5, Kairi greatly valued speaking in English and readily embraced the school's ideology of being "international", though she was unable to integrate into the mainstream English-speaking group. She felt that that the male Japanese students were not being "international". She complained to me that the male students were creating walls around themselves, which she called "Japaneseness", ${ }^{80}$ by refusing to mingle with other students.

In contrast, Kairi ventured out of the Japanese hangout area to be with her own set of nonJapanese friends. Kairi usually hangs out with them when she is not hanging out with the Japanese crowd. These friends, all of whom were female, included a Dutch, white American, Iranian, a black Canadian, Indian, and Mongolian students among others. As the only Japanese senior who spoke in English to a visibly mixed group of friends, Kairi won the school administrators' approval for being "international" in a way that fitted the school's ideal. The new Japanese teacher, Horie sensei, said that the principal had asked her how they can push other Japanese students to be like Kairi.

Kairi's perception of the Japanese boys failing to practise the dominant form of cosmopolitanism was reflected back to her in their supposed lack of interest in her as a potential partner. Kairi felt that the male Japanese students did not relate to her as someone from the opposite sex, but more as a "pal" due to her tomboyish nature and, according to her Japanese teacher, because she does not fit their ideal of beauty. Kairi said (Interview, 23 February 2009),

Kubota sense ${ }^{81}$ told me that the kind of woman the boys in my grade have in mind is the kind whose eyes are pachikuri...who blinks her large, cute eyes like this (Kairi demonstrates by opening her eyes wide, raising her eyebrows, making two perfect circles with both her index fingers and thumbs in front of her eyes]. Her eye lashes don't

\footnotetext{
80 "Nihonjin to iu kabe" in the original, which literally means, "a wall called being Japanese".

${ }^{81}$ Kairi's Japanese literature teacher.
} 
point downwards, ${ }^{82}$ has long hair, and is small like this [gestures]. In a way, she's like a pet. That's the kind of girl they idealize...So I initially wondered if there was something wrong with me. They don't see me as a woman at all...So I told Kubota sensei that they refuse to see me as a woman. And she said that it's because the kind of woman they picture in their minds is the kind who represent the old, stereotypical kawaii" type. "So they're the ones who are behind the times," she said...She said, "So you have to live knowing that they're behind the times and snub them."

Kairi was tall for a Japanese girl and had small eyes. Kubota sensei told Kairi that in this day and age women need to be independent, able to build a career and a family, and follow through with their own vision for life. Kairi seemed fond of Kubota sensei for creating space for her where she did not fit the mould, and admired Kubota sensei for being an "independent woman".

But Kubota sensei's advice to Kairi about snubbing the boys played out like comedy one day when I sat chatting with the male students at the Japanese hangout area. Kairi walked past the Japanese bench in her usual brisk way with her green bag slung over one shoulder. As she passed us, she greeted me with an "A, Danau san konnichiwa (Oh, hi Danau)". She waved at me without slowing her pace. I said " $\mathrm{Hi}$ " back to her in Japanese as she continued walking past us to join her girlfriends on the other bench. She had completely ignored the three male Japanese students who were sitting on either side of me.

The boys looked at each other in disbelief, whispered something, and then snickered. I asked what was the matter. Kenta began explaining as Koichi piped in with a word or two every so often and Katsu (a short form of his surname "Katsumata"), a pale, thin, soft-spoken young man, quietly smiled in agreement. The gist of their discontent was that Kairi had no respect for them. "In her eyes, we're just like rocks lying on the side of the road...no, not even rocks. Little pebbles! That's right! We're nothing more than little pebbles that are not worth a glance to her!" Kenta had been sitting on the edge of the bench when he started. But seeing that I was paying attention to him and his audience was growing (five other Japanese students, both male and female, had joined us), he became more and more animated as he expounded his analysis, and eventually stood up as his talk escalated into a full blown theatrical Japanese

\footnotetext{
${ }^{82}$ Many East Asians have straight lashes that point downward.

${ }^{83}$ Literally, it means "cute". When used in reference to young women, it implies doll-like and helpless in nature, and mangga-like in appearance.
} 
manzai-like performance. ${ }^{84}$

The audience joined in the game by interrupting Kenta with questions to undermine his argument, which in the manzai spirit of things gave him further license to rattle off his take on the situation. Occasionally, Koichi jeeringly commented from the sidelines: "'I've got nothing to learn from the likes of you anyway,' that's how she thinks of us." These comments just gave more fuel to Kenta. "We're nothing! Worthless in our little corner. Crushed little stones. That's how she sees us." Kenta elaborated, not just in words, but with his whole being and body. A couple of times Kenta spoke in such a frenzy that he had to stop, or acted like he had to stop, to catch his breath. When one of us said, "Look, he's gotten so excited that he's out of breath," Kenta would feign shortness of breath just a while longer. Kenta enjoyed the effect of his performance on the audience and continued at fever pitch while Koichi quipped, "She's the kind who will have a hard time when she gets out in the world where you need to know how to get on with people."

It was clear that the young men did not feel that Kairi thought much of them. Initially, I thought the boys were overreacting, but Kairi completely ignored the boys again as she greeted me on another occasion a few weeks later. It was not that the boys did not care about Kairi as a friend. I had seen them banter fondly with her at other times (even after the above incident). As far as sexual attraction went, however, they were not interested. Perhaps Kairi's attitude was brought on by the boys' initial lack of interest in her, which would mean that they have themselves to blame for the way she ignored them. Indeed, some of them dated girls who somewhat fit the "cute" stereotype, but not all.

Contrary to Kubota sensei's theory, Koichi was not interested in "stereotypically kawaii" girls:

People often tell me that I go for looks, and well, I guess that's true. Looks are paramount. (Laughs) But if you ask me what kind of girls I get attracted to, well, I don't like the girly kind of girls...you know, the burikko ${ }^{85}$ kind, or the kind of girls who are really delicate and demure, I don't really like them. I like it when the girl is a bit feisty...or is passionate, you know, something like that is nice. It's really refreshing to see when

\footnotetext{
${ }^{84}$ Manzai refers to the Japanese standup comedy usually performed by a team of two comedians where one plays a character who makes ridiculous comments on various matters and the other plays a rational character who tries to bring his mate into line by interrupting him ('tsukkomu' in Japanese) with questions. The questioning often does not work as it simply encourages his mate to say more ridiculous things.

85 "Burikko" refers to girls or women who habitually perform an exaggerated form of 'cuteness', e.g. high pitched voice, speech style.
} 
they're like that, like a bit masculine or there's a hint of masculinity about them.

Koichi's description of the kind of girls he finds attractive echoes the kind of women Kairi admired and possibly resembled. Despite this, Koichi was not interested in Kairi. Why?

Another possible reason is Kairi's lack of respect for Koichi and the other Japanese boys for not being "international". As I explained in Chapter 9, Koichi was a cultural hybrid, but his hybridity was devalued due to his lack of Euro-American cultural capital. Having grown up in Indonesia and being fluent in Indonesian in addition to Japanese, Koichi related to Indonesian and other Asian students with ease. Koichi was also enrolled in the same advanced English class for nonnative speakers as Kairi, indicating that their English skills were on a par with each other. However, he was not the (Euro-American) cosmopolitan that Kairi admired and aspired to be. Perceptions like these explain Koichi's suspicion that those who are white or drawn to whiteness may not be interested in him as I detail below.

\section{Pre-emptive strike}

While the Indian boys highlighted the desirability of whiteness in their partners, others who were not white rejected it. Some put their lack of interest in the "western" students down to cultural difference. Others, especially those who did not have the cultural capital to comfortably interact with the dominant English-speaking group, were more explicit about the impact of their position in the socio-cultural hierarchy on their lack of connection with western students. The male students in the latter group assumed that western girls would not be interested in them. Koichi, who had had Japanese and Korean girlfriends, told me that he was open to girls of any cultural background until I asked whether that included western girls. It then became obvious that western girls had not even entered his mind.

Aaah, western girls, they're like, really up there...I bet western girls look at the Japanese and think, "Ugh"...western girls are definitely not into Japanese men, no way...I mean, if you think about it, there's more good looking guys among the westerners. I reckon western men are better suited to western women, even in terms of the type [of guys they like]. And, you know, there's a lot more good looking (western) guys. So, you know, that's how it plays out. That's the reality. westerners [prefer] westerners... 
Instead of stating whether or not he found "western girls" attractive, Koichi explained that they would not be interested in him. He implied that his lack of interest in them was because Japanese men were perceived as inferior to "western men".

Men considered as Other to the dominant culture are, for example, infantilized. Kavita, a female Indian student who hung out with the "fountain groups", spoke of a male Korean student of the same grade in a friendly, but paternalistic, way: "Sae Ryun is so cute. Not in a 'He's hot' kind of way, but in a baby kind of way." Sae Ryun was stripped of his sexuality. This act of infantilizing the Other reflects colonial discourses of subordinate races. Said (1985[1978]) argues that the Orient is commonly depicted as childlike and feminine. Hence, Koichi believed that Japanese men did not fit western notions of male attractiveness. Racialization of beauty intersects with the school's ideology of being "international", which privileges Euro-American capital, and influences who students find attractive.

Language abilities also limit interaction between groups, which then prevents students from expanding their preferences for partners. I asked Koichi whether he had ever been attracted to a "western" girl, even though he may not have dated any. He responded,

There have been occasions where I thought a girl was cute or beautiful, but they never developed into romantic feelings. I guess it's because we don't get to interact much. There might be a western girl who I might think is cute, but I only ever see them and don't get to speak to them or get to know them. Things would probably be different if we could get to know each other.

Koichi did not have much opportunity to interact with "western girls". In Chapter 9 I wrote that Koichi desired to hang out with the English-speaking group, or "westerners" as he called them, but was unable to. He put it down to his limited ability to fluidly communicate in English with humour, but he also admitted to feeling uneasy about approaching the "westerners". In the same way that some students retreat into the groups they feel comfortable with because they have the cultural capital to fluidly operate in those groups, so too do their preferences for partners suggest the use of a pre-emptive protection mechanism: they may think of "westerners" as collectively good looking, but they are not attracted to them as individuals due to the anticipated rejection. 
A male student expressed this sentiment of pre-emptive protection in an extremely misogynistic way that turned pre-emptive protection into a pre-emptive strike. Like most of the male Asian students who were not from the mainstream group, this student said he preferred Asian girls. As for white girls, he said that they were attractive, but they are the kind that "you use and dispose of (pake buang)". But it sounded as though he was putting on a tough façade. He did not have the means to "use and dispose" western girls, since to do so would require him to have first gained their attention. He did not have the cultural capital to do so. He was the only boy who made such comments and therefore does not represent the general attitude of my interviewees. I use this data only to highlight a pattern among marginalized men who denigrate women perceived to be a member of the superior group in order to protect their own sense of masculinity. As Chatterjee (1993) argues, women symbolize the purity of the nation, and therefore desecrating them is equivalent to mounting an underhanded attack on the masculinity of the men in the superior group.

Aya and Kayako explicitly stated their lack of interest in white guys was a result of the cultural hierarchy. We were at an end-of-year social gathering organized by the Japanese students and held at a popular Korean barbeque restaurant. One or two of the senior boys drank alcohol but the rest did not. Only those who were Japanese or partly Japanese (and one Korean friend of a senior Japanese student) attended the gathering. One of the lively older girls, Ellie, started asking the younger students about their ideal "types" as a fun conversation starter, so I played along and asked questions to keep the discussion going. ${ }^{86}$ Many took their turn, stating their preferences which varied one to the other: Japanese, Asian, or bule (white). Aya, who was in $11^{\text {th }}$ grade and of mixed Indonesian and Japanese descent, said she preferred an Asian guy, but not Korean due to what she perceived as irreconcilable cultural differences. Others like Kayako and Isamu who were in $10^{\text {th }}$ grade preferred Japanese, though Isamu did not mind Koreans. According to Isamu, "westerners" throw around the words "I love you, I love you" too cheaply-at least from what he saw of Hollywood movies. He thus felt they were culturally incompatible. I then asked Aya, "What about a white guy?" Aya answered with a resounding, "No." She explained, "Because they look down on us." "Yeahhh, I know," Kayako piped in. "Yeah, you can tell, can't you," responded Aya.

Both Aya and Kayako had moved from the Japanese school to TIS in $9^{\text {th }}$ grade and English was their second language. They explained that they feel looked down upon when they try to speak

\footnotetext{
${ }^{86}$ At one point, Aya asked me whether I was asking for the sake of my research and I said yes. I thought this would make her stop talking about it, but she did not stop.
} 
English to the western students and are not taken seriously or not understood during group work due to their inferior English skills. "When they say, 'Huh? Huh?' I just go gara gara gara." Kayako used an onomatopoeic Japanese expression which signifies a crumbling sound to describe how it makes her feel. She supplemented this with gestures-shaking her head slightly from side to side while moving both hands downwards in front of her as she wiggled all ten fingers, as though to imitate the collapse of the twin towers in 2001. Kayako looked despondent. Aya sat in silence but serious agreement, nodding her head lightly. Their limited English skills prevented Aya and Kayako from speaking confidently, thus inviting responses from the English-speaking students that further discouraged them, and instilled a sense of inferiority in them. As a pre-emptive move to avoid feeling rejected, they refused to consider students from the English-speaking group as potential partners.

In contrast, the younger girls seemed infatuated with white boys. When asked about preferences, the $9^{\text {th }}$ grade girls took a split second to respond in unison, "Bule!" Most of them were fluent in English. But I argue that it is partly their young age that created a strong attraction towards whiteness. A study by (Joyner \& Kao, 2005) shows that in the United States, incidences of interracial relationships decrease as people age and the anticipation of marriage grows stronger. A senior Indonesian girl stated that she was attracted to "bules" when she was younger, but not anymore. With age comes a more nuanced view of socio-cultural relations, which means one does not merely gravitate towards that which is constructed as superior.

Generally speaking, however, girls were more open to boys in higher status groups than boys to girls in higher status groups (Meerwald, 2002). Most of the boys from the non-mainstream English-speaking groups were Asian and they consistently and without hesitation stated that they preferred Asian girls to white girls. Girls, on the other hand, were more open to having a white partner. These patterns attest to a gender hierarchy whereby women "marry up" (hypergamy) and men "marry down" (hypogamy).

\section{“Endogamy" for transnational youth? ${ }^{87}$}

I have hitherto written about the effects of whiteness in encouraging either obvious desires for white partners or (the reverse) ethnically endogamous preferences that appear to reject

\footnotetext{
${ }^{87}$ I am not writing about marriage, but I use the word "endogamy" to explore the way transnational youth may feel attracted to others "like themselves".
} 
whiteness. What then does endogamy look like for transnational youth who are cultural hybrids?

\section{Chinese Southeast Asians}

Midori was the only one among the Japanese-speaking students who had an exclusive preference for the ethnic Chinese from Southeast Asia. Her preference was perhaps influenced by the fact that her mother was a Chinese Indonesian. During one of her breaks, I was chatting with her and her Chinese Indonesian boyfriend about partner preferences. Midori had a habit of rattling off highly politically incorrect statements one after another without considering the implications. Some friends attributed this to her personality. She determinedly stated her preference for the ethnic Chinese from Southeast Asia. They were the only ones she considered attractive. She did not like western guys. Japanese guys were uninteresting. As for dark-skinned guys like native Indonesians, "They look dirty," she claimed. Midori's darkskinned, half-Javanese friend Aya was sitting just a few feet away from us. Luckily, Aya was engrossed with her Nintendo DS2. "Why dirty," I asked, "What about Aya?" Midori immediately backtracked with, "Friends are different. They can be dark. That's okay. But not guys." Some East Asian students were prejudiced against darker skin in their preferences for partners.

\section{Westernized Asians and Asianized westerners}

Then Midori asked me about my preference. As it was only fair for me to reciprocate by answering, I told her that although I had been attracted to people of many different backgrounds, given a choice I preferred to be with a westernized Asian or Asianized westerner because that was the closest match to my own cultural background. Midori betrayed a look of mild shock upon hearing my answer-as though I had crossed over to the enemy's camp by allying myself with the "oppressors". She proceeded to ask me a series of questions that put me on the defensive. I explained that being culturally mixed meant that I had to deal with cultural difference every day and therefore wanted to keep that difference to a minimum in my relationship. She did not seem convinced that I was not betraying "my own".

This was partly because the people she had in mind were different to the people I had in mind. For Midori, "westernized Asian" and "Asianized westerner" referred to the high status English- 
speakers, and did not include the "cafeteria people" I mentioned in Chapters 8 and 9. I tried to clarify, "I'm not just talking about the guys over there (pointing to where the "white kids" benches were). But also guys like Ernest and Marco and their group." "But they're daggy," Midori countered. It was my turn to be surprised. I then realized that I had envisioned Ernest, Marco, and their friends growing into confident, responsible, and successful adults. I also had in mind some of the friendlier "fountain people" as adults who would have matured and become more open to people from different walks of life. So I assured Midori that Ernest and Marco will grow into fine young men in a few years, and so will some of the others. But Midori could only imagine them as teenagers mired in the cultural hierarchy of the school. As far as she was concerned, I either desired whiteness (i.e. suffered internalized racism) or had bad taste.

Indians with western accents

I asked Anaya about the kind of guys she gets attracted to. As previously mentioned (Chapter 7), Anaya is a female student who self-identifies as a Spanish passport-holding Indian raised in Indonesia and hangs out with the mainstream English-speaking crowd.

ANAYA: Indian, definitely...I've never been attracted to anyone at the school...All the guys I've ever got interested in have always been Indian. But I don't know if it's, I don't know if it's because I know that if I allowed myself talk to like someone outside it would get me into trouble.

DT: Oh, with your parents?

ANAYA: Yeah...Or because it's like actually I don't have any interest in them.

DT: ...Are your parents pretty strict on this?

ANAYA: My parents are pretty open. I know in the end they'd be like, "You know what, it's your life."...Obviously they're gonna be hurt, they definitely...Because...I don't know, it's just how it is...That's what I mean, responsibility of like...that's the reality of it: it's that they would be hurt by it. But, in the end of course they're not gonna wanna see me unhappy and they're gonna be like, "Do what you want." 
Anaya's reference to her parents suggests that she is aware she may have been socialized into preferring Indian men. She explained she feels a sense of "responsibility" towards her parents and other family members to be "a good daughter", which defined her as a woman. But her description of the kind of Indian men she liked suggested that there were other influences.

ANAYA: Cultural...very, very, very, very open...If I were to be attracted to a guy it would be because...he was about or as international as me and...accepting.

DT: Does his accent when he speaks English matter?

ANAYA: It's funny you ask that...I guess so because none of the guys I've been attracted to, they've all been Indian, but none of them have had an Indian accent...One's had an American, one's had a Spanish accent...This guy, he was like, he is like...like, oh my God (flushes). He speaks like, okay, he speaks broken English and I speak broken Spanish, and so we communicate with broken English and broken Spanish. And so it's really interesting, but yeah...And...one guy had a British accent.

Anaya acknowledged that her preference was to some extent due to her socialization as Indian and in turn her desire to be a "good daughter". But her transnational upbringing added nuance as seen in her preference for Indian men with western accents and "international". Anaya herself spoke with an Americanized accent. Each of the above examples shows a preference for likeness ("endogamy") among transnational youth-a preference that is not defined entirely by ethnicity, but also by cultural orientation that may encompass being "international".

\section{Sex and the transgression of class and racial lines}

The study of intimate relations can highlight group boundaries such as those based on class and "race". Relationships between foreign men and Indonesian women were highly visible in Jakarta despite being few in number. The stories told about them sometimes carried moments of discomfort over how sexual unions transgressed carefully guarded boundaries of class, ethnicity, and sexual morality. These moments of discomfort reinforce boundaries while 
simultaneously transgressing them. Perceptions, especially stereotypes, about white and Asian couples impacted upon the way transnational youth and others in transnational spaces felt about their own attraction to those who were different.

"When you're a nice girl, you don't hang out with foreigners"

Vianny, a mother of one of the TIS students, was Indonesian, a former Fulbright scholar, and daughter to Dutch-educated parents who were descended from Javanese aristocrats. She was married to a white American man who she met at a Fulbright gathering in Jakarta. Vianny says of her father's initial reaction to her marriage (Interview, 15 June 2009),

My dad wasn't very happy that I was marrying a foreigner when I was dating him. Because when you're a nice girl, you don't hang out with foreigners. You don't marry with a bule or whatever, or hang out with a bule. If you're a nice girl, come from a nice family, you're a well educated person, you come from a nice family...because sometimes in Indonesia when you're with foreigners: "Oh, what kind of girl [she emphasizes "girl" with a derogatory tone] you are. You know what I mean?

Vianny was referring to the perception that Indonesian women who date white men are morally suspect. Accusing women who marry out for being sexually loose is a strategy for maintaining ethnic boundaries. Baldassar (1999) argues that women are markers of ethnic boundaries, meaning that women from the out-group are often considered morally suspect, while those in the in-group need to have their purity protected.

Western expatriates were often surprised that Vianny did not fit the stereotype of the uneducated, lower-class "gold digger". Vianny recounted conversations she had had with them,

"I never seen Indonesian like you." What do you mean? I don't have five eyes or three noses, you know? "All I see is workers and maids." Excuse me?...Before, I really don't know how to react. I really still don't know. But I don't think it's my problem. They're stupid, they're ignorance. That's it. And they think, "Oh ya, they want to marry foreigners so they can have a better life." Ladies, I never clean the bathroom, now I have to clean the bathroom when I go back [to the US]. Do you think it's better 
life?...Even my friend was so funny. "How come you speak very good English? Where did you learn it?" Oh, on the flight, from there, here. "And how did you meet your husband?" In a bar [sarcastically]...you know?

Vianny felt uncomfortable being lumped together with Indonesian women who were from a socio-economically lower status than her, though she simultaneously questioned her own discomfort since it implied that she too was prejudiced towards the other Indonesian women. She explains, "I feel like it's not supposed to be like that. Everybody's the same. But sometimes it just put me in the defensive."

In Indonesia, stereotypes about relationships between Indonesian women and white men are particularly loaded with political, social, and moral insinuations due to the massive gaps in living standards and colonial baggage of racial discourses. One particular stereotype dominated perceptions regarding sexual unions between foreign men and Indonesian women-that the women were of disrepute and hankering after money. Living in Jakarta, it was difficult not to notice that many of the racially mixed couples were made up of older, expatriate, white men and Indonesian women who were possibly twenty years younger and economically less well off. The perception was that many of the women were either former maids or sex workers.

The most conspicuous couples were like the ones I met at the English-speaking church I attended during fieldwork. The church congregation was made up of mostly locals with a significant number of foreigners, including westerners. There was an old, white-haired man who looked past retirement age. He did not seem likeable. He was married to an Indonesian woman, possibly in her thirties, who had the appearance of a former escort worker from a lower-class background. She had very long, slightly wavy hair typical of Javanese Indonesians, wore heels and red lipstick, dressed in a "sexy" way that was different from the other women in the congregation, and walked with a straight back and air of superiority for having married a white man. It was difficult not to notice her because she did not have the bodily hexis that would allow her to blend in with the mostly middle and upper-middle class congregation who appeared "respectable" and "modest" - not that she seemed to want to blend in. They had two young children. While they were not in the majority, couples like this were not an uncommon sight. 
"But I'm not like those mba-mba"

These sights make university students Dina and Camellia apprehensive about the way people may perceive them when they date white men. Both were Indonesian and Dina had had a transnational upbringing (see Chapter 5). Dina and Camellia animatedly told me about their experience of interracial relationships as we chatted over dinner at Sizzler's in one of Jakarta's many posh malls. Camellia, who had gone to Europe as an exchange student in high school, said: "And then like I was, fear that this kind of people will see me like..."

Dina, Camellia's best friend, finished the sentence for her, "You're just an ordinary girl chasing for his wealth." They tried to explain that many Indonesians, including themselves, have a negative perception towards Indonesian women marrying foreigners.

Camellia continued to explain her frustration with her own feelings of wanting to distance herself from those "other" Indonesian women. "It's like, 'But I'm not like those mba-mba am I?' You get what I mean with that mba-mba?"

"To be judged on how you judge other people right? Hah!!" added Dina.

"Mba" is a Javanese term of deference meaning "older sister", but in places like Jakarta it is also used to refer to younger women or women working as maids and shop assistants, jobs usually associated with the lower class. Dina and Camellia were trying to distance themselves from lower class women as though to say that if they did find a white man desirable, it was not because he was white. They were conscious that even feelings of attraction are mediated by the notion that "white" is superior and desirable. Sexual desirability is embedded within social hierarchies.

Similarly, Daniel, a TIS student whose father was American and mother was Danish (Chapter 9), had no preference as to the cultural background of whom he dated, but he had been reluctant about dating Asian girls even when he had been attracted to one. He explained,

...there's a subconscious or outside forces that influence that. Like, let's say, [in] the past I've liked Indonesian girls, but at times I would be reluctant to start any relationship with them 'cause there's a kind of stigma in western society or something 
like that. I'm sure you know, if you walk in Pondok Indah mall, and you see a 50 year old white guy with a 20 year old Indonesian girl, it just fits that stereotype. And so, sometimes I've been afraid of-not so much of my parents-but of what my family in Denmark will think if I send them a photo from prom and [there's] this is a short little Indonesian girl that I meet. I mean, they probably may even assume that she doesn't even speak English. So, that's kinda made me reluctant at times, but other than that, there's not much preference.

Transnational youth find themselves having to navigate geographies of power in their cosmopolitan practice of engaging with the Other in one of the most intimate of relationships. To borrow Stoler's (1992, p. 551) words, it is in intimate relations that issues of class, gender, and race converge "in a grid of transgressions" which tap into "metropolitan and [post]colonial politics at the same time."

\section{Becoming "Indonesian", becoming "men"}

Relevant to this discussion is the way Indonesian-speaking students engaged the school's ideology of being "international" by using their wealth to challenge it, though in gendered ways. I focus on Indonesian-speaking boys who drew on nationalistic discourses of being Indonesian to establish their elite status, which carries currency in the Indonesian national context, within the transnational space of TIS.

\section{"Visitors must have respect"}

In terms of inter-group relations, the mainstream and high-status English-speaking groups got along best with the Indonesian-speaking groups due to a general shared interest in drinking and clubbing, but they were also competitive with regard to status. For example, Shane, a student from the Indonesian-speaking group said, "Sometimes they're arrogant. They walk around like they own the place. So we put them in their place. It's my country. This is my home. So visitors must have respect. [But] some of them don't."

Though Shane's mother was Indonesian and his father British, he considers himself more 
Indonesian than British. "Here in Indonesia, I can make conversation with anyone I see. From Bali to wherever I go, upper class to lower class, even [rickshaw] drivers and the beggars," Shane gestured with his hand as he spoke. "But then when I go to England, it's a different story. I don't really know what to talk about." Speaking of the western students, he says, “When I hang out with them, I just don't feel that connection. It doesn't feel right. It doesn't feel comfortable." There was no sense of mutual intelligibility.

"And what does the school social hierarchy look like? Who's at the top and who's at the bottom," I asked.

"Indo, bule and then Korean, and Japanese," he answered with confidence.

As previously mentioned, social hierarchies in schools may appear to be about personalities, but Ortner $(2002,2003)$ argues that it is underpinned by class structures. Among the differences that Shane described between him and the bule students, he cited the fact that they usually ride taxis instead of being chauffeured around or driving their own cars like he did. The class difference became clear when I once bumped into Shane and Kenji, among others, during my visit to Splash, a teenage beer garden located in Kemang (a neighbourhood where many expatriate families lived) and frequented by students from TIS, other international/foreign schools, as well as local elite teenagers. I had gone by taxi with a couple of Australian friends I had met in Jakarta. They were both older than me and we all felt very out of place as soon as we walked in due to our age. Anyone could freely order alcoholic beverages or shisha from the stalls surrounding the wooden tables. From the beer garden we could see an outdoor futsal pitch where two teams of adult westerners were playing each other. There were a number of Indonesian men who appeared to be bodyguards congregating near the entrance. They had large physical builds, had crew cut hair, and were dressed in baju safari (dark navy blue or grey short sleeve outfits that somewhat resembled Chinese tunic suits). They were standing around and waiting, and later disappeared as some of the clients left.

Shane and Kenji arrived later and chatted with us. It was November 2009 and both of them had graduated from TIS earlier in the year in June. Shane had enrolled at the prestigious University of Indonesia and hated it. He could not "connect" with the other students because they had a different lifestyle, i.e. they did not come from a wealthy family as he did. Later in 
the night, my friends and I wanted to catch a taxi to go home. I asked Shane for a ride to the main road and he was happy to oblige. We got into his tuned, black, sports Mercedes Benz. I sat in the front passenger seat. It felt impressively posh. Instead of the side of the main road, Shane dropped us off at a hotel lobby. As he drove in, he stopped by the security guard at the entrance, rolled down his window and asked, with a cool, alpha male vibe, for the guard to find us a taxi. The guard, who was older than Shane, immediately obliged with a, "Yes, boss." Shane carried a great sense of entitlement to place, which he used to shelter me, a woman, and my friends, who were foreigners, from the larger society by mobilizing the services of those who were from the lower-class.

At TIS, the contest for the top spot was a competition between the cultural capital of the western students and the economic capital of students from the local elite. Those who are socialized in western ways have the advantage of being familiar with the culture of the staff; Indonesian-speaking students counter this by making a show of their economic capital. For example, to host a party, Indonesian students might club together, each student chipping in to hire out a posh Jakarta club (and some bodyguards). One student explained that the actual cost is less than what the other students think but they leave the others second-guessing the cost of hiring out the club to play up their own financial capability.

\section{Defending girls}

Similarly, Dae Sik, who I quoted at the beginning of Chapter 1, racialized and constructed the "white kids," or "bule" as he called them, as outsiders while claiming to belong to Indonesia despite being a Korean national himself. Dae Sik had grown up in Indonesia, was a native speaker of Indonesian, had a bodily hexis that blended in better with the Indonesian than the Korean students, and felt better able to connect with Indonesians than Koreans. The constructs of class, race, ethnicity, nationality, and gender intersected in Dae Sik's expression of an oppositional identity to the bules and claim to "my country" (Indonesia), and impacted upon the behaviour of a teenage boy. A flashpoint occurred before my fieldwork, which I reconstructed through the stories that students told me. In these stories Dae Sik and his mates asserted their place in both the transnational space of TIS and national space of Indonesia in a nationalistic, racial, classed, and gendered way.

One of the girls in the Indonesian-speaking group, Sandra, had gone through a family tragedy 
when the flashpoint in question took place. One story has it that during this time one of the boys from the Indonesian group took her under his wing, and together with his mates supported her through the ordeal. Anaya explained, "One of the boys took [Sandra] as a sister and has been taking care of her and stuff like that after the whole incident...All of the boys have gotten really protective over her" (Interview 27 April 2009). But one night the students were out clubbing when one of the white male students jokingly called her a "slut" for "dancing with one of the guys in a club."

According to Anaya, it was meant as a light-hearted tease, but the Indonesian students "took it literally" and were offended. I had interviewed the boy before and spoken to him on many other occasions. He impressed me as a very respectful, capable, and friendly young man, so his comment seemed out of character. However, not having been present on the night, I can only proceed with the stories I had heard and discuss the nuances in the storytelling as opposed to the actual intent. Dae Sik and his Indonesian friends went to pay the boy a visit at his home with the company of hired policemen. I relay it here in Anaya's words.

ANAYA: They actually sent people to his house, knocking on his door. His mom answered the door and [it] was like, "We need to speak to [Liam]." And in front of [Liam's] parents they made [Liam] apologize to [Sandra].

DT: [Sandra] was there too?

ANAYA: Yeah...this is what I heard. But yeah, and they were like, "You better watch out." You know, like, "If you do it again," like, "you know what we're capable of doing..."

DT: Do you feel the [Indonesians] do that because they seriously are angry or is it more just like a show?

ANAYA: A show, it's a show they put up. I don't feel like they're actually...they, they don't really have anything [to be] angry about, you know, 'cause they have everything that they want. They're like, uhh I want a dog, I get a dog; or I want a phone, I get a phone; I wanna...you know?...I think it was just to put up a show. And then of course [Liam] would go and tell his friends, and then it would be like, "Oh my God, the Indos have, like, this power." 
"Power" was indeed being put on show through this threatening home visit. According to another informant, the "people" that Dae Sik and cohort "sent" or brought along to Liam's house were hired policemen. Even as teenagers they had recourse to the state apparatus to make a show of power, which they combined with the use of intimidation tactics. It signified eliteness and the construction of a sense of belonging (to Indonesia) that is born out of a sense of power. There were other spectacular stories about some of the Indonesian boys using their economic capital to hire police, bodyguards and security guards to make a show of their power. Ownership of guns was also mentioned though I was unable to verify this.

Dae Sik used the defence of women as reason for his nationalist claims. Ethnic boundaries are maintained by casting out-group women as morally suspect and in-group women as pure, chaste, and therefore in need for protection. Those capable of providing that protection are able to claim insider status, albeit based on a gender hierarchy that gives men power over women. As a Korean who grew up in Indonesia, Dae Sik could not relate to his Koreans peers and his claim to Indonesia was precarious. By proving himself powerful and masculine enough to provide protection to an Indonesian girl whose reputation was at stake, he was claiming himself worthy to be Indonesian. Both Dae Sik and Shane drew on gendered, nationalistic discourses to assert a sense of place in Indonesia in the face of the ambiguity of their hybrid identities.

Tim, who is from the high-status English-speaking group, felt that the Indonesian students were "superior".

TIM: We'd get into fights with them a lot...because we don't know which...well, not me personally, but a few of my friends...Because we don't talk as much, we don't know which girls are available, and stuff like that. So someone would go dance with them and then get in a huge fight...

DT: Over girls...

TIM: Yeah...and other things. They feel...I feel like they feel like they're very superior because they have a lot of money and they know a lot of very, like, important people that can (laughs) really do, like, a lot of harm to us...But I don't know, I guess, I guess 
it's okay in some ways. (Laughs) 'Cause they're...they're hard as a group to hang out with, like, if there's a lot of them. But a few of them are really nice. There's some that I won't talk to, but there's others that are really nice.

Tim refers to the Indonesian students' wealth and their social capital derived from their links to Indonesia's elite and state apparatus, as factors that make them superior. The competition for the top spot is expressed through competition for girls, which, as one Indonesian student explained, is just about boys making a big deal out of nothing just so they have something to fight over (Chatterjee, 1993).

In articulating his perceptions of the "white kids," Dae Sik drew on a nationalist, anti-colonialist discourse. It is as though Dae Sik, in taking the initiative to represent Indonesia, is fulfilling the "paranoid fantasy" of "colonial desire" whereby the colonized/dominated (momentarily) inverts the hierarchy and becomes the colonizer/dominating. Bhabha (1994, p. 44) writes, "It is always in relation to the place of the Other that colonial desire is articulated: the phantasmic space of possession that no one subject can singly or fixedly occupy, and therefore permits the dream of the inversion of roles."

Dae Sik took recourse to the Indonesian state apparatus to drive home the point that the "white kids" did not belong in Indonesia. The use of an Indonesian nationalist discourse reduced those who adhered to the school's ideology of being "international" into a white Other. This stands in stark contrast to the story related by the vice principal in Chapter 6 of his disappointment at the failure of the state to protect his children from substance abuse. His lack of access to state protection highlighted the foreignness of Indonesia and the transnationality of his own life, thereby making him feel cosmopolitan. Instead, Dae Sik and cohort used the state to construct the expatriates as intruders, not cosmopolitans.

There are male students in both the English-speaking and Indonesian-speaking groups who choose to express their masculinity by a show of wealth and power. Jun, a male student whose father was Japanese and mother was Indonesian and hung out with students from many different language groups, said in passing that the bule students are "wannabe gangsters" who try to act rich but are in fact not. Thus, although many of the dynamics I have described are common to teenagers under many different circumstances, what is pertinent are the national and cosmopolitan discourses that transnational youth draw upon to express their sense of 
belonging and place. The way they draw upon these discourses is heavily influenced by the global economic structure that informs perceptions of cultural hierarchy. Dae Sik was clearly aware of this hierarchy and it determined with whom he competed. Dae Sik said, over a chat, he did not care if Asians made negative remarks about Korea, but he would be offended if bules made similar remarks.

I double-checked with him, "All Asians?"

"Yeah, all Asians. They can say whatever and it doesn't matter," he responded with confidence.

"Are you sure?" I pressed him.

"Any Asians," confirmed Dae Sik without a shadow of doubt.

So I decided to strike, "Even the Japanese?"

Dae Sik looked like he was caught out and quickly backtracked on his words. "Uh, no, no. Okay, okay, what I meant was: any Asian except the Japanese. If a Japanese or bule say shit about Korea, I'll give them shit. But any other Asians, it's okay. I don't care." Dae Sik smiled as though to acknowledge that he had underestimated my understanding of cultural dynamics.

Clearly, the only opinions that mattered to Dae Sik were those of people who were associated, either racially or by nationality, with countries and societies whose socio-economic standing was higher than Korea's. I have used Dae Sik extensively as an example due to his exaggerated and clear expressions of how transnational youth draw upon the discourses available to them to negotiate cultural hierarchies. However, these same dynamics were at work in nuanced ways with other transnational youth.

\section{Conclusion}

Young people at international schools are expected to be "international" and open to difference by virtue of their education and transnational upbringing. However, the processes 
involved in becoming "international" are fraught with tensions because they are embedded within national and transnational structures of power. This chapter interrogated the ways in which issues of culture, "race", class, and gender intersect and influence (hetero)sexual attraction among students at an international high school in Indonesia. Students racialized beauty. Some were attracted to whiteness in a potential partner, while others rejected it as a defence mechanism. Even when students were open to difference, who they were attracted to and who they believed were attracted to them sometimes had little to do with being "international". Rather they navigate around colonial and capitalist discourses that privileged whiteness, not only in relation to sexual desirability but also in the way being "international" was defined by the school. Furthermore, some students asserted their masculinity, negotiated their hybridity, and became Indonesian by drawing on nationalistic discourses. In the process, they racialized western transnational youth as white Others, thus illustrating the shifting notions of being "international".

The intricacies of intimate relations make it at once the most vulnerable and unsusceptible frontier to processes of cosmopolitanization. The privileging of Euro-American capital in transnational spaces affected perceptions of sexual desirability, attraction and the range of potential partners, like it does choice of friends. As in the colonial era that Stoler (1992, p. 552) studied, the cosmopolitan practices of intimate relations were "worked through a psychologizing and naturalizing impulse that embedded gender inequalities, sexual privilege, class priorities, and racial superiority in a tangled political field." In the next chapter, I analyse more closely the ambiguous, shifting nature of racialized categories and young people's ambivalence towards cosmopolitan practices. 


\section{Chapter 11}

\section{Cosmopolitan ambivalence}

In this chapter, I focus even more closely on the situational, ambivalent nature of cosmopolitan practises. I begin by showing that those who are of mixed European and Asian descent occupy a racially ambiguous space whereby they situationally shift between being white and Asian. Similarly, students of mixed Japanese and Indonesian descent find their identities shift between being Japanese, Indonesian, and "international" and they use these shifts to subvert relations of power. The data show that becoming "Asian" and becoming "western" are mutually constitutive with becoming "international", thereby establishing the notion that cosmopolitan practices are situational and embedded within national, regional, and global structures. It is within this context that I revisit the main ritual that showcased the school's ideology of being "international"-United Nations Day. I bring the analysis of the Euro-American nature of the school's ideology to bear upon the way students and teachers perceived and managed UN Day clubs and performances. Students compete with each other to become "international".

As I do this I emphasize that processes of cosmopolitanization are characterized by a sense of ambivalence inherent in hybrid identities and engagement with the Other. Although I argue that Euro-American capital is privileged at TIS, I conclude that the experience of cultural marginalization is shared by transnational youth even though they experience it at different times in different ways depending on their background in terms of culture, "race", class, and gender, which affect their positionality.

\section{Becoming "white", becoming "Asian"}

Transnational youth of mixed Asian and European descent shift positionally depending on the context due to their racially ambiguous physical appearance. In this section, I use two participants, one from the "normal" English-speaking groups (Maura) and one from the highstatus English-speaking group ( $\mathrm{Tim}$ ) as examples. In the West they were perceived as Asian and felt marginal, in Asia they were perceived as white or western and felt dominant. At TIS, the other students referred to them as "white kids" or bule, but they self-identified as "culturally 
Asian".

\section{Shifting positionalities}

Maura's mother is Filipino and her father is Italian American, and her racially ambiguous physical appearance caused her to shift between being perceived as mixed, Asian, and white in different contexts. Maura grew up almost exclusively in Asia, having been born in Indonesia from where she moved to Thailand, Bangladesh, Philippines, then back to Indonesia, attending international schools for most of that time. According to Maura, she was part of the dominant culture at the international school in the Philippines because it was made up mostly of children of mixed heritage (part Filipino) and locals (Interview, 28 April 2009):

[The international school in the Philippines (TISP)] was really great. It's not really so much an international school, mostly because most of the kids are like me, mixed half Filipino-half American kids. So that's like, the majority of the population are Filipinos mixed with, like, a white. Yeah, with a Caucasian. Like, my best friends were SwissFilipino, Singaporean-Filipino, American-Filipino...So like, all our moms would be Filipino and then our dads would all like yeah...across the world. (Laughs) Yeah, mainly white.

So then that's why like [TISP] didn't really feel like an international school because we all spoke Filipino. We are all like you know...we all knew Manila really well...A bunch of us...we kind of all grew up together you know...I have friends there who I have been friends with since I was literally six or seven.

In Maura's view, the local elements of the international school made it less "international". As I showed in Chapter 6, proximity with the local compromises the "international" feel of the school. The local enhances "felt cosmopolitanism" in so far as it provides a backdrop for being "international", but it detracts from the internationalism once the distance is diminished and the boundaries between the "local" and "international" are blurred (Calhoun, 2008, p. 106). The lack of mobility (i.e. she had long term friends) also detracted from the sense of being "international".

The family background of Maura and her peers in Manila evinced a gendered hierarchy to the 
cross-cultural marriages represented at her international school. The parents from the local population were mostly mothers, while the foreign parents, who were usually from a more developed country and white, were fathers. This was typical also of cross-cultural couples in Jakarta and among parents of TIS students. Even when the mother was not Indonesian, she would often be from a less developed country than the father.

Although Maura was part of the norm at TISP, her positionality was situational. When she went to the United States, her passport country, Maura shifted from being normal to "Asian" and therefore marginal to the dominant culture, while in Asia (outside of TISP) she became white.

MAURA: In the States I kinda look like some of the people, well (thinks and changes her mind)...no not really...I dunno...

DANAU: Do you feel more comfortable there?

MAURA: Oh, I hate being in the States. Whenever I go to the States...I always go through Chicago, so I walk into the Chicago airport I have like cultural shock 'cause everyone's like white. It freaks me out. I've lived in Asia all my whole life, so then it's like I'm used to seeing Asians everywhere and like walking into an airport and being the tallest person in the airport, you know...It's when I'm in Asia I feel like...I guess 'cause I'm white I feel like...no, it sounds bad, never mind...

DT: Go on...

MAURA: If you're white in Asia you have the sense of power because you're white in Asia. Do you get what I mean? So yeah, then when I'm in the States, everyone else is white. I am the same as them. So then, not only do [I] feel, like, intimidated, they scare me, they're louder than Asians, they're ruder than Asians, they're yeah...I'm kind of have an Asian mentality...

In Asia, Maura was perceived by locals as white, which gave her a "sense of power" because she could draw on colonial discourses of race that constructs "white" as superior and contemporary capitalist discourse that continue to construct "the West" as superior. She 
internalized this power relation, which made her feel insecure in the U.S. where she was intimidated by whiteness. In the U.S., her own whiteness does not set her apart to mark her as privileged and more powerful than the others. She felt she has an "Asian mentality" and later claimed "I'm an Asian," despite the fact that students from the non-English-speaking groups at TIS considered her and her friends as "white". Being "Asian", "white", or "international" is situational.

Tim, whose mother is Taiwanese and father is white American, was similarly ambivalent about his positionality. Tim was born in the United States; when he was four he moved to Jakarta; then to Kalimantan (Indonesia) in $2^{\text {nd }}$ grade and studied at a small international school that only had seventeen students; back to Jakarta for $4^{\text {th }}$ grade; back to the United States where he enrolled in $5^{\text {th }}$ grade at a public school for seven months; to Japan from $5^{\text {th }}$ to $8^{\text {th }}$ grade; back to Jakarta to finish $8^{\text {th }}$ grade at an international school that was smaller than TIS; then moved schools and enrolled at TIS in $9^{\text {th }}$ grade. Tim claims, "I say I'm from the States. But my mom is Taiwanese...That's usually what I do. But, to me, I actually don't feel like I belong anywhere, like, home to me is where my family is." The impact of mobility on his sense of home echoed that described in the TCK literature (Pollock \& Van Reken, 2009[2001]).

Tim found it difficult fitting in when he moved "back" to the United States in $5^{\text {th }}$ grade (about 11 years old; Interview, 4 May 2009).

TIM: I really, for some reason, didn't want to be Asian. I wanted to fit in like an American student. I think that really affected me in some ways. Just because I look different and...I didn't want to because I felt like people were looking at me seeing how I was different sort of, yeah...It made me self-conscious...It would be really hard for me to join games and stuff that they were playing because I felt like I wouldn't be accepted just because of the way I looked...It would be hard for me to talk to them because I'm scared they would judge me and be like, "Oh, you're stupid," or whatever. So that affected me in that way.

DT: Does it still affect you?

TIM: No. I haven't really thought about it, so it's so hard for me to explain. (Laughs) 
DT: (Laughs) Okay. Moving to Japan, what was that like?

TIM: ...I remember going to school and it was really strange because in the States, I felt like I was Asian. But then when I went to Japan, I felt more western on the way people were treating me. And I felt more welcome, like all the kids wanted to talk to me, and wanted to know where I was from. And like they tried really hard to be my friends and I really liked that....Moving there was really nice 'cause the school...there were about 45 kids per grade, and everyone sort of hung out with everyone. There was no, like, cultural difference.

DT: No cultural difference between...?

TIM: Between...there were a few other American students, or Caucasian students, and we mixed all with the Japanese kids. Like, they would talk in Japanese sometimes to each other, but most times you could go over there and ask "Hey, what's up?" And they'll be like, "Oh, so and so..." and they would tell us. It wasn't like the States where I felt afraid to kind of go up to people and ask about stuff like that.

In the U.S., Tim felt he was "Asian" and was perceived as Asian, which made him feel unaccepted. Whereas in Japan, he felt "more western", "more welcome", and his peers "tried really hard" to be his friend-they were interested in getting to know him. He did not feel intimidated about approaching his peers. Like Maura, Tim's positionality shifted upwards as he moved from the West to Asia due to the perception that those with Euro-American capital are superior to those without. Tim also internalized this perception, which affected his sense of confidence in approaching his peers in the US. Like Maura, Tim identified as Asian. He said, "Culturally, I consider myself more Asian than western" because "I've lived overseas, basically my whole life...in Asia, and I feel I look more Asian." Tim cited his physical appearance in comparison to his white peers in the U.S. as one of the reasons for identifying as Asian. Tim's own identification was in stark contrast to how he was perceived by other students at TIS, where he was part of the high status "white kids" group.

Maura said, "When I think of hierarchy, the only reason they're higher than us is because they think they are...and we let them." "[W]e let them" indicates that cultural hierarchies are internalized as habitus - "a system of dispositions that incline actors to act, think, and feel in 
ways consistent with the limits of structure" (Ortner, 2006, p. 109). They are also constructed in relation to economic hierarchies. Tim and Maura grew up in environments where colonial racial discourses of white superiority intersect with capitalist structures in visible ways. Tim said,

One of the things that I find really strange is when I'm here, most of the workers like in McDonalds, in all these restaurants are Asian, and then going back to the States and having, like... giving orders to someone who is white or Caucasian is really strange to me. Like, I feel it's, it's really weird. I don't know why. It's just something about it is strange to me.

Growing up in an environment where class division overlaps with racial difference visibly reinforces the notion that Euro-American capital is superior. Transnational youth internalize the conflation of racial whiteness with class superiority, which affects their perception of themselves and others, and consequently their social interaction with others.

\section{Friendships based on shared interest?}

Although both Maura and Tim claimed that their friendships were forged based on shared interests, they tacitly recognized that cultural sameness and hierarchies may have a role in shaping with whom they became friends. Maura said:

In my group we're international, 'cause we have Australian, Canadians, and Americans and yeah...oh, that's actually the three we have (laughs); oh, there's an English; oh, a French. Yeah, but we're all, like, white except for [Lila] (laughs), but...who's basically white. Like, her mentality and stuff... I mean, I guess it's kind of, like, racist...well, not racist, it's just being really, you know...when it all boils down to it, we're all friends...really.

Lila was of African descent but adopted by white Canadian parents and was culturally white Canadian. While Maura claimed that her friends were "international" and were simply "friends", her reference to Lila's mentality as "basically white" indicates that she recognized they shared a cultural sameness. The fact that Maura feels intimidated around those who are "white" suggests that she was aware that cultural hierarchies make it difficult for those in a 
marginal position to approach those in a dominant position. However, when Maura described her own friendships, these hierarchies mattered less because "when it all boils down to it" they were just "friends".

Tim cited "interests" multiple times as the reason underlying why he gets along with some and not with others. However, as he explained his inability to connect with Americans, he slipped between talking about diverging interests and about differences based on physical appearance and culture.

Well, I didn't fit in for one. I didn't really have a lot of friends, just because everyone...I don't know what it was...I think it was just how I grew up was different [from] them and I just couldn't fit in. I didn't have the same interests as them...I don't think the students really liked me, I look different from one, 'cause everyone was American there. And then I was Asian. So I guess they didn't really accept me for that.

While he recognizes that differences in their upbringing meant that his interests diverged from his American peers, he was also aware that his physical appearance affected his sense of marginality and led him to feel that they did not "accept" him. As for his friends at TIS, Tim says, "I found that we had more or less the same interest, and I started going out to like Splash (a beer garden) and all those places with them. And it was really cool. I started to fit in." Outside his immediate circle of friends, Tim feels that "the Indonesians, the Chindos" and "the more white people" go out while the Korean students "stay and study," and thus he says of the Koreans, "I feel like we don't really mesh like that. Like, we'll just go different ways." But when he speaks of TIS's social hierarchy, these differences and his lack of interest in the Korean students overlap with his perception that they are "lower" in the hierarchy:

I feel, on the top of the food chain, would be the Chindos. And then after that, I don't know...I don't really hang out with the Koreans very much, so maybe I feel like they're lower.

While diverging interests contribute greatly to the formation of social groups among transnational youth, these divergences are moderated by perceived cultural hierarchies through which value is attached to various interests. Going out (i.e. drinking and clubbing) is seen as interesting, while studying without going out (since some do both) like the Koreans is 
not.

Cultural hierarchies are nuanced, and a sense of ambivalence permeates the experiences of transnational youth. For Maura and Tim, their positionality shifts depending on whether they have more or less Euro-American capital compared to the dominant majority in the given context. Their racially ambiguous physical appearance affects the way others perceive and treat them as well as how secure they feel in different contexts.

\section{Becoming not-Indonesian}

The experiences of transnational youth and their cosmopolitan practices are mired in the structures that form their habitus. Levi spoke to me at some length about his ill-feelings towards Indonesia over a chat in the presence of another student, Maya, who was working on her laptop (Field notes, 29 September 2009). We sat at a table near the fountain that was usually occupied by the "normal" senior English-speaking groups of which Maya was usually a part. Levi, also a senior, occasionally visited these groups although he usually hung out with the "stoners", known as the partygoers. Ironically, Levi was not a regular partygoer because his father had come to Indonesia as an American Christian missionary. Levi was not usually allowed to go clubbing, and had to spend time serving the community and going on mission trips.

I asked Levi about his background, and he told me that he was American. I double-checked with him because I had heard that he was partly Indonesian, but Levi denied it. He reiterated that he was American. As I sat there looking confused, Maya piped in and said, "Yes you are. You are half Indonesian." At this, Levi conceded that his mother was Indonesian, but he added that he does not like Indonesia. "Don't say that," retorted Maya, whose mother was Indonesian and father was a Filipino raised in Indonesia. But Levi continued, "I hate Indonesia. I don't like anything about it-the food, the place. I can't wait to graduate and get out of here." Levi also stated that he was not Asian, and that he did not like being called Asian. At this point, Maya made a clear stand. She told Levi that he was being racist and asked him to stop. When he continued, Maya declared she could not listen to him any more, closed her laptop (which coincidentally was running out of battery), and left. 
Levi used to go to national plus and other local schools, and was fluent in Indonesian. But he insisted that he was "just American," and planned to go to a military college in the United States (where he had hardly ever lived) because he wanted to do his duty to "serve the country." Levi wanted to leave Indonesia and never come back, though he would have to since his grandparents were still in Indonesia. Levi said his mother came from a poor Indonesian family. He could not understand what his father had seen in his mother to want to marry her since Levi believed his mother was unattractive. Levi also disliked it when his Indonesian cousins say that he is rich. "Because I'm not. We're middle class," explained Levi. In his view he was middle class by American standards, i.e. normal.

It is difficult to determine the exact reasons behind his negative views toward Indonesia. But we can infer that Levi's desire to distance himself from Indonesia, figuratively and geographically, reflected an attempt to navigate around social stereotypes and the perception that Indonesia is inferior. Levi wanted to be a normal, middle-class American, not a poor, ugly Indonesian. Levi referred to his interest in attending military college in his attempt to identify with his father's American background. Regardless of whether or not he eventually attended such a college, Levi's use of nationalism to express his identity was common to male TIS students whose hybrid identities were precarious and needed to be constantly asserted. Transnational youth, like Levi, are not the embodied beacon of a "happy hybridity": they embody the burden of social hierarchies that reflect national and transnational economic hierarchies (Lo, 2000, p. 153).

\section{Becoming "Japanese", becoming “haafu" 88}

Levi's desire to distance himself from Indonesia was shared by those who were of mixed Japanese and Indonesian descent. Ellie and Aya, whose fathers are Japanese and mothers are Indonesian, used their shifting positionalities and drew on TIS's ideology of being "international" to subvert national hierarchies. Ellie and Aya used to go to the Japanese school in Jakarta where the dominant culture was represented by those who were "pure" Japanese. Being only "half" Japanese, they performed "Japaneseness" and downplayed their "Indonesianness". They did this to gain access to the dominant (Japanese) culture and escape being marginalized. But at TIS, where diversity was celebrated, Ellie and Aya used a different

88 "Haafu" is the Japanese pronounciation of "half" and refers to mixed descent. 
strategy-they used their mixed background to subvert the hierarchy that privileges "pure Japaneseness".

\section{"Southeast Asians are...just a factory outlet"}

Early on in my fieldwork, I learnt that Ellie, Aya and their friend Midori spoke Indonesian, but noticed that they never spoke it in school. Even when Indonesian students spoke to them in Indonesian, they responded in English, a language in which they were not entirely comfortable. Several times I asked them why, and each time they avoided answering my question - that is, until we were in an enclosed room where they were sure that no one could hear them. ${ }^{89}$ Once it was obvious that we had privacy, they were more than eager to talk.

"I want to blend in as a Japanese, so I don't speak it," explained Ellie on not speaking Indonesian. "It's turned into a habit, so now I can't speak Indonesian at all anymore...sort of."

"Yeah, yeah, I know what you mean," Aya piped in. "I hate it when they [the Japanese] say, 'You're mixed, aren't ya,' because it feels as though they're putting up a wall between us."

"Yeah, it feels like they're looking down on you," said Ellie. Then she continued as she put on a cold, condescending tone, "It's like, 'Oh, so you're a haafu, an Indonesian haafu". Ellie and Aya were finishing each other's thoughts, attesting to the similarities of their experiences of the superiority of "Japaneseness".

Ellie provided a sketch of the cultural hierarchy that is in large part dependent on global economic hierarchies and intrudes upon the social dynamics among students. She believes that the Japanese think of white people as, metaphorically speaking, "branded goods". While apologetic of her metaphor, she continued to share the rest of the picture. "The Chinese are, like, locally made," she contended.

"At the end of the day, it's all about skin colour," Aya noted.

"And Southeast Asians are...let's see..." Ellie pondered a little and declared, "just a factory

${ }^{89}$ Discussions with Ellie and Aya were conducted in Japanese. 
outlet." As I burst out laughing at her description, she added, "Seriously, like, kaki lima ${ }^{90}$ or something."

The school is a site of reproduction for global economic hierarchies that are internalized as cultural hierarchies, true to Bourdieu's (1986, p. 252) claim that, "economic capital is at the root of all the other types of capital." But Bourdieu (1986, p. 252) goes a little further, positing that, "these transformed, disguised forms of economic capital, never entirely reducible to that definition, produce their most specific effects only to the extent that they conceal (not least from their possessors) the fact that economic capital is at their root." Aya's comment about "skin colour" and Ellie's capitalistic metaphor suggest that economic and racial hierarchies intersect. Ellie's observations suggest that the Japanese acknowledge the superiority of the West and inferiority of Southeast Asians, including Indonesia, in relation to Japan. The economic root of racial hierarchies that were constructed during colonialism is perpetuated without the full knowledge of those participating in its perpetuation.

Ellie and Aya chose to distance themselves from Indonesia by rejecting the use of their Indonesian cultural capital in order to naturalize their belonging with the Japanese in the same way that Levi tried to distance himself from Indonesia in order to identify as American. Cultural and racial hierarchies based on economic hierarchies have a profound influence on the subjectivities and behaviour of transnational youth as they need to navigate around these constructions.

\section{Subverting national hierarchies}

However, Ellie and Aya's positionality shifted at TIS where their mixed background turned into cosmopolitan cultural capital. Ellie explained that when she told western students she has a mixed background, "They say to me, 'Oh, half Indo?' It's like, it's easier [for me] to make friends than for the pure Japanese." Being mixed meant that others were more interested in getting to know her. Ellie, whose mother is Batak Indonesian and who, by Indonesian standards, would be considered light-skinned, was keenly aware of her new-found cultural capital where the ideology of being "international", as opposed to ethnic purity, prevailed.

In contrast, her friend Aya did not feel as empowered in the new environment. Aya had darker

${ }^{90}$ An Indonesian term meaning "itinerant hawker" who sell the cheapest food available. 
skin and, unlike Ellie who had epicanthic folds, Aya had double fold eyelids. These features made her appear more Javanese ${ }^{91}$ than Japanese. While Ellie could pass as a Japanese, Aya could not. But Aya, whose middle name is Rachael, did agree on some points and added, "Oh, yeah, yeah. I know. [It's better] when I say I'm a haafu. Also, my name...they'll suddenly change their attitude towards me when I tell them my name is [Rachael]."

"Do you get it?" says Ellie to me. "It's like, seriously, I thought, 'Oh, so Koreans and Japanese are really looked down upon here, it's the reverse (compared to the Japanese school)."'

Aya nodded in agreement as she said, "Yeah, yeah...I suppose in that sense it's kind of better [here]."

"Seriously, to be honest, to be quite blunt, it's like, 'Sorry folks." By "folks", Ellie was referring to her Japanese friends and implied that it was now her turn, as a haafu, to feel closer to the dominant culture while the "pure" Japanese were more marginalized. Then she added, "[This] is just between us, yeah," to indicate that it was not something she would talk about openly with her Japanese friends who were not of mixed descent. "So, because of that, I can make friends [here]. And it's like, I think for the first time in my life I feel proud to be a haafu." Aya and Ellie, being mixed Indonesian and Japanese, found their haafu identities carried more currency in the international school than at the Japanese school.

However, Aya and Ellie felt that the cosmopolitan capital from their hybrid identity would not have currency in Japan, in the same way that Tim's cosmopolitan capital did not have currency in the U.S. Aya, for example, claimed that she chose to remain in Indonesia to attend TIS for high school due to her mixed background instead of going to Japan as many of her Japanese schoolmates did. "I thought that maybe if I went to high school in Japan it might be the same as the Japanese school here, and I didn't want that. I wanted a change, like, in terms of life, you know, like the way they discriminate against haafus...It's bad enough here in Indonesia...I figure it would be worse in Japan." But she planned to go to university in Japan because, she said, "University students are already adults, so I have this image that they probably won't be as cliquey...Plus I want to experience what it's like to study in Japan at least once." Many transnational youth were infatuated with their parents' country, which was also often their country of passport (Chapter 9). They wanted to experience life, particularly as a student, in

\footnotetext{
${ }^{91}$ The dominant ethnic group in Indonesia.
} 
that place they had heard so much about and visited but never actually lived in as a local. Even so, some, like Aya and Ellie, were aware that they would experience various social spaces differently from their peers due to their cosmopolitan capital.

The dominant culture has the power to define the rules of the game, while others must either play by the rules or contest it in their attempt to decrease their sense of marginalization. Ellie was able to subvert the Japanese hierarchy when she moved to TIS at the start of high school by drawing on the discourse of being "international" TIS. Different aspects of their hybrid identities become available to them as tools to diffuse their sense of marginalization at different times depending on the dominant culture of their social environment. Ellie and Aya still felt marginalized compared to students who were more westernized, but they (though more so Ellie than Aya) had a better feel for the cosmopolitan game than their "pure" Japanese friends. Neither transnational educational spaces nor cosmopolitan practices are neutral. Both intersect with global, regional, and national structures to cause variability in young people's experiences of a transnational upbringing.

\section{Competing to become "international"}

Students drew on the discourses of the school's ideology of being "international" to enhance their own positionings not only as individuals, but also collectively. In this section, I bring together various themes covered in this thesis through an analysis of how the UN Day clubs were interpreted and managed. "Being international" is not just an ideal, it is a strategic positioning of oneself within a complex intersection of hierarchies.

\section{Diversity made visible and invisible by race}

A teacher I spoke to had the impression that the Indian club had the most diverse membership among the "national" clubs that performed. As evidence, one of them noted they clearly remembered that at least one of the performers was white. They also felt that the Japanese and Korean clubs seemed most ethnically homogenous. Another teacher pointed out that he had observed the Japanese club practising and had heard them giving instructions in Japanese, thus concluding that they were all Japanese. But the leaders (mainly Erina, the club president, and her two close friends) in the Japanese club were giving instructions in Japanese not 
because the members were all Japanese. Instead, they were adamantly refusing to use English for reasons that were not made clear to me (I return to this point later).

The staff members I spoke to were taken by surprise when I told them that approximately 20 per cent of the members in the Indian club were of non-Indian descent, while as much as approximately 40 per cent of the Japanese club was either of non-Japanese descent or only of part Japanese descent. I posit that the diversity in the Indian club was more readily apparent to the audience because they had two students who were white and two who were of mixed white and Asian descent. Meanwhile, the Japanese club looked homogeneous because their members appeared "racially" similar as they were all of Asian descent, though from different nationalities, ethnicities, and linguistic backgrounds. The nationalities they represented included Vietnam, Laos, Philippines, Indonesia, Malaysia, China, and India. While the Korean club was indeed made up of members who were all of Korean descent, the Chinese club was also diverse linguistically and in terms of nationality. Most were of Chinese descent, but they were of different nationalities, and spoke different languages as their native tongue: Mandarin, Indonesian, English, and Tagalog. Their main language of communication during practice was English. However, as with the Japanese club, the cultural, linguistic and national diversity of the Chinese club remained invisible due to the "racial" semblance of its members. Diversity is most visible when it crosses difference that is constructed through colonial discourses of race, which Du Bois (\& Edwards 2007[1903], p. 3) refers to as the "color-line".

Reproducing cosmopolitan hierarchies like fractal patterns ${ }^{92}$

Although the staff perceived the Japanese club as homogenously Japanese, the club members' perception of themselves was more nuanced. I hung out with them through many of their practice sessions, some of which were held in the Japanese teacher's classroom. These sessions ended with long casual after-school chats about anything from club activities and relationships to "expats" in the red-light districts of Thailand. The Japanese club had a reputation for putting on excellent performances, and it was clear from their conversations that they perceived the Korean club as their main competitor. They were competing with the Koreans on two fronts. Firstly, they competed with the Korean club for performative excellence as a matter of national pride. Many non-Japanese students in the club said that they joined because they were impressed by the club's performance in previous years. The

\footnotetext{
92 "A curve or geometrical figure, each part of which has the same statistical character as the whole" (Oxford Dictionaries).
} 
Japanese club's popularity as well as the popularity of Japanese language classes among Asian students reflected Japan's cultural power that is derived from its position in the economic hierarchy in the region. ${ }^{93}$ Secondly, the Japanese students competed for a superior position to be "international" as defined by the school's ideology. Members of the Japanese club who were either of full or partial Japanese descent spoke accusingly of the ethnic homogeneity of the Korean club, who allegedly were not allowing non-Koreans to join the club and were excessive with their practice schedule.

It is significant that the Japanese students were conscious of the ideology of being "international". Whether or not the Japanese club was in fact more inclusive is a secondary matter. Members of the Japanese club marked the ethnic homogeneity of the Korean club and constructed it as parochial. This enabled the Japanese students to feel as though they were more international in the way they managed their UN Day club compared to the Korean club. At TIS, ethnic homogeneity acted as "a marker" of the quintessential Other. Hage (1998, p. 57) argues that in Australia, Aboriginal Blackness acts as a marker that

... allows various non-Black an access to Whiteness. All the cappuccinos, macchiatos and caffe lattes of the world that are neither black nor white, skin-colour wise, can use the Blackness of the Aboriginal people to emphasise their non-Blackness and their capacity to enter the field of Whiteness.

At TIS, ethnic or national homogeneity represented blackness within the ideology of being "international". The Japanese students distanced themselves from the ethnic homogeneity of the Korean club to access a degree of cosmopolitan capital that was otherwise out of their reach due to their limited fluency in English and Euro-American capital. The Japanese students accepted the legitimacy of the ideology of being international and submitted to its symbolic power, which Bourdieu (1991, p. 164) explains "is that invisible power which can be exercised only with the complicity of those who do not want to know that they are subject to it or even that they themselves exercise it." This reinforced the Japanese students' sense of superiority vis-à-vis the Korean students, a sentiment that reflects the rivalry for economic and soft-power dominance as well the history of Japanese colonialism in the region. The practice of being "international" that privileges ethnic, national, and racial diversity becomes a badge of distinction.

\footnotetext{
${ }^{93}$ See Nye (2004, p. 11) for a discussion on the way cultural power is a resource that can be the basis of a country's "soft power".
} 
Notwithstanding their attempt to compete to be "international", the Japanese club leaders reinforced Japanese normativity within the club. As I mentioned earlier, the leaders were adamant about using Japanese to give instructions even though a large portion of the members could not understand Japanese. Some of the Japanese-speaking students ${ }^{94}$ took turns to interpret the instructions into English, but they did not always do so. Sometimes the non-Japanese speaking students could not keep up with the dance routine as they were not always clear on what they were supposed to do. There was a core Japanese-speaking group who held offices in the club, were dedicated to choreographing and practising the routine, and were responsible for teaching it to the other members, namely the non-Japanese-speaking and younger Japanese-speaking members. This contributed to the variable quality in their ability to dance the routine. Although they all took turns dancing in the front row, the non-Japanese speaking students were relegated to dance mostly in the back rows for the performance while the better dancers, i.e. the older Japanese-speakers, danced mostly in the front rows to model the dancing.

The leaders seemed ambivalent about the non-Japanese-speaking members, whose presence was beneficial for the club's image of being international and thus tolerated, but not accepted (W. Brown, 2006). For example, Midori, who often made impulsive comments, casually said that she wished Aisha's Muslim headscarf would fall off while dancing. Although this was said only in the presence of Japanese-speaking members and Aisha knew nothing of it, on the day of the performance Aisha voluntarily removed her headscarf because she felt it appropriate to do so. Non-Japanese Asian students enriched the "international" image of the Japanese club, but they were relegated to an inferior position that reflected regional socio-economic hierarchies.

It may appear contradictory that the Japanese students constructed themselves as "international" while simultaneously reinforcing the dominance of Japaneseness. However, this is the precise principle underpinning the school's ideology of being "international". Those with Euro-American capital construct themselves as "international" while simultaneously reinforcing the dominant position of Euro-American capital by contrasting themselves with the cosmopolitan blackness, so to speak, of the non-English-speaking language groups. These groups were tolerated and even necessary for enriching the diversity of the school. Hage

\footnotetext{
${ }^{94}$ I use "Japanese-speaking" instead of "Japanese" to indicate that they may be of full or partial Japanese descent.
} 
(1998, p. 121) argues that the value of minority cultures "lies in their function as enriching cultures." They made the school look "international". But in most cases students had to acquire Euro-American capital (i.e. assimilate) to be accepted. The leaders of the Japanese club were drawing on the school's ideology of being "international" and reproducing a Japanese version of the ideology within the club like a fractal pattern.

The non-inclusive attitudes of the Japanese-speaking leaders towards those who were not Japanese seemed to go unnoticed by those who were the target of these attitudes, or at least I did not hear them complain about it. However, these attitudes were a source of indignation to some of the other Japanese-speaking members. Chitchats in Horie sensei's classroom, which turned into a Japanese hangout area after school, were filled with complaints about the leaders when the leaders were not present. Naomi, who was a native speaker of English and usually hung out with the English-speaking groups in her grade, was particularly vocal about her displeasure with the club's leadership. However, on another occasion, as discussed in Chapter 8, I saw her unintentionally reinforce the dominance of the Euro-American school culture over Korean boys by participating in the construction of Koreans as the nameless, faceless Other. Naomi reproduced the fractal pattern. She marked the non-inclusive attitudes of her Japanese peers as cosmopolitan blackness, thereby positioning herself as being more "international". But in another context Naomi reinforced the dominance of Euro-American culture. Cosmopolitan practices are situational both for the leaders of the Japanese club as well as Naomi-they shift between practicing cosmopolitan engagement with the Other and cultural dominance over the Other depending on the context.

As the performance day approached, the tension over the club leadership exploded during a dress rehearsal. Erina, the club president, and the other dancers were on stage when a disagreement arose over how they would end the performance. I was with Horie sensei in the audience seats watching the performance. Erina and Horie sensei argued back and forth for a while until Horie sensei suddenly raised her voice and scolded Erina in the presence of all. Erina broke into tears as her closest friends comforted her. Having "hung out" with both Horie sensei and Erina, I felt uncomfortable because I did not want to seem as though I was taking sides on the matter by virtue of being near the teacher at the time of the incident.

Horie sensei later explained that Erina and her two close friends were too proud, which prevented them from breaking out of their shell to mingle with non-Japanese students. Erina 
was the student who had looked pleasantly relieved when she found out I spoke Japanese the first time we met. I had also seen her face stiffen as she found herself unable to participate in a small group discussion during class. Perhaps this was why she and her friends had been adamant about giving out instructions in Japanese-to exercise agency when they could in an otherwise marginalizing environment (e.g. Foley, 1996). Perhaps their pride had been a defence mechanism against feeling paralysed in a transnational space that privileged EuroAmerican capital.

\section{A new "We are the world"}

United Nations Day was as a kaleidoscopic showcase of visible diversity, as I described in Chapter 4. It served the purposes of the school's ideology of being "international". UN Day was the only designated day on which students of non-Euro-American backgrounds took centre stage both literally and figuratively. They were given a license to be something other than "western". In fact, students from western countries struggled to find a way to express their "culture" on UN Day that visually compared with the "ethnic cultures". While a handful came dressed as a medieval knight or Uncle Sam, their main expression of identity was in the form of T-shirts printed with their national flag or in the colour of their national sports teams (usually soccer). On this day, the non-Euro-American, and more generally the non-Anglophone, elements of the school received validation as something "enriching" for the cosmopolitanism of the dominant culture (Hage, 1998, p. 121).

However, the UN Day performance clubs that were organized along national imaginaries had several contradictory consequences. On the one hand, they pandered to the romanticization of visible diversity. On the other hand, they reinforced national boundaries. A student claimed that United Nations Day made them (as it did me) feel excluded because they did not belong to any national group. Specifically, the competitive nationalistic spirit between the Japanese and Korean clubs was of concern to the staff as it was counterproductive to the school's cosmopolitan project of breaking down cultural boundaries. James, one of the coordinating staff for the performances related that the staff was considering making changes to the way UN Day was organized.

[We] are gonna do something different with the UN Day next year for a couple of reasons. One, we feel that the program has just become kinda stale, because it's been 
done in the same way for so long. But also there's this, you know, it's actually, like, national identity competition day...(Laughs) It is. It's like who's gonna be better, the Japanese or the Koreans? And you know, now the Indians have gotten more people involved, right? But it really is. And so our idea is to try to get representatives from each of the groups, and over a weekend workshop-this comes from an ISTA...an international theatres association model-do a festival approach where we collaborate...So the Korean leaders can say, "We wanna do this section of Korean drumming," but instead of it being only the Koreans that learn it, everybody in an ensemble learns it. So everybody can bring in influences from their culture. But we're gonna...synthesize and then make a, you now, a blending...And we all learn to do things from each other's cultures. To us that's much more what [TIS] is really about.

James was addressing the fact that the design of United Nations Day was outmoded. Its emphasis on visible diversity comes out of a multicultural model that is premised on cultures being distinct and designed within a national framework for nation-states to cope with a diversifying society. The model was not designed for a transnational framework where identity, in the words of Hall (1993, p. 362), "is always an open, complex, unfinished game always under construction." James' suggestion for a new way of organizing the performance is an attempt to accommodate the hybridity of transnational youth.

Nonetheless, UN Day was the day when those who were usually relegated to a position of parochial Other were able to express themselves and "exist" in a positive way, to borrow Jenny's words from Chapter 8. James comments,

But I think we're gonna have a hard time selling it to the Japanese and the Koreans and the Indian community because there's so much national pride, and we're taking away an opportunity for them to exhibit their national pride, so I think we're gonna get a lot of resistance...What we're gonna say is, this is gonna be an old format...we're gonna return to performances at lunch when they're doing that on stage outdoors. So they can still have that option but it's not as sexy as the stage [indoors]...You still have the opportunity if that's what you wanna do. So we're not, so people can't say we're taking that away, but we want to take the emphasis off the show in here (the theatre), off the nationalism in the show in the [theatre] into something that's more, really, truly, "We are the world." 
The nationalistic overtones of the performances caused the school to want to rectify the situation by redefining the rules of engagement. In James' view, the national clubs, especially the Korean and Japanese clubs, allegedly failed in attracting wider membership because their practice schedule was too rigorous. The performance was held at the end of November, and James explains,

I think that's partly because the rehearsal schedule is really demanding. I mean, those kids are working on that, I think, in August ${ }^{95}$ and they meet on Saturdays. I mean it's very intense and what they do is incredible...and I watched that, and there's part of me that goes, well we're not gonna get that.

The way the Korean and Japanese students practise was not something that "we", i.e. the Euro-American staff and students, were going to "get" because it was different from the norm.

Cosmopolitanism needs to be practised on the terms of those of the dominant culture, not of those in a marginal position. Ultimately, the school held the power to define and change the rules of the game. Hage (1998, p. 121) contends that this "discourse of enrichment" veils the ability of the dominant culture to assign value to other cultures; the act of displaying minority cultures in a good light "mystifies the deeper division between holding the power to value (negatively or positively) and not holding it."

\section{Conclusion}

In line with its ideology of being "international", TIS encourages students to engage with difference, but its practices occur within a transnational educational space where global, regional, and national structures intersect. Students draw upon the discourses prescribed by these structures to reinforce their own superior position in the global or regional hierarchies, or subvert national structures. As a result, the pattern through which minority cultures enrich the dominant Euro-American culture by making it look "international" while it retains its dominance is repeated like fractals in the transnational space of TIS. The pattern set by the dominant culture was repeated on a smaller scale within the Japanese club. Although Erina

\footnotetext{
${ }^{95}$ School starts in the last week of August.
} 
and her friends did not have the cultural capital to play the cosmopolitan game, they nevertheless internalized the rules of the game, which privileged Euro-American capital. They played by the same rules in their attempt to reduce their own sense of marginalization. Erina and her friends exercised agency within the Euro-American transnational space in ways that reflected the confines of their habitus. The non-neutrality of transnational spaces created a hierarchy among those competing to be "international".

All are complicit in reproducing the structures that support the school's ideology of being "international". Students, parents, and teachers are, however, complicit in different ways in different contexts. Transnational youth share a sense of ambivalence due to their experience of cultural marginalization, but experience it differently in different contexts depending on their positionality, which in turn is affected by their cultural background. 


\section{Chapter 12}

\section{Conclusion: Growing up in a transnational world}

This thesis explored the experiences of young people growing up in a transnational world. It focused on an international high school in Indonesia whose students experience a high-level of international mobility either directly or indirectly. I referred to them as "transnational youth" to acknowledge that they share the experience of feeling third cultured, whereby they exist between essentialist social categories that are traditionally defined based on the nation-state. Nevertheless, their transnational experiences are varied. Therefore I examined the tension between the shared transnational experiences and the different cosmopolitan practices of these young people. In order to examine this tension, I interrogated the dominant form of cosmopolitanism practised at an international school, which I referred to as the school's ideology of being "international". I then analysed the way different groups of students engaged with this ideology within the socio-historical context of a capitalist, postcolonial world.

This study illustrated that the shared experience of a transnational upbringing is tempered by factors such as culture, "race", class, nationality, and gender. These factors mediate actors' positionality within social hierarchies, which in turn impact transnational youth differently. In concluding, I review my main arguments and draw attention to the analytical and methodological contributions this thesis has made to the literature, while acknowledging the limitations of this study by suggesting possible areas for future research.

\section{Methodological cosmopolitanism}

I chose to collect most of the empirical data at an international school because it offered a relatively finite space where I could immerse myself in the social lives of transnational youth. The main challenge of this study was bringing the various groups of people who were at the field site under a single analytical framework and situating their experiences within the present socio-historical context.

I used methodological cosmopolitanism as the overarching analytical framework for examining 
the groups of people and social processes relating to the field site that have hitherto been studied separately. I treated cosmopolitan practices of engaging with the other as the norm at TIS. By taking cosmopolitanism as the norm, I avoided dichotomous categorizations of TIS students according to whether or not they were "international" or Third Culture Kids. The young people I studied all had a transnational upbringing and were equal targets of the school's project of educating them to become "international".

TIS's ideology of being "international" represents a set of ideas and practices about engaging peaceably with others across difference. Being "international" was characterized by having a global outlook as well as: a propensity to engage with the Other who are defined by their visible differences (mainly "race"), speaking (natural) English, being associated with the (western) expatriate community, distance from the local, Euro-American capital, and being socialized into the transnational middle-class. To be "international", students had to have what I collectively refer to as (Euro-American) cosmopolitan cultural and social capital. I thus demonstrated that the ideology of being "international" was a Eurocentric form of cosmopolitanism, which illuminates the contemporary "global currency of whiteness" (Carey, Boucher, \& Ellinghaus, 2009, p. 5).

With this in mind, I examined the way transnational youth related to each other in their daily lives at TIS. The data show that their cosmopolitan practices are diverse and situationally embedded within the socio-historical contexts of global structures of power. The school's ideology of being "international" promotes an idea of social cohesion through which a global community was imagined, but it also reproduces both national and transnational class structures through the privileging of Euro-American capital.

This thesis brought the children of expatriates of diverse nationalities and of the local population into one analytical field without losing site of the multiple structures that affect their lives. At TIS, being "international" was packaged as an ideal that all students should pursue. In order to become "international", students had to acquire cosmopolitan capital, which overlapped with Euro-American capital. However, students were differently positioned in this pursuit due to the diversity of their cultural backgrounds. Some students were favourably positioned to acquire cosmopolitan capital because they were fluent in English and had acquired Euro-American capital through their home or school environment. Others were not. The different positionalities of students influenced the creation of different language 
groups among them that frustrated the school's mission of producing "global citizens".

I conceptualized TIS as a transnational educational space where multiple national and transnational structures converged. These structures placed varying demands on students in accordance with their future aspirations regarding where they would go to college, work, and live. Some had to maintain a balance between Euro-American cosmopolitan capital and the national capital that would enable them to work in their passport countries. Students, parents, and teachers who were part of the dominant school culture perceived the attempts by nonwestern students to acquire Euro-American capital without becoming "international" as inauthentic. In contrast, I demonstrated that students who did not gain the school's approval as being "international" in fact practised alternative forms of cosmopolitanism.

Ambivalence characterized the way cosmopolitan practices were perceived as "international", "western", "Asian", "Indonesian", etc. depending on whose perception was in question. Students become "international" by becoming "western", "Asian", "Indonesian", "Korean", and/or "Japanese", etc. Many of these processes were mutually constitutive ways of practising cosmopolitanism that emerged out of socio-cultural inequalities. Clifford $(1997$, p. 10) states that, "what matters politically is who deploys nationality or transnationality, authenticity or hybridity against whom, with what relative power." The staff inadvertently exercised symbolic power by tacitly or not so tacitly recognizing certain students or student groups over others as "international" or "TCK" (Bourdieu \& Thompson, 1991). Those who had the cultural capital to feel comfortable in the English-speaking groups were perceived as "international", while those who did not were perceived as ethnocentric. Their cosmopolitan practices were invisible.

There was a contradiction in the school's ideology of being "international" -it promoted a deracialized, colour-blind view of the world, but its cosmopolitan practices are dependent on the visibility of racial differences. The cultural sameness of those with Euro-American capital was rendered invisible by their racial diversity. Jacqueline Lo $(2000$, p. 153$)$ refers to this celebration of diversity as "happy hybridity", which pays little heed to the "tension, conflict or contradiction" inherent in inter-cultural encounters and thereby "masks and perpetuates structural inequalities." It does not take into account that for those without Euro-American cultural capital, the English-speaking groups can be inaccessible. The school's ideology of being "international" universalizes a Euro-American construct of cosmopolitanism. It created a hierarchy of cosmopolitan practices. Students competed to be "international" within the confines of the dominant form of cosmopolitanism as represented by the school's ideology of 
being "international". Alternative forms of cosmopolitanism were relegated to an inferior position by virtue of not being recognized as "international". Hage (1998) argues that being cosmopolitan, in this Euro-American sense, is an ideal that has to be constantly desired and sought after though never reached. It is "by feeling qualified to yearn for such a position" that people are identified as cosmopolitan (Hage, 1998, p. 58).

Even so, the ideology of being "international" reproduces class by enabling transnational youth the "capacity to aspire" in a globalizing world-a capacity which Appadurai (2004, p. 68) argues is more developed in the "relatively rich and powerful". Appadurai (2004, p. 68) writes that those who are better off "are more able to produce justifications, narratives, metaphors, and pathways through which bundles of goods and services are actually tied to wider social scenes and contexts, and to still more abstract norms and beliefs." It is in this sense that the ideology of being "international" becomes the vehicle through which socio-economic structures in both national and transnational contexts are reproduced.

\section{Contributions to the literature}

This thesis contributes to the literature by using an anthropological approach to situate the experiences of transnational youth in their socio-historical context of a globalizing, capitalist, postcolonial world. The literature on transnational youth that uses "Third Culture Kids" as its main analytical framework provides crucial insight into the impact of mobility on individual identity development and intercultural competence. However, its mainly psychological and educational approaches mean that this literature generally sings a unified praise of being "international" without critically examining relations of power. In contrast, the limited literature in the field of anthropology critically analyses transnational youth as an elite class of young people enmeshed in the global capitalist system (e.g. Goodman, 1990; O'Reilly, 2009; Peterson, 2011). However, this literature tends to focus on transnational youth of one nationality and does not integrate the study of expatriate and local youth in a transnational space.

The postcolonial context has largely remained absent from discussions due to the literature's emphasis on the globalizing present. Timothy Brennan (2008, p. 38) argues that contemporary capitalist societies 
are at once presentist-that is, viewing each moment as the only reality while expunging the past in a gesture of calculated antihistoricism-and modernist in the technical sense of needing to judge every current discovery as an utterly new departure, an absolute rupture with all that went before.

The theoretical rupture between the colonial past and post-colonial present has significant implications for literature on transnational youth. Currently, the literature on Third Culture Kids and international schools, which are relevant to the study of transnational youth, emphasize the West in the globalizing present while overlooking the economic and cultural legacies of colonialism on the capitalist present. Mobility among children and youth is perceived as a relatively new phenomenon arising out of the contemporary system of global capitalism, free from the colonial discourses that influence the construction of transnational identities and spaces. The literature generally does not make explicit the socio-historical continuity of colonial discourses of race and Eurocentrism in the experiences of transnational youth. ${ }^{96}$

This thesis contributes analytically to the literature in several ways. First, I integrated the study of transnational youth of many nationalities, including the children of both expatriates and locals, in a transnational educational space. I used methodological cosmopolitanism to integrate them and both the national and transnational structures that influence their behaviour into one analytical framework. Second, the anthropological approach allowed me to examine the impact of national and transnational class structures on transnational youth and their pursuit of cosmopolitan capital. This situates them in a globalizing, capitalist world. Third, this thesis brought the contemporary significance of colony and metropole in the study of transnational youth into a single analytic field using a postcolonial approach. It reflected on the colonial genealogy of Euro-American capital in reproducing both global/transnational and local/national class structures in contemporary times (Cooper \& Stoler, 1989). Thus, I argued that the Indonesian context is significant not only as a backdrop for enhancing the feeling of being "international", but also as the national context of a transnational space. Recognizing the national context allowed me to integrate the study of local Indonesian students with the study of expatriate students. I used a postcolonial approach to highlight the socio-historical continuity of colonial discourses in the experiences of transnational youth, without losing sight

\footnotetext{
${ }^{96}$ I have only located one non-anthropological work that includes respondents who have had an internationally mobile upbringing that touches upon this (Sparrow, 2000).
} 
of the influence of contemporary capitalist discourses. ${ }^{97}$

By employing "cosmopolitanism" as the analytical starting point, I was able to examine the complex ways in which the social lives of transnational youth are affected by international mobility and their everyday engagement with difference. It merged the study of many disparate social groups and processes into one analytical field. It also highlighted the intricate ways in which culture, "race", class, and gender hierarchies intersect to create a multifaceted, multidimensional hegemony of a Euro-American form of cosmopolitanism. This included an analysis of the hegemony of English and its power to form the subjectivities of transnational youth. Transnational youth negotiate social boundaries as a matter of everyday living due to their liminality, thus yielding concentrated data on how these boundaries are constructed and shifted (Barth, 1994).

\section{Implications for future research}

In Chapter 4, I quoted Daniel who argued that students do not automatically become "international" through immersion in an international school. He said, "[T]here needs to be other elements." This thesis has proved Daniel's point. However, more research needs to be done to find the "other elements" required to design workable alternatives to the immersion model.

\section{Diversity of international schools}

There are a few possible areas of research relating to the formal aspects of international schooling. I have shown that teachers and other staff play important roles in acting as gatekeepers for the ideology of being "international" and as cultural brokers between students and the dominant culture of the school. More study can be done on how the cultural competency of teachers affect student integration into the school with a view to proposing practical measures that can be implemented at international schools.

While this thesis focused on TIS, I did spend two weeks at another international school in Jakarta where the student demographic was significantly different. The school was smaller and

\footnotetext{
${ }^{97}$ See Revathi Krishnaswamy $(2007$, p. 2) for a discussion of approaches that integrate globalization and postcolonial theories.
} 
the student body was almost entirely Asian, with a handful of students of European or mixed European and Asian descent. While the teachers were still mostly white and Anglophone, the Asian students overall had a more casual rapport with the teachers. Although the social hierarchy was less pronounced due to the smaller number of students, those who seemed popular were the Indonesian students who had economic capital and were westernized or were of mixed descent, thus still reflecting the social hierarchy at TIS. Noticeably different from TIS was the greater presence (in number) of Southeast Asian students, especially those from the poorer countries such as Burma, Laos and Cambodia, and of a handful of African students. This can be attributed to the lower tuition fees compared to TIS. Similarly, I heard that international schools with even lower tuition fees have a higher percentage of African students than both of the schools I was acquainted with through research. This suggests that global economic structures have a direct impact on student demographics whereby the more expensive international schools have more students from developed countries and the less expensive ones have more students from developing countries. More research can be done to see how global economic structures are reproduced through the differences between international schools.

In addition, future research needs to take into account the impact that changing global structures have on international schools and the experiences of transnational youth in these schools. As various regions develop economically and the demand for international education rises, more and more international schools that interpret being "international" through different cultural lenses will be established. While this research is based on data collected at an international school where the dominant school culture is oriented towards the "West", future research could explore the cultural dynamics of international schools that, like TIS, actively engage with notions of cosmopolitanism and have a diverse student body in terms of nationality, but emphasize other cultural influences or whose teaching staff are from nonAnglophone or non-western countries. Examples of potential field sites are: Islamic international schools that have a diverse student body from various Muslim countries and interpret internationalism through an Islamic cultural lens, or international schools that incorporate Singaporean-style pedagogy into their international curriculum and whose student body is diverse but predominantly from Asia.

Finally, this thesis focused on the hidden curriculum of the school, but future studies could focus on the formal curriculum. For example, research could focus on the impact of the 
International Baccalaureate program on cosmopolitan practices.

\section{Social lives}

Although transnational youth do spend much of their time within the international school community, their social lives outside the school campus present potential for further research. For example, students in this dissertation often referred to stories of incidents at nightclubs and off-campus social events organized by the students in relation to their inter-group relationships and their experiences of repatriation. The seemingly unencumbered access to alcohol and nightclubs that transnational youth have in countries that do not enforce laws on underage drinking was often raised as an issue and seemed to impact the formation of social groups at school. Indonesian-speaking students were said to frequent more expensive clubs than the English-speaking students, thus illustrating that socio-economic differences among transnational youth may result in different socializing patterns outside of school. Furthermore, although the beer garden I went to was dominated by teenagers, the nightclubs they frequented were mainly adult-dominated spaces. For some transnational youth, access to these spaces from a young age may have implications for their social development, as well as have an impact on their experience of repatriation to countries where age restrictions are more strictly enforced.

In addition, future research could focus on the interaction among transnational youth as well as their interaction with locals outside the school campus. I have mentioned that the host country nationals who worked at TIS remained largely invisible to the students because they occupied positions more lowly positions than the expatriate workers. Research that focuses on their social lives outside the international school could provide more in-depth understanding of the effect that the host country has on transnational youth. Future research could also explore the experiences of transnational youth within the various expatriate communities that they are a part of (e.g. American, German, and Korean communities), and how the way these communities are situated within the host country shapes the social lives of transnational youth both on and off campus. By exploring the experiences of transnational youth within the context of the broader expatriate communities and host society, these future studies would fill the gap that occurs between this ethnographic work on the children of expatriates within the international school context and those on adult expatriates within the context of the broader expatriate communities and host society (Fechter, 2007; Leggett, 2003; Shimoda, 2011). 
Because many of the adult transnational actors are also the parents of transnational youth, such research could lead to a greater understanding of impact of living transnationally as families.

Additionally, the use of social media is a potential area of research due to its prevalence in the lives of young people. For example, Facebook, Twitter, and Skype offer a means of connecting with the friends that many have spread across the globe due to the international moves they make, but the impact of social media on young people's transnational upbringing has yet to be studied. Social media also appeared to be sites where social exclusion and interaction occurred that would not have occurred otherwise. While social media had the potential to connect students, they may also reinforced the differences between the language-based groups. The Japanese-speaking students commonly had a Facebook account to connect with their nonJapanese friends and a Mixi ${ }^{98}$ account to connect with their Japanese friends. In addition to language differences between the two media, they used interfaces that appealed to different aesthetic tastes, thus visibly attesting to the different cultural capital that is required to use and enjoy them. The way cultural capital influences transnational youth's interactions online could be an important area of research.

\section{Applying methodological cosmopolitanism to other groups}

Future research could focus on transnational youth who are less privileged economically or in other ways, such as children of temporary migrant workers (e.g. maids) or children of refugees in refugee camps. Such research could offer a comparison for young people's experience of a transnational upbringing. Methodological cosmopolitanism can also be applied to adults in transnational spaces because, as Fechter and Walsh (Fechter \& Walsh, 2010) note, existing research has yet to bring western expatriates, expatriates of other nationalities, and locals from the host country into one analytical field. The lives of adults in transnational space are relevant because many of them are parents of transnational youth. Furthermore, those who have a transnational upbringing often work as expatriates as adults.

In summary, this thesis has used the shared experiences of a transnational upbringing among the cohort I studied as a starting point to investigate the way young people interact with each other as they make sense of their ambivalent, shifting places in an increasingly globalizing

\footnotetext{
${ }^{98}$ A Japanese social medium that is similar to Facebook.
} 
world. It has shown that even their cosmopolitan practices are tempered by economic and social structures that define social boundaries, and in fact reproduce these structures both in national and transnational contexts. The way transnational youth engage with the ideology of being "international" reveals the complex nature of the whiteness of being "international", as well as the way relations of power are reproduced as patterns within a pattern like fractals. More significantly, this study of transnational youth highlights the diversity of cosmopolitan practices.

I used methodological cosmopolitanism to analyse the data on transnational youth and spaces, while simultaneously using the data and a postcolonial approach to critique practices of cosmopolitanism. This thesis has explored the complex set of factors that make transnational youth a heterogeneous group, but an exploration of their differences, it must be remembered, was made possible by first acknowledging their shared experience of liminality in their transnational upbringing. Although they may not hang out together, Maura, who appeared in Chapter 11, believed that growing up outside of their parents' cultural milieu meant that the American, Indonesian, Korean and Japanese "kids" shared something: "We're all kinda, have a collective culture together." 


\section{References}

Abu-Rabia, Aref. (2008). A native Palestinian anthropologist in Palestinian-Israeli cosmopolitanism. In P. Werbner (Ed.), Anthropology and the new cosmopolitanism: rooted, feminist and vernacular perspectives (pp. 159-171). Oxford; New York: Berg.

Allan, Michael. (2004). Cultural borderlands: cultural dissonance in the international school. In E. Murphy (Ed.), Culture and the international school: living, learning and communicating across cultures (Vol. 2, pp. 89-97). Saxmundham: Peridot Press.

Amit, Vered. (2000). Constructing the field: ethnographic fieldwork in the contemporary world. London: Routledge.

Amit, Vered. (2010). Student mobility and internationalisation: rationales, rhetoric and'institutional isomorphism'. Anthropology in Action, 17(1), 6-18.

Amit-Talai, Vered, \& Wulff, Helena. (1995). Youth cultures: a cross-cultural perspective. London: Routledge.

Anderson, Benedict R. O'G. (1983). Imagined communities: reflections on the origin and spread of nationalism. London: Verso.

Ang, len. (2001). On not speaking Chinese: living between Asia and the West. New York \& London: Routledge.

Appadurai, Arjun. (1996). Modernity at large: cultural dimensions of globalization. Minneapolis: University of Minnesota Press.

Appadurai, Arjun. (2004). The capacity to aspire: culture and the terms of recognition. In V. Rao \& M. Walton (Eds.), Culture and public action (pp. 59-84). Standford, Calif.: Stanford University Press.

Appiah, Kwame Anthony. (1998). Cosmopolitan patriots. In P. Cheah \& B. Robbins (Eds.), Cosmopolitics: thinking and feeling beyond the nation (pp. 91-114). Minneapolis: University of Minnesota Press.

Appiah, Kwame Anthony. (2006). Cosmopolitanism: ethics in a world of strangers (1st ed.). New York: W.W. Norton.

Ashcroft, Bill. (2001). Post-colonial transformation. London; New York: Routledge.

Ashcroft, Bill, Griffiths, Gareth, \& Tiffin, Helen. (2006). The post-colonial studies reader (2nd ed.). London \& New York: Routledge.

Baldassar, Loretta. (1999). Marias and marriage: ethnicity, gender and sexuality among ItaloAustralian youth in Perth. Journal of Sociology, 35(1).

Baldassar, Loretta. (2001). Visits home: migration experiences between Italy and Australia. Carlton South, Vic.: Melbourne University Press.

Barth, Fredrik. (1994). Ethnic groups and boundaries: the social organization of culture difference. Oslo: Pensumtjeneste.

Bashkow, Ira. (2004). A neo-Boasian conception of cultural boundaries. American Anthropologist, 106(3), 443-458. doi: 10.1525/aa.2004.106.3.443

Beck, Ulrich, \& Sznaider, Natan. (2006). Unpacking cosmopolitanism for the social sciences: a research agenda. The British Journal of Sociology, 57(1), 1-23.

Beck, Ulrich, \& Sznaider, Natan. (2010). Unpacking cosmopolitanism for the social sciences: a research agenda. The British Journal of Sociology, 61, 381-403. doi: 10.1111/j.14684446.2009.01250.x

Bell-Villada, Gene H., \& Sichel, Nina (Eds.). (2011). Writing out of limbo. Newcastle upon Tyne: Cambridge Scholars Publishing.

Benson, Michaela, \& O'Reilly, Karen. (2009). Lifestyle migration : expectations, aspirations and experiences. Farnham: Ashgate.

Berzonsky, Michael D. (2005). Ego identity: a personal standpoint in a postmodern world. Identity, 5(2), 125 - 136. 
Bhabha, Homi K. (1984). Of mimicry and man: the ambivalence of colonial discourse. October, 28, 125-133.

Bhabha, Homi K. (1990). The third space. In J. Rutherford (Ed.), Identity: community, culture, difference (pp. 207-221). London: Lawrence \& Wishart Limited.

Bhabha, Homi K. (1994). The location of culture. London \& New York: Routledge.

Bhabha, Homi K. (1996). Unsatisfied: notes on vernacular cosmopolitanism. In L. GarcíaMoreno \& P. C. Pfeiffer (Eds.), Text and nation: cross-disciplinary essays on cultural and national identities (pp. 191-207). Columbia, SC: Camden House.

Blommaert, Jan. (2010). The sociolinguistics of globalization. New York: Cambridge University Press.

Bolon, Anne Sophie. (2002). At home abroad / third culture kids: nowhere to call home but I like being a global nomad, International Herald Tribune. Retrieved from http://www.iht.com/articles/2002/10/26/rkid_ed3_php?page=1

Bottomley, Gillian. (1992). From another place: migration and the politics of culture. Cambridge, England; Melbourne: Cambridge University Press.

Bourdieu, Pierre. (1984). Distinction: a social critique of the judgement of taste (R. Nice, Trans.). London: Routledge.

Bourdieu, Pierre. (1986). The forms of capital. In J. G. Richardson (Ed.), Handbook of theory and research for the sociology of education (pp. 241-258). Westport, Conneticut: Greenwood Press.

Bourdieu, Pierre. (1989). Social space and symbolic power. Sociological Theory, 7(1), 14-25.

Bourdieu, Pierre. (1990). The logic of practice (R. Nice, Trans.). Cambridge, UK: Polity Press.

Bourdieu, Pierre, \& Thompson, John B. (1991). Language and symbolic power. Oxford: Polity Press.

Brennan, Timothy. (2008). Postcolonial studies and globalization theory. In R. Krishnaswamy \& J. C. Hawley (Eds.), The postcolonial and the global (pp. 329 p.). Minneapolis: University of Minnesota Press.

Brown, Phillip, \& Lauder, Hugh. (2009). Globalization, international education, and the formation of a transnational class? Yearbook of the National Society for the Study of Education (Wiley-Blackwell), 108(2), 130-147. doi: 10.1111/j.1744-7984.2009.01165.x

Brown, Wendy. (2006). Regulating aversion: tolerance in the age of identity and empire. Princeton, New Jersey: Princeton University Press.

Bunzl, Matti. (2004). Boas, Foucault, and the "native anthropologist": notes toward a neoBoasian anthropology. American Anthropologist, 106(3), 435-442. doi: 10.1525/aa.2004.106.3.435

Burck, Charlotte. (2005). Multilingual living: explorations of language and subjectivity. Houndmills, Basingstoke, Hampshire; New York: Palgrave Machmillan.

Calhoun, Craig. (2008). Cosmopolitanism in the modern social imaginary. Daedalus, 137(3), 105-114.

Caputo, Virginia. (1995). Anthropology's silent 'others': a consideration of some conceptual and methodological issues for the study of youth and children's cultures. In V. AmitTalai \& H. Wulff (Eds.), Youth cultures: a cross-cultural perspective (pp. 19-42). London: Routledge.

Carey, Jane, Boucher, Leigh, \& Ellinghaus, Katherine. (2009). Re-orienting whiteness: a new agenda for the field. In L. Boucher, J. Carey \& K. Ellinghaus (Eds.), Re-orienting whiteness: transnational perspectives on the history of an identity. New York: Palgrave Macmillan. Retrieved from Ebook Library.

Chatterjee, Partha. (1993). The nation and its fragments: colonial and postcolonial histories. Princeton, N.J.: Princeton University Press.

Cheah, Pheng, \& Robbins, Bruce. (1998). Cosmopolitics: thinking and feeling beyond the nation. Minneapolis: University of Minnesota Press. 
Cillessen, Antonius H. N., \& Mayeux, Lara. (2007). Expectations and perceptions at school transitions: the role of peer status and aggression. Journal of School Psychology, 45(5), 567-586. doi: DOI: 10.1016/j.jsp.2007.05.004

Clifford, James. (1986). Introduction: partial truths. In J. Clifford \& G. E. Marcus (Eds.), Writing culture: the poetics and politics of ethnography (pp. 1-26). Berkeley: University of California Press.

Clifford, James. (1997). Routes: travel and translation in the late twentieth century. Cambridge, Mass.: Harvard University Press.

Coleman, John C. (2011). The nature of adolescence (4th ed.). London \& New York: Routledge.

Coles, Anne, \& Fechter, Anne-Meike. (2008). Gender and family among transnational professionals. New York: Routledge.

Cooper, Frederick, \& Stoler, Ann L. (1989). Introduction tensions of empire: colonial controld and visions of rule. American Ethnologist, 16(4), 609-621.

Delanty, Gerard. (2009). The cosmopolitan imagination the renewal of critical social theory (pp. $x, 296$ p.). Retrieved from Eook Library

Dolby, Nadine, \& Rahman, Aliya. (2008). Research in international education. Review of Educational Research, 78(3), 676-726. doi: 10.3102/0034654308320291

Downie, Richard Dixon. (1976). Re-entry experiences and identity formation of third culture experienced dependent American youth: an exploratory study. (Ph.D. dissertation), Michigan State University, East Lansing, Michigan.

Du Bois, W. E. B., \& Edwards, Brent Hayes. (2007[1903]). The souls of Black folk. Oxford \& New York: Oxford University Press.

Dyer, Richard. (1997). White. London \& New York: Routledge.

EARCOS. (2010). Global citizenship. Retrieved February 16, 2013, from http://www.earcos.org/other_award.php

El-Zein, Abbas. (2002). Being elsewhere: on longing and belonging. In G. Hage (Ed.), ArabAustralians today: citizenship and belonging (pp. 225-240). Carlton South, Vic.: Melbourne University Press.

Erikson, Erik H. (1959). Identity and the life cycle: selected papers. New York: International Universities Press.

Erikson, Erik H. (1968). Identity: youth, and crisis. New York: W.W. Norton.

Erikson, Erik H. (2008). The problem of ego identity. In D. L. Browning (Ed.), Adolescent identities: a collection of readings (pp. 223-240). New York: The Analytic Press.

Expat Web Site Association Jakarta. (2013). International schools in Jakarta. Living in Indonesia: a site for expatriates. Retrieved April 25, 2013, from http://www.expat.or.id/orgs/schools.html

Fail, Helen. (2002). An examination of the life histories of a group of former international school students. (PhD dissertation), University of Bath, Bath, UK.

Fail, Helen, Thompson, Jeff, \& Walker, George. (2004). Belonging, identity and Third Culture Kids: life histories of former international school students. Journal of Research in International Education, 3(3), 319-338. doi: 10.1177/1475240904047358

Farrer, James. (2010). 'New Shanghailanders' or 'New Shanghainese': Western Expatriates' Narratives of Emplacement in Shanghai. Journal of Ethnic and Migration Studies, 36(8), 1211 - 1228.

Fechter, Anne-Meike. (2007). Transnational lives: expatriates in Indonesia. Aldershot: Ashgate.

Fechter, Anne-Meike, \& Walsh, Katie. (2010). Examining 'expatriate' continuities: postcolonial approaches to mobile professionals. Journal of Ethnic and Migration Studies, 36(8), $1197-1210$.

Ferstad, Corrine Freitas (2002). A sense of home: what constitutes a sense of home and community for pre-adolescent and adolescent youth living in international transition? (Ph.D. dissertation), Union Institute \& University, Cincinnati, Ohio. 
Field, Norma. (1996). Texts of childhood in inter-nationalizing Japan. In L. García-Moreno \& P. C. Pfeiffer (Eds.), Text and nation: cross-disciplinary essays on cultural and national identities (pp. 143-172). Columbia, SC: Camden House.

Foley, Douglas E. (1996). The silent Indian as a cultural production. In B. A. Levinson, D. E. Foley \& D. C. Holland (Eds.), The cultural production of the educated person: critical ethnographies of schooling and local practice (pp. 79-91). Albany, New York: State University of New York Press.

Foner, Nancy. (2002). Second-generation transnationalism, then and now. In P. Levitt \& M. C. Waters (Eds.), The changing face of home: the transnational lives of the second generation. New York: Russel Sage Foundation.

Foner, Nancy, \& Kasinitz, Philip. (2007). The second generation. In M. C. Waters, R. Ueda \& H. B. Marrow (Eds.), The new Americans: a guide to immigration since 1965: Harvard University Press.

Frankenberg, Ruth (Ed.). (1997). Displacing whiteness essays in social and cultural criticism. Durham, NC: Duke University Press.

Frederick, Leah Ruth. (1996). Balancing the four major influences on transcultural students through an educational environment. (Ph.D. dissertation), The University of Georgia, Athens, Georgia.

Geertz, Clifford. (1960). The Javanese kijaji: the changing role of a cultural broker. Comparative Studies in Society and History, 2(02), 228-249.

Geertz, Clifford. (1973). The interpretation of cultures: selected essays. New York: Basic Books.

Gellar, A. Charles. (2002). International education: a commitment to universal values. In M. Hayden, J. Thompson \& G. Walker (Eds.), International education in practice: dimensions for national \& international schools. London: Kogan Page.

Gerke, Solvay. (2000). Global lifestyles under local conditions: the new Indonesian middle class. In B.-H. Chua (Ed.), Consumption in Asia: lifestyle and identities (1 ed., pp. 135158). London \& New York: Routledge.

Goodman, Roger. (1990). Japan's 'international youth': the emergence of a new class of schoolchildren. Oxford \& New York: Clarendon Press \& Oxford University Press.

Hage, Ghassan. (1998). White nation: fantasies of white supremacy in a multicultural society. Sydney: Pluto Press.

Hage, Ghassan. (2005). A not so multi-sited ethnography of a not so imagined community. Anthropological Theory, 5(4), 463-475. doi: 10.1177/1463499605059232

Hage, Ghassan (Producer). (2009, 18 July 2011). The open mind and its enemies: anthropology and the passion of the political, part 1. SlowTV. [Inaugural distinguished lecture in anthropology] Retrieved from http://www.themonthly.com.au/anthropology-andpassion-political-ghassan-hage-2230

Hall, Stuart. (1993). Culture, community, nation. Cultural Studies, 7(3), 349-363.

Hall, Stuart. (1995). Fantasy, identity, politics. In E. Carter, J. Donald \& J. Squires (Eds.), Cultural Remix: theories of politics and the popular (pp. 63-69). London: Lawrence \& Wishart.

Hall, Stuart. (1996a). Gramsci's relevance for the study of race and ethnicity. In D. Morley \& K.H. Chen (Eds.), Stuart Hall: critical dialogues in cultural studies (pp. 411-440). New York: Routledge.

Hall, Stuart. (1996b). Who needs an identity? In S. Hall \& P. du Gay (Eds.), Questions of cultural identity (pp. 1-17). London: SAGE Publications.

Hall, Stuart, \& Werbner, Pnina. (2008). Cosmopolitanism, globalisation and diaspora: Stuart Hall in conversation with Pnina Werbner. In P. Werbner (Ed.), Anthropology and the new cosmopolitanism: rooted, feminist and vernacular perspectives. Oxford; New York: Berg.

Hannerz, Ulf. (1996). Transnational connections culture, people, places (pp. ix, 201 p.). Retrieved from Ebook Library 
Hansen, David. (2010). Chasing butterflies without a net: interpreting cosmopolitanism. Studies in philosophy and education, 29(2), 151-166.

Hayden, Mary. (2006). Introduction to international education. London: Sage Publications Ltd.

Hayden, Mary. (2011). Transnational spaces of education: the growth of the international school sector. Globalisation, Societies and Education, 9(2), 211-224. doi: 10.1080/14767724.2011.577203

Hayden, Mary, \& Thompson, Jeff. (1995). International schools and international education: a relationship reviewed. Oxford Review of Education, 21(3), 327-345.

Hayden, Mary, Thompson, Jeff, \& Walker, George. (2002). International education in practice: dimensions for national \& international schools. London: Kogan Page.

Hill, lan. (2007). Multicultural and international education: never the twain shall meet? International Review of Education, 53(3), 245-264.

Hill, Ian. (2012). Evolution of education for international mindedness. Journal of Research in International Education, 11(3), 245-261. doi: 10.1177/1475240912461990

Hoon, Chang-Yau. (2008). Chinese identity in post-Suharto Indonesia: culture, politics and media. Brighton, England; Portland, Oregon: Sussex Academic Press.

Imam, Syeda Rumnaz (2005). English as a global language and the question of nation-building education in Bangladesh. Comparative Education, 41(4), 471-486. doi: 10.1080/03050060500317588

International Baccalaureate Organization. (2013a). History of the International Baccalaureate. Retrieved April 20, 2013, from http://www.ibo.org/history/

International Baccalaureate Organization. (2013b). IB fast facts. Retrieved April 23, 2013, from http://www.ibo.org/facts/fastfacts/index.cfm

International Baccalaureate Organization. (2013c). Mission and strategy. Retrieved February 16, 2013, from http://www.ibo.org/mission/

Irvine, Jacqueline Jordan. (1989). Beyond role models: an examination of cultural influences on the pedagogical perspectives of black teachers. Peabody Journal of Education, 66(4), 51-63.

James, Kieran. (2005). International education: the concept, and its relationship to intercultural education. Journal of Research in International Education, 4(3), 313-332. doi: $10.1177 / 1475240905057812$

Jenkins, Richard. (1992). Pierre Bourdieu. London ; New York: Routledge.

Jenkins, Richard. (1997). Rethinking ethnicity: arguments and explorations. London: Sage.

Jensen, Lene Arnett. (2008). Coming of age in a multicultural world. In D. L. Browning (Ed.), Adolescent identities: a collection of readings (pp. 3-18). New York: The Analytic Press.

Jordan, Kathleen A. Finn. (1981). The adaptation process of third culture dependent youth as they re-enter the United States and enter college: an exploratory study. (Ph.D. disseration), Michigan State University.

Joyner, Kara, \& Kao, Grace. (2005). Interracial relationships and the transition to adulthood. American Sociological Review, 70(4), 563-581.

Kanan, Hana M., \& Baker, Ahmad M. (2006). Influence of international schools on the perception of local students' individual and collective identities, career aspirations and choice of university. Journal of Research in International Education, 5(3), 251-268. doi: $10.1177 / 1475240906069448$

Kanno, Yasuko. (2000). Kikokushijo as bicultural. International Journal of Intercultural Relations, 24(3), 361-382.

Kinney, David A. (1993). From nerds to normals: the recovery of identity among adolescents from middle school to high school. Sociology of Education, 66(1), 21-40.

Konno, Ayako. (2005). Examining the relationship between ethnic identity and adjustment in Asian international students: understanding the experience of Third Culture Kids. (Psy. D. dissertation), Chicago School of Professional Psychology, Chicago. 
Korpela, Mari. (2010). A Postcolonial Imagination? Westerners Searching for Authenticity in India. Journal of Ethnic and Migration Studies, 36(8), 1299-1315. doi: 10.1080/13691831003687725

Krishnaswamy, N., \& Burde, Archana S. (2004[1998]). The politics of Indians' English: linguistic colonialism and the expanding English empire. Delhi ; Oxford: Oxford University Press.

Krishnaswamy, Revathi, \& Hawley, John C. (2007). Postcolonial and the global (pp. 1 online resource $(340$ p.)). Retrieved from Ebook Library

Kumaravadivelu, B. (2006). Dangerous liason: globalization, empire and TESOL. In J. Edge (Ed.), (Re-) locating TESOL in an age of empire (pp. 1-26). Basingstoke, England \& New York: Palgrave Macmillan.

Kustulasari, Ag. (2009). The International Standard School Project in Indonesia: a policy document analysis. (Master of Arts), Ohio State University, Ohio.

Lallo, Oren. (2008). Falafel à la baguette: global packaging for local core in international schools. In J. Resnik (Ed.), The production of educational knowledge in the global era (pp. 169-183). Rotterdam: Sense Publishers.

Langford, Mary. (1998). Global nomads, Third Culture Kids and international Schools. In M. Hayden \& J. Thompson (Eds.), International education: principles and practice. London: Kogan Page.

Laub, Dori. (2005). From speechlessness to narrative: the cases of Holocaust historians and of psychiatrically hospitalized survivors. Literature and Medicine, 24(2), 253-265.

Lease, A. Michele, Musgrove, Karen T., \& Axelrod, Jennifer L. (2002). Dimensions of social status in preadolescent peer groups: likability, perceived popularity, and social dominance. Social Development, 11(4), 508-533.

Lefebvre, Henri. (1991). The production of space (D. Nicholson-Smith, Trans.). Oxford: Basil Blackwell.

Leggett, William H. (2003). Culture, power, difference: managing ambivalence and producing identity in the transnational corporate offices of Jakarta, Indonesia. (Ph.D. dissertation), University of Illinois at Urbana-Champaign, Urbana, Illinois.

Leggett, William H. (2005). Terror and the colonial imagination at work in the transnational corporate spaces of Jakarta, Indonesia. Identities, 12(2), 271-302. doi: $10.1080 / 10702890590950618$

Leggett, William H. (2010). Institutionalising the colonial imagination: Chinese middlemen and the transnational corporate office in Jakarta, Indonesia. Journal of Ethnic and Migration Studies, 36(8), 1265 - 1278.

Leonard, Pauline. (2010). Work, identity and change? Post/colonial encounters in Hong Kong. Journal of Ethnic and Migration Studies, 36(8), 1247-1263. doi: 10.1080/13691831003687691

Levinson, Bradley A., \& Holland, Dorothy C. (1996). The cultural production of the educated person: an introduction. In B. A. Levinson, D. E. Foley \& D. C. Holland (Eds.), The cultural production of the educated person: critical ethnographies of schooling and local practice (pp. 1-54). Albany, New York: State University of New York Press.

Lindegaard, Marie Rosenkrantz. (2009). Navigating terrains of violence: how South African male youngsters negotiate social change. Social Dynamics, 35(1), 19-35.

Linger, Daniel Touro. (2005). Anthropology through a double lens: public and personal worlds in human theory. Philadelphia: University of Pennsylvania Press.

Lo, Jacqueline. (2000). Beyond happy hybridity: performing Asian-Australian identities. In I. Ang, S. Chalmers, L. Law \& M. Thomas (Eds.), Alter/Asians: Asian-Australian identities in art, media and popular culture. Annandale, NSW: Pluto Press.

Malinowski, Bronislaw. (1922). Argonauts of the Western Pacific. London,: G. Routledge \& sons. 
Matthews, Julie, \& Sidhu, Ravinder. (2005). Desperately seeking the global subject: international education, citizenship and cosmopolitanism. Globalisation, Societies \& Education, 3(1), 49-66.

Mayall, Jyoti. (2010). National plus schools and the Indonesian national education policy: background, function and major issues. (Ed.D. dissertation), University of Western Australia, Perth, Australia.

McCaig, Norma M. (2002). Raised in the margin of the mosaic: global nomads balance worlds within. International Educator, 2002(Spring), 10-17.

McLachlan, Debra A. (2007). Global nomads in an international school: families in transition. Journal of Research in International Education, 6(2), 233-249. doi: 10.1177/1475240907078615

Meerwald, Agnes May Lin. (2002). Chineseness at the crossroads: negotiations of Chineseness and the politics of liminality in diasporic Chinese women's lives in Australia. In J. Currie, S. Volet \& W. Martino (Eds.).

Mignolo, Walter D. (2000). The many faces of cosmo-polis: border thinking and critical cosmopolitanism. Public Culture, 12(3), 721.

Mitchell, Katharyne. (2003). Educating the national citizen in neoliberal times: from the multicultural self to the strategic cosmopolitan. Transactions of the Institute of British Geographers, 28(4), 387-403.

Morley, David. (2000). Home territories: media, mobility and identity. London: Routledge.

Mysbergh, James H. (1957). The Indonesian Elite. Far Eastern Survey, 26(3), 38-42. doi: $10.2307 / 3024308$

Narayan, Kirin. (1993). How native is a 'native' anthropologist? American Anthropologist, 95(3), 671-686.

Nilan, Pam, \& Feixa, Carles. (2006). Global youth? Hybrid identities, plural worlds. New York \& Abingdon, Oxon: Routledge.

Nussbaum, Martha Craven. (1996). Patriotism and cosmopolitanism. In M. C. Nussbaum \& J. Cohen (Eds.), For love of country: debating the limits of patriotism. Boston: Beacon Press.

Nye, Joseph S. (2004). Soft power: the means to success in world politics (1st ed.). New York: Public Affairs.

O'Reilly, Karen. (2009). The children of the hunters: self-realization projects and class reproduction. In M. Benson \& K. O'Reilly (Eds.), Lifestyle migration: expectations, aspirations and experiences. Farnham: Ashgate.

Ortner, Sherry B. (2002). 'Burned like a tattoo': high school social categories and 'American culture'. Ethnography, 3(2), 115-148. doi: 10.1177/1466138102003002001

Ortner, Sherry B. (2003). New Jersey dreaming: capital, culture, and the class of '58. Durham, N.C.: Duke University Press.

Ortner, Sherry B. (2006). Anthropology and social theory: culture, power, and the acting subject. Durham: Duke University Press.

Oxford Dictionaries.). "fractal". Oxford Dictionaries. April 2010. Retrieved 7 November 2012, from http://oxforddictionaries.com/definition/english/fractal

Oxford Dictionaries.). "interpellate". Oxford Dictionaries. April 2010. Retrieved 7 November 2012, from http://oxforddictionaries.com/definition/english/interpellate

Parker, Lyn. (2003). From subjects to citizens: Balinese villagers in the Indonesian nation-state. Copenhagen: NIAS.

Parry, Benita. (1991). The contradictions of cultural studies. Transition(53), 37-45.

Pennycook, Alastair. (1998). English and the discourses of colonialism. London \& New York: Routledge.

Peterson, Mark Allen. (2011). Connected in Cairo: growing up cosmopolitan in the modern Middle East. Bloomington: Indiana University Press. 
Phillips, John. (2002). The third way: lessons from international education. Journal of Research in International Education, 1(2), 159-181. doi: 10.1177/147524002764248121

Phillipson, Robert. (1992). Linguistic imperialism. Oxford \& New York: Oxford University Press.

Phinney, Jean S. (1990). Ethnic identity in adolescents and adults: review of research. Psychological Bulletin, 108(3), 499-514.

Phinney, Jean S. (2008). Ethnic identity exploration in emerging adulthood. In D. L. Browning (Ed.), Adolescent identities: a collection of readings (pp. 47-66). New York: The Analytic Press.

Pollock, David C., \& Van Reken, Ruth. (2009[2001]). Third Culture Kids: growing up among worlds. Boston: Intercultural Press.

Pollock, David C., \& Van Reken, Ruth E. (2001). Third culture kids: the experience of growing up among worlds. Boston \& London: Nicholas Brealey Publishing.

Rapport, Nigel., \& Dawson, Andrew. (1998). Home and movement: a polemic. In N. Rapport \& A. Dawson (Eds.), Migrants of identity (pp. 19-38). Oxford \& New York: Berg.

Resnik, Julia. (2008). The construction of the global worker through international education. In J. Resnik (Ed.), The production of educational knowledge in the global era (pp. 147167). Rotterdam: Sense Publishers.

Rizvi, Fazal. (2009). Global mobility and the challenges of educational research and policy. Yearbook of the National Society for the Study of Education, 108(2), 268-289. doi: 10.1111/j.1744-7984.2009.01172.x

Said, Edward W. (1985[1978]). Orientalism. Harmondsworth: Penguin.

Said, Edward W. (1994). Culture and imperialism (1st Vintage Books ed.). New York: Vintage Books.

Schachter, Elli P. (2005). Erikson meets the postmodern: Can classic identity theory rise to the challenge? Identity, 5(2), 137 - 160.

Schaetti, Barbara F. (2000). Global nomad identity: hypothesizing a developmental model. (Ph.D. dissertation), The Union Institute, Ohio.

Schwartz, Seth J. (2001). The evolution of Eriksonian and, neo-Eriksonian identity theory and research: a review and integration. Identity, 1(1), 7-58.

Schwartz, Seth J., Côté, James E., \& Arnett, Jeffrey Jensen. (2005). Identity and agency in emerging adulthood. Youth \& Society, 37(2), 201-229. doi: 10.1177/0044118x05275965

Selosoemardjan. (1962). Social changes in Jogjakarta. Ithaca, N.Y.: Cornell University Press.

Shimoda, Yukimi. (2011). From the porous spaces on the bubble: the life and work of Japanese expatriate employees in Indonesia and their relations with the host society. (Ph.D. dissertation), The University of Western Australia, Perth, Australia.

Sklair, Leslie. (2001). The transnational capitalist class. Oxford; Malden, Mass.: Blackwell.

Smith, Michael P. (2001). Transnational urbanism: Locating globalization. Malden: Blackwell Publishing.

Snyder, Benson R. (1970). The hidden curriculum. New York: Alred A. Knopf.

Sparrow, Lise M. (2000). Beyond multicultural man: complexities of identity. International Journal of Intercultural Relations, 24(2), 173-201.

Stoler, Ann Laura. (1992). Sexual affronts and racial frontiers: European identities and the cultural politics of exclusion in colonial Southeast Asia. Comparative Studies in Society and History, 34(3), 514-551.

Stoler, Ann Laura. (1995). Race and the education of desire: Foucault's History of sexuality and the colonial order of things. Durham: Duke University Press.

Straffon, David A. (2003). Assessing the intercultural sensitivity of high school students attending an international school. International Journal of Intercultural Relations, $27(4), 487-501$. 
Tamatea, Laurence. (2008). A practical and reflexive liberal-humanist approach to international mindedness in international schools: case studies from Malaysia and Brunei. Journal of Research in International Education, 7(1), 55-76. doi: 10.1177/1475240907086888

Twine, France Winddance. (1997). Brown-skinned white girls: class, culture, and the construction of white identity in suburban communities. In R. Frankenberg (Ed.), Displacing whiteness essays in social and cultural criticism. Durham, NC: Duke University Press.

U.S. Department of State. (2013). Who we are and what we do: consular affairs by the numbers. $\quad$ Retrieved 20 April 2013, 2013, from http://travel.state.gov/pdf/ca_fact_sheet.pdf

Useem, John, Useem, Ruth, \& Donoghue, John. (1963). Men in the middle of the third culture: the roles of American and non-western people in cross-cultural administration. Human Organization, 22(3), 169-179.

Useem, Ruth Hill, \& Downie, Richard D. (1976). Third-culture kids. Today's Education, 65(3), 103-105.

Van der Veer, Peter. (2002). Colonial cosmopolitanism. In S. Vertovec \& R. Cohen (Eds.), Conceiving cosmopolitanism: theory, context and practice (pp. 165-179). Oxford: Oxford University Press.

Van Reken, Ruth. (n.d.). TCK relationships and grief. Retrieved August 14, 2008, from http://tckacademy.com/class/001/tckclassminicourse001.pdf

Vertovec, Steven. (2007). Super-diversity and its implications. Ethnic and Racial Studies, 30(6), 1024-1054.

Vertovec, Steven, \& Cohen, Robin. (2002). Conceiving cosmopolitanism: theory, context and practice. Oxford: Oxford University Press.

Villegas, Ana Marı'a, \& Irvine, Jacqueline Jordan. (2010). Diversifying the teaching force: an examination of major arguments. The Urban Review, 42(3), 175-192.

Walters, Kate. (2006). A story to tell: the identity development of women growing up as third culture kids. (M.A. dissertation), Trinity Western University, Langley.

Weenink, Don. (2008). Cosmopolitanism as a form of capital. Sociology, 42(6), 1089-1106. doi: 10.1177/0038038508096935

Werbner, Pnina. (1999). Global pathways. Working class cosmopolitans and the creation of transnational ethnic worlds*. Social Anthropology, 7(1), 17-35. doi: 10.1111/j.14698676.1999.tb00176.x

Werbner, Pnina (Ed.). (2008). Anthropology and the new cosmopolitanism: rooted, feminist and vernacular perspectives. Oxford; New York: Berg.

Willis, Paul E. (1977). Learning to labour: how working class kids get working class jobs. Farnborough, England: Saxon House.

Wimmer, Andreas, \& Glick Schiller, Nina. (2002). Methodological nationalism and beyond: nation-state building, migration and the social sciences. Global Networks, 2(4), 301334. doi: 10.1111/1471-0374.00043

Wise, Amanda. (2010). Sensuous multiculturalism: emotional landscapes of inter-ethnic living in Australian suburbia. Journal of Ethnic and Migration Studies, 36(6), 917 - 937.

Wurgaft, Nina. (2006). Also known as: an exploration of cultural hybridity. (Psy.D. dissertation), Antioch New England Graduate School, Keene, New Hampshire.

Wylie, Michael. (2008). Internationalizing curriculum: framing theory and practice in international schools. Journal of Research in International Education, 7(1), 5-19. doi: $10.1177 / 1475240907086885$

Yeo, Wee Loon. (2010). Belonging to 'Chinatown': a study of Asian boarders in a West Australian private boarding school. International Studies in Sociology of Education, 20(1), 55 - 66. 
Yoneyama, Shoko. (2000). Student discourse on tokokyohi (school phobia/refusal) in Japan: burnout or empowerment? British Journal of Sociology of Education, 21(1), 77-94. doi: $10.1080 / 01425690095171$ 